\title{
PROTECTION OF PARTICIPANTS IN A PROPOSED TREATMENT- BASED ALTERNATIVE TO PRISON FOR MEN WHO HAVE SEXUALLY ASSAULTED AN ADULT
}

\author{
Danica McGovern \\ A thesis submitted to the Victoria University of Wellington in fulfilment of the \\ requirements for the degree of Doctor of Philosophy
}

Victoria University of Wellington

2019 



\begin{abstract}
This thesis examines the proposed "treatment track" for men who have sexually assaulted an adult. The treatment track would offer community-based rehabilitation as an alternative to imprisonment when a perpetrator pleads guilty and is assessed as suitable for entry. It has the potential to increase reporting of sexual assaults of adults, decrease attrition in the processing of those complaints, provide a less distressing experience for complainants, and reduce reoffending. The treatment track has broad public support in principle, but work is required to develop the idea into a model and assess its feasibility.
\end{abstract}

In this thesis, I consider whether the treatment track - as part of the criminal justice process - could offer sufficient protection for the liberties of its potential and actual participants. I use Roberts' discussion of penal minimalism as a theoretical framework, which has not been applied to alternative ways of resolving offending before. I conclude that the treatment track could not yet fulfil the requirements of penal minimalism.

Overall, the thesis advances the development of fair and effective alternative resolutions of serious offending. It does this by considering how one such alternative could be designed so that it respects fundamental liberties, developing sentencing theory to make it applicable to this new context, and by proposing an empirical research agenda guided by the requirements of penal minimalism.

The thesis argues the following:

The first condition of penal minimalism is that the state's preventive duty should be exercised only where there is sufficiently serious harm to warrant intervention by the criminal justice process. In this context, it must be established that sexual recidivism is a serious enough problem to warrant intervention with legally-mandated, potentially intrusive treatment and risk management measures. Official conviction rates suggest no pressing need for more widely available treatment to reduce recidivism by men convicted of sexually assaulting an adult. I argue, however, that the self-report literature on undetected perpetration and the under-reporting and attrition figures in sexual cases indicate that repeat sexual violence perpetration (both by men whose offending currently results in a conviction and those whose offending has not been formally detected) is a 
serious problem requiring intervention, thus fulfilling the first condition of penal minimalism.

The second condition of penal minimalism is that the proposed reform is likely to be effective in preventing the identified harm. I argue that the treatment track could reduce sexual recidivism if it achieved either of two things. First, it could bring into the criminal justice process perpetrators of sexual violence who are likely to reoffend without intervention and with whom there would not otherwise be any intervention to reduce their risk of reoffending. Secondly, the treatment track could reduce reoffending by men who would currently be convicted of a sexual offence and imprisoned, more effectively than current sentencing and correctional practice. I synthesise the various relevant bodies of empirical evidence to try to answer these questions, highlighting the wide gaps in knowledge that mean it cannot be concluded that the treatment track would be effective in reducing sexual reoffending.

The third condition of penal minimalism is that the proposed reform should not infringe unduly on the liberties of the accused/offender. I focus on whether the treatment track could be designed to be equivalent in severity to the sentence of imprisonment that would otherwise be imposed. I develop the theory on the principle of proportionality to accommodate resolutions such as the treatment track which are restorative and/or treatment-based, and argue that it is possible for the treatment track and a sentence of imprisonment to be of equivalent severity. I then consider whether, despite equivalence in severity, the treatment track could coerce potential participants into pleading guilty and accepting psychological treatment, both interferences with their liberty. 


\section{CONTENTS}

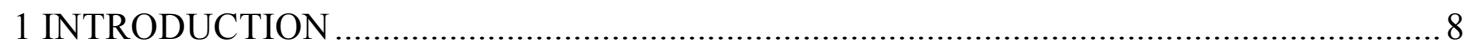

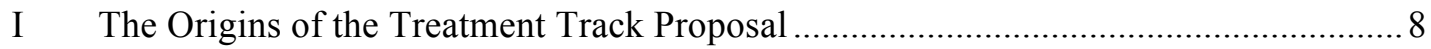

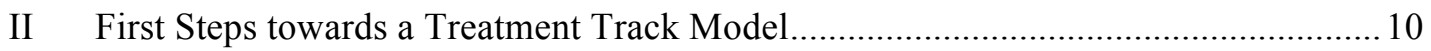

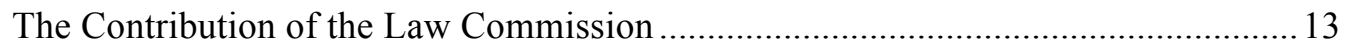

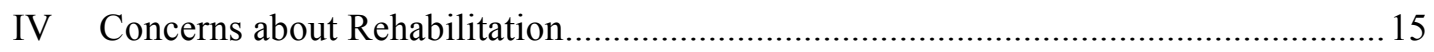

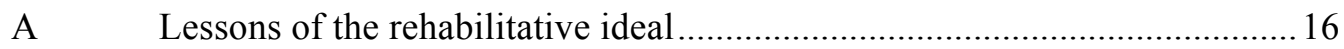

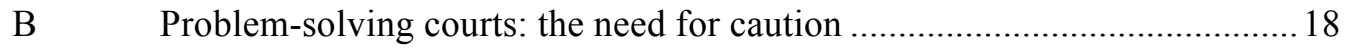

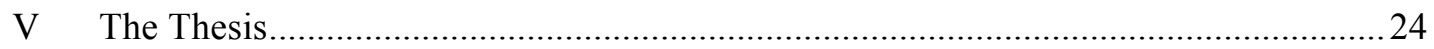

A Starting point: Rehabilitation and punishment in the treatment track...........24

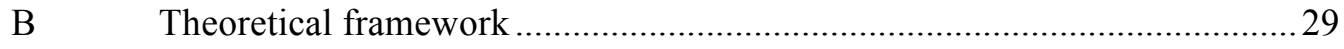

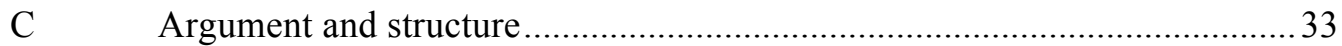

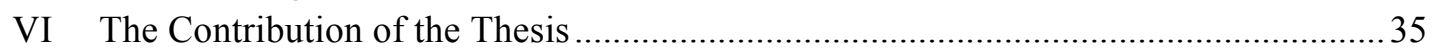















III Law Reform Context ...................................................................................... 42









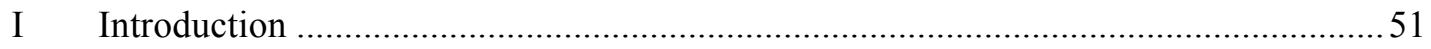

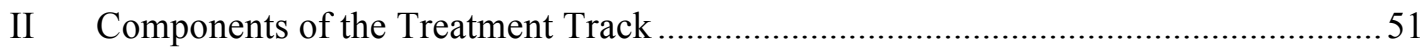

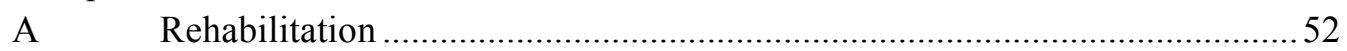

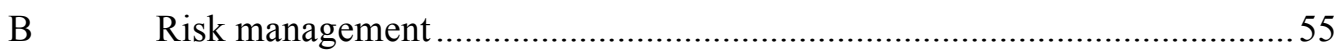

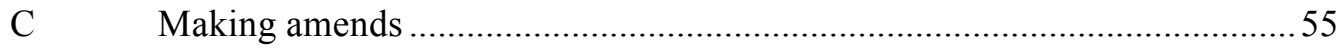

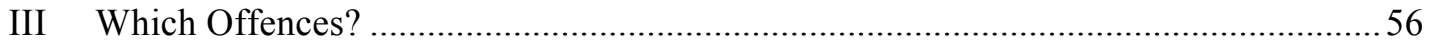



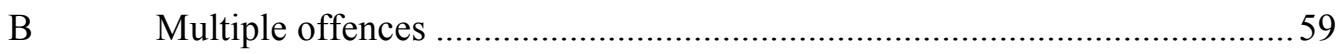

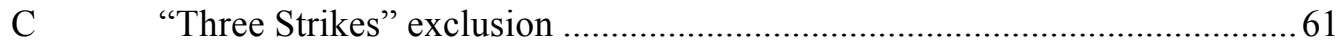

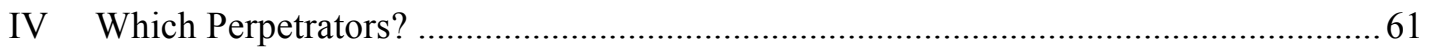

A "Ordinarily convicted offenders" and "ordinarily undetected

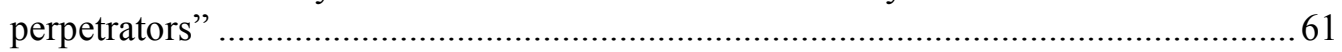

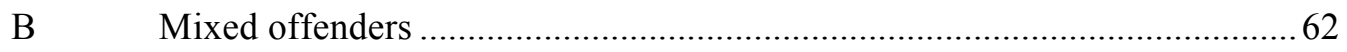

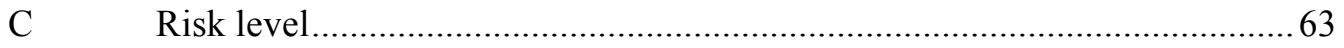

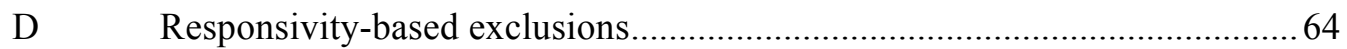

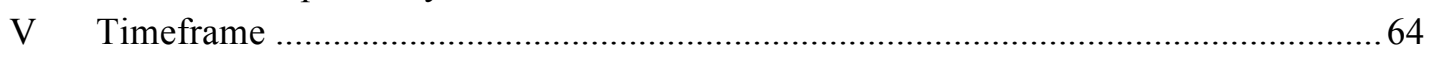

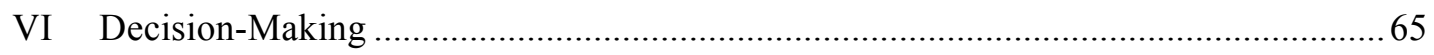

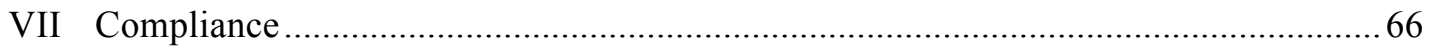




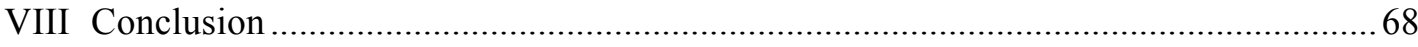

4 THE FIRST CONDITION OF PENAL MINIMALISM: IS THE TREATMENT

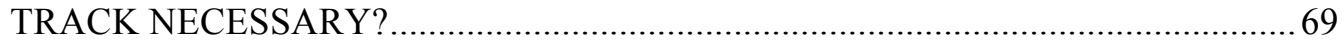

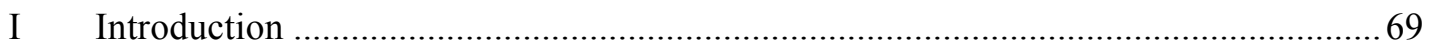

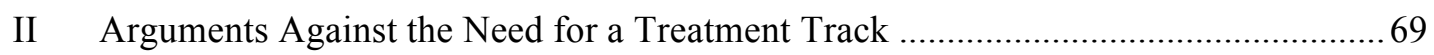

A Low overall official sexual recidivism rates ............................................ 70

B Those who need treatment are already offered it ....................................... 71

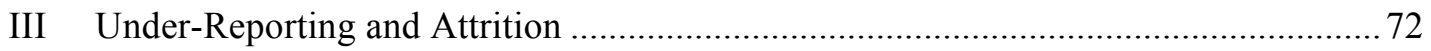

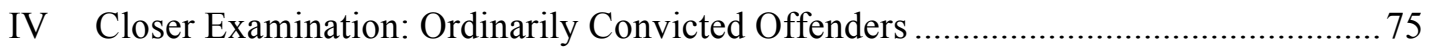

V Repeat Undetected Perpetrators: Prolific Offenders ................................................... 79

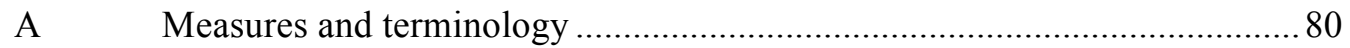

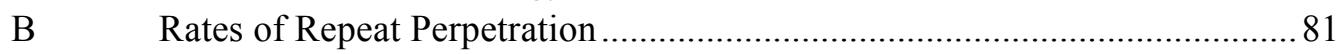

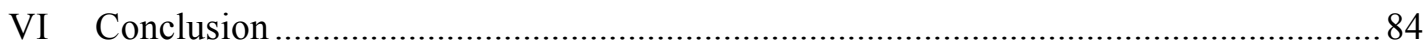

5 THE SECOND CONDITION OF PENAL MINIMALISM: COULD THE TREATMENT TRACK INTERVENE EFFECTIVELY WITH ORDINARILY

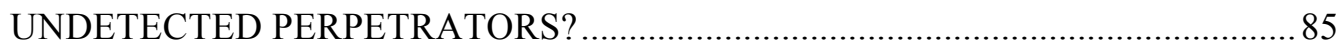

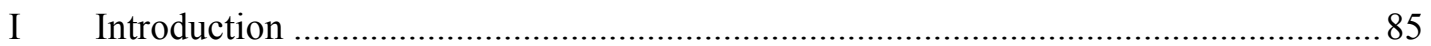

II Could the Treatment Track Bring Ordinarily Undetected Perpetrators into the

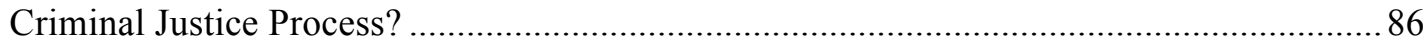

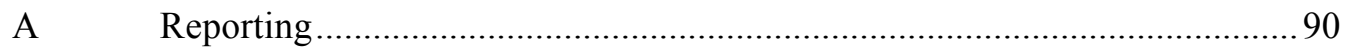

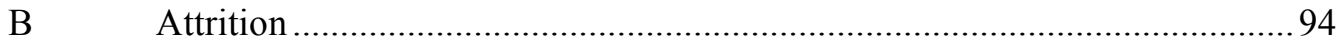

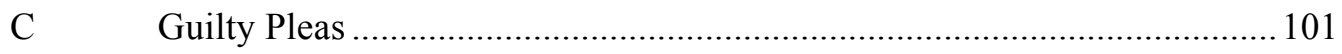

D Conclusion: Is it likely the treatment track would bring in ordinarily

undetected perpetrators? ................................................................................ 112

III Could the Treatment Track Intervene Effectively with Ordinarily Undetected

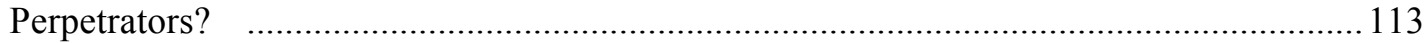

A Risk Assessment with Ordinarily Undetected Perpetrators .........................113

B Assessing Risk in the Treatment Track context .........................................116

C Conclusion on Effectiveness of Intervention with Ordinarily Undetected

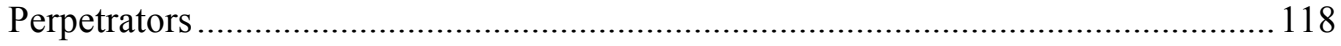

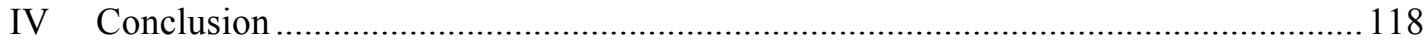

6 THE SECOND CONDITION OF PENAL MINIMALISM, CONTINUED: COULD THE TREATMENT TRACK INTERVENE EFFECTIVELY WITH

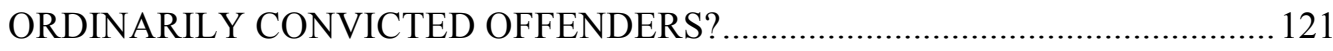

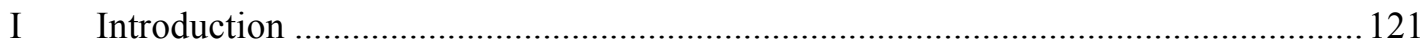

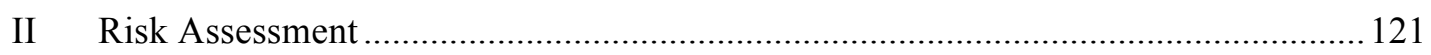

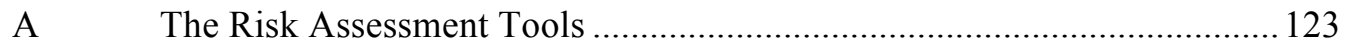

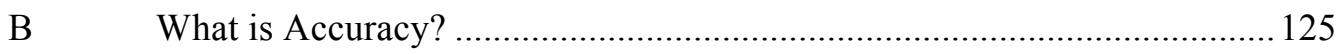

C Which features are important? ........................................................... 131

D How accurately do the tools discriminate between recidivists and non-

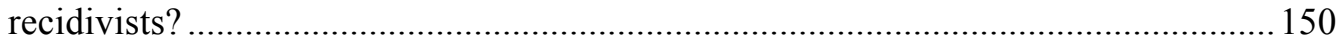

E How closely do observed recidivism rates correspond with predicted

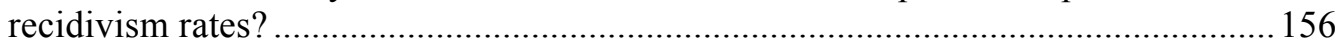

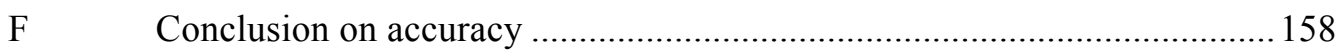

G Are Risk Predictions Valid in Light of Under-Reporting and Attrition?.... 160

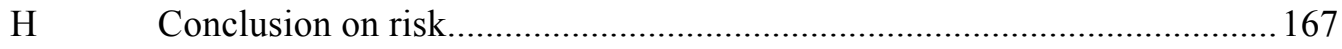

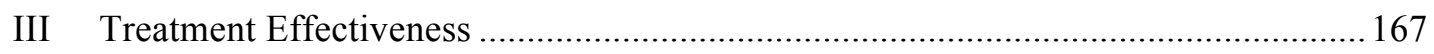




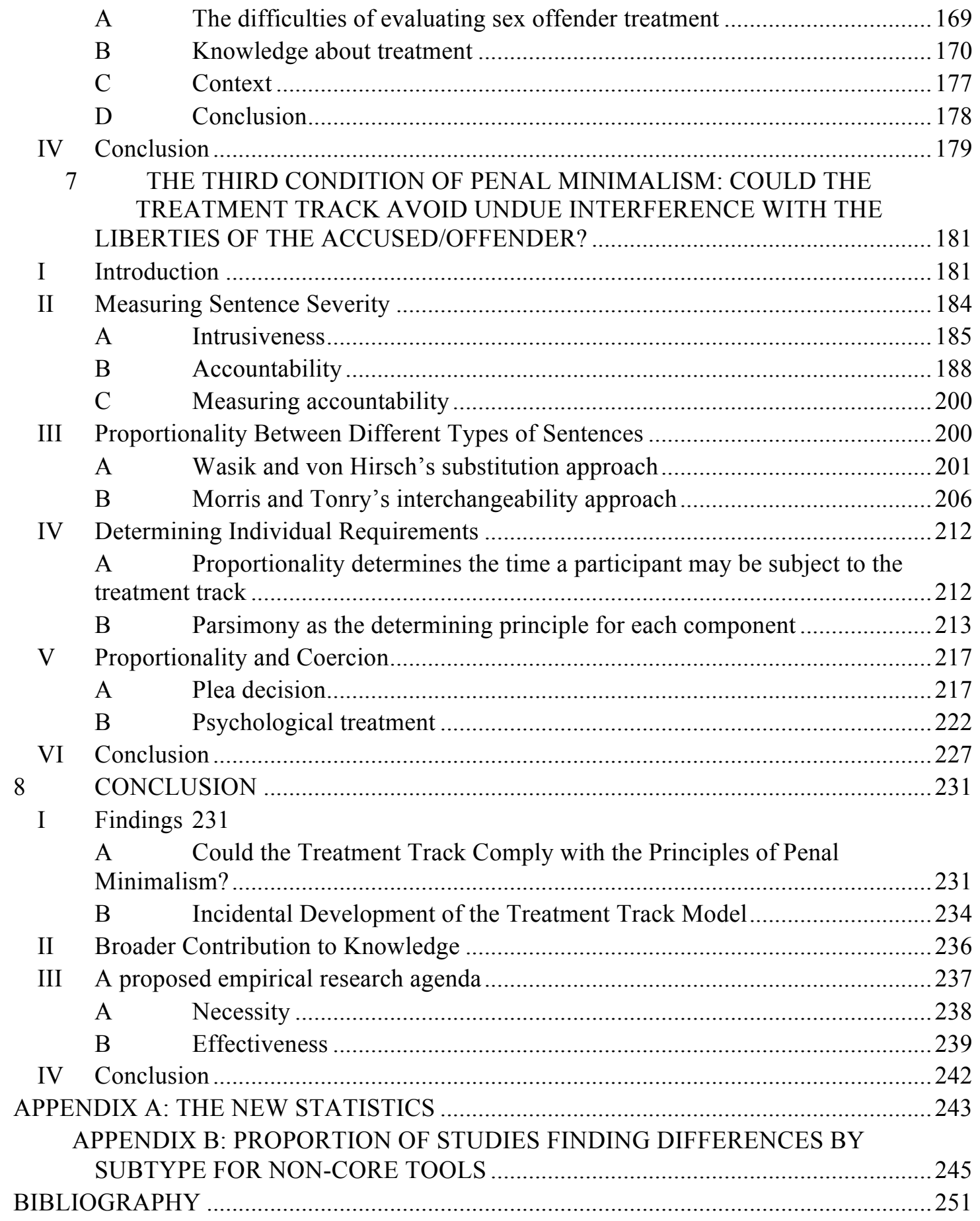




\section{Introduction}

[T] he only purpose for which power can be rightfully exercised over any member of a civilised community, against his will, is to prevent harm to others. His own good, either physical or moral, is not a sufficient warrant. ${ }^{1}$

Often we are in the uncomfortable position of knowing something more than nothing, but much less than everything; knowing precisely where on the spectrum of uncertainty we lie in any given predictive context is essential to making good evidence-based decisions. $^{2}$

\section{The Origins of the Treatment Track Proposal}

Law reform in the area of sexual violence has focused on how to reduce the distress experienced by complainants. A great deal of work has been done over the last three decades in pursuit of this aim, examining how to reform trial processes and rules of evidence. $^{3}$ However, from very early on, various commentators have expressed the view that procedural reform of the existing process for dealing with complaints of sexual offending can only do so much to reduce the traumatic nature of the trial process for complainants.

Rape Study, published in 1983, was the first comprehensive examination of the experience of complainants in rape cases in New Zealand. ${ }^{4}$ It highlighted the distress suffered by complainants as a result of their involvement in the criminal justice process and outlined procedural reforms that could reduce that distress. ${ }^{5}$ Many of those reforms

\footnotetext{
$1 \quad$ John Stuart Mill On Liberty (Cambridge University Press, Cambridge, 2011) at 22 (first published in 1859).

2 Tim Hughes "Predictive Analytics for Policy and Practice: Reflections from the Criminal Justice System" (2015) 11 Policy Quarterly 37 at 39.

3 See for example (in the New Zealand context) Warren Young Rape Study Volume 1: A Discussion of Law and Practice (Department of Justice, Wellington, 1983); The Proceedings of "Rape: Ten Years' Progress? An Inter-Disciplinary Conference (Wellington, March 1996); EW Thomas "Was Eve Merely Framed; or Was She Forsaken?" [1994] NZLJ 368; Taskforce for Action on Sexual Violence Te Toiora Mata Tauherenga - Report of the Taskforce for Action on Sexual Violence, Incorporating Views of Te Ohāki a Hine - National Network Ending Sexual Violence Together (Ministry of Justice, Wellington, 2009); Venezia Kingi and Jan Jordan Responding to Sexual Violence: Pathways to Recovery (Wellington, Ministry of Women's Affairs, 2009). Young, above n 3, at i. At 124-156.
} 
were enacted in $1985 .^{6}$ However, the authors of Rape Study were frank in their view that giving evidence would always be a harrowing experience for complainants, and that procedural reform is limited in the extent to which it can mitigate complainants' distress. ${ }^{7}$

In 1994, Justice Ted Thomas wrote of his experience as a High Court Judge presiding over rape trials, detailing the trauma suffered by complainants. He acknowledged the positive impact of the 1985 reforms, but was adamant that more needed to be done. He recommended a number of substantive and procedural reforms, but prefaced his recommendations with a disclaimer: ${ }^{8}$

I will not pretend, however, that the measures I will propose for consideration will suffice to extinguish the complainant's Courtroom ordeal. Indeed, the suggested reforms may serve only to demonstrate that a more fundamental change to the system is required if the victim is to be treated humanely, and is to receive the justice to which she too is entitled.

Two years later, at the Doctors for Sexual Abuse Care Conference Rape: Ten Years' Progress? An Inter-Disciplinary Conference, Young (one of the authors of Rape Study) argued: ${ }^{9}$

The message from the conference is that the criminal justice system is not geared to meet the needs of victims... We need to be looking for alternative ways of dealing with complaints which can best address the needs of victims. Such alternative methods may include restorative justice or marae justice but we need to be open to other innovative possibilities and be prepared to experiment and evaluate them. That is where I hope we will have moved to in ten years' time.

The hoped-for alternatives did not emerge in the ten years following the conference. However, in 2008, the Law Commission issued its report Disclosure to Court of

The reforms were enacted by the Crimes Amendment Act (No. 3) 1985, the Evidence Amendment Act (No. 2) 1985, and the Summary Proceedings Amendment Act (No. 4) 1985. The reforms included the requirement to clear the court while the complainant gives evidence, a presumption that the complainant's evidence at the preliminary hearing will be in written form, prohibition on the disclosure of the complainant's address and occupation in court, removal of the corroboration warning, and some reforms to the rules on recent complaint and the complainant's sexual history. For further information, see Gerry Orchard "Sexual Violation: The Rape Law Reform Legislation" (1987) 12 NZULR 97 at 107-113.

Young, above n 3, at 124-125.

Thomas, above $\mathrm{n}$, at 373 .

Young, above n 3, at 164 . 
Defendants' Previous Convictions, Similar Offending and Bad Character. That work was undertaken in response to public concern about the acquittals of three police officers who were tried for raping Louise Nicholas. In the foreword to that report, the Law Commission stated that it had received evidence of a number of problems with the trial process for sexual offences, but that those problems could not be cured by changes to the rules of evidence because they flow from the adversarial system itself. Investigation of alternatives was outside the scope of the project, but the Law Commission recommended that further work be done. ${ }^{10}$

On the basis of that recommendation, legal academics Elisabeth McDonald, Yvette Tinsley, and Jeremy Finn investigated whether changing to an inquisitorial process might provide a solution. They confined themselves to cases involving sexual assaults of adult victims. They rejected a wholesale shift to an inquisitorial process, and instead recommended a number of innovative changes to the current process that would significantly improve the experience of complainants in cases that have to go to trial. However, they too were convinced that if the experience of complainants is to be improved, alternatives to the current process are needed. ${ }^{11}$ They began exploring several alternatives, including a treatment track. ${ }^{12}$

\section{First Steps towards a Treatment Track Model}

McDonald and Tinsley proposed a basic model for a treatment track. The treatment track would offer community-based rehabilitation as an alternative to imprisonment when a perpetrator pleads guilty and is assessed as suitable for entry. ${ }^{13}$ It would be one of a range of options available for resolving complaints of sexual offending, along with the traditional trial process (with some modifications to reduce trauma to complainants and improve fairness in the process) and possibly some form of restorative justice that could sit outside the criminal justice process altogether. McDonald and Tinsley argued that greater flexibility in approach would allow the criminal justice process to respond to the range of situations in which sexual offending occurs. By offering a community-based resolution in exchange for a guilty plea, the treatment track could incentivise guilty pleas,

$10 \quad$ Law Commission Disclosure to the Court of Defendants' Previous Convictions, Similar Offending and Bad Character (NZLC R103, 2008) at v-vi.

11 Elisabeth McDonald and Yvette Tinsley "Rejecting "One Size Fits All": Recommending a Range of Responses" in Elisabeth McDonald and Yvette Tinsley (eds) From "Real Rape" to Real Justice: Prosecuting Rape in New Zealand (Victoria University Press, Wellington, 2011) 377 at 377-380.

12 At $377-438$.

13 At 389-392. 
thereby reducing the number of victims subjected to the trial process. They also suggested that the availability of a community-based resolution may make victims more willing to report offending and co-operate with prosecutions, and police/prosecutors more willing to charge suspects and continue with prosecutions, thereby helping to address under-reporting and attrition. McDonald and Tinsley noted that establishing a treatment track would also increase the availability of rehabilitation for sexual offenders: no community-based treatment programmes are currently funded in New Zealand for people who have sexually assaulted an adult. ${ }^{14}$

McDonald and Tinsley made some preliminary suggestions about how the treatment track might be designed, adapting the New South Wales Pre-Trial Diversion of Offenders Programme, known as Cedar Cottage. Cedar Cottage operated in New South Wales from 1989-2014, and accepted referrals for men charged with intra-familial child sexual offending. ${ }^{15}$ As McDonald and Tinsley envisaged it, an offender would apply for entry to the treatment track and be assessed for suitability. If accepted, the offender would plead guilty and sentencing would be adjourned under s 25 of the Sentencing Act 2002, which allows for sentencing to be adjourned so that an offender can complete treatment or make reparation to the victim. If the offender breached the conditions of the treatment track, he or she would return to court for sentencing. In suitable cases, the offender's family or whānau (Māori family grouping) could be invited to be involved. A treatment programme based on tikanga Māori principles (the Māori way of doing things) could be offered. Victims would be kept informed of progress in treatment if they so wish. ${ }^{16}$

The treatment track model would be similar to a problem-solving court in that it would operate post-guilty plea and pre-sentence and a specialist multi-agency team would be

14 At 377-380. Some clinical psychologists in private practice may offer individual treatment to clients concerned about their sexual behavior, but these are not structured programmes and must be self-funded. "Pre-habilitation" - treatment for adults who are sexually attracted to children but have not yet committed an offence - is also being investigated in New Zealand ("Annual Conference 2017” (November 2017) New Zealand Psychological Society $<$ http://www.psychology.org.nz/wp-content/uploads/Sarah-Christofferson-Child-Sexual-AbusePREHABILITATION.pdf $>$ ) but there is no comparable preventive project for people considering sexually assaulting another adult.

15 "The NSW Pre-Trial Diversion of Offenders Program (Cedar Cottage)" Western Sydney Local Health District <http://www.wslhd.health.nsw.gov.au/Cedar-Cottage>.

16 McDonald and Tinsley, above n 11, at 389-391. 
involved. ${ }^{17}$ However, McDonald and Tinsley envisaged that the judge's role would be limited to resolving situations when a participant does not comply with the requirements of the treatment track and to final disposition: on-going monitoring of treatment progress would be left to the multi-agency team, as it would have the expertise required and that approach would be more cost-effective than the resource-intensive nature of judicial monitoring. ${ }^{18}$ The treatment track would not be a court-based process in the way that the problem-solving court model is. For that reason, I use the term "treatment track" rather than "treatment court".

McDonald and Tinsley considered that the treatment track should operate pre-sentence rather than post-sentence for two reasons. First, offenders would have an incentive to comply with the requirements of the treatment track, because failure to comply would result in a sentence of imprisonment being imposed. Secondly, if a community-based sentence were imposed outright, there would be limited recourse if the offender failed to comply with the requirements of the treatment track. ${ }^{19}$

Issues requiring further research that McDonald and Tinsley raised included the treatment programme(s) to be offered and the offences and offenders for which the treatment track should be available. Another issue they raised is how sentencing could take account of an offender's withdrawal from the treatment track or the termination of an offender's participation. It is important that partial completion of the treatment track is taken into account at sentencing. If offenders are not given credit for partial completion, they will be punished more harshly than they would be had they not entered the treatment track at all. $^{20}$

McDonald and Tinsley suggested that the Law Commission, which had embarked on a parallel project on alternative pre-trial and trial processes, ${ }^{21}$ was best placed to undertake the wider consultation required to develop the idea further. ${ }^{22}$

\footnotetext{
17 Problem-solving courts are a judicial invention aimed at addressing an underlying cause of reoffending for individuals (often alcohol or drug dependence, homelessness, or mental health problems). They are discussed in more detail in Part II2 below.

18 McDonald and Tinsley, above n 11, at 391

19 At 392.

$20 \quad$ At 392.

21 "Alternative Models for Prosecuting and Trying Criminal Cases" Law Commission $<$ http://lawcom.govt.nz/our-projects/alternative-models-prosecuting-and-trying-criminal-cases $>$

22 McDonald and Tinsley, above n 11, at 392.
} 


\section{The Contribution of the Law Commission}

The Law Commission began its project in 2010. The terms of reference it received for the project were as follows: ${ }^{23}$

The Law Commission is asked to undertake a high-level review of pre-trial and trial processes in criminal cases. In particular, it should consider whether the adversary framework within which those processes operate should be modified or fundamentally changed in order to improve the system's fairness, effectiveness and efficiency.

The Commission should include within its review an examination of inquisitorial models and consider whether all or any part of such models would be suitable for incorporation into the New Zealand system.

The Commission is asked to put particular emphasis upon the extent to which a new framework and/or new processes should be developed to deal with sex offence cases. However, it should also consider the desirability of alternative approaches in other categories of cases such as those involving child victims and witnesses and family violence, and it should consider the extent to which the system needs to be modified more generally.

The Law Commission worked in collaboration with McDonald and Tinsley. The steering group for its project included "representatives from the judiciary, police, prosecution and defence bars, community service providers working with victims of sexual offending and offender treatment services." ${ }^{24}$ The Law Commission published an Issues Paper, outlining what it saw as the problems establishing a treatment track could help to address (echoing McDonald and Tinsley's work): ${ }^{25}$

The fact that the outcome of a conviction for a sexual offence (almost invariably a substantial term of imprisonment) is presently an inflexible one has a number of adverse consequences. Particularly, in cases that rely on circumstantial evidence and assessments of credibility, guilty defendants may be reluctant to admit guilt because the penalty is so high; police and prosecutors may question the likelihood of

\footnotetext{
23 Law Commission Alternative Pre-Trial and Trial Processes: Possible Reforms (NZLC IP30, 2012) at 6.

$24 \quad$ At 1

25 At $44-45$.
} 
conviction; and fact-finders may not be willing to convict, especially when the defendant does not fit the stereotype of the "real" rapist.

A long sentence of imprisonment may also be at odds with the resolution sought by the victim (particularly when sexual offending occurs in the context of an ongoing relationship). It fails to take the opportunity presented by the offender's appearance in the criminal court to address the factors that led to the offending (such as the offender's attitudes to sexual relationships), and to draw on the range of expertise now available in the community to enable it to do so. It does little to encourage defendants to accept responsibility for their behaviour. It uses the blunt and expensive instrument of long terms of imprisonment that (with the exception of those child sex offenders who undergo the treatment programmes run in two specialist prison units ${ }^{26}$ ) largely fail to reduce the risk that the behaviour will recur.

The Law Commission received public submissions, most of which strongly supported the treatment track proposal. It provided the following overview of the submissions: ${ }^{27}$

In summary, this proposal was very strongly supported by submitters. It was supported, at least provisionally, by all legal stakeholders, sexual and family violence sector organisations and other organisations that commented on it, and most individuals.

Arguments in favour included that it would better address the needs of some defendants and complainants by encouraging acceptance of responsibility and participation in treatment, and providing greater flexibility in sentencing options, in particular cases. Reporting may increase since imprisonment would not be the only possible outcome of a conviction. It would be likely to increase guilty pleas and may reduce reoffending due to the provision of treatment. It was commonly noted that specialised participants including lawyers and judges would be required. More analysis would be useful regarding the costs and savings of the process.

However, a small number of submitters noted significant objections to the proposal. Key concerns included the perception of lenient treatment of sexual offenders and a diminishment in the perceived seriousness of sexual offending; the risk of coercion or pressure on victims to agree to the process; concerns about coercion or pressure on the accused to plead guilty; it could be cost and resource intensive in terms of

\footnotetext{
$26 \quad$ Special Treatment Units at Spring Hill, Waikeria, and Christchurch Men's Prisons now offer the Adult Sex Offender Treatment Programme to men who have been convicted of a sexual offence against an adult victim and are assessed as being at high or medium-high risk of sexual recidivism. 
specialist providers and programmes to address sexual offending (although this could lead to savings in the longer term).

The Law Commission discontinued the reform project in March 2012, on the basis that it was not a legislative priority at that time. ${ }^{28}$ It published a summary of public submissions and then ceased work on the project. $^{29}$

I began this thesis intending to pick up the treatment track idea where the Law Commission left off, on the basis that the idea was still worth pursuing because of its potential benefits and the support for the idea indicated in the Law Commission's consultation. Then in November 2014, the newly appointed Minister of Justice Amy Adams announced that she had asked the Law Commission to resume work on the alternative trial processes project as a priority, and to report back by August $2015 .{ }^{30}$ The Law Commission did not develop the treatment track proposal further in its report because of the limited timeframe available for the project and the complexity of the issues involved. However, I met with a researcher from the Law Commission prior to the publication of the final report to discuss the work that would be required to develop a treatment track model and assess its feasibility. The Law Commission included that information in the final report (published in December 2015) and recommended that the government consider funding a long-term research project that would allow the work to be undertaken. ${ }^{31}$ I hope that this thesis will contribute towards the development of that research agenda.

\section{Concerns about Rehabilitation}

My approach to the proposed treatment track is influenced by concerns about how rehabilitation has been used in correctional settings in the past and how it is currently being used in certain court settings. In this section, I record in a very broad and general way some of the criticisms of "the Rehabilitative Ideal" (in the mid-20 $0^{\text {th }}$ century) and the problem-solving courts operating today. I do not attempt to prove that the criticisms are

\footnotetext{
28 Law Commission Alternative Pre-Trial and Trial Processes: Summary of Submissions to Consultation (NZLC MP, 2012) at 1.

29 At 1

30 "Commission resumes alternative trial processes review" Law Commission $<$ http://www.lawcom.govt.nz/news/commission-resumes-alternative-trial-processes-review $>$.

31 Law Commission The Justice Response to Victims of Sexual Violence: Criminal Trials and Alternative Processes (NZLC R136, 2015) at 107-108.
} 
justified, as doing so is not the central concern of this thesis. Rather, I record them as background to the development of the thesis.

\section{A Lessons of the rehabilitative ideal}

The proposed treatment track would have legally-mandated correctional treatment at its heart. My approach to the idea is influenced by criticisms of the period of $20^{\text {th }}$ century penal history sometimes termed "the Rehabilitative Ideal", in which rehabilitation was considered a primary justification of sentencing, and judges and correctional staff had wide discretion to pursue rehabilitative aims. Under the Rehabilitative Ideal, judgements about the dangerousness of an offender and his or her rehabilitative potential, rather than the seriousness of the offending, were the key determinants of the sentence imposed. This meant that people who had committed similar offences could receive vastly different sentences, and indeterminate sentences were common. ${ }^{32}$ Rehabilitation was not necessarily effective, and some programmes made offenders more likely to reoffend. ${ }^{33}$ Further, the regime was criticised as inhumane and hypocritical, because, under the guise of rehabilitation, the state could engage in practices that caused significant suffering, free from the constraints that would be in place if the practices were labelled as punishment rather than rehabilitation. ${ }^{34}$

In 1976, a committee led by Andrew von Hirsch published Doing Justice, a report calling for a move away from the Rehabilitative Ideal and towards a desert-based model: ${ }^{35}$

Permeating this report is a determination to do less rather than more - an insistence on not doing harm. The quality of heady optimism and confidence of reformers in the past, and their belief that they could solve the problem of crime and eradicate the presence of deviancy, will not be found in this document. Instead, we have here a crucial shift in perspective from a commitment to do good to a commitment to do as little mischief as possible...

$\overline{32}$

Andrew von Hirsch and Lisa Maher "Should Penal Rehabilitationism Be Revived?" in Andrew von Hirsch and Andrew Ashworth (eds) Principled Sentencing: Readings on Theory and Policy (2 ed, Hart Publishing, Oxford, 1998) at 31.

At 27-28; Francis Allen "The Decline of the Rehabilitative Ideal" in Andrew von Hirsch and Andrew Ashworth (eds) Principled Sentencing: Readings on Theory and Policy (2 ed, Hart Publishing, Oxford, 1998) at 17-18.

Andrew von Hirsch Doing Justice: The Choice of Punishments (Hill and Wang, New York, 1976); Allen, above n 33, at 15-17. There were, of course, a wide range of practices under the rubric of rehabilitation, some of which were entirely unobjectionable, such as job training and literacy and numeracy skills.

Von Hirsch, above n 34, at xxxiv-xxxix. 
It is not easy to abandon the rehabilitative model, for it was a scheme born to optimism, and faith, and humanism... We believe the rehabilitative model abounded with internal inconsistencies which inevitably offered opportunities for exploitation - that were, just as inevitably, accepted. It produced unexpected abhorrent consequences and numerous unpredicted side effects that were less humane or liberal than its proponents had anticipated.

The shift to desert-based sentencing has not been complete: rehabilitation (along with other utilitarian aims) remains a justification for sentencing and is incorporated into many sentences as a matter of correctional practice. ${ }^{36}$

In the 40 years since Doing Justice was published, knowledge about risk assessment and rehabilitation has grown substantially. ${ }^{37}$ Further, limits on sentencing discretion have become the norm, driven by desert theory's emphasis on proportionality and consistency. ${ }^{38}$ However, the similarities between the proposed treatment track and practice under the Rehabilitative Ideal should ring alarm bells. The treatment track has legally-mandated treatment at its heart. It would operate in the period between plea and sentence, which is not currently regulated by legislation or the common law, allowing criminal justice decision-makers a great deal of discretion. As will be discussed in the thesis, risk assessment and management would be central components of the treatment track, and the requirements imposed on participants would need to be individualised to perhaps a greater extent than would be expected in current sentencing practice.

$36 \quad$ Sentencing Act 2002, s 7.

37 The work of DA Andrews and James Bonta in developing the Risk-Need-Responsivity Model of Offender Rehabilitation, first published in 1994, revolutionised the field. See James Bonta and DA Andrews The Psychology of Criminal Conduct (6 ed, Routledge, New York, 2017) for the most recent statement of the theory.

38 In New Zealand, this is reflected in the publication by the Court of Appeal of guideline judgments setting out a sentencing process and providing guidance on sentence lengths, beginning with $R v$ Taueki [2005] 3 NZLR 372 (CA). The guideline judgment for sexual violation is $R v A M$ [2010] NZCA 114, [2010] 2 NZLR 750. The Sentencing Council Act 2007 would have established a Sentencing Council to produce sentencing guidelines with input from a range of experts and public consultation. Draft sentencing guidelines were produced by the Sentencing Establishment Unit (a section of the New Zealand Law Commission - for more information see "Sentencing Establishment Unit" Law Commission <http://www.lawcom.govt.nz/our-projects/sentencingestablishment-unit>) but the legislation was never brought into force and was repealed in June 2017. There are indications, however, that the new Labour-led government may reintroduce something similar to the Sentencing Council "Judges' sentencing lacks consistency" Newshub (2 December 2017) <http:/www.newshub.co.nz/home/politics/2017/12/judges-sentencing-lacksconsistency-andrew-little.html>. 
It is important that new ways of responding to offending do not undo the progress made towards fairness, and that if they are to incorporate rehabilitation and risk assessment, they are based on realistic appraisals of the effectiveness of rehabilitation and the accuracy of risk assessment. If a treatment track is established, we must heed the lessons of the past and regulate the treatment track carefully to avoid the unintended consequences described in Doing Justice. ${ }^{39}$

And in case these concerns seem archaic, it is important to note that the problem-solving courts now spreading across the country are open to many of the same criticisms as practices during the Rehabilitative Ideal, indicating that the issues are alive and well.

\section{B Problem-solving courts: the need for caution}

My approach to the treatment track idea is also influenced by what I consider to be some of the problems with a more recent phenomenon, problem-solving courts. In this section, I draw on criticisms that have been made of problem-solving courts, with two aims in mind. First, I wish to note an additional reason the problem-solving court model should not be adopted for the design of the treatment track, namely that the model offers insufficent protection of the liberties of participants. Secondly, I wish to caution against relying on good intentions on the part of reformers to protect the interests of the accused/offender. Protections for the accused/offender must be built into any criminal justice response rather than relying on the goodness of the professionals involved.

Problem-solving courts attempt to address the "revolving door" problem of the same defendants coming before the courts again and again. ${ }^{40}$ Judges wanted to do more to address the underlying causes of the offending than the conventional court process allowed. ${ }^{41}$ They established the first drug court in Florida in 1989. It involved a multidisciplinary team, led by the Judge, working together to supervise defendants' completion of drug treatment. Participants appeared regularly in front of the judge, who rewarded them for progress in treatment and punished them for relapse or other breaches. ${ }^{42}$

\footnotetext{
$39 \quad$ Von Hirsch, above n 34.

$40 \quad$ Peggy Fulton Hora, William Schma and John Rosenthal "Therapeutic Jurisprudence and the Drug Court Movement: Revolutionizing the Criminal Justice System's Response to Drug Abuse and Crime in America" (1999) 74 Notre Dame L Rev 439 at 456.

41 Ibid.

$42 \quad$ At $454-455$.
} 
The problem-solving court model spread across North America, Australia, and New Zealand and expanded its subject matter beyond substance use disorders. The Christchurch Youth Drug Court, established in 2002, was New Zealand's first experiment with the problem-solving court model. ${ }^{43}$ In the adult jurisdiction, an Alcohol and Other Drug Court (AODTC) is being piloted in Auckland and Waitakere and there are two problem-solving courts for homeless offenders - Te Kooti o Timatanga Hou (the New Beginnings Court) in Auckland and the Special Circumstances Court in Wellington. ${ }^{44}$

Problem-solving courts are a pragmatic, practice-driven phenomenon. In the late 1990s, however, drug court judges noticed that therapeutic jurisprudence could be applied to the problem-solving court approach. ${ }^{45}$ Therapeutic jurisprudence is a perspective on law developed by legal academics David Wexler and Bruce Winick. ${ }^{46}$ It originated in mental health law, with Wexler and Winick arguing that practitioners, policy-makers, and academics should take into account the effects of law and legal processes on the mental health of people subject to proceedings. ${ }^{47}$ Therapeutic jurisprudence soon began to be applied to other areas of law. ${ }^{48}$ The perspective has two central tenets. The first is that laws, legal processes, and legal actors can have "therapeutic" or "anti-therapeutic" effects. Secondly, "therapeutic" effects should be sought where they can be achieved in a way that is consistent with important legal aims and values. ${ }^{49}$ Drug courts came to be seen as practising therapeutic jurisprudence, with the "therapeutic" effects being that offenders received treatment for their substance use disorders and in the process built better lives for themselves. ${ }^{50}$

While proponents of problem-solving courts claim to be applying therapeutic jurisprudence, the requirement that therapeutic effects be sought within the bounds of law

\footnotetext{
43 Sue Carswell Process Evaluation of the Christchurch Youth Drug Court Pilot (Ministry of Justice, Wellington, 2004) at 13.

44 “Therapeutic Courts" Ministry of Justice < https:/www.justice.govt.nz/courts/criminal/therapeuticcourts $/>$.

$45 \quad$ Hora, Schma and Rosenthal, above $\mathrm{n} 40$.

46 David Wexler and Bruce Winick Essays in Therapeutic Jurisprudence (Carolina Academic Press, North Carolina, 1992).

47 At $\mathrm{x}$

48 For an early example, see David Wexler and Bruce Winick (eds) Law in a Therapeutic Key: Developments in Therapeutic Jurisprudence (Carolina Academic Press, North Carolina, 1996).

49 David Wexler "An Orientation to Therapeutic Jurisprudence” (1994) 20 New England Journal on Criminal and Civil Confinement 259 at 259-260.

50 Bruce Winick and David Wexler "Drug Treatment Court: Therapeutic Jurisprudence Applied" (2015) 18 Touro Law Review 479.
} 
and procedural fairness is, in my view, neglected in the problem-solving court model. In support of that view, I summarise Nolan's explanation of how protections for the accused/offender are sidelined in the problem-solving court model, creating the same sorts of problems that plagued the rehabilitative ideal. ${ }^{51}$ Nolan was writing about the United States drug courts, but I demonstrate the applicability of his concerns to New Zealand's AODTC (which was modelled on the US Drug Court best practice principles $^{52}$ ).

Nolan argued that rather than trying to achieve so-called therapeutic outcomes within the confines of traditional views about procedural and substantive justice, the meaning of "justice" has itself been re-defined in problem-solving courts. ${ }^{53}$ He quoted Judge Hora (a founder of the US Drug Court movement, who also has an advisory position in New Zealand's AODTC pilot): ${ }^{54}$

Okay, so traditionally justice is applying the law in an equal and fair manner. Justice is fulfilling sentencing goals such as retribution, rehabilitation, restitution, and so forth. And the way it's redefined [in drug courts] is, the whole idea of this approach, is you have people who have a disease called alcoholism and/or addiction. And what is just is getting them well rather than punishing them for their disease.

When "justice" is redefined to mean "recovery", "healing", or "helping", Nolan argued, traditional legal aims and values become irrelevant. ${ }^{55}$ He has shown how drug court proponents have defended their practice against the kinds of criticisms made of the rehabilitative ideal, justifying the practices on the basis that they are "therapeutic" and in the best interests of the accused/offender - even when they violate fundamental legal values instituted for the protection of individuals from the power of the state. If everything a problem-solving court does is justified as necessary to "help" an offender, then the offender is not seen as being in need of protection from the court and legal values become irrelevant. ${ }^{56}$

\footnotetext{
$51 \quad$ James Nolan "Redefining Criminal Courts: Problem-Solving and the Meaning of Justice" (2003) 40 Am Crim L Rev 1541.

52 Katey Thom, Stella Black and Michele Yeoman Ngā Whenu Raranga/ Weaving Strands: The therapeutic framework of Te Whare Whakapiki Wairua/ The Alcohol and Other Drug Treatment Court (University of Auckland, Auckland, 2017) at 8-9.

$53 \quad$ Nolan, above $\mathrm{n} 51$.

$54 \quad$ At 1553 (Nolan's emphasis).

$55 \quad$ Ibid.

56 Richard Boldt "Rehabilitative Punishment and the Drug Treatment Court Movement" (1998) 76 Wash ULQ 1206 at 1242.
} 
That tendency can also be seen in the AODTC, most notably in a series of reports by Thom and Black purporting to set out its therapeutic framework. They describe a framework made up of four strands: law, lore (tikanga Māori), recovery, and US DTC best practice. ${ }^{57}$ Although protection of the public from reoffending (a traditional concern of the courts) is emphasised in their discussion of the law strand, the use of legal mechanisms to contain reoffending is then reframed as being of therapeutic benefit to participants: ${ }^{58}$

So from a therapeutic angle you know that whilst, for example, rules, the court rules, the drug court rules, the bail conditions, while they can at times seem unreasonable to the participants, they have to be tailored in such a way for their [participants'] own benefit.

In this way of thinking, "recovery" becomes both the aim of the court and the interest of the participant, replacing traditional notions about the interests of the accused/offender such as prevention or minimization of loss of liberty. ${ }^{59}$

Reframing "justice" to mean "recovery", and characterising the court as acting in the ultimate best interests of the participant can mean that it is seen as unnecessary to protect participants from the power of the state. Problem-solving courts have been criticised for imposing disproportionately severe punishment and for intruding too far into the lives of participants. For example, drug court judges often say that drug court is harder for participants than prison, because of the onerousness of the requirements they must fulfill (such as completing treatment programmes, complying with bail conditions intended to reduce the risk of recidivism or relapse, complying with drug and alcohol testing, undertaking community service, and making frequent court appearances). ${ }^{60}$ The sanctions that can be imposed for non-compliance add an additional layer of severity, and a participant who exits the drug court before completing its requirements may be sentenced as usual - experiencing a double penalty. ${ }^{61}$ Although there are guidelines about the length of time each "phase" of the drug court programme is expected to take, it is common for phases to take longer than advertised (to account for relapse or slower

\begin{tabular}{ll}
\hline 57 & Thom, Black and Yeoman, above n 52. \\
58 & AODTC Court Team member \#20, quoted at 7. \\
59 & Nolan, above n 51. \\
60 & At $1552-1557$. \\
61 & At $1555-1556$.
\end{tabular}


progress in treatment) and participants must commit to the drug court for an indeterminate period of time. ${ }^{62}$

Nolan has described how drug court proponents dismiss concerns about disproportionately severe punishment. Consistent with their redefinition of justice, founders of the US drug court movement have called concerns about disproportionate severity an "unfounded apprehension" that reflects a lack of understanding of therapeutic jurisprudence. ${ }^{63}$ Similarly, indeterminacy has been justified on the basis that it is necessary for therapeutic reasons (for example to break down denial and to "institute a feeling of responsibility in otherwise unresponsive defendants") - with concerns about the fairness of indeterminacy simply ignored. ${ }^{64}$

Indeed, punitive practices in drug courts have been re-labelled in therapeutic terms (for example, periods of incarceration have been called "motivational jail" and sanctions described as "restructuring of the defendant's lifestyle" and "not really punishment at all, but a therapeutic response"). ${ }^{65}$ When punishment is not acknowledged as such, it is much more difficult to institute proper controls on its use, including maintaining proportionality with the seriousness of the offence and the sentence that the offender would otherwise receive. $^{66}$

Nolan also described US drug court judges seeking the power to order random searches of participants, their homes, and their vehicles (justified as not "a sanction so much as an additional therapeutic intervention that will help them succeed") and expanding their reach beyond participants (people who have committed an offence) to include the ability to order participants' partners to attend counselling or anger management classes. ${ }^{67}$ There is nothing in the design of the AODTC to stop judges attempting the same in New Zealand.

In addition, the kinds of procedural protections that would normally help to restrain the power of the state and protect the liberty of people subject to the criminal justice process tend not to have been built into problem-solving courts. This is perhaps most notable in

\footnotetext{
$62 \quad$ At $1557-1558$.

63 At 1556, citing Hora, Schma and Rosenthal, above n 40, at 523.

64 Nolan at 1558, quoting William McColl "Baltimore City’s Drug Treatment Court: Theory and Practice in an Emerging Field" (1996) 55 MD L Rev 467 at 497.

65 At 1556-1557, citing Hora, Schma and Rosenthal, above $\mathrm{n} 40$.

66 The definition of punishment I use in this thesis is discussed further below.

$67 \quad$ Nolan, above n 51, at 1562.
} 
respect of the role of defence counsel in problem-solving courts, which has been the subject of much criticism. ${ }^{68}$ In keeping with the supposed alignment of the interests of the court and the participant, the role of defence counsel is reconfigured: ${ }^{69}$

I mean your role is really to look after the interests of the client but of course that is challenged by the fact that actually the interest of the client is their recovery.

While the lawyer quoted goes on to talk about ensuring clients are represented in court and treated fairly, Thom and Black immediately bring the description of counsel's role back to the "therapeutic" ethos of the AODTC: ${ }^{70}$

All the practices of the defence counsel, therefore, were shaped by the goal of participant recovery - even if this meant making a decision that was contrary to their participant's wishes in the first instance.

The role of the judge is also reconfigured in problem-solving courts. The judge leads the multi-disciplinary team and has ultimate decision-making power in respect of treatment issues as well as those issues within the more conventional role of the judge. ${ }^{71}$ Hoffman has described problem-solving court judges as "amateur therapists with the power of real judges" highlighting the potential for judges to make decisions outside their expertise and to enforce those decisions with the power of the criminal justice process. ${ }^{72}$ That potential is heightened by the fact that problem-solving courts take place in the period between plea and sentence, which is unregulated. Judges effectively have unlimited discretion.

I consider in this thesis whether the treatment track could be developed in a way that ensures it will not be subject to the same kinds of criticisms as problem-solving courts. An important first step is to be very clear about the goals of the treatment track and to

68 Tamar Meekins "Risky Business: Criminal Specialty Courts and the Ethical Obligations of the Zealous Criminal Defender" (2007) 12 Berkeley J Crim L 75; Mae Quinn "Whose Team Am I On, Anyway? Musings of a Public Defender about Drug Treatment Court Practice" (2000) NYU Review of Law and Social Change 37.

69 AODTC Court Team member \#11, quoted in Katey Thom, Stella Black and Michele Yeoman Ngā Whenu Raranga/ Weaving Strands: The roles of Te Whare Whakapiki Wairua/ The Alcohol and Other Drug Treatment Court Team (University of Auckland, Auckland, 2017) at 15.

At 15 .

At 25 .

Morris Hoffman "Therapeutic Jurisprudence, Neo-Rehabilitationism, and Judicial Collectivism: The Least Dangerous Branch Becomes Most Dangerous" (2002) 29 Fordham Urban LJ 2063 at 2072 . 
identify when and how those goals might conflict with the interests of participants or potential participants. Acknowledging those areas of conflict and providing for substantive and procedural protections of the participant's interests will be important. A framework that provides greater assistance than therapeutic jurisprudence as to what those interests might be will also be useful, and for that reason I do not pursue therapuetic jurisprudence as a possible theoretical framework for the treatment track. I expand on these points in the following section.

\section{$V$ The Thesis}

In this section, I explain my starting point for the thesis, outline the theoretical framework, give a brief statement of the thesis and set out its structure, and finish by describing its contribution to knowledge.

\section{A Starting point: Rehabilitation and punishment in the treatment track}

The treatment track was initially proposed as part of a project focused on improving victims' experiences of the criminal justice process. One of the possible benefits of a treatment track is that it could offer some victims of sexual offending an option for resolution of that offending that they consider more appropriate and that is arrived at by a less distressing process than the current one. The treatment track would also require the offender to make amends to the victim, as far as is possible and in a way that is acceptable to the victim. ${ }^{73}$ I do not, however, approach the treatment track as having the primary rationale of improving victims' experiences of the criminal justice process. I characterise the treatment track as primarily an intervention to reduce re-offending by sex offenders. The reason for this choice is the centrality of treatment - the purpose of which is to reduce reoffending ${ }^{74}$ - to the treatment track.

Although the primary purpose of the treatment track is to prevent further sexual offending, and it takes place before the offender is formally sentenced, I begin from the point that the treatment track is, in fact, punishment. In this section I explain the reasons I conceptualise it as punishment.

\footnotetext{
73 This component was not part of the original treatment track model, but I discuss its inclusion in Chapter 3.

74 Admittedly the purpose of treatment is somewhat contested, an issue I discuss below.
} 
The best-known definition of punishment is Hart's, which I adopt for the purposes of this thesis: ${ }^{75}$

(i) it may involve consequences normally considered unpleasant;

(ii) it is for an offence against legal rules;

(iii) it is of an actual or supposed offender for his offence;

(iv) it may be intentionally administered by human beings other than the offender; and

(v) the authority is constituted by the relevant legal system.

The first element I discuss in more depth in Chapter 7, but essentially the treatment track imposes a number of burdens on the participant that are likely to be experienced as onerous, and therefore that element is satisfied. In terms of the second and third elements, to be eligible for the treatment track the person must have been charged with a relevant sexual offence and have pleaded guilty (making him at least a supposed offender, although the possibility of miscarriages of justice arising from the plea incentive is also discussed further in Chapter 7$){ }^{76}$ The treatment track would be administered as part of the criminal justice process (so intentionally by human beings other than the offender) and would thus fulfil the fourth element. In respect of the fifth element, while the details of how the treatment track would be set up (that is, whether by statute or in some other way) are outside the scope of the thesis, the authority would be found in New Zealand's legal system.

While the treatment track can and should be considered punishment within Hart's definition, it would not be a formal sentence, because it would operate in the period between plea and sentence. After the guilty plea is entered, sentencing would be adjourned (under s 25 of the Sentencing Act) to allow the offender to complete the requirements of the treatment track. If a treatment track participant completed all requirements of the treatment track satisfactorily, the participant would be convicted and discharged under s 108, with a note on the record that the requirements of the treatment track have been completed. No further sentence would be imposed on the offender.

75 HLA Hart Punishment and Responsibility (2 ed, Oxford University Press, Oxford, 2008) at 4-5. Ashworth and Zedner prefer a definition of punishment that includes censure as the rationale for hard treatment (Andrew Ashworth and Lucia Zedner Preventive Justice (Oxford University Press, New York, 2014) at 14. As will be discussed in Chapter 7, I consider that desert theory is not the best fit for the treatment track, so accordingly I prefer Hart's definition.

76 A "relevant sexual offence" is defined in Chapter 3. 
Completing the treatment track would be sufficient grounds to displace the presumption of imprisonment for sexual violation in s $128 \mathrm{~B}$ of the Crimes Act.

It is also important to consider the status of treatment itself, as it is the main component of the treatment track. There has been some discussion in the psychology literature about the relationship between treatment and punishment, most notably in a special issue of Aggression and Violent Behavior. ${ }^{77}$ Ward argued that treatment should be seen as separate but complementary to punishment, rather than as punishment in itself. ${ }^{78}$ Differences in context and understandings of treatment and punishment explain the different conclusions we have reached. Ward was discussing treatment as something offered to offenders who are serving a sentence - who are already being "punished" in common parlance - rather than as the central component of the resolution of offending. Moreover, the impetus for Ward's work was his desire to develop a richer understanding of the ethical obligations of programme developers and therapists, and he was not working within an explicitly liberal framework. ${ }^{79}$ He did not, accordingly, begin from a point of suspicion about over-extension of the power of the state. This is reflected in his choice of Duff's Communication Theory as his conceptualisation of punishment (which could be described as a "liberal communitarian" theory ${ }^{80}$ ) and Ward's view of treatment as having the dual purposes of reducing reoffending and improving offenders' lives (explained fully in his work on the Good Lives Model ${ }^{81}$ ).

For my purposes, I consider it essential to characterise treatment as punishment in the context of the treatment track. The treatment that participants would complete as part of the treatment track is legally-mandated: while their consent is required, the alternative to participation in the treatment track would be a sentence of imprisonment or the risk of one if they decided to defend the charge at trial. ${ }^{82}$ Further, while psychological treatment

$77 \quad$ See for example Tony Ward and Astrid Birgden "Accountability and dignity: Ethical issues in forensic and correctional practice" (2009) 14 Aggression and Violent Behavior 227; Tony Ward and Karen Salmon "The Ethics of Punishment: Correctional practice implications" (2009) 14 Aggression and Violent Behavior 239; Bill Glaser "Treaters or punishers? The ethical role of mental health clinicians in sex offender programs" (2009) 14 Aggression and Violent Behavior 248.

78 Ward and Birgden, above n 77; Ward and Salmon, above n 77.

79 Ibid.

80 RA Duff Punishment, Communication and Community (Oxford University Press, Oxford, 2001) at 46-52.

81 For a comprehensive explication, see D Richard Laws and Tony Ward Desistance from Sex Offending: Alternatives to Throwing Away the Keys (The Guilford Press, New York, 2011) at 175279.

82 The potential coerciveness of this situation is discussed in Chapter 7. 
for sexual offenders is intended to prevent criminal behaviour, it targets participants' ways of thinking, processing and expressing emotions, their sexuality, and their ways of relating to others. ${ }^{83}$ Psychological treatment also aims to change behaviour that can lead to sexual offending but is not necessarily criminal in itself, such as use of alcohol or pornography and association with antisocial peers. ${ }^{84}$ While participants must decide for themselves to make these changes, the treatment process is potentially very intrusive because it is intended to change participants. The legally-mandated and potentially intrusive nature of treatment in the context of the treatment track makes it important to characterise it as punishment.

Characterising treatment as punishment does not give treatment providers licence to "punish" participants (shame or humiliate them, for example). The characterisation of treatment as punishment simply reflects the burdens that are inherent in a legallymandated, potentially intrusive process. I agree with Ward that it would be unethical for treatment providers to "punish" participants. These behaviours are also likely to be unhelpful in reducing reoffending. The treatment alliance ("a collaborative relationship between therapist and client that can facilitate positive change" ${ }^{\$ 25}$ ) is important for treatment success, and engaging in those types of behaviours is likely to undermine the treatment alliance. ${ }^{86}$ As reducing reoffending is the purpose of treatment, only interventions that are empirically-linked to that goal (or at least can reasonably be thought to be linked to it, given that relatively little is known about the mechanisms which make treatment effective ${ }^{87}$ ) or that are necessary to enable engagement with the programme

\footnotetext{
83 Nick Wilson, Glen Kilgour and Devon Polaschek "Treating high-risk rapists in a New Zealand intensive prison programme" in Devon Polaschek (ed) Treatment Programmes for High Risk Offenders (Routledge, New York, 2016) at 121-122.

$84 \quad$ Ibid.

85 Elizabeth Ross Investigating the Relationship Between the Therapeutic Alliance and Treatment Outcome in Violent Offender Treatment (Unpublished doctoral thesis, Victoria University of Wellington, 2008) at 26. For more information, see Elizabeth Ross, Devon Polaschek, and Tony Ward "The therapeutic alliance: A theoretical revision for offender rehabilitation" (2008) 13 Aggression and Violent Behavior 462.

86 William Marshall and others Rehabilitating Sexual Offenders: A Strength-Based Approach (American Psychological Association, Washington DC, 2011) at 63-76.

87 Devon Polaschek, Julia Yesberg, Rebecca Bell, Allanah Casey and Sophie Dickson "Intensive psychological treatment of high-risk violent offenders: Outcomes and pre-release mechanisms" (2016) 22 Psychology, Crime and Law 344 at 344-346.
} 
should be included in treatment programmes. ${ }^{88}$ Interventions for any other purpose should not be included.

An example is interventions intended to increase empathy for the victim. The evidence suggests that lacking empathy for one's victim has little or no relationship with reoffending. ${ }^{89}$ Many sex offender treatment programmes, however, include role-play tasks in which the participant assumes the role of the victim, to enable the participant to develop empathy for the victim. ${ }^{90}$ If empathy is, indeed, unrelated to reoffending (rather than the absence of relationship actually being due to problems with the way empathy has been measured, a possibility canvassed by Mann and Barnett in their thoughtful discussion of empathy interventions ${ }^{91}$ ) then tasks intended to increase empathy should not be included in treatment. The purpose of including them would be to increase feelings of guilt or shame in the participant, which might be considered morally right but do not help to reduce reoffending. ${ }^{92}$

If treatment is carried out in an ethical and evidence-based way, it should improve the lives of participants, and I see that as another potential benefit of the treatment track. There are two main high level models of correctional treatment: the Risk-NeedResponsivity Model (the RNR) and the Good Lives Model (GLM). My discussion of treatment in the thesis is grounded more in the RNR Model, because it has a stronger evidence base and is more practicable to implement. ${ }^{93}$ Both models aim to improve offenders' lives alongside reducing reoffending, but there is a difference in the emphasis placed on benefits for the offender. As signalled in the title of the model, improving offenders' lives has a central role in the GLM, and intervention under that model should not be confined to addressing those factors that are thought to contribute to reoffending. In the RNR, on the other hand, treatment is confined to those factors related to

88 These kinds of interventions may actually include building up participants' self-esteem, because that can enable them to better engage in the difficult work of treatment. See for example Marshall and others, above n 86, at 94. Karl Hanson and Kelly Morton-Bourgon "The Characteristics of Persistent Sexual Offenders: A Meta-Analysis of Recidivism Studies" (2005) 73 Journal of Consulting and Clinical Psychology 1154 at 1159. Ruth Mann and Georgia Barnett "Victim Empathy Intervention with Sexual Offenders: Rehabilitation, Punishment, or Correctional Quackery?” (2012) 25 Sexual Abuse 282 at 284-286.

$91 \quad$ At $288-289$.

92 At 293-296.

93 Devon Polaschek "An appraisal of the risk-need-responsivity (RNR) model of offender rehabilitation and its application in correctional treatment" (2012) 17 Legal and Criminological Psychology 1 at 7. 
reoffending or that need to be addressed to enable the offender to engage in treatment, but reducing reoffending is seen as also likely to improve offenders' lives. For example, the kinds of skills that RNR-compliant programmes teach, such as emotional regulation and problem-solving, are necessary for reducing recidivism and also make life easier for offenders. ${ }^{94}$ The slightly narrower ambit of the RNR model is a better fit with my concern to prevent over-extension of state power in the design and operation of the treatment track, another reason why I draw predominantly on RNR literature in my discussion of treatment.

Even if the benefits to treatment track participants were substantial, as I hope they would be, the treatment track cannot be justified on the basis that it would improve offenders' lives. The coercive and potentially intrusive intervention by the criminal justice process inherent in legally-mandated treatment cannot be justified on the basis of benefits to the participants. This kind of intervention can only be justified on the basis that it is necessary to prevent harm to others. ${ }^{95}$ Respect for the harm principle is a key difference between how I consider the treatment track should be designed and the way that problemsolving courts operate, in that in the latter restrictions on the liberty of participants are framed as being in their ultimate best interests. ${ }^{96}$

\section{B Theoretical framework}

Whether the treatment track or other proposed law reform is justifiable and, if so, how it should be designed, depends in part on what we consider to be the role of the criminal justice process and what values or principles we think should underpin the criminal law and its implementation. Our understanding of the criminal justice process and the criminal law, in turn, depends in part on how we conceive of the role of the state.

A liberal understanding of the role of the state underpins the perspective I take in this thesis. I adopt Roberts' definition of contemporary liberalism: ${ }^{97}$

Liberalism is a secular political morality which, in its currently dominant deontological strains, takes individual human beings as the primary units of ethical concern and is fundamentally orientated towards safeguarding individuals' liberty and promoting their

94 At 9-10.

$95 \quad$ Mill, above n 1 , at 22.

96 See the discussion in the previous section.

97 Paul Roberts "Criminal Law Theory and the Limits of Liberalism" in AP Simester, Antje du BoisPedain and Ulfrid Neumann (eds) Liberal Criminal Theory: Essays for Andreas von Hirsch (Hart Publishing, Oxford, 2014) at 337. 
personal autonomy. It does this without denying the socially-situated nature of the self, or neglecting (what it takes to be) the appropriate demands of distributive justice.

Central to liberal political thought is the proposition that the state has a duty to prevent harm, in order to secure the liberty of citizens. ${ }^{98}$ At the same time, safeguarding liberty requires that the state only interfere with the liberty of individuals as far as is necessary to safeguard the liberty of others. This requirement is Mill's harm principle (quoted above as the epigraph to this chapter). ${ }^{99}$

In accordance with the central concern for liberty, when the criminal justice process is used to prevent harm, the principle of penal minimalism (restraint in the exercise of the powers of the criminal law) should be operative. ${ }^{100}$ Roberts argues that penal minimalism captures the values of a liberal approach to the criminal law and to the operation of each stage of the criminal process. ${ }^{101}$

Penal minimalism, and the liberal theory underlying it, are mainstream ideas in Western thinking about criminal justice. In the contemporary New Zealand context, these concepts underpin discussions of the proper scope of the criminal law and the balance between the powers of the state to investigate, prosecute, and punish criminal offending and the rights of individuals to be free from state intrusion into their lives. ${ }^{102}$ Penal minimalism is also helpful in the context of serious over-representation of Māori in the criminal justice system, an unfortunate feature of the New Zealand criminal justice system. ${ }^{103}$ Māori have been on the receiving end of destructive state intervention since colonisation began, so a theoretical framework that seeks to restrain the power of the state is valuable. ${ }^{104}$

\footnotetext{
$98 \quad$ See the discussion in Ashworth and Zedner, above $\mathrm{n} 75$, at 7-10.

99 Mill, above n 1, at 22.

$100 \quad$ Roberts, above $\mathrm{n} 97$, at 339.

101 Ibid

102 See for example AP Simester and Warren Brookbanks Principles of Criminal Law (4 ed, Thomson Reuters, 2012) at 767-788; Law Commission Review of the Search and Surveillance Act 2012: Issues Paper (NZLC IP40, 2016) at 12; Law Commission Harmful Digital Communications: The Adequacy of Current Sanctions and Remedies (NZLC MP, 2012) at 26; Law Commission Invasion of Privacy: Penalties and Remedies (NZLC R113, 2010) at 17-18.

Kim Workman "Māori Over-Representation in the Criminal Justice System - Does Structural Discrimination Have Anything to Do with It?" (Rethinking Crime and Punishment, Wellington, 2011). Ibid.
} 
Looking towards the development of a truly bicultural system of justice, however, the appropriateness of the theoretical framework I have adopted is open to question. The liberal conception of the state and the individualised notions of responsibility inherent to the theory are foreign to te ao Māori (the Māori world). ${ }^{105}$ It may be that the theory is simply incompatible with te ao Māori. On the other hand, it may serve as a useful external framework to protect people from state over-reach, within which there is room to develop a specifically Māori approach. The proper relationship between Māori and Pākehā understandings of justice is a question that has not yet been answered and is beyond the scope of this thesis. The question of the compatibility of penal minimalism with te ao Māori is ultimately one for Māori to answer, and the shape of a bicultural criminal justice system is one to be developed in partnership. For those reasons, I cannot commit more firmly at this point about the appropriateness of penal minimalism in a bicutural system of justice for Aotearoa New Zealand, except to reiterate that there seems to me that it is valuable in any system to question and try to restrain the use of punishment by those in authority.

Penal minimalism has not yet been applied to proposed alternative resolutions of criminal offending, as far as I am aware. However, the conditions I suggest are grounded in general principles of criminal law, the criminal process, sentencing, and preventive justice that can all be seen as specific manifestations of penal minimalism. ${ }^{106}$ Where necessary I explain below why I think they apply also in the context of alternative resolutions of criminal offending. I argue that three conditions must be fulfilled in order for proposed alternative resolutions of criminal offending to comply with the principle of penal minimalism.

The first condition of penal minimalism is that the state's preventive duty should be exercised only where there is sufficiently serious harm to warrant intervention by the criminal justice process. This condition is derived from Feinberg's refinement of Mill's harm principle, in which Feinberg argued that the harm must be more than trivial to justify intervention by the criminal law. ${ }^{107}$ In this case, of course, it is not the legitimacy of criminalisation that is at issue but the use of a coercive process directed at reducing

$105 \quad$ Khylee Quince "Maori tikanga and the criminal justice system" in Julia Tolmie and Warren Brookbanks (eds) Criminal Justice in New Zealand (LexisNexis, Wellington, 2007) at 336-342.

"Preventive justice" is the term Ashworth and Zedner use in their work on criminal law or "criminal law-like" measures used by the state to prevent future harm. See Ashworth and Zedner, above $\mathrm{n} 75$.

107 Joel Feinberg The Moral Limits of the Criminal Law Volume 1: Harm to Others (Oxford University Press, Oxford, 1987) at 188-189. 
sexual reoffending. The concern behind the principle, however, limiting the use of the coercive powers of the criminal justice process to situations where intervention is necessary, is relevant to criminal processes as well as to criminalisation. Similarly, Ashworth and Zedner argue that coercive preventive measures are only justified to prevent serious physical (violent or sexual) future harms. ${ }^{108}$

There is no question that sexual assault causes serious harm and is properly a core criminal offence. However, for the first condition of penal minimalism to be fulfilled, it must also be established that sexual recidivism is a serious enough problem to warrant intervention with legally-mandated, potentially intrusive treatment. Accordingly, in Chapter 4 I look at how often people who have committed a sexual offence reoffend, and consider whether the rates of sexual recidivism warrant an intervention aimed at reducing it.

The second condition of penal minimalism is that the proposed reform is likely to be effective in preventing the identified harm. This condition is also derived from Feinberg's work. He put the following gloss on the harm principle: ${ }^{109}$

It is always a good reason in support of penal legislation that it would probably be effective in preventing (eliminating, reducing) harm to persons other than the actor and there is probably no other means that is equally effective at no greater cost to other values.

Again, Feinberg was writing in the context of criminalisation, but the principle equally applies to criminal justice processes.

I argue in the thesis that the treatment track could reduce sexual recidivism if it achieved either of two things. First, it could bring into the criminal justice process perpetrators of sexual violence who are likely to reoffend and with whom there would not otherwise be any intervention to reduce their risk of reoffending. Secondly, the treatment track could reduce reoffending by men who would ordinarily be convicted of a sexual offence and imprisoned. In Chapters 5 and 6, I explore whether there is empirical evidence that the treatment track could reduce recidivism in these ways.

\footnotetext{
$108 \quad$ Ashworth and Zedner, above n 75, at 22.

109 Feinberg, above n 107, at 26.
} 
The third condition of penal minimalism is that the proposed reform should not infringe unduly on the liberties of the accused/offender. At the heart of this condition is what Zedner and Ashworth refer to as "the paradox of liberty": 110

[A] major justification for taking preventive powers is to secure or enhance the liberty of individuals, but ... one possible effect of such powers is to deprive some individuals of their liberty. The paradox cannot be resolved by saying that it is all a question of balance, and that the loss of liberty for some has to be balanced against the overall gain in liberty generally. That is an unsatisfactory argument because it fails to respect liberty as a fundamental right, and also fails to recognise that the loss of liberty may fall disproportionately upon certain minority groups. If liberty is to be duly respected, the state's powers - justified as the minimum necessary powers to achieve an acceptable degree of prevention - should be so adjusted as to ensure that the liberty of all persons involved is preserved so far as possible.

In this quote Zedner and Ashworth draw attention to the status of individuals as rightsbearers in liberal theories, and characterise liberty as a fundamental right. Accordingly, they say, the liberty of any individual should not be curtailed more than is strictly necessary to prevent harm to others. Relatedly, individuals have certain procedural rights that limit the power of the state to deprive them of liberty arbitrarily or otherwise unfairly.

In the context of the treatment track, two sets of concerns are relevant. The first is substantive, the protection of proportionality between offence seriousness and the severity of the sentence or other response to it. The second set of concerns relate to procedural protections for the liberties of participants and potential participants. These two areas of concern are manifestations of penal minimalism because they are concerned with restraining the ability of the state to interfere with the liberty of individuals, by imposing limits on the degree of interference. I explore whether a treatment track could be designed in a way that could respect those two sets of protections.

\section{Argument and structure}

My over-arching argument is that it cannot be determined whether the treatment track would fulfil the conditions of penal minimalism until the necessary empirical research has been undertaken. I conclude the thesis by proposing a research agenda that prioritises the work necessary to take the treatment track idea forward.

$110 \quad$ Ashworth and Zedner, above n 75, at 257. 
In Chapter 2, I discuss the methodology of the thesis. The purpose of this chapter is to explain more fully the decisions I have made about the scope of the thesis. The chapter also makes explicit the values that underlie those decisions and my approach to the issues I discuss in the main body of the thesis.

While I am not aiming to develop a model for the treatment track, I have had to make certain decisions about what the model might look like as a precondition to being able to analyse whether the treatment track could fulfil the conditions of penal minimalism. In Chapter 3, I record those decisions as background to the rest of the thesis. I also note issues that would require consideration at a later date if the treatment track were considered feasible, but which cannot be addressed until the preliminary work has been done.

In Chapter 4, I consider the justification for intervening to reduce reoffending by sex offenders, which is relevant to the first condition of penal minimalism (whether the treatment track is necessary). I outline the research on official recidivism rates by convicted sex offenders and critique those findings, to argue that there is a need to increase the availability of treatment for sex offenders. I also discuss what is known about rates of repeat sexual violence perpetration by ordinarily undetected perpetrators, arguing that there is a small group of men who are responsible for a large amount of sexual violence, and that the treatment track should aim to identify and intervene with these men in particular.

I then discuss whether the treatment track is likely to be able to prevent harm by reducing reoffending, which is relevant to the second condition of penal minimalism (whether the treatment track would be effective). There are two ways in which it could achieve this aim. The first would be if the treatment track enabled the criminal justice process to intervene with perpetrators whose offending would not ordinarily result in a conviction but who are likely to continue offending without intervention. In Chapter 5, I explore whether there is sufficient evidence to suggest that the treatment track could bring some ordinarily undetected perpetrators who are at risk of reoffending into the criminal justice process, by increasing reporting, decreasing attrition, and/or incentivising guilty pleas. I then consider whether the treatment track is likely to be able to intervene safely and effectively with those perpetrators, examining what is known about risk assessment, treatment and risk management with ordinarily undetected perpetrators.

The second way in which the treatment track could reduce reoffending is if it enabled effective rehabilitation of men who would ordinarily be convicted of sexual offences and 
who would be eligible for the treatment track. As good risk assessment is required for good treatment, in Chapter 6 I consider the evidence base for the accuracy and validity of risk assessment with this group, arguing there are some concerning gaps in the evidence that ought to be filled. I outline what is known about the effectiveness of treatment with ordinarily convicted sexual offenders, again highlighting substantial gaps in the evidence base.

I turn to a discussion of the third condition of penal minimalism, which is that the reform should not infringe unduly on the liberties of the offender (the third condition of penal minimalism). In Chapter 7, I explore whether the treatment track could comply with the principle of proportionality, focusing on equivalence between the treatment track and the sentence that would ordinarily be imposed for sexual offending. I then consider whether the treatment track could coerce potential participants into pleading guilty and accepting psychological treatment, despite equivalence in severity with the sentence that would otherwise be imposed.

I conclude the thesis by setting out in Chapter 8 a research agenda that would enable the treatment track idea to be developed further and that links the research I am recommending be undertaken to wider issues in the criminal justice process.

\section{The Contribution of the Thesis}

The main thing I want the reader to take away from this thesis is a message of caution. The problems with the current way of responding to sexual offending seem intractable, and alternative resolutions - particulary those that promise a more compassionate and constructive way of addressing offending - are therefore very attractive. However, I have discovered in this research that there are serious gaps in knowledge. We do not know whether a treatment track could reduce reoffending or respect the liberties of participants. Until those gaps are filled, a treatment track - or any other response that relies on effective risk assessment and rehabilitation of men who have sexually assaulted an adult - should not be established.

The thesis contributes to knowledge about men whose sexual offending against adults ordinarily goes undetected in the criminal justice process. It highlights the empirical finding that there is a small number of men who are responsible for the majority of undetected sexual offences, and brings together what is known about those men to create a starting point for developing a risk assessment tool. 
Another important contribution to knowledge this thesis makes is about men who are ordinarily convicted of sexual offences. It reveals that not nearly enough is known about the accuracy of the most commonly used risk assessment tools with men who have been convicted of a sexual assault against an adult in New Zealand. This is important to know when assessing the feasibility of a treatment track. It also calls into question the current use of these tools for decisions that deprive offenders of liberty for extensive periods (for example preventive detention, extended supervision orders, and public protection orders). In respect of the validity of the risk assessment tools, the thesis contributes to knowledge by analysing risk assessment with ordinarily convicted sex offenders in light of the literature on under-reporting, attrition, and the effect of the "real rape" bias in the processing of sexual cases. The concern may not be as serious as it has previously been argued to be, but questions remain.

Turning now to theory, the thesis develops a way to compare the severity of different types of sentences or resolutions that includes those with a restorative and/or rehabilitative component. This is important because it allows for different types of sentences and alternative resolutions to be used interchangeably without breaching the principle of proportionality. Empirical investigation that would enable translation of theory into practice is also identified.

\section{Conclusion}

Having established the background to this thesis and its aims, structure, and contribution, I move on in Chapter 2 to discuss in more depth the methodology. 


\section{Methodology}

\section{Introduction}

The purpose of this chapter is to explain further some of the decisions I have made about the thesis. I begin by outlining in Part II how the research developed, as background to the choices I have made about the scope of the thesis, which are discussed in Part III. In Part IV, I locate the work in its law reform context. In Part V I discuss the methods I have used, and finish in Part VI by providing some key definitions.

\section{The Development of the Thesis}

The thesis I have written is not the one I originally set out to write. In this section, I outline the major ways the thesis changed over time, as background to my explanation in the rest of this chapter of the choices I have made about how to conduct the research. The difficulties I encountered along the way - themselves discoveries - became central to the argument I make in the thesis and its contribution to knowledge.

\section{A An increasingly modest aim}

Initially, I had planned to develop a comprehensive model for a treatment track that would be ready to implement in New Zealand. My objective was to develop a model that was evidence-based and would comply with what I considered to be fundamental principles of the criminal justice process. However, it became clear about 18 months into the research that neither the theoretical development nor the empirical investigation had been done that would allow me to develop an evidence-based, principled treatment track model.

I considered selecting one issue to investigate in depth. That would probably have involved undertaking empirical research on a narrowly defined issue, as I had realised that even the necessary theoretical development required a better evidence base if it was to be grounded in reality. Despite being narrowly defined, much of the empirical research required is complex and sensitive (particularly in relation to undetected sexual offending) so would be difficult to manage within the scope of a thesis also trying to 
advance the principled analysis. I decided that the better option at this stage would be to retain a big picture view of the treatment track idea and identify the gaps in knowledge that must be filled as preliminary steps towards designing the model and assessing the feasibility of a treatment track. A research agenda could then be developed to guide the necessary empirical research. Retaining the big picture focus was also a better fit for my skills and interests than undertaking empirical research would have been.

I continued synthesising existing evidence and highlighting major gaps, with a view to constructing a research agenda prioritising issues requiring empirical investigation. I also began to undertake some theoretical development myself, to start a discussion of what it would mean for the treatment track to operate in a principled way and how it might need to be designed in order to do so. I could only do the development to the point where more empirical research was needed, however.

As the work progressed, I found that even this narrower scope was too wide. The work was difficult because of the range of different bodies of literature and disciplinary perspectives that I needed to master, the complexity of the issues, and the extent of the gaps in knowledge. In particular, the analysis of the evidence in relation to how accurate existing risk assessment tools would be with the likely treatment track population (which eventually formed the core of Chapter 6) was extremely time-consuming and challenging. There is a large body of literature on the accuracy of risk assessment, but it had not before been analysed from the perspective of whether there was sufficient empirical support for the use of those tools in a community-based, rehabilitative alternative to prison. Moreover, presenting the analysis in a way that was accessible for a legal audience, without losing its robustness from a psychological perspective, involved considerable thought and effort. For those reasons, I narrowed the scope further, selecting a few issues to focus on, rather than trying to identify what needs to be discovered in relation to all issues relevant to the treatment track.

\section{B The elusive theoretical framework}

I had begun the research process with a search for a theoretical framework that would help me reconcile all the different values and interests I thought the treatment track engaged, while also being straightforward enough to be able to be used as a unifying framework for the thesis. I considered a range of different frameworks, but could not find one that fit these requirements. I would have liked to ground my ideas about what "principled" meant in a single theory of criminal justice. However, I could not find one theory of criminal justice that included all the principles, values, interests, and aims that I considered relevant in the context of the treatment track. 
Accordingly (drawing on Zedner's typology of normative theories of criminal justice ${ }^{1}$ ) I decided it would not be possible to ground my analysis in either an overarching theory of criminal justice or of criminal justice as a form of social justice, but that I would have to settle for identifying the relevant principles and values without necessarily having them incorporated into a theory as such. I identified procedural and substantive fairness, proportionality, and community and victim safety as important values.

It was only when I was close to a full draft that I could identify the common thread running through the issues I had chosen to focus on and my approach to them. I realised that what was most important to me was that there were some limits on the power of the criminal justice process in alternative resolutions, just as there are in the traditional process. After reading Roberts' chapter in Liberal Criminal Justice Theories: Essays for Andreas von Hirsch, I identified penal minimalism as an overarching principle that could provide the theoretical framework for the thesis, tying together my choice of issues to focus on and the values underpinning my analysis. ${ }^{2}$ Identifying penal minimalism as the overarching principle helped to resolve issues I was still grappling with about the scope of the thesis and my approach to particular issues, so I knew it was the right framework. At that point I restructured the thesis using the penal minimalism framework and used the framework to help me rework my arguments.

\section{Implications for the scope of the thesis}

Penal minimalism is not the only perspective from which the proposed treatment track could be analysed. In this section, I note other perspectives that I think could illuminate different issues with the treatment track, but that I could not include within the scope of the thesis.

Adopting penal minimalism as the theoretical framework of the thesis enabled me to consider an oft-neglected aspect of alternative resolutions for criminal offending: protection for the accused/offender. Traditional concerns with procedural and substantive

Lucia Zedner Criminal Justice (Oxford University Press, Oxford, 2004) at 25-31; Andrew Ashworth and Lucia Zedner Preventive Justice Justice (Oxford University Press, New York, 2014) at 6 .

Paul Roberts "Criminal Law Theory and the Limits of Liberalism" in AP Simester, Antje du BoisPedain and Ulfrid Neumann (eds) Liberal Criminal Theory: Essays for Andreas von Hirsch (Hart Publishing, Oxford, 2014). See Chapter 1, Part VB for a full exposition of the theoretical framework adopted. 
fairness tend to be overlooked in the enthusiasm for doing something "positive" to "help" the offender and the community. Moreover, my disciplinary background (law and psychology) enabled me to undertake an analysis from the perspective of penal minimalism, and the framework was the best fit for issues I was already focusing on in the thesis. Specifically, penal minimalism worked well as an organising tool for drawing together the empirical and the theoretical, enabling me to consider how to develop the treatment track in a principled way.

It would be valuable to look more closely at how the interests of the victim should be protected in the treatment track. Although it is somewhat offender-focused, in the sense that its objective is to reduce sexual recidivism, victims may be affected by decisions made at a number of points in the treatment track (including referral of the accused to the treatment track and the decision whether to accept the accused as a participant, the stipulated facts of the offending to which the accused pleads guilty, the risk management conditions imposed on the offender, and the agreement about how the offender should make amends for the offending). A useful next step would be to consider whether and how the victim's views should be taken into account when making these decisions, keeping in mind the potentially competing interests of the accused/offender and the public and the desirability of consistency. It is also possible that when the victim knows the accused/offender well, the victim may be able to provide insight that is valuable for risk assessment and that could not be obtained in other ways. Further empirical exploration of the value of incorporating information of this sort into risk assessment may also be beneficial.

Another important consideration is how well the treatment track would serve Māori. Kaupapa Māori research could reveal quite different issues with the basic concept and point in different directions for the treatment track design, which would then need to be considered alongside the issues raised by the penal minimalism analysis (reflecting the bicultural foundation of New Zealand's public life). It would be useful for someone with expertise in conducting Kaupapa Māori research and the authority to comment on tikanga Māori to consider the treatment track idea further.

Analysis using a social justice approach could also be undertaken. Consistent with the liberal grounding of my analysis, I leave to one side most of the structural inequalities relevant to criminal offending and the response of the criminal justice process to it. In particular in this context, there may be a risk of the treatment track being used only for middle-class Pakeha perpetrators of sexual violence, while Māori perpetrators and those 
from lower socio-economic groups continue to be imprisoned at disproportionately high rates. $^{3}$ Consideration of these issues, drawing on the relevant sociological research, would also add a useful perspective to be considered alongside the analysis I undertake in this thesis.

An important question is whether the treatment track (or other alternative resolutions for sexual offending) could ever be accepted as legitimate by the public. I have stayed away as much as possible from questions about what is publicly and politically acceptable, because I think this research would be done better by criminologists or policy workers with expertise in this area. Questions about legitimacy are probably also best addressed using the public engagement approach to law reform (discussed below) rather than the more academic approach I have taken in the thesis. The question of public acceptability is probably best considered once the idea has been analysed also from the three perspectives identified above, so that a full picture of the possibilities of the treatment track can be presented and consulted on.

Finally, in their project, McDonald and Tinsley focused on sexual assaults committed by adults against adult victims. ${ }^{4}$ I do the same, but restrict my discussion to male perpetrators, because men perpetrate the vast majority of sexual assaults against adult victims and because most of the research, particularly in respect of risk assessment and rehabilitation, is with male perpetrators. ${ }^{5}$ Different issues may arise with female perpetrators that would require more discussion than there is space for in this thesis.

3 Over-representation of Māori was noted as a concern in the 2015 report of the United Nations Committtee Against Torture Concluding observations on the sixth periodic report of New Zealand (CAT/C/NZL/CO/6, 2 June 2015) at 5. Elisabeth McDonald and Rachel Souness "From "real rape" to real justice in New Zealand Aotearoa: The reform project" in Elisabeth McDonald and Yvette Tinsley (eds) From "Real Rape"to Real Justice: Prosecuting Rape in New Zealand (Victoria university Press, Wellington, 2011) at 48-49.

New Zealand Family Violence Clearinghouse Data Summary 6: Child Sexual Abuse and Adult Sexual Assault Perpetration by Gender (June, 2017). In relation to the research, the most influential meta-analyses of psychological research did not include studies with female sexual offenders: Karl Hanson and Monique Bussière "Predicting relapse: A meta-analysis of sexual recidivism studies" (1998) 66 Journal of Consulting and Clinical Psychology 348; Karl Hanson and Kelly MortonBourgon "The Characteristics of Persistent Sexual Offenders" (2005) 73 Journal of Consulting and Clinical Psychology 1154; Karl Hanson and Kelly Morton-Bourgon "The accuracy of recidivism risk assessments for sexual offenders: A meta-analysis of 118 prediction studies" (2009) 21 Psychological Assessment 1. One of the meta-analyses included three studies (of a total of 23) which had a small number (less than 10 per cent) of female offenders in their samples: Karl Hanson, 


\section{Law Reform Context}

This thesis is part of a larger law reform project, developing alternative processes for responding to sexual violence. In this section, I identify where my thesis sits in the law reform context. To do so, I draw on literature about institutional law reform. Although this is a doctoral thesis rather than an institutional project (that is, one undertaken by a Law Commission, government department, or other body) that literature is nonetheless helpful for articulating my approach.

Two approaches to law reform have been identified: the research institute approach (producing detailed reports that are the result of independent research and draw on academic literature) and the community engagement process (where community consultation guides law reform, and the reports produced are intended to be accessible to a wide audience). ${ }^{6}$ McDonald and Tinsley's research involved both approaches to law reform, while the Law Commission's was weighted more heavily towards the community engagement approach.

My thesis follows the research institute approach, which I think is appropriate for the stage of the project as well as necessary given the nature and resource limitations of doctoral research. Consultation has already established that there is support for the idea of a treatment track, and the next step is to work out the details of how it might be designed and whether it is likely to be feasible. ${ }^{7}$ For the questions I have ultimately decided to ask in the thesis, which require in-depth normative analysis and evaluation of the empirical literature, the research institute approach is the more appropriate one. In respect of some issues discussed in the thesis, however, consultation would nonetheless be helpful, and I indicate where that is the case.

I also note at this point that while this is a law reform project, I do not advocate in the thesis for either victims or offenders. One of the reasons I chose to develop the treatment track idea was because of its potential to provide a less harmful, more constructive

Guy Bourgon, Leslie Helmus and Shannon Hodgson "The Principles of Effective Correctional Treatment Also Apply to Sexual Offenders: A Meta-Analysis" (2009) 36 Criminal Justice and Behavior 865 at 875.

$6 \quad$ Kieran Tranter "Citation Practices of the Australian Law Reform Commission in Final Reports 1992-2012" (2015) 38 UNSW Law Journal 323 at 327.

7 Law Commission Alternative Pre-Trial and Trial Processes: Summary of Submissions to Consultation (NZLC MP, 2012) at 98-105. 
resolution for serious offending, which could be of benefit to victims, offenders, those close to members of both groups, and to the wider public. I did not, however, have a specific advocacy goal in mind. The treatment track raises interesting and difficult issues that also bear on current practice and more widely are relevant to the search for better responses to criminal offending. Given the uncertainties around the issues I discuss, it would be premature and possibly counterproductive to take an advocacy approach in this thesis.

Although I set out with the hope of contributing to law reform, events since I began the research have indicated there is limited political will for the adoption of alternative resolutions for sexual offending. That is illustrated by the history of the Law Commission's alternative trial processes project, which (as outlined in Chapter 1) was aborted before public submissions had even closed, then revived some time later with a timeframe that was too short for the issues to be addressed thoroughly. ${ }^{8}$

I approached the thesis with McDonald and Tinsley's warning about the fickleness of the political context in mind. They said that law and policy reform goals should not on their own determine the research questions, methodology, or conclusions. ${ }^{9}$ The decisions I have made about the thesis reflect what I think is most important for an academic contribution to the area, covering issues in depth that might be neglected in a more political or time-constrained context. I consider that approach to be preferable to adopting the perspective that would be most likely to garner political support for change, which might be efficiency gains for the criminal justice process or victims' interests (although the latter is perhaps unlikely given the influence of punitive law and order groups such as the Sensible Sentencing Trust that hold themselves out as speaking for victims and that are highly unlikely to support alternative resolutions).

It is possible that the thesis may nonetheless make some contribution to law reform. McDonald and Tinsley suggested that even in a climate with little political will for change, academic research can contribute to law reform by encouraging further research, providing background to future law reform efforts when political interest revives, and by bringing attention to issues that have been ignored or that could not be progressed due to

\footnotetext{
$8 \quad$ For an indication of the pressures facing the Law Commission at the time, see Aimee Gulliver "Law Commission "stretched to the limit"" (19 February 2015) Stuff $<$ http://www.stuff.co.nz/national/politics/66401130/law-commission-stretched-to-the-limit>.

9 Elisabeth McDonald and Yvette Tinsley “"The Law as it Should Be” When Prosecuting Sexual Offences: The Contribution of Legal Academics to Law Reform” (2013) 25 NZULR 758 at 778.
} 
a lack of evidence. ${ }^{10}$ The thesis draws attention to the need for the development of the evidence base in relation to a number of key issues relevant to alternative resolutions for sexual offending. The research agenda I propose at the end of the thesis is directed towards the aim of encouraging future research. I also draw attention to the need for restraint of the power of the criminal justice process in relation to alternative resolutions, an issue that has been largely ignored in the proliferation of problem-solving courts throughout New Zealand. I undertake some theoretical development as a step towards progressing the very difficult issue of how best to ensure procedural and substantive fairness for the accused/offender, which may be of use for a treatment track or in other alternative resolutions.

\section{Method}

The main method I use in the thesis is normative analysis, examining whether the proposed treatment track could comply with the principle of penal minimalism. Where potential breaches of the principle are identified, I evaluate (as far as possible, given the limitations of the empirical evidence) the extent of the breach and whether it could be mitigated. The dearth of empirical evidence means I cannot come to a conclusion about whether the treatment track would comply with penal minimalism, so I propose a research agenda by way of conclusion.

I have employed two additional methods to enable me to do the normative analysis. The first is theoretical development. I needed to develop sentencing theory to apply it to alternative resolutions to offending, so that I could consider whether the treatment track could be designed with sufficient protection for consistency and proportionality (important aspects of preventing undue interference with the liberty of the accused/offender, the third condition of penal minimalism).

The second method I have employed in aid of the normative analysis is synthesis and critique of empirical evidence. While the over-arching question I ask in the thesis is a normative one (would the treatment track fulfil the requirements of penal minimalism?) the answer relies on the availability of a good evidence base. The normative and empirical questions are inter-related, as illustrated by the following table: 


\begin{tabular}{|l|l|l|}
\hline $\begin{array}{l}\text { Condition of penal } \\
\text { minimalism }\end{array}$ & Empirical question & Normative question \\
\hline Is the TT necessary? & $\begin{array}{l}\text { How likely are sex offenders } \\
\text { to reoffend? }\end{array}$ & $\begin{array}{l}\text { Is recidivism a serious enough } \\
\text { problem warrant } \\
\text { intervention in a new way? }\end{array}$ \\
\hline $\begin{array}{l}\text { Is the TT likely to be effective } \\
\text { in solving the problem? }\end{array}$ & $\begin{array}{l}\text { What could the TT do to } \\
\text { reduce reoffending? How } \\
\text { effective is it likely to be? }\end{array}$ & $\begin{array}{l}\text { How much of a difference } \\
\text { does the TT have to make? } \\
\text { How sure do we need to be } \\
\text { about its effectiveness? }\end{array}$ \\
\hline $\begin{array}{l}\text { Is the TT able to solve the } \\
\text { problem without infringing } \\
\text { unduly on the liberties of the } \\
\text { accused/offender? }\end{array}$ & $\begin{array}{l}\text { What liberties are threatened? } \\
\text { will infringe on these liberties? }\end{array}$ & $\begin{array}{l}\text { How much infringement is too } \\
\text { much, given the potentially } \\
\text { competing interests and the } \\
\text { relative importance of those } \\
\text { interests in the CJP? }\end{array}$ \\
\hline
\end{tabular}

The empirical evidence I draw on comes from psychology and criminology. To be able to marshal that evidence for the normative analysis, I have needed to synthesise it within and across the disciplines. Several relevant bodies of literature have developed separately from each other, each painting only a partial picture. I use reasoning to bring the separate bodies of literature together to explain why I think there are major gaps in knowledge. In some places I also use reasoning to hypothesise what might be found if the empirical research were undertaken. I critique the reliability and validity of the research using standards internal to the disciplines from which the research is sourced, in order to evaluate the strength of the evidence base the normative analysis relies on.

The task of synthesising and critiquing the evidence was most demanding in respect of the risk assessment literature. I was asking different questions to those that tend to be asked about risk assessment, because my synthesis of different bodies of literature had revealed new questions. I have also had to explain in more detail than would normally be done (in either law or psychology) how risk assessment measures and the statistics used to assess the accuracy of risk assessment work, because that is central to my argument.

Accordingly, it has been difficult to try to make the discussion accessible and interesting to non-specialist readers while still including the detail required to support my argument and move the literature forward. Consistent with my decision to take the research institute approach to law reform rather than the community engagement approach, I have 
kept the detail that I think is necessary for a specialist academic audience. ${ }^{11}$ I plan to publish articles written with a wider audience in mind to disseminate the results of my research to potentially interested people from a range of backgrounds and areas of expertise.

When assessing the adequacy of the evidence base for law reform purposes, there is a normative overlay not necessarily present in empirical psychological or criminological work. The question of how certain we need to be about the evidence before undertaking law reform on the basis of that evidence is really a normative question, and one that I have grappled with throughout the thesis. There were several specific challenges that fed into my conclusion that it would be premature to establish a treatment track at this point and that influenced the research agenda I propose at the end of the thesis.

First, much of the research I draw on relates to questions in which uncertainty is inherent because the questions require prediction of the future. (How likely is it that someone will reoffend? Will the risk management conditions available be enough to contain the risk of reoffending while the person completes treatment? Will treatment stop the person from reoffending?) There are multiple layers of uncertainty around risk assessment, in particular. Risk assessment measures can provide a probability that a person sharing certain characteristics with the offender will reoffend - the first layer of uncertainty. As will be discussed in depth in Chapter 6, research assessing the accuracy of risk assessment measures provides a probability that a person convicted of a new offence will have a higher score on the risk assessment measure than a person not convicted of a new offence - a second layer of uncertainty. That figure, however, is only an estimate of the true probability that an offender convicted of a new offence will have a higher score on the risk assessment measure - a third layer of uncertainty. The estimate sits within a range of other plausible figures, and how likely it is that the true figure sits within that range of figures is again a matter of probability. The risk assessment evidence can, therefore, be understood as an uncertainty around an uncertainty around an uncertainty.

A second difficulty with the normative question of how certain we must be before adopting a reform such as the treatment track is that much of the evidence required is about relatively hidden phenomena. One of the main concerns of the treatment track is to provide another resolution option that might bring people whose offending would not ordinarily be detected into the criminal justice process. But because that offending is undetected, it is more difficult to research. Similarly, the reasons victims do not report

11 John Burrows “Academics and Law Reform” (2013) 25 NZULR 667 at 673-674. 
offences against them and the characteristics of those victims and offences are more difficult to establish than for offences that are reported. Of course these questions can and have been investigated, but compared with offences resulting in conviction, much less is known about them.

The inherent uncertainty and hidden nature of some of the phenomena relevant to whether the treatment track could comply with the principles of penal minimalism pose a challenge for the ideal of evidence-based law reform. Are there issues for which it might not be possible to establish a strong evidence base? And if so, is that an argument in favour of trying the treatment track anyway, as an experiment (a controversial idea, given the seriousness of the harm caused by sexual violence)? Or is it an argument against any reforms for which a strong evidence base cannot be established (ruling out reforms which could make a positive difference and even help to produce some of the evidence themselves)? For most of the issues I discuss in the thesis, it is not necessary to make that decision: there is still more research that can reasonably be done before it can be concluded that the evidence base cannot be obtained. I do, however, keep in mind the inherent uncertainty and hidden nature of some of the issues when I evaluate the adequacy of the current evidence base - absolute certainty in the evidence cannot be expected. Context is also important when evaluating the adequacy of the evidence. With ordinarily undetected offending, we might conclude that some intervention is better than nothing, regardless of uncertainty. With ordinarily convicted offenders, on the other hand, the uncertainty probably leads to the conclusion that it would not be acceptable to try to keep them in the community rather than in prison at this point. These are issues I discuss further in the thesis and in the risk agenda proposed at the end.

A third challenge for determining whether there is a sufficient evidence base to conclude that the treatment track could fulfil the requirements of penal minimalism is that one of primary disciplines from which the evidence is drawn - correctional psychology - is a young discipline. ${ }^{12}$ There is much left to discover. Compounding that difficulty is that science is in the midst of what has come to be known as "the replication crisis" (the finding that many well-known studies have failed to replicate when repeated by independent researchers, calling into question the reliability of published studies across

12 The first edition of The Psychology of Criminal Conduct (the foundational text for the discipline) was published as recently as 1994 . 
disciplines including psychology). ${ }^{13}$ The replication crisis has spurred strong criticism of the way that the reliability of findings is usually assessed statistically (null hypothesis significance testing), on the basis that this type of analysis makes it appear that findings are more certain than they are in reality. ${ }^{14}$ Against this background, it is important to look closely at the psychological evidence relevant to any proposed law reform, something I do in the thesis.

Finally, throughout the thesis I bear in mind a caveat that applies to law reform generally. In assessing the likely effectiveness of a proposed law reform, it is important to be realistic about how much change any legal reform can make. Change will always be incremental, and cannot occur in isolation from broader social and political changes.

\section{$V$ Definitions}

I use the term "perpetrator" to refer to any persom who has committed a sexual offence, whether or not they have been charged or convicted. "Offender" refers to a person has been convicted of a sexual offence. From time to time I use "suspect" to refer to a person who is the subject of a police investigation of a sexual assault complaint and "accused" to refer to a person who has been charged with a sexual offence.

I use "victim" to refer to a person who has been sexually assaulted, whether or not that person identifies the behaviour as a criminal offence and regardless of whether or not there is any legal outcome. I use "complainant" to refer to the victim of a sexual assault in the pre-trial and trial stages of a prosecution. I generally use these terms in the singular, but a sexual assault can of course involve multiple victims and/or perpetrators. Victims may be of any gender, but I sometimes use female pronouns because women are the largest group of victims. ${ }^{15}$

For a brief summary, see Harold Pashler and Eric-Jan Wagenmakers "Editors' Introduction to the Special Section on Replicability in Psychological Science: A Crisis of Confidence?” (2012) 7 Perspectives on Psychological Science 528.

14 I adopt the recommendations made by Geoff Cumming in Understanding The New Statistics: Effect Sizes, Confidence Intervals, and Meta-Analysis (Routledge, New York, 2012). My approach is explained in Appendix A. men: New Zealand Crime and Safety Survey Main Findings Report (Ministry of Justice, 2015) at 51. 
"Sexual assault" refers to a contact sexual offence (for example sexual violation by rape or unlawful sexual connection, indecent assault).

The term "real rape" refers to the stereotypical sexual assault - the perpetrator is a stranger to the victim, uses a weapon and overt physical violence, the victim fights back and is physically injured and so on. ${ }^{16}$ These are the minority of sexual assaults, but the victim is more likely to believed and supported, and the perpetrator (if identified) is more likely to be prosecuted and convicted. I contrast "real rapes" with "everyday rapes", which occur much more frequently than "real rapes".

An "everyday rape" is a sexual assault where the victim and perpetrator are known to each other (whether in an intimate relationship, dating, friends, colleagues, casual acquaintances, family member or other relationship), and there is little or no overt physical violence beyond that inherent in the offence. If an "everyday rape" is reported to the police, the issue is usually whether the victim consented to the sexual activity or whether the alleged perpetrator believed on reasonable grounds that the victim consented. $^{17}$

The term "acquaintance rape" is used more frequently to describe this type of assault, but I use "everyday rape" instead because an offence in which the victim and the offender are not known to each other but has none of the other characteristics of a "real rape" (for example, an offence occurring at a party when the victim is intoxicated and perhaps consented to sexual activity earlier in the evening) would also fall under the umbrella of an "everyday rape". Conversely, a "real rape" may be committed by an acquaintance of the victim, but its characteristics may be such that it will still be perceived as "real" (for example, if it involves the abduction and extended detention of a friend or colleague and overt physical violence is used).

"Ordinarily undetected perpetrators" are perpetrators whose offending does not currently result in a conviction, but who we may wish to bring into the criminal justice process via the treatment track. "Ordinarily convicted offenders" are men whose sexual assault of an adult has resulted in a conviction.

$16 \quad$ Susan Estrich Real Rape (Harvard University Press, Cambridge Massachusetts, 1987).

17 Graeme Panckhurst "Consent in Rape: An Elusive Concept" in J Bruce Robertson (ed) Essays on Criminal Law (Brookers, Wellington, 2004) at 182. 


\section{Conclusion}

Chapters 1 and 2 have provided information about the aims of the thesis and decisions I have made about the approach to take. The next chapter is a transitional one - it begins the original contribution of the thesis, with further development of the treatment track idea, but its purpose is primarily as background for the discussion in Chapter 4 and following of whether the treatment track could comply with penal minimalism. 


\section{The Treatment Track Model}

\section{Introduction}

The basic model for the treatment track is that described by McDonald and Tinsley and outlined in Chapter 1 of this thesis: in suitable cases, participants are referred to treatment in the community in exchange for a guilty plea. In this chapter, I expand on parts of that model and add some additional components that I consider necessary for the treatment track to achieve justice in each case. I also highlight issues that require further development but cannot be addressed within the scope of this thesis.

For reasons that will become apparent throughout the thesis, I cannot give a detailed and comprehensive description of how the treatment track should operate. That can only be done once more is known about the likely participants and the needs and wishes of their victims. The purpose of this chapter is to provide background for the discussion in the rest of the thesis, to record general decisions I have needed to make in the course of the research about how I think the treatment track should be designed, and to indicate areas requiring further research.

In Part II, I outline decisions I have made in the course of the research about how the treatment track should be designed, and highlight issues still requiring further exploration. In Part III I discuss which offences should be eligible, and in Part IV which offenders. In Part V, I consider briefly what the timeframe for the treatment track might be.

\section{Components of the Treatment Track}

In this section, I outline the components of the treatment track, describing each component in terms of its primary purpose. The first two components, rehabilitation and risk management, focus on reducing recidivism. The third component is making amends.

The boundaries between the different components are not as clear as they will perhaps appear from the way I have divided them. The components with the primary purpose of 
reducing recidivism could also be thought of as making amends (for example, the victim might consider the offender getting treatment to be part of his amends). Similarly, components with the purpose of making amends might be important in some cases for desistance (for example, as part of the identity change that is considered an important part of the desistance process or simply as an additional opportunity to monitor the offender's behaviour

$\left.{ }^{1}\right)$. Finally, all the components can be understood as holding the offender accountable for the offending, something I discuss in depth in Chapter 8.

\section{A Rehabilitation}

The rehabilitation component of the treatment track comprises psychological treatment and other measures that build "social and psychological capital" to reduce the likelihood that the participant will reoffend. ${ }^{2}$

\section{Treatment}

At this point, it is not possible to specify exactly what the treatment component of the treatment track would involve, because the programme has to be designed to be suitable for the risk level, treatment needs, and responsivity issues (issues that get in the way of participants engaging fully with treatment) of the participants. ${ }^{3}$ Although it may be possible to make an educated guess about the risk, need and responsivity issues of men who would ordinarily be convicted of a sexual offence and might be interested in the treatment track (based on what is known from research with samples of convicted sex offenders), the treatment track also aims to bring in people whose offending would not normally be reported or result in a conviction. ${ }^{4}$ Much less is known about these men, so the content of a treatment programme should not be confirmed until participants are identified and assessed. Eligibility criteria could help to narrow down the range of risk and responsivity issues, but that on its own is not enough to design a suitable programme without knowledge of the participants. ${ }^{5}$

$1 \quad$ Svenja Goebbels, Tony Ward and Gwenda Willis "An integrative theory of desistance from sex offending" (2012) 17 Aggression and Violent Behavior 453.

2 D Richard Laws and Tony Ward Desistance from Sex Offending: Alternatives to Throwing Away the Keys (Guildford Press, New York, 2010) at 175.

3 These are the core principles of treatment programmes that reduce reoffending. These are set out in James Bonta and DA Andrews The Psychology of Criminal Conduct (6 ed, Routledge, New York, 2017).

$4 \quad$ See Chapters 4 and 5 of this thesis for a full discussion of this issue.

5 I discuss eligibility criteria in a preliminary way in Parts III and IV of this chapter, and indicate issues that require further research. 
It is likely, however, that the starting point for designing a treatment programme for the treatment track would be the programmes currently operating in New Zealand prisons for men who have sexually assaulted an adult. The Adult Sex Offender Treatment Programme (the ASOTP) is a ten-month group programme that runs four mornings a week. It is supplemented by weekly individual sessions, to address issues that prevent men from participating fully in the group and to cover anything that is not appropriate to be addressed in the group. Not enough graduates of the ASOTP have been released in order to evaluate how effectively the programme reduces recidivism, but an evaluation carried out in 2013 found that graduates of the programme did demonstrate reduction in risk on a range of variables related to recidivism. ${ }^{6}$ The ASOTP has also been used as a model for a community-based programme, the Adult Sexual Assault Programme (ASAP). The ASAP has not been implemented, but the Introduction to the manual argues that it would be practicable to deliver a treatment programme in the community for men who have sexually assaulted an adult. ${ }^{7}$

The length, intensity, and exact material to be covered in the programme would have to be considered carefully once participants are identified. The ASOTP was designed for men with severe personality pathology, which may not be the case with the treatment track participants, particularly those whose offending would not currently be reported. The first module of the programme in particular may be able to be shortened for the treatment track participants if they do not have personality pathology to the same extent as the ASOTP participants. The treatment track participants may also not have the same kinds of responsivity issues as the ASOTP participants, which could reduce the need for individual therapy sessions alongside the group ones. Finally, a less intensive and/or shorter programme might be required, if the treatment track participants are lower risk than the ASOTP participants (which is likely as many of the ASOTP participants have been sentenced to preventive detention, so by defintion are considered to pose too great a risk to be in the community ${ }^{8}$ ) or have fewer responsivity issues needing to be addressed in the course of the programme (as "process issues" for the group to work through or as issues to be focused on in individual and group sessions).

\footnotetext{
$6 \quad$ Nick Wilson, Glen Kilgour and Devon Polaschek "Treating high-risk rapists in a New Zealand intensive prison programme" (2013) 19 Psychology, Crime and Law 527 at 541.

7 Adult Sexual Assault Programme Manual (Wellstop, Wellington, 2009) (on file with author).

$8 \quad$ Wilson, Kilgour and Polaschek, above n 6, at 539.
} 
The ASOTP may need to be adapted for delivery in the community, particularly given the range of obligations treatment track participants would have (discussed in Parts B-D below). How the treatment programme is delivered would need careful consideration, because its intensity is an important factor in effectiveness. ${ }^{9}$ Delivering a programme in the community as opposed to prison has advantages and disadvantages: ensuring attendance is more difficult in the community, but being in the community offers a wider range of opportunities to practise the skills being developed in treatment, which should be capitalised on for maximum effectiveness.

Treatment should also target non-sexual recidivism. Men who have been convicted of sexually assaulting an adult are more likely to be convicted of a non-sexually violent or non-violent offence after release than to be convicted of another sexual offence. ${ }^{10}$ Another reason the ASOTP may be a good starting point for the design of the treatment programme delivered in the treatment track is that it addresses general criminogenic needs as well as sexual deviance (because both are implicated in sexual offending). ${ }^{11}$ It is therefore likely to be effective also in reducing non-sexual recidivism because it addresses those general criminogenic needs.

\section{Other desistance-focused measures}

Pro-social support networks, employment, stable accommodation, and supportive intimate relationships are also important factors in reducing reoffending by sex offenders. ${ }^{12}$ It should be ensured that these factors are addressed, where necessary, as part of the treatment track.

Bonta and Andrews, above n 3, at 190.

10 James Vess and Alex Skelton "Sexual and violent recidivism by offender type and actuarial risk: reoffending rates for rapists, child molesters and mixed-victim offenders" (2010) 16 Psychology, Crime and Law 541 at 550. See also Danielle Harris, Stephen Smallbone, Susan Dennison and Raymond Knight "Specialization and Versatility in Sexual Offenders Referred for Civil Commitment" (2009) 37 Journal of Criminal Justice 37 at 42 for evidence that few contact adult offenders specialise in sexual offending, but that mixed offenders were more likely to.

11 Nick Wilson, Glen Kilgour and Devon Polaschek "Treating high-risk rapists in a New Zealand intensive prison programme" in Devon Polaschek (ed) Treatment Programmes for High Risk Offenders (Routledge, New York, 2016) at 123.

12 Karl Hanson and Andrew Harris "Where Should We Intervene? Dynamic Predictors of Sexual Assault Recidivism” (2000) 27 Criminal Justice and Behavior 6; Karl Hanson and Kelly MortonBourgon "The Characteristics of Persistent Sex Offenders: A meta-analysis of recidivism studies" (2005) 73 Journal of Clinical and Consulting Psychology 1154; Gwenda Willis and Randy Grace "Assessment of Community Reintegration Planning for Sex Offenders: Poor planning predicts recidivism" (2009) 36 Criminal Justice and Behavior 494. 
The desistance-related needs of treatment track participants may depend on whether they are more like "ordinarily convicted offenders" or "ordinarily undetected perpetrators". The former may never have had the kind of social and psychological capital discussed in the desistance literature. Ordinarily undetected perpetrators may have had those things, but be at risk of losing them because of the intervention by the criminal justice process. In that case, it would be important for the treatment track to try to "buffer" the effects of the detection of the offending in order to reduce the likelihood that the consequences of detection will actually make it more likely that the person will reoffend.

\section{B Risk management}

Another important component of the treatment track is risk management. The offender's risk of reoffending must be contained while he completes treatment, and possibly (depending on the level of risk) also after the completion of the programme. A variety of risk management options are available. Which are used will depend on the level and kind of risk posed by the offender and what resources are available. Risk management measures may include restrictions on residence (to live in an approved residence away from victims and potential victims), curfews, geographic restrictions monitored electronically or by GPS, conditions that the participant not have contact with victims or other offenders, and prohibition on use of alcohol and other drugs (monitored by drug tests). The police would probably need to work collaboratively with the treatment team to ensure that risk is managed appropriately. Victims could also develop safety plans with the police and specialist support organisations such as Rape Crisis or Women's Refuge, for their safety and peace of mind.

Risk management as "earning back" freedom could also be considered part of making amends for the offending: the offender must comply with restrictions and other requirements to prove that he is trustworthy.

\section{Making amends}

To enable the treatment track to provide a more comprehensive justice response, a restorative component should be added to the model. Treatment focuses on preventing future offending, but restorative justice is a way of redressing the harm that has already been done and holding offenders accountable for their behaviour. ${ }^{13}$

Howard Zehr Changing Lenses: A New Focus for Crime and Justice (Herald Press, Scottsdale Pennsylvania,1990). 
The practices of Project Restore - a service specialising in restorative processes for sexual offending currently operating in Auckland - provide guidance as to the kinds of restorative practices that might be appropriate in the treatment track. ${ }^{14}$ Preparation for a restorative process may be extensive, depending on the needs of those involved. ${ }^{15}$ Project Restore emphasises flexibility: the victim need not be involved at all, can be represented by others, and can engage with the process in ways other than a face-to-face meeting with the offender. ${ }^{16}$ Accordingly, the definition of the restorative process is broad: it refers to any process which aims to enable the offender to understand the harm he caused, take responsibility for it, and make amends as far as possible.

The amends component of the treatment track might include apologies, financial reparation to the victim, donation to a support agency or other organisation, community work, agreement about the future conduct of the relationship between the victim and the offender, and anything else appropriate to the situation and agreed upon by the parties, a facilitator, and possibly the treatment providers or criminal justice officials involved (if relevant to risk and/or rehabilitation). Adopting the flexibility of approach favoured by Project Restore might also extend to flexibility in timing. The amends component could be undertaken before, after, or even during treatment, depending on the needs of the victim and the readiness of the offender to participate appropriately, although the situation is of course more complicated if their timelines conflict.

\section{Which Offences?}

The treatment track is intended to be used an alternative to prison (not to community based sentences) and so it needs to be available for relatively serious offences. In this section, I outline which offences those should be and discuss the issue of eligibility when a person has committed multiple offences.

\section{A Relevant offences}

I propose that to be eligible for the treatment track, a person must have been charged with at least one of the following offences, and must not also be charged with murder (because

\footnotetext{
$14 \quad$ Shirley Jülich and others Project Restore: An Exploratory Study of Restorative Justice and Sexual Violence (AUT University, 2010).

15 At $34-36$.

16 At $38-40$.
} 
the sexual offence should generally be the most serious offence the person is charged with). ${ }^{17}$

The relevant sexual offences are those contact sexual offences that may be committed against a person aged 16 years or older: ${ }^{18}$

\begin{tabular}{|l|l|l|l|}
\hline & $\begin{array}{l}\text { Section of Crimes } \\
\text { Act 1961 }\end{array}$ & Offence & Maximum Penalty \\
\hline Core offences & $128 \mathrm{~B}$ & Sexual violation & 20 years \\
\cline { 2 - 4 } & 129 & Attempted sexual violation & 10 years \\
\cline { 2 - 4 } & 129 & $\begin{array}{l}\text { Assault with intent to commit sexual } \\
\text { violation }\end{array}$ & 10 years \\
\cline { 2 - 5 } & 135 & Indecent assault & 7 years \\
\cline { 2 - 5 } Charges & 208 & $\begin{array}{l}\text { Abduction for the purpose of sexual } \\
\text { connection }\end{array}$ & 14 years \\
\hline Alternative & $129 \mathrm{~A}$ & $\begin{array}{l}\text { Sexual conduct with consent induced } \\
\text { by certain threats }\end{array}$ & 14 years \\
\cline { 2 - 5 } & 131 & $\begin{array}{l}\text { Sexual conduct with a dependent } \\
\text { family member }\end{array}$ & 7 years \\
\cline { 2 - 5 } & 138 & $\begin{array}{l}\text { Sexual exploitation of a person with a } \\
\text { significant impairment }\end{array}$ & 10 years \\
\hline Misc. & $142 \mathrm{~A}$ & $\begin{array}{l}\text { Compelling an indecent act with an } \\
\text { animal }\end{array}$ & 14 years \\
\hline
\end{tabular}

Not all instances of these offences would be eligible for the treatment track. Further refinement on the basis of offence seriousness is necessary to maintain proportionality in responding to offences, an issue that is discussed fully in Chapter 8.

$17 \quad$ There may be exceptions to this, where the sexual offence has a lower maximum penalty than an accompanying offence (such as indecent assault and aggravated robbery, for example) where the overall seriousness might suggest that the person should still be eligible for the treatment track. These situations should be considered on a case by case basis.

18 Although some of the offences do not necessarily involve physical contact, for example attempted sexual violation.

19 A dependent family member is defined in the Act as a person aged under 18 years. For the purposes of the thesis, a person charged with this offence would be eligible for the treatment track if the victim was aged 16 or 17 years. 
In brief, however: At the bottom end of the seriousness range, I propose that only offences that would attract an end sentence (after personal aggravating and mitigating factors and the guilty plea are taken into account) of more than two years should be eligible for the treatment track. This is because the treatment track is intended as an alternative to a sentence of imprisonment (not to existing community-based sentences or to home detention) and home detention and community-based sentences can already be substituted for a prison sentence of up to two years. ${ }^{20}$ At the top end of the seriousness range, I propose that the offence must have a starting point (under $R v A M$, the Court of Appeal's guideline judgment for sexual violation) of eight years or less. ${ }^{21}$ That excludes instances of sexual violation with significant aggravating factors, such as serious physical violence, home invasion, use of a weapon, and prolonged detention, on the basis that these offences are too serious for anything but a custodial sentence. ${ }^{22}$

The treatment track is not intended to be used for sexual violence occurring within an intimate relationship characterised by coercive control of the victim by the perpetrator and accompanied by serious physical violence. These instances of offending are too serious for the treatment track. ${ }^{23}$ The treatment track is probably most likely to be of use when there is a pre-existing relationship of some sort (whether intimate or not) between the victim and the offender. ${ }^{24}$ The treatment track may also be of use for sexual violence committed by a stranger or someone the victim has just met or is only slightly acquainted with, but where the circumstances put the violence more into the "everyday rape" category, such as the rape of an intoxicated person at a party.

Offences under s $142 \mathrm{~A}$ are probably most likely to occur within a coercive intimate relationship or as part of extensive child sexual abuse, so it is unlikely that a perpetrator charged under s 142A will be eligible for the treatment track. I have included the offence on the list of eligible offences, however, because if it occurred on its own or in combination with other sexual offences at the lower end of the seriousness scale, it is possible that the offending would fall into the seriousness band for which the treatment track is intended.

\footnotetext{
20 Sentencing Act 2002, s 15A.

$21 \quad R v A M[2010]$ NZCA 114, [2010] 2 NZLR 750.

22 See $R v A M$, above $\mathrm{n} 21$, for a full list of generally accepted aggravating factors in sexual violation cases.

23 The seriousness issue is discussed extensively in Chapter 7.

24 While breach of trust is an aggravating feature at sentencing, in practice the existence of a relationship is not usually enough on its own to move an offence with no other aggravating features from band one to band two: $R v A M$, above $\mathrm{n} 21$.
} 


\section{B Multiple offences}

Situations in which a potential treatment track participant has been charged with a number of offences, particularly if the offences are a mix of sexual and non-sexual offences, pose a challenge for the treatment track. One of the objections cited by the then Minister of Justice to the use of alternative resolution processes for sexual offending was that related non-sexual offending would still have to be dealt with by the traditional process. $^{25}$ In this section, I discuss the situations in which the treatment track can accommodate cases involving multiple offences.

The criterion I propose is: the offender has not also been charged with unrelated, nonsexual offending for which a sentence of imprisonment exceeding two years would normally be imposed cumulatively on the sentence for the sexual offending.

Because the treatment track can be used for offending that would attract an end sentence of more than two years and with a starting point below eight years' imprisonment, it can accommodate cases in which the accused is charged with multiple sexual offences, or sexual and non-sexual offences in respect of which concurrent sentences would be imposed, as long as the person pleads guilty to all of them (potentially after some negotiation) and the starting point, adjusted for totality, does not exceed eight years.

The more difficult situation would be if a person were charged with non-sexual offending that is separate from the incident(s) involving the sexual offending. Currently, the cases usually proceed separately, but if convicted the person may be sentenced for all the offending at the same time. The sentence for the unrelated offending would usually be cumulative on the sentence for the sexual offending (and any non-sexual offending related to the sexual offending). Should a person who is willing to plead guilty to sexual offending (and any related non-sexual offending) be eligible for the treatment track if the person is also charged with unrelated non-sexual offending?

I think the best option would be to try to build a response to unrelated offending into the treatment track. In circumstances where a community-based sentence could or would be imposed for the unrelated offending, the sentence could be incorporated into the requirements of the treatment track for the offender. The main issue is the appropriateness of the sentence: this option would only be workable if it was possible to

25 Rod Vaughn "Sexual violence reform - change at last" ADLS (Auckland, 5 February 2016) $<$ http://www.adls.org.nz/for-the-profession/news-and-opinion/2016/2/5/sexual-violence-reformchange-at-last/>. 
identify a community-based sentence of sufficient severity to satisfy retributive requirements that also works well with the requirements of the treatment track.

The other option would be to require that the person enter a guilty plea to the sexual (and any related non-sexual) offending, then address the other charges in the normal way, which may include a defended hearing if the charges are not admitted. If convicted, the person would then serve the sentence imposed before entering the treatment track. I think that approach is less workable, however, for two reasons.

First, delay will be an issue, particularly if the sentence imposed is a lengthy term of imprisonment or a community-based sentence that takes considerable time to complete. Delay in the offender entering the treatment track could impact on the ability of the treatment track to reduce secondary victimisation, because delay can be a source of stress and can impede recovery. ${ }^{26}$ Delay also increases the risk of an offender seeking to vacate the guilty plea. One way to limit delay while the person serves the sentence on the unrelated offences would be to adopt a cut-off as part of the eligibility criteria: if a person has been charged with unrelated offences, the sentence imposed on those charges must not exceed, say, two years. A sentencing indication on the unrelated charges could be used to determine whether the person meets the eligibility criteria for entry into the treatment track.

The second issue that arises if unrelated offences are required to be addressed before an offender enters the treatment track is management of the risk of sexual recidivism in the period between entering a guilty plea to the sexual (and related) offending and entering the treatment track. The sexual (and related) offending would need to be taken into account when determining bail conditions and/or the sentence imposed for the unrelated offending.

For these reasons, I think the first approach - that the offender has not also been charged with unrelated, non-sexual offending for which a sentence of imprisonment exceeding two years would normally be imposed cumulatively on the sentence for the sexual offending - is preferable.

$26 \quad$ Jeremy Finn, Elisabeth McDonald and Yvette Tinsley "The potential impact of other proposed reforms on processes in sexual violence cases" in Elisabeth McDonald and Yvette Tinsley (eds) From "Real Rape" to Real Justice: Prosecuting Rape in New Zealand (Victoria University Press, Wellington, 2011) at 108. 


\section{C “Three Strikes" exclusion}

Section 86 of the Sentencing Act imposes "additional consequences for repeated serious violent offending". ${ }^{27}$ When a person is convicted of a serious violent or sexual offence (specified in the Act, but including all the eligible offences listed above), the Court must issue a first warning. If the person is convicted of a second serious violent or sexual offence, the Court must issue a final warning and sentence the person to serve their sentence without parole. If the person is convicted of a third serious violent or sexual offence, they must be sentenced to the maximum sentence available for the offence.

Because s 86 requires the judge to warn the person upon conviction (not sentence), the three strikes provisions would apply to the treatment track, even though it would not be a formal sentence. A person who is pleading guilty to a second or third offence would not be eligible for the treatment track, because the section limits judicial discretion to imposing a prison sentence as specified in s 86 .

\section{Which Perpetrators?}

There are a number of important considerations when determining which perpetrators should be eligibile for the treatment track. In this section, I outline four such considerations: whether the treatment track is primarily for those who would currently be convicted of a sexual offence or whether it should aim to include also those whose behaviour currently escapes formal notice, whether the treatment track should be for men who have sexually assaulted adults exclusively or whether it should include men who have also sexually assaulted a child, what level of risk of reoffending the treatment track is appropriate for, and whether certain perpetrators might have to be excluded from the treatment track on the basis that their needs or characteristics cannot be accommodated.

\section{A "Ordinarily convicted offenders" and "ordinarily undetected perpetrators"}

The treatment track could be appropriate for two groups of men. The first is those who would ordinarily be charged with a sexual offence and whose cases would proceed to trial, but might be willing to plead guilty if a less severe penalty was available. That is likely to be a fairly small group of people, given the under-reporting and attrition rates in

27 The government announced on 1 November 2017 that it planned to repeal the three strikes law, but that has yet to occur. "Three strikes law to be scrapped: Little" Radio New Zealand (online ed, New Zealand, 1 November 2017) <https:/www.radionz.co.nz/news/political/342837/three-strikes-law-tobe-scrapped-little>. 
sexual cases - the proportion of sexual offences resulting in a conviction is tiny, sometimes estimated to be as small as one per cent. ${ }^{28}$

When reducing recidivism is the starting point for the treatment track, it is useful to consider also men whose offending would not currently be reported or prosecuted, or whose cases may not reach trial. The purpose of reducing recidivism is to improve public safety. Having any substantial impact on public safety will require targeting also perpetrators who are not currently captured by the criminal justice process.

Accordingly, throughout the thesis I talk about two groups: "ordinarily convicted offenders" and "ordinarily undetected perpetrators". The issues are much more difficult with ordinarily undetected perpetrators, and it may be that the treatment track would be unlikely to be able to bring many of them into the criminal justice process. ${ }^{29}$ Even if the treatment track would not be effective with ordinarily undetected perpetrators, discussing the issues is a good start for thinking about what could work with them, whether that may be a criminal justice intervention or something outside the criminal justice process.

\section{B Mixed offenders}

To be eligible for the treatment track, a person must have been charged with a relevant sexual offence against an adult victim. Some men who meet that criterion may have sexually abused a child in the past. Should those men ("mixed offenders") be eligible for the treatment track?

Treatment is more widely available to men who have a child victim in their offence histories than to men with exclusively adult victims. The custodial treatment programmes for child sex offenders (Te Piriti and Kia Marama) accept lower risk offenders than the ASOTP does, and the Department of Corrections also offers a short custodial intervention programme designed specifically for low risk child sex offenders. ${ }^{30}$ In addition, community-based programmes are available for men who have sexually abused a child (WELLSTOP, SAFE and STOP). ${ }^{31}$ Mixed offenders are, accordingly,

\footnotetext{
28 "Sexual Abuse Statistics" HELP: Support for Sexual Abuse Survivors $<$ http://helpauckland.org.nz/get-info/statistics>.

29 These issues are the subject of Chapter 5.

$30 \quad$ "Rehabilitation Programmes" Department of Corrections

$<$ http://www.corrections.govt.nz/working_with_offenders/prison_sentences/employment_and_sup port_programmes/rehabilitation_programmes.html $>$.

31 WELLSTOP $<$ www.wellstop.org.nz $>$; STOP $<$ http://www.stop.org.nz/>; SAFE $<$ http://www.safenetwork.org.nz/professional-services $>$.
} 
much more likely to be able to access treatment than men with exclusively adult victims, so there is not a particularly strong case for including mixed offenders in the treatment track in terms of its primary rationale (reducing sexual recidivism).

However, the secondary rationale of reducing secondary victimisation does support including mixed offenders in the treatment track. If the treatment track would result in a less distressing process and/or outcome than the conventional response to sexual offending for the adult victim of a mixed offender, then that option should be available.

Including mixed offenders in the treatment track would present some additional challenges for treatment and risk management, which I will discuss further in Chapters 5 and 6.

\section{Risk level}

The risk that the potential participant will reoffend is also important when considering eligibility for the treatment track. The criteria I propose is that the person poses a high enough risk of sexual recidivism that he needs treatment to reduce it, but his risk of (all kinds of) recidivism is not so high that it cannot be managed in the community.

The reasons for requiring that risk be high enough that the person needs treatment is primarily a resource issue: there is no point in using valuable criminal justice resources to treat a person who does not need it. There is also some evidence that treating offenders who pose a low risk of reoffending can increase their likelihood of reoffending, so there is also a public safety element to this criterion. ${ }^{32}$ Public safety also underlies the criterion that the person's risk be able to be managed in the community. While the focus of the treatment track is on reducing sexual recidivism, it is important to be mindful that perpetrators of sexual violence can also pose a risk of other kinds of recidivism, which should also be taken into account when assessing whether the person can be kept in the community without undue risk to the public. $^{33}$

The point at which a person's risk of reoffending is too low for them to need treatment and the point at which it is too high to be contained in the community are not fixed points, however. The risk principle of the Risk Need Responsivity model says that the amount of treatment should be matched to the offender's risk of reoffending and that

$32 \quad$ Bonta and Andrews, above n 3, at 190-191.

33 Arul Nadesu Reconviction Rates of Sex Offenders: Five year follow-up study (Department of Corrections, 2011) at 12-13. 
higher risk offenders should be prioritised for treatment because it is with them that treatment can make the biggest difference. ${ }^{34}$ Programmes tend to be designed with a particular risk level in mind. ${ }^{35}$ However, the point at which an offender's risk is too low for treatment to be beneficial has not been established.

In terms of containing risk in the community, the point at which a person's risk of reoffending becomes too high to be contained depends on the risk management measures available, the resources that can be invested, and the degree and type (sexual, non-sexual violent, and general recidivism) of risk that the community is willing to tolerate.

These are complex questions that require consultation and further work at the policy level. For those reasons, I am not able to refine the risk-related criteria any further within the scope of this thesis. Even if I could, the empirical basis for risk assessment with New Zealand men who have sexually assaulted an adult (discussed in depth in Chapter 6) is not yet developed enough to conclude that decisions based on risk assessment are accurate enough.

\section{Responsivity-based exclusions}

There may be certain characteristics or problems personal to individual prospective participants that can affect their ability to engage with treatment. Some of these, such as psychosis, must be treated before a person can engage with treatment. Others, such as intellectual disability, require adaptation in how treatment is delivered. Which potential responsivity factors can be accommodated in the treatment track is subject to the resources available, so cannot be determined at this stage in the work. If the treatment track idea is to be progressed, however, guidelines on responsivity-based exclusions should be created in advance to increase consistency in decision-making about eligibility.

\section{$V$ Timeframe}

The time a participant should be subject to the treatment track should be the length of the term of imprisonment that the offence would ordinarily attract (that is, the starting point of the sentence determined according to $R v A M$ for sexual violation and case law for the other types of sexual offending ${ }^{36}$ ) minus the 25 per cent discount available for an early guilty plea. ${ }^{37}$ The reasons for this are discussed fully in Chapter 7. In essence, however,

\footnotetext{
$34 \quad$ Bonta and Andrews, above n 3, at 47-48.

35 For example, the ASOTP was designed for high and medium-high risk offenders.

$36 \quad R v A M[2010]$ NZCA 114, [2010] 2 NZLR 750.

$37 \quad$ Hessell $v R$ [2010] NZSC 135, [2011] 1 NZLR 607.
} 
I argue that - in accordance with penal minimalism - desert should limit the length of time that the state may interfere with the liberty of the participant. Further, the demands of the treatment track are (in my view) roughly equivalent in onerousness to a prison sentence, making it appropriate to adopt the same timeframe as if the person was sentenced to imprisonment.

\section{Decision-Making}

A judge, acting in the traditional role of impartial arbiter, should make decisions about eligibility for the treatment track, the requirements to be imposed on a participant, the determination of any breach of risk management conditions or concerns about progress in treatment, and the completion or termination of participation in the treatment track. In making these decisions, the judge should take into account information provided by police, probation, treatment providers, the victim or the victim's representative, and the accused/offender. In contrast to the role of the judge in problem-solving courts, the judge does not have a "therapeutic relationship" with the participant. ${ }^{38}$ Treatment should be provided by qualified psychologists.

The interests of the accused/offender should be represented by counsel, acting in accordance with the traditional ethical requirements of zealous advocacy. ${ }^{39}$ Defence counsel should represent the client's interests from the client's perspective and experience, not from that of other institutional players. ${ }^{40}$ This requires recognition that the aims of the treatment track and the interests of the accused/participant are not necessarily aligned.

The timeframe around admission to the treatment track should allow for defence counsel to give due consideration to the charges and the initial material disclosed by police, in order to advise their client about the plea decision.

Decisions about whether a prospective participant is eligible for the treatment track should be made in accordance with previously established criteria. These criteria should

$\overline{38}$

Morris Hoffman "Therapeutic Jurisprudence, Neo-Rehabilitationism, and Judicial Collectivism: The Least Dangerous Branch Becomes Most Dangerous" (2002) 29 Fordham Urb LJ 2063 at 2067.

39 Tamar Meekins "“'Specialized Justice": The Over-Emergence of Specialty Courts and the Threat of a New Criminal Defense Paradigm" (2006) 40 Suffolk U LRev 1.

40 Richard Boldt "Rehabilitative Punishment and the Drug Treatment Court Movement" (1998) 76 Wash ULQ 1205 at 1241-1243. 
set out who should advise the judge in relation to each criterion. For example, the treatment needs of a prospective participant are solely the responsibility of the treatment provider, and the treatment provider's views should be conclusive on that point, subject to any challenge about the adequacy of the information on which those views were reached or other serious problems with the decision-making process.

A liaison could be appointed to assist the judge to understand and interpret any psychological or other specialist information relevant to decisions the judge is required to make. The liaison should have sufficient expertise to advise the judge on complex psychological matters, should themselves be impartial, and should act in an advisory capacity only.

Day-to-day decisions about treatment should be made by the treatment providers, who have the required expertise. If the treatment providers or the participant consider that a treatment decision might have a significant impact on the interests of the accused (for example, extending the duration of treatment) they should apply to the judge to have that considered. Clear parameters about the kinds of decisions left to treatment providers and those which should be referred to the judge should be established in advance (in consultation with treatment providers).

Risk management conditions should be the least restrictive possible to contain the risk to public safety. They must be clearly related to the risk posed by the individual participant and subject to regular review. Applications to increase the restrictiveness of conditions may be made to the judge on an urgent basis without notice to the participant, but must then be reviewed.

\section{Compliance}

Treatment track participants will be on bail, which means the police are responsible for checking compliance with bail conditions, and they can arrest that participant if he is not complying with bail conditions. Beyond that, risk management is the responsibility of the probation officers seconded to the treatment track (though the probation officer should consult with the police and with treatment providers on a regular basis to ensure they are as fully informed about current risk level as possible). Areas of responsibility between police and probation should be agreed in advance, as well as a process for consultation. 
The system of graduated sanctions adopted in some problem-solving courts should not be used in the treatment track. ${ }^{41}$ Whatever logic it may have in the context of substance use disorders, it is not applicable to a community-based treatment process for sexual offending. Instead, participants should be encouraged and assisted to comply with the conditions of the treatment track, unless there is a serious risk to public safety or the safety of other participants or staff, in which case their participation in the treatment track may be terminated and the person held on remand until sentencing.

In terms of compliance with risk management conditions, a distinction should be made between conduct constituting a criminal offence, conduct which is proximate enough to an offence to raise serious concern about public safety, and other lesser breaches. For the two former categories of breaches, the protection of public safety should be the first consideration. For the latter, the probation officer should consider carefully the context of the breach. Does it indicate that the participant is struggling to comply with the conditions because of a capacity issue (such as lack of organisational skills, depression, anxiety-related avoidance) or because of external or situational demands or barriers (such as competing priorities such as work or family responsibilities, lack of transport, financial problems)? In these situations, the probation officer should work with the participant to overcome the difficulty in the first instance, in consultation with the treatment providers if necessary. It is only if the problem is persistent and does not respond to efforts to address it that it should be referred to the judge as a non-compliance issue. There should also be a process for verifying breaches arising as a result of emergencies or other circumstances beyond the participant's control (for example temporary illness preventing the person from attending an appointment or treatment session).

Non-engagement in treatment and disruptive behaviour are for the treatment provider to address in the first instance, but the treatment provider may apply to the court to have the person removed from treatment if the problem is serious and ongoing. In this situation, the person's participation in the treatment track should be terminated, and he should be held on remand until he can be sentenced.

In the event that a person's participation may be terminated, there should be a hearing to establish the fact of the breach of the risk management conditions or persistent nonengagement with treatment. That hearing should follow the normal requirements of

$41 \quad$ For an outline of the rewards and sanctions in the New Zealand context, see Formative Evaluation for the Alcohol and Other Drug Treatment Court Pilot (Ministry of Justice, 2014) at 22-23. 
procedural fairness, including consistency and transparency in decision-making. The decision should be made in writing, with reasons given, and the participant should have the opportunity to appeal it.

\section{Conclusion}

This chapter set out decisions I have made about how the treatment track should be designed, because it is necessary background for the discussion beginning in the next chapter of whether the treatment track could comply with penal minimalism. Further work is required on the details of the design, as noted in the chapter.

From this point onwards, the thesis discusses the over-arching of whether the treatment track could comply with the requirements of penal minimalism. The next chapter discusses the first of these requirements: necessity. 


\section{The First Condition of Penal Minimalism: Is the Treatment Track Necessary?}

\section{Introduction}

The first condition of penal minimalism is that there must be serious enough harm to warrant the proposed intervention. As discussed in Chapter 1, the relevant harm is sexual reoffending. In this chapter, I examine whether there is a need for an intervention such as the treatment track to reduce sexual reoffending. If there is, then the first condition of penal minimalism is satisfied.

On the face of it, there appears to be little need for another intervention to reduce sexual reoffending. As I will discuss in Part II, few men who have been convicted of a sexual offence against an adult are convicted of another sexual offence, those prisoners who are assessed as being at high enough risk of sexual recidivism to require treatment are offered it in prison, and community-based treatment providers report little demand for treatment for men who have sexually assaulted an adult.

However, the under-reporting and attrition statistics (discussed in Part III) cast doubt on those conclusions. It may be that the low official sexual recidivism rates for men who have been convicted of a sexual offence are an artefact of criminal justice processes rather than a reflection of reality. I discuss the evidence for that possibility in Part IV. Moreover, the lack of demand for community-based treatment may reflect not an absence of need for treatment but an absence of acknowledgement on the part of perpetrators and those aware of their behaviour that treatment is needed or unwillingness on the part of perpetrators to participate in treatment. In Part V, I consider what is known about repeat perpetration of sexual violence by men who have not been convicted of a sexual offence, arguing that there is a case that intervention is needed with about two-thirds of ordinarily undetected perpetrators.

\section{Arguments Against the Need for a Treatment Track}


Those familiar with the correctional psychology literature on recidivism by sexual offenders may have several reasons for thinking that there is no need for any additional intervention to reduce sexual recidivism: that overall sexual recidivism rates are low and that prisoners convicted of a sexual offence and assessed as being at medium or high risk of sexual recidivism are already offered treatment. Those working in organisations providing community-based treatment to people with sexually harmful behaviour may further object that there is little demand for treatment of men who have sexually assaulted an adult. In this section, I expand on those objections slightly to provide context for the rest of this chapter.

\section{A Low overall official sexual recidivism rates}

Convicted sex offenders are relatively unlikely to be convicted of a new sexual offence after they have been released from prison. A New Zealand study found that few convicted adult male sex offenders were reimprisoned for another sexual offence against an adult victim within five years of their release. Fewer than 10 per cent of those who were serving a second or subsequent sentence for a sexual offence against an adult victim ("recidivists") were re-imprisoned for a sexual offence against an adult victim, while the rate of re-imprisonment for those serving their first sentence for a sexual offence against an adult victim ("first-timers") was approximately half of that. ${ }^{1}$ A small number of men who had been convicted of a sexual offence against an adult were re-imprisoned for a sexual offence against a child (3.8 per cent of recidivists and 1.4 per cent of first-time sexual offenders). ${ }^{2}$

First-timers were as likely to be re-imprisoned for a violent offence as for a sexual offence against an adult victim, and were more likely to be re-imprisoned for another type

of offence altogether. ${ }^{3}$ Recidivist sex offenders were more likely to be re-imprisoned for violence or another offence type than for a sexual offence against an adult victim. ${ }^{4}$

Looking at these figures in isolation from the literature on under-reporting, attrition, and self-reported undetected offending, there appears to be little need for intervention to reduce sexual recidivism by men convicted of a sexual offence: most of them do not reoffend sexually anyway. As will be discussed in Part III and IV, however, these figures

\footnotetext{
$1 \quad$ Arul Nadesu Reconviction Rates of Sex Offenders: Five year follow-up study: Sex offenders against children vs offenders against adults (Department of Corrections, 2011) at 13. At 13. At 12 . At 13 .
} 
should not be taken at face value: the need for treatment may well be greater than is apparent in the correctional psychology literature.

\section{B Those who need treatment are already offered it}

While the overall rates of reconviction for a sexual offence are relatively low, some men are at much higher risk of sexual reconviction. Vess and Skelton classified men by their risk of sexual recidivism according to the Automated Sexual Recidivism Scale (ASRS), an actuarial risk assessment measure used by the New Zealand Department of Corrections. They reported the number of men at each risk level on the ASRS who were convicted of a sexual offence during the follow-up period, which was on average 15 years. $^{5}$

Of men with only adult victims in their sexual offence histories, 6.2 per cent of those classified as being at low risk of sexual recidivism were convicted of another sexual offence during the follow-up period, while 14.9 per cent of those at medium risk and 34.5 per cent of those at high risk were convicted of another sexual offence. ${ }^{6}$ The pattern of re-conviction across risk level was similar for mixed offenders (men with both child and adult victims in their sexual offence histories). 6.7 per cent of men assessed as being at low risk, 18.8 per cent of those at medium risk, and 36.4 per cent of mixed offenders at high risk of sexual recidivism were convicted of a sexual offence during the follow-up period. $^{7} 63$ per cent of mixed offenders who were convicted of a new sexual offence offended against a child, while 30 per cent offended against an adult, and 7 per cent offended against both an adult and a child in the follow-up period. ${ }^{8}$

Treatment to reduce the risk of sexual recidivism is already offered to male prisoners who have been convicted of a sexual offence or an offence with a sexual motivation or element against an adult, and who are assessed as being at medium-high or high risk of sexual recidivism. ${ }^{9}$ Offenders may also participate in general rehabilitation programmes, such as drug and alcohol treatment and the high or medium intensity rehabilitation

\footnotetext{
$5 \quad$ James Vess and Alex Skelton "Sexual and violent recidivism by offender type and actuarial risk: reoffending rates for rapists, child molesters and mixed-victim offenders" (2010) 16 Psychology, Crime and Law 541 at 545.

$6 \quad$ At 546.

At 546.

At 547.

Nick Wilson, Glen Kilgour and Devon Polaschek "Treating High-Risk Rapists in a New Zealand Intensive Prison Programme” (2013) Psychology, Crime and Law 1 at 13.
} 
programmes. ${ }^{10}$ The Department of Corrections allocates treatment in accordance with the Risk Principle of the Risk-Need-Responsivity Model. The Risk Principle says that the amount of treatment offered to an offender should be proportionate to the level of risk posed, with higher risk offenders receiving more treatment than lower risk offenders. ${ }^{11}$ Although the evidence supporting the Risk Principle, especially with sex offenders, is less robust than we might hope for, compliance with the Risk Principle is still best practice. The reasons for not treating lower risk offenders is that treatment is not usually shown to reduce recidivism rates amongst this group and in some studies has been found to increase them. ${ }^{12}$

Moreover, community-based treatment providers (who could accept perpetrators for treatment even if they have not been convicted of a sexual offence) report minimal demand for treatment for men who have sexually assaulted an adult. ${ }^{13}$

Accordingly, it could be argued that the Department of Corrections already offers treatment to all those sex offenders who need it, and there is no need for a treatment track. In the next section, however, I argue that the figures on under-reporting and attrition belie that assumption, as do the indications from self-report research (discussed in Part IV below).

\section{Under-Reporting and Attrition}

In this section I argue that relying solely on convictions for information about sexual recidivism probably substantially underestimates sexual recidivism rates and thus the need for treatment. It may be that convicted sex offenders commit more sexual offences

\footnotetext{
"Specialist Units" Department of Corrections
}

http://www.corrections.govt.nz/working_with_offenders/prison_sentences/employment_and_supp ort_programmes/rehabilitation_programmes/specialist_units.html and "Rehabilitation Units"

Department of Corrections

$<$ http://www.corrections.govt.nz/working_with_offenders/prison_sentences/employment_and_sup port_programmes/rehabilitation_programmes.html>.

11 James Bonta and DA Andrews The Psychology of Criminal Conduct (6 ed, Routledge, New York, 2017 ) at 190. The accuracy and validity of the tools used to measure risk are the subject of extensive discussion in Chapter 6 of this thesis.

12 For a review, see Helen Wakeling, Ruth Mann and Adam Carter "Do Low-risk Sexual Offenders Need Treatment?” (2012) 51 Howard Journal of Criminal Justice 286 at 289-291.

13 WELLSTOP, Personal Communication, on file with author. 
than those they are convicted of (and therefore more of them need treatment than are currently offered it) and/or that some men whose sexual offending has never resulted in a conviction are likely to reoffend if they do not receive treatment (and are not currently accessing it).

The New Zealand Crime and Safety Survey (the NZCASS) is the main source of information in New Zealand about crime experienced by individuals and households, whether or not it is reported to the police. It is difficult to obtain a reliable estimate of the proportion of sexual offences that are reported to the police, because the samples of people who have experienced a sexual offence are small. The most recent estimate that can be considered statistically reliable is from the NZCASS 2006, which found that only 9 per cent of sexual victimisations occurring in 2005 were reported to the police (in this context, a "sexual victimisation" is an incident or group of related incidents involving at least one sexual offence). ${ }^{14}$ Low reporting rates have also been found in overseas studies with larger sample sizes. For example, reporting rates for sexual offences have been estimated to be 5 per cent in Canada ${ }^{15}$ and 16.9 per cent in Australia. ${ }^{16}$ The Crime Survey for England and Wales found an average of 15 per cent of sexual violation offences against women were reported to the police in three twelve-month periods (20102013). ${ }^{17}$ If the 9 per cent figure is accurate for New Zealand, then 91 per cent of sexual victimisations do not enter the criminal justice process at all.

Of the small proportion of sexual victimisations that are reported to the police, less than one third are prosecuted, and fewer than half of those prosecuted result in a conviction. In 2009, the New Zealand Ministry of Women's Affairs published a report that analysed attrition in the criminal justice process in respect of cases initially recorded by the police as sexual violation ("the Attrition Study"). ${ }^{18}$ Attrition refers to cases not proceeding to the next stage of the process. The researchers analysed file information extracted from the National Intelligence Application database for all sexual violation offences against adults recorded by the New Zealand police in the period 1 July 2005-31 December 2007.

\footnotetext{
$\overline{14}$ New Zealand Crime and Safety Survey: Key Findings (Ministry of Justice, Wellington, 2006) at 35.

15 Samuel Perreault Criminal Victimization in Canada, 2014 (Statistics Canada, 2015) at 25.

16 Personal Safety Survey 2012, Table 17, available at
<http://www.abs.gov.au/AUSSTATS/abs@.nsf/DetailsPage/4906.02012>.

17 An Overview of Sexual Offending in England and Wales (Ministry of Justice, Home Office, and Office for National Statistics, 2013) at 16.

18 Sue Triggs and others Responding to Sexual Violence: Attrition in the New Zealand Criminal Justice System (Ministry of Women's Affairs, Wellington, 2009).
} 
There were 1,955 cases (comprising 2,888 offences). ${ }^{19}$ An adult victim was defined as a person aged 16 years or older. 90 per cent of offences in the sample were sexual violation by rape or unlawful sexual connection. ${ }^{20}$ The remaining ten per cent included attempted sexual violation by rape or unlawful sexual connection and other offences involving sexual violation (incest, inducing sexual connection, and sexual exploitation of a person with significant impairment). ${ }^{21}$

A sexual violation charge was laid in only 31 per cent of cases involving a sexual violation complaint made to the police. ${ }^{22}$ Of those cases in which charges were laid, 42 per cent resulted in a conviction for a sexual violation offence and a further three per cent resulted in a conviction for a related charge (sexual or non-sexual violence or other type of offence arising from the same incident or incidents as the sexual violation charges). ${ }^{23}$

These statistics make clear that the official conviction rates are an enormous underestimate of the true amount of sexual violence committed. The fact that most sexual offending does not result in a conviction is not, however, in itself as argument that sexual re-offending is higher than represented in the official conviction statistics and therefore that more people need treatment than are currently offered it. If all undetected sexual offences were committed by people who have never been convicted of a sexual offence, and none of the perpetrators repeatedly committed sexual offences, it could not be argued that treatment must be made more widely available to reduce recidivism. Primary prevention strategies would be important, but probably not psychological treatment designed to reduce recidivism. However, that scenario seems unlikely. It is more probable that many of the offences that do not result in a conviction are committed by repeat perpetrators - some of whom will never have been convicted of a sexual offence.

In Parts IV and V, I discuss this further, making the argument that there is a greater need for treatment to reduce sexual recidivism than there appears on the basis of the official statistics and the demand for community-based treatment.

\begin{tabular}{ll}
\hline 19 & At 10. \\
20 & At 10. \\
21 & At 85. \\
22 & At 34. \\
23 & At $56-57$.
\end{tabular}




\section{Closer Examination: Ordinarily Convicted Offenders}

We do not know how much of the sexual offending not resulting in a conviction revealed by the NZCASS and the Attrition Study is committed by men who have been convicted of a sexual offence. One way to obtain this information is to ask convicted sex offenders how many sexual offences they have committed but not been convicted of. Two such self-report studies have been undertaken, both of which indicated high levels of undetected sexual offending by convicted sex offenders.

In a study published in 1982, Groth, Longo and McFadin surveyed men held at a secure treatment centre in Florida and in a maximum security prison in Connecticut. ${ }^{24}$ There were 83 men who had sexually assaulted an adult in the sample and they had been convicted of a mean of 2.8 sexual assaults each. ${ }^{25}$ The number of undetected sexual assaults reported by the men ranged from 0 to 250 . The authors calculated a mean of 5.2 undetected rapes per participant, but in calculating the mean they excluded 7 men who reported 50 or more undetected sexual assaults each. ${ }^{26} 67.1$ per cent of the men reported committing more than one undetected sexual assault. ${ }^{27}$

Weinrott and Saylor also found high numbers of undetected sexual offences reported by convicted sex offenders. ${ }^{28}$ They surveyed men who had been committed to a secure hospital as "sexual psychopaths" ("individuals who are presumed to specialise in sexual misconduct, whose deviant behaviour is beyond self-control, and who would not normally meet the diagnostic criteria for Antisocial Personality Disorder" ${ }^{29}$ ). 37 of the men in the sample had been arrested for an attempted or completed rape of a woman. These men had been charged with 66 offences between them, with a mean of 1.8 victims each. ${ }^{30}$ However, they reported committing 433 attempted or completed rapes, with a mean of 11.7 and a median of 6 victims each. ${ }^{31}$

\footnotetext{
24 AN Groth, RE Longo and JB McFadin "Undetected recidivism among rapists and child molesters" (1982) 28 Crime and Delinquency 450.

$25 \quad$ At 452.

$26 \quad$ At 453.

$27 \quad$ At 454 .

28 Mark Weinrott and Maureen Saylor "Self-Report of Crimes Committed by Sex Offenders" (1991) 6 Journal of Interpersonal Violence 286.

29 At 289. People who do not meet the criteria for anti-social personality disorder are not, of course, psychopaths within the accepted usages of the term.

$30 \quad$ At 291.

$31 \quad$ At 291.
} 
The rapists in Weinrott and Saylor's study did not limit themselves to contact sexual offending against adults. 32 per cent of the men arrested for a sexual offence against a woman admitted to sexual contact with a child, although only half of them had been charged with an offence against a child. ${ }^{32} 33$ per cent of the men also reported indecent exposure in the year preceding commitment. ${ }^{33}$

If these studies are representative of undetected sexual offending committed by convicted sex offenders in contemporary New Zealand, there is serious reason for doubt about the validity of the official recidivism figures and a much greater need for rehabilitation than there appears to be on the face of the official figures. The extent to which these studies are indicative of undetected sexual offending by convicted sex offenders in contemporary New Zealand is, however, unclear - both studies are North American and from some time ago.

Logically, we might think that men who have already been convicted of a sexual offence are less likely to escape conviction for another sexual offence than they may have been in the past. In New Zealand currently, if an offender is on parole or subject to an extended supervision order he will be subject to some restrictions and oversight (such as reporting requirements), so any offending is more likely to be detected. The Attrition Study also found that men with previous sexual convictions were more likely to be prosecuted when a complaint of sexual offending was made against them than men who did not have that history. $^{34}$ If the case proceeds to trial, evidence of the previous offending may be admitted in certain circumstances, which can increase the likelihood of a conviction. ${ }^{35}$ Nonetheless, there is still scope for convicted sexual offenders to commit undetected sexual offences: monitoring is not infallible, most offenders are not subject to intensive or long-term monitoring, and most offences are not reported to the police (so the effects of offending history on prosecution and evidence decisions make no difference to the detection of most offences).

Weinrott and Saylor also found that their participants committed a large amount of undetected non-sexual offending and that they were relatively versatile offenders. The mean number of non-sexual offences in the year preceding institutional commitment was

\footnotetext{
$32 \quad$ At 291.

33 At 292.

$34 \quad$ Triggs and others, above $\mathrm{n} 18$, at 77-78.

35 Evidence Act 2006, ss 40-43.
} 
304.8 per man who had sexually assaulted an adult, and the median 165.5. Each of these participants reported at least one non-sexual offence (although some of the non-sexual offences might have been concurrent with sexual offences). Many of them committed serious non-sexual violence in the year preceding commitment. 2 per cent admitted to aggravated assault without sexual contact or intent. ${ }^{36}$ Nearly half of them had assaulted a partner or spouse (494 offences) and about 1 in 4 assaulted a child (225 offences). The mean number of different offences (out of 22 possible) was 10.5. Contrary to the description of the sample as men who specialise in sexual offending and do not have antisocial personality disorder, the self-reported undetected non-sexual offending indicates that the sample was highly criminal. Again, better monitoring of offenders in contemporary New Zealand may mean that the proportion of undetected non-sexual offences is lower, but if this study generalises to contemporary New Zealand, convicted sex offenders are probably still doing a great deal of undetected non-sexual offending as well as undetected sexual offending. Intervening effectively to reduce sexual reoffending could also have the benefit of reducing non-sexual offending, another reason in support of establishing a treatment track.

Another way to obtain information about undetected sexual offending by convicted sex offenders is to use unofficial sources of data on offence-related sexual behaviour, making use of the monitoring to which some convicted sex offenders are subject. In their evaluation of the Thames Valley Project (a community-based assessment and treatment programme for adult male sex offenders) Falshaw, Friendship and Bates calculated official reconviction rates, but also used a wider definition of sexual recidivism: "offencerelated behaviour, legal or illegal, with a clear sexual motivation, eg. a convicted child sexual offender found loitering outside a primary school."37 Information about sexual recidivism was obtained from probation services, the police, health authorities, psychological services, and social services. ${ }^{38}$ When sexual recidivism was combined with official reconviction data, the rate of recidivism for the sample was 21 per cent over a mean of three years and eleven months at risk, substantially higher than the 9 per cent found in the study when official conviction data only was used. ${ }^{39}$

\footnotetext{
$36 \quad$ Weinrott and Saylor, above n 28, at 293.

37 Louise Falshaw, Caroline Friendship and Andrew Bates Sexual Offenders - measuring reconviction, reoffending and recidivism (Home office Research, Development and Statistics Directorate, London, 2003) at 2.

38 Louise Falshaw and others "Assessing reconviction, reoffending and recidivism in a sample of UK sexual offenders" (2003) 8 Legal and Criminological Psychology 207 at 210. At 213.
} 
There are some limitations of the study that should be borne in mind. It is not known how many of the incidents captured by the definition of recidivism used in the Thames Valley Project study were in fact sexual offences or would have progressed to sexual offending without intervention. It may be that the figure accordingly overestimates reoffending. At the same time, there may be other incidents that were sexual offences that were not detected or recorded. Additionally, the Thames Valley Project sample was not comprised solely of men who have been convicted of sexually assaulting an adult. It included men who had sexually abused a child. As different types of sex offenders are thought to reoffend at different rates (on the basis of official conviction data, anyway) it may be that the recidivism rate found in the project is not representative of the sexual recidivism rate for men who have been convicted of sexually assaulting an adult. ${ }^{40}$ The authors also noted that men who had admitted committing a sexual offence could be referred to treatment by other services or refer themselves, even if they had not been convicted of an offence. ${ }^{41}$ It is not stated how many participants in the study had not been convicted of a sexual offence and the data is not broken down by conviction status. We do not know, accordingly, whether the sexual recidivism rate is representative of sexual recidivism by men convicted of sexually assaulting an adult.

Nonetheless, the Thames Valley Project study provides evidence that sex offenders who have some oversight in the community by treatment providers, probation, police, and health services still engage in behaviour that is or could progress to a sexual offence but does not result in a conviction, so official conviction rates are probably an underestimate of reoffending by convicted sex offenders. The offenders in the Thames Valley study had also all participated in treatment: ${ }^{42}$ the rates of sexual recidivism are likely to be higher for untreated offenders of a similar risk level (provided that treatment is effective, of course, a matter that will be discussed in Chapter 6). The need for treatment of known sex offenders is accordingly likely to be greater than that suggested by official conviction rates.

That official reconviction rates underestimate actual reoffending rates (possibly quite dramatically) may be an argument for extending the availability of custodial treatment to prisoners assessed as low or medium-low risk. If reoffending rates are higher across the board than indicated by reconviction rates, even those assessed as being at lower risk may

\footnotetext{
40 Andrew Harris and Karl Hanson Sex Offender Recidivism: A Simple Question (Public Safety and Emergency Preparedness Canada, Ottawa, 2004) at 7.

$41 \quad$ Falshaw and others, above n 38, at 210.

42 Falshaw, Friendship and Bates, above n 37, at 2.
} 
benefit from (some) treatment to reduce recidivism rates - still bearing in mind that the risk principle says that those at highest risk should receive the most intervention. If reoffending rates are not evenly distributed but higher for some offenders than for others, there is also a possibility that some of those assessed as being at lower risk are not in fact at lower risk relative to other sex offenders - it may be that their reoffending is just less likely to be detected. ${ }^{43}$

The main point, however, is that the possibility that the true reoffending rates of convicted sex offenders are substantially higher than represented by official convictions. Sexual reoffending may, then, be a serious enough problem that establishing an intervention such as the treatment track is justified, fulfilling the first condition of penal minimalism.

In the next part, I discuss what I consider to be a stronger argument that there is need for an intervention to reduce recidivism: the very high rate of repeat undetected sexual offending by men whose behaviour does not currently come to the attention of the criminal justice process.

\section{$V$ Repeat Undetected Perpetrators: Prolific Offenders}

Although community-based treatment providers report that there is limited demand for treatment for men who have sexually assaulted an adult, the research suggests that there is a small group of prolific sexual offenders whose offending remains undetected. This finding is based on a body of literature, almost all of it from the United States, looking at self-reported rates of sexual assault perpetration. In this section I highlight the main findings from that research, arguing that - to the extent it generalises to contemporary New Zealand - it establishes a need for an intervention to reduce sexual reoffending by this group. Effective intervention with the small group of prolific undetected sexual offenders could substantially reduce the amount of sexual violence perpetrated overall.

This section should be read with the caveat that what the figures cannot establish is that treatment is required. It may be that any kind of intervention that holds perpetrators accountable for the harm they have caused and communicates to them the wrongfulness of the behaviour could prevent reoffending. This group is potentially different to the people discussed in the previous section, who reoffend after being convicted of a sexual

43 This is an argument I return to in Chapter 6. 
offence and punished for it - the need for treatment to change the behaviour of the former group is more clearly established than for a group with whom there has not previously been any formal intervention.

\section{A Measures and terminology}

Most self-report studies measuring repeat perpetration of sexual violence in nonincarcerated samples use student participants, although a handful have used community men or military recruits. The studies use questionnaires (usually the Sexual Experiences Survey, "the SES") to ask participants about behaviours they have engaged in and the tactics they used. In respect of the SES, the behaviours are unwanted sexual touching (including kissing, fondling, and removing a person's clothing) and attempted or completed non-consensual vaginal, oral or anal penetration (including digital penetration and penetration with an object). The tactics are force, threats of force, taking advantage of a person too intoxicated to stop what was happening, and verbal coercion short of a threat to use force (including threatening to spread rumours about the person, threatening to end the relationship with the person, and continued verbal pressure after the person has said no).

Sexual penetration achieved using the kinds of verbal coercion included in the SES is not an offence, ${ }^{44}$ but these behaviours were included in the SES because of their harmful effects on victims. ${ }^{45}$ Throughout my discussion, I have used only attempted and completed rape wherever possible, in order to avoid including in the analysis sexually harmful behaviour that does not constitute an offence. That is because the studies tended to treat attempted and completed rape as one category, and everything else as a second category. That decision means excluding indecent assaults, which are of course criminal, but a more conservative estimate is probably preferable to including behaviour that is not criminal.

44 Several types of verbal coercion can form the basis of an offence, however. Section 129A of the Crimes Act 1961 ("sexual conduct with consent induced by certain threats") creates a lesser offence (maximum penalty 14 years) for verbal coercion in a limited range of circumstances. These are when consent is induced by a threat to commit an imprisonable offence not involving force, to disclose information that would seriously damage a person's reputation or to make improper use of an occupational or vocational position or a commercial relationship. 361. 
The authors of the SES classified non-consensual vaginal, oral or anal penetration committed by force, a threat of force or when the victim was too intoxicated to stop what was happening as acts likely to meet the legal definition of rape. The definition corresponds broadly with New Zealand's definition of sexual violation, although differs slightly in two ways. First, the SES asks about sexual acts with a person "who did not consent". The wording of that question requires that the person answering the question know there was no consent, and does not capture situations in which the person lacked reasonable grounds for belief in consent, which are also offences in New Zealand law. ${ }^{46}$ Secondly, the SES defines attempted rape as "trying to" commit a particular act "even though it did not happen." It may be that some of the incidents captured as attempts by the SES did not progress far enough to be an attempt in law.

The other measure occasionally used in the literature is the Abuse Perpetration Index ("the API"). The API defines rape as sexual intercourse (not specified further) achieved by force, threat of force, or when the person is too intoxicated to resist sexual advances. The API may be interpreted more narrowly by study participants than the SES definition, because it does not specify the types of penetration constituting rape to include explicitly all those in the SES definition. Further, the tactics for oral sex do not include taking advantage of a person too intoxicated to resist.

\section{$B$ Rates of Repeat Perpetration}

Between 6.4 and 24.5 per cent of participants reported attempting or completing rape since the age of 14 . Some of the variation between studies may have been due to differences in age: the study that found the highest proportion for each measure used a community sample that was older than the student and military samples. ${ }^{47}$ Older participants (probably a higher percentage of whom have been sexually active) have had more time to perpetrate acts of sexual violence.

Approximately two-thirds of men who acknowledge ever perpetrating an act of sexual violence are repeat perpetrators. Lisak and Miller found that 63.3 per cent of male students who had ever attempted or completed rape had done so more than once. ${ }^{48}$

\footnotetext{
46 Crimes Act 1961, s 128.

$47 \quad$ Antonia Abbey and others "Patterns of Sexual Aggression in a Community Sample of Young Men: Risk Factors Associated with Persistence, Desistance, and Initiation Over a 1-Year Interval" (2011) Psychology of Violence 1.

48 David Lisak and Paul Miller "Repeat Rape and Multiple Offending Among Undetected Rapists" (2002) 17 Violence and Victims 73.
} 
McWhorter and others found that in a sample surveyed at the end of their first year of military service, 71 per cent of men who reported having attempted or completed rape since the age of 14 had done so on two or more occasions. ${ }^{49}$

Zinzow and Thompson conducted a longitudinal study with male students. They measured sexual violence perpetration at eight time points (between the participant's $14^{\text {th }}$ birthday and entering university, during the four academic years, and in the summer break between each academic year). They found that 30 per cent of participants reported that they had perpetrated at least one act of sexual violence. Of those participants, 42 per cent offended at two time points, 22 per cent offended at three time points, 14 per cent offended at four time points, and 23 per cent offended at five or more time points. ${ }^{50}$

Even when the rates of perpetration over a single year are examined, the rates of repeat offending are high. Calzada, Brown and Doyle found that, of those male students who had completed a rape over the past year, 26 per cent of them did so "several times" or "often". 51 There is a great deal of variation in the number of acts of sexual violence committed by repeat perpetrators. Lisak and Miller found a mean of 5.8 attempted or completed rapes by repeat rapists. ${ }^{52}$ However, the very high standard deviation (7.7) indicates that the range is very large, and the median (3) might be a better measure of the number of offences committed by the majority of perpetrators. It is clear, however, that repeat rapists are responsible for a very high proportion of attempted and completed rapes. McWhorter and colleagues found that 95 per cent of the attempted and completed rapes reported by their sample of military servicemen were committed by repeat rapists. ${ }^{53}$

Diversity in the choice of victim (stranger or acquaintance) and tactics used (assaulting an incapacitated victim or using/threatening to use force) is associated with higher rates of offending. McWhorter and colleagues found a small group of perpetrators (4 per cent of the men in their sample who had attempted or completed rape) who had offended against

$49 \quad$ Stephanie McWhorter and others "Reports of Rape Perpetration by Newly Enlisted Male Navy Personnel" (2009) 24 Violence and Victims 204.

$50 \quad$ Heidi Zinzow and Martie Thompson "A Longitudinal Study of Risk Factors for Repeated Sexual Coercion and Assault in US College Men” (2015) 44 Archives of Sexual Behavior 213 at 217.

51 Esther Calzada, Elissa Brown and Megan Doyle "Psychiatric Symptoms as a Predictor of Sexual Aggression Among Male College Students" (2011) 20 Journal of Aggression, Maltreatment and Trauma 726.

52 Lisak and Miller, above n 48. "Repeat rapist" includes men who have attempted as well as completed rape.

53 McWhorter and others, above n 49. 
both strangers and acquaintances and used both incapacitation and force/threats of force. The perpetrators in that group reported having attempted or completed a mean of 29.75 rapes each. ${ }^{54}$ Identifying and intervening effectively with that group would substantially reduce the number of rapes committed overall.

It should be noted, however, that even those perpetrators who confine themselves to attempted or completed rapes of incapacitated victims with whom they are acquainted (the type of offence least likely to be considered a "real rape") are likely to be repeat perpetrators. McWhorter and others found that on average, perpetrators in this group (which formed 51 per cent of their sample) committed a mean of 3.6 attempted or completed rapes each. ${ }^{55}$

Even amongst repeat perpetrators, not all are equally in need of treatment. Thompson, Swartout and Koss identified four trajectories for sexual violence perpetration in a student sample. $^{56} 71$ per cent of their sample showed little or no sexual violence perpetration during the four years of the study and 12 per cent showed decreasing levels of sexual assault over that time. However, 8 per cent showed increasing levels of sexual assault perpetration and 9 per cent of the sample persisted with high levels of sexual violence perpetration across the four years of the study. ${ }^{57}$ The 17 per cent of perpetrators whose sexual violence perpetration is increasing or persistently high should be the primary targets for intervention to reduce recidivism.

Effective intervention with repeat undetected perpetrators of sexual violence could also reduce the perpetration of other forms of abuse. Lisak and Miller asked participants about physical intimate partner violence, sexual assault other than rape or attempted rape, and physical and sexual abuse of children. The repeat rapists reported committing a mean of 13.75 abusive acts each, which was significantly higher than the mean of 3.98 abusive acts reported by one-off rapists and 1.41 abusive acts reported by non-rapists. ${ }^{58}$ The repeat rapists were responsible for 1045 of the 1225 abusive acts (including rape and attempted rape) perpetrated by the 120 rapists in the sample. ${ }^{59}$ Aggression towards women also appears to continue over time. Malamuth and colleagues found that male 
students' self-reported sexual aggression predicted sexual and non-sexual aggression towards women ten years later. ${ }^{60}$

Whether repeat undetected perpetrators of sexual violence are also engaging in more general non-sexual violence (that is, towards people other than women and children) and non-violent offending is not yet known. As will be discussed later in the thesis, it would be important to know for treatment and risk management purposes whether undetected perpetrators are generally anti-social, or limit themselves to violence towards women and children. But for present purposes, the justification for establishing a treatment track to intervene to reduce reoffending by repeat undetected perpetrators is even stronger if it could reduce non-sexual as well as sexual offending.

\section{Conclusion}

Although sexual reoffending not resulting in a conviction remains somewhat hidden, the evidence available - while limited - suggests that reoffending rates are substantially higher than indicated by official reconviction rates. It is likely that more men who have been convicted of a sexual offence against an adult reoffend than are reconvicted, suggesting that there may be a need to extend the availability of treatment. Amongst men who have committed a sexual offence but not been convicted of one, there appears to be a small group of repeat perpetrators who are prolific offenders.

It would be useful to investigate the extent of undetected offending, both by convicted sex offenders and undetected perpetrators, in contemporary New Zealand to gain a better picture of the need for intervention to reduce reoffending. On the basis of the evidence available, however, the first condition of penal minimalism is satisfied. Sexual reoffending is a serious enough problem that some additional intervention is required.

Having established that the first condition of penal minimalism is satisfied, I move on to consider, in Chapters 5 and 6, whether the treatment track could fulfil the second condition - that it is able to intervene effectively to reduce reoffending. I begin in Chapter 5 with a discussion of the evidence base in relation to men whose sexual offending would not currently result in a conviction, then move on in Chapter 6 to discuss whether the treatment track could reduce reoffending by men whose offending does currently result in a conviction.

60 Neil Malamuth, Daniel Linz, Christopher Heavey, Gordon Barnes and Michelle Acker "Using the Confluence Model to Predict Men's Conflict with Women: A 10-Year Follow-Up Study" (1995) 69 Journal of Personality and Social Psychology 353 at 360. 


\section{The Second Condition of Penal Minimalism: Could the Treatment Track Intervene Effectively with Ordinarily Undetected Perpetrators?}

\section{Introduction}

The second condition of penal minimalism is that the proposed reform is likely to be effective in preventing the identified harm, in this case sexual reoffending. In this chapter, I consider the evidence base for that condition in respect of men whose sexual offending does not currently result in intervention by the criminal justice process, but who might be candidates for the treatment track ("ordinarily undetected perpetrators"). As argued in Chapter 4, this group of people may well be responsible for the largest proportion of sexual violence committed, so it is important to be able to identify those at risk of further offending and intervene with them to reduce that likelihood.

Much of this chapter is speculative: at this point, no definitive answer is possible about whether the treatment track could intervene effectively with this group. Many of the questions I ask have not been the subject of direct empirical investigation, perhaps because of the relatively hidden nature of much of the offending behaviour, and because the focus of most correctional psychology research has been, for understandable reasons, on intervention with those perpetrators who come to the attention of the criminal justice process. Accordingly, this chapter should be read more as an attempt to create a mandate for further empirical research, rather than an argument for or against the likely effectiveness of a treatment track.

In Part II, I explore whether any existing evidence indicates that establishing a treatment track could bring ordinarily undetected perpetrators into the criminal justice process. In Part III, I consider whether there is any evidence that the treatment track could reduce reoffending by ordinarily undetected perpetrators once they are involved. 


\section{Could the Treatment Track Bring Ordinarily Undetected Perpetrators into the Criminal Justice Process?}

If the treatment track is to reduce sexual reoffending substantially, it must bring into the criminal justice process repeat perpetrators of sexual assault whose offending would not currently result in a conviction and with whom the criminal justice process would not, therefore, be able to intervene. ${ }^{1}$ There must also be a way to identify those perpetrators who are in need of treatment to reduce the likelihood they will reoffend. Those people must then agree to participate in the treatment track.

Under-reporting of sexual offences and attrition during the prosecution process are barriers to intervention. As discussed in Chapter 4, most sexual offences never come to the attention of the criminal justice process. Fewer than ten per cent of sexual offences against adults are reported to the police, most of those that are reported are not prosecuted, and only about half of those offences that are prosecuted result in a conviction. ${ }^{2}$ In this section, I consider whether the treatment track could help to increase reporting and decrease attrition.

There is a substantial body of literature on factors contributing to under-reporting and attrition. The reasons victims of sexual offences decide not to report offences to the police include shame or embarrassment, ${ }^{3}$ not wanting others to know, ${ }^{4}$ not acknowledging the incident as a sexual offence, ${ }^{5}$ feeling they have dealt with it themselves, ${ }^{6}$ fear of not being believed or belief that the complaint could not be

$1 \quad$ As argued in Chapter 4, a small group of repeat perpetrators is responsible for a large proportion of sexual assaults committed overall.

2 See the discussion in Chapter 4, Part III.

3 Heidi Zinzow and Martie Thompson "Barriers to Reporting Sexual Victimization: Prevalence and Correlates among Undergraduate Women" (2011) 20 Journal of Aggression, Maltreatment and Trauma 711 at 717; Jeffrey Jones and others "Why Women Don't Report Sexual Assault to the Police: The Influence of Psychosocial Variables and Traumatic Injury" (2009) 36 The Journal of Emergency Medicine 417 at 420-421.

$4 \quad$ Kate Wolitzky-Taylor and others "Is Reporting of Rape on the Rise? A Comparison of Women with Reported versus Unreported Rape Experiences in the National Women's Study-Replication” (2011) 26 Journal of Interpersonal Violence 807 at 817; Zinzow and Thompson, above n 3, at 717; Jones and others, above n 3, at 420-421.

5 Zinzow and Thompson, above n 3, at 717 .

6 Ibid. 
substantiated, ${ }^{7}$ fear of reprisal by the perpetrator, ${ }^{8}$ and fear of the criminal justice process. ${ }^{9}$ People are less likely to report "everyday rapes" than "real rapes." 10

Amongst reported cases, insufficient evidence is a key reason why charges are not laid or prosecutions are discontinued. ${ }^{11}$ If the victim has provided inconsistent accounts of the incident, is recorded as having made a previous false complaint, or if there is evidence casting doubt on a victim's account, the case is unlikely to be prosecuted. ${ }^{12}$ The more a case conforms to the "real rape" stereotype, the more likely it is to be prosecuted and result in a conviction. ${ }^{13}$ Relatedly, victim vulnerability can be a factor in attrition. ${ }^{14} \mathrm{~A}$ major source of attrition is victim withdrawal from the process, particularly at the investigation stage. When the victim has accessed specialist support services, has a good relationship with the police, and a suspect has been identified, withdrawal has been found to be less likely. ${ }^{15}$

McDonald and Tinsley uncovered another factor that can stop the criminal justice process from being able to intervene with perpetrators of sexual violence. They found a

$7 \quad$ Wolitzky-Taylor and others, above n 4, at 817; Jones and others, above n 3, at 420-421.

8 Wolitzky-Taylor and others, above n 4, at 816-817; Jones and others, above n 3, at 420-421.

9 Zinzow and Thompson, above n 3, at 717; Jones and others, above n 3, at 420-421.

10 Wolitzky-Taylor and others "Reporting Rape in a National Sample of College Women" (2011) 59 Journal of American College Health 582 at 585-586; Wolitzky-Taylor and others, above n 4, at 819.

11 Jennifer Brown, Carys Hamilton and Darragh O’Neill “Characteristics associated with rape attrition and the role played by scepticisim or legal rationality by investigators and prosecutors" (2007) 13 Psychology Crime and Law 355 at 361-364; Eryn O’Neal, Katharine Tellis and Cassia Spohn "Prosecuting Intimate Partner Sexual Assault: Legal and Extra-Legal Factors that Influence Charging Decisions" (2015) 21 Violence Against Women 1237 at 1246-1247.

12 Katrin Hohl and Elisabeth Stanko "Complaints of rape and the criminal justice system: Fresh evidence on the attrition problem in England and Wales" (2015) 12 European Journal of Criminology 325 at 334-335; Marianne Hester and Sarah-Jane Lilley "Rape investigation and attrition in acquaintance, domestic violence and historical rape cases" (2016) J Investig Psych Offender Profil 1 at 12 .

13 Hohl and Stanko, above n 12, at 334-335; Kathleen Daly and Brigitte Bouhours Rape and Attrition in the Legal Process: A Comparative Analysis of Five Countries (University of Chicago, Chicago, 2010) at 613-616; Shane Muldoon, S Caroline Taylor and Caroline Norma "Patterned Characteristics of Continued and Discontinued Sexual Assault Complaints in the Criminal Justice Process” (2013) 24 Current Issues Crim Just 395 at 403-413; O’Neal, Tellis and Spohn, above n 11, at $1247-1252$.

14 Muldoon, Taylor and Norma, above n 13, at 404-405; Emma Williams, Jennifer Norman and Daniela Wunsch “Too Little Too Late: Assessing Vulnerability” (2009) 3 Policing 355 at 358-359.

15 Hester and Lilley, above n 12, at 9-11; Hohl and Stanko, above n 12, at 333-334. 
consensus among those working with victims, defence counsel, police, prosecutors, and judges that the high sentences imposed in sexual cases (particularly for sexual violation by rape, with its 20 year maximum penalty, starting point of 6-8 years, and presumption of imprisonment) also kept perpetrators of sexual violence out of the criminal justice process. ${ }^{16}$ Particularly striking are the interactions they describe between decisions made by different actors at different stages of the process: ${ }^{17}$

The impact of [the high sentencing levels] on the decisions made by defendants, complainants, fact-finders, police, prosecutors and defence counsel should not be under-estimated. For example, often there will be little evidence beyond the stories of the complainant and the defendant, particularly where forensic evidence is less helpful because there is no denial that sexual intercourse took place and/or there are no physical injuries. In these situations, guilty defendants may be reluctant to admit guilt where the potential penalty is so high; police and prosecutors may question the likelihood of conviction; and fact-finders may not be willing to convict, especially where the defendant does not fit the stereotype of an offender who is a "powerful, bad, stranger to the victim". This is complicated further where there is an ongoing or previous relationship between the complainant and the defendant: the complainant may wish for the behavior to stop, but may not want the defendant to be imprisoned.

The treatment track could help to address two of the factors contributing to underreporting and attrition: the impact of high sentencing levels (by providing an alternative to imprisonment) and fear of the trial process (by incentivising guilty pleas). Unfortunately, however, not much is known about these two factors.

The unanimity McDonald and Tinsley found amongst people with different roles and involved at different stages of the process indicates that the high sentencing levels and inflexibility of sentencing do contribute to under-reporting and attrition in sexual cases. However, consultation with those working in the area cannot tell us how much of an impact sentencing has on under-reporting and attrition, or whether establishing a treatment track (that is, offering an alternative to a sentence of imprisonment) could increase the number of perpetrators with whom the criminal justice process can intervene

Elisabeth McDonald and Rachel Souness "From "real rape" to real justice in New Zealand Aotearoa: The reform project" in Elisabeth McDonald and Yvette Tinsley (eds) From "Real Rape" to Real Justice: Prosecuting Rape in New Zealand (Victoria University Press, Wellington, 2011) at 51.

17 Elisabeth McDoanld and Yvette Tinsley "Rejecting "one size fits all”: Recommending a range of responses" in Elisabeth McDonald and Yvette Tinsley (eds) From "Real Rape" to Real Justice: Prosecuting Rape in New Zealand (Victoria University Press, Wellington, 2011) at 378. 
(by increasing reporting, prosecutions, and the proportion of guilty pleas). There is relatively limited empirical investigation of the extent to which sentencing influences reporting of sexual offences, and the literature is silent as to the impact of sentencing on attrition.

Two studies undertaken in the United States have found that not wanting the perpetrator to be imprisoned or suffer other negative consequences was an important reason victims did not report offences to the police. In a study with university students in the United States, Zinzow and Thompson found that 33 per cent of participants endorsed not reporting a sexual offence because they did not want the perpetrator "arrested, jailed, deported, stressed" and 12 per cent because they did not want the relationship to end. ${ }^{18}$ Not wanting the perpetrator to go to jail was also one of the three most common reasons for not reporting cited by women who had undergone a forensic medical examination after a sexual assault. ${ }^{19}$

In terms of the impact of the trial process, while the research indicates that many victims do not report offences because of the difficulty of the criminal justice process, studies do not usually break the criminal justice process down into its different stages or parts. Understanding the impact of fear of the different parts is important because if a treatment track is established, victims would still need to report an offence to the police, engage in the investigation process, and have some degree of involvement with a prosecution. Establishing a treatment track can remove the need for some complainants to go through a trial, and may reduce delay in the resolution of the matter (in this case entry of a guilty plea), but we do not know how much of an impact on decision-making the trial process has compared with other aspects of the criminal justice process and therefore how much of an impact removing the trial component would have.

There is no empirical research about the impact of the trial process specifically on victim withdrawal (or reporting) in sexual cases. However, some support comes from a study conducted in the United States with women who were victims of intimate partner violence. Sara Hare interviewed 94 women in a midwestern state whose current or former partners had been charged with (non-sexual) offences against them. ${ }^{20}$ She asked the women whether or not they supported charges being laid and the case proceeding to

\footnotetext{
$18 \quad$ Zinzow and Thompson, above $\mathrm{n} 3$, at 718.

19 Jones and others, above $\mathrm{n} 3$, at 420-421.

20 Sara Hare "Intimate Partner Violence: Victims' Opinions About Going to Trial” (2010) 25 J Fam Viol 765 at 767.
} 
trial, and their reasons for their preference about the case proceeding to trial. She found that 70 per cent of the women wanted the perpetrator to be charged, but only 37 per cent wanted the case to go to trial. The women who did not want the case to proceed to trial gave a total of 71 reasons for their views. Some of the reasons given were about the prosecution process, for example not wanting to recount the experience in court, not wanting their children to have to give evidence, and wanting to move on with their lives rather than having to wait for a trial. ${ }^{21}$ Many of the women wanted the defendant to be rehabilitated or incapacitated, but either did not want to go through a trial to achieve those outcomes or did not believe that those outcomes would be achieved by going to trial. $^{22}$

In the absence of local quantitative data that could establish how much of a difference a treatment track might make to reporting and attrition, in this chapter, I look for some "windows" in the New Zealand reporting and attrition literature - places where these two factors might be at play, even though they are not identified explicitly. It should be borne in mind throughout the discussion that we cannot tell how much impact those factors actually have on reporting and attrition. It may well be that their impact is less than the other (better researched) factors or that addressing sentencing levels and fear of the trial process would not make much of a difference unless the other factors are addressed also.

\section{A Reporting}

In this section, I draw on research about the reasons victims do not report sexual offences to the police, looking for indirect evidence that some victims may decide not to report offences because they do not want the perpetrator to go to prison (discussed in section one) or because they do not wish to go through the trial process (section two).

\section{Non-reporting to avoid imprisonment of the perpetrator}

The idea that some sexual violence victims may not want the perpetrator imprisoned may on the surface appear surprising, because of the seriousness of the offending and the degree of harm suffered by most victims. However, most sexual offences are committed by someone the victim knows. The NZCASS 2006 found that 39 per cent of female victims of sexual violence were victimised by an intimate partner, 2 per cent by a family member other than a partner, 55 per cent by someone else known to the victim, and 15

\begin{tabular}{ll}
\hline 21 & At 771-772. \\
22 & At 772-773.
\end{tabular}


per cent by a stranger. ${ }^{23}$ More recent overseas surveys all found that for sexual violation specifically, the perpetrator is most likely to be the victim's partner or former partner. ${ }^{24}$

It is difficult to know how many victims did not report an incident because they did not want the perpetrator to go to prison. Victimisation surveys ask victims why they did not report an incident, and code the responses. Not wanting the offender to go to prison is not coded, but may be captured by other codes. The results for reasons for non-reporting given by victims of sexual offences in the NZCASS 2008 are recorded in the table below: ${ }^{25}$

\begin{tabular}{|l|l|}
\hline & $\%$ of victims \\
\hline Private matter/dealt with it myself & 43 \\
\hline $\begin{array}{l}\text { Shame/embarrassment/ } \\
\text { further humiliation }\end{array}$ & $37^{*}$ \\
\hline $\begin{array}{l}\text { Too trivial/no loss/not worth reporting/unsuccessful attempt } \\
\text { Police couldn't have done anything/wouldn't have been interested }\end{array}$ & $28^{*}$ \\
\hline Fear of reprisals/would make matters worse & $18^{*}$ \\
\hline Didn't have enough evidence to report it & $13^{*}$ \\
\hline Didn't want to get offender into trouble & $12^{*}$ \\
\hline Inconvenient/too much trouble & $10^{*}$ \\
\hline Other/don't know & $10^{*}$ \\
\hline Dislike/fear of police & $4^{*}$ \\
\hline Reported to other authorities & $2 *$ \\
\hline
\end{tabular}

* High relative standard error ( $>20$ per cent).

23 Families Commission Family Violence Statistics Report (Wellington, 2009) at 162. The total is more than 100 per cent because more than one type of offender may be reported.

24 An Overview of Sexual Offending in England and Wales (Ministry of Justice, Home Office and the Office for National Statistics, 2013) at 16; Female Victims of Sexual Violence, 1994-2010 (US Department of Justice, 2013) at 4; National Intimate Partner and Sexual Violence Survey: 2010 Summary Report (National Center for Injury Prevention and Control, Atlanta, Georgia, 2011) at 22.

25 New Zealand Crime and Safety Survey: Main Findings Report (Ministry of Justice, Wellington, 2009) at 139.

$26 \quad$ Multiple responses possible. 
The most obvious code that could include victims who did not want the perpetrator to go to prison is "didn't want the offender to get into trouble". While that category may have included victims who would consider police involvement, a charge, or a conviction to be serious enough trouble not to report the incident, it may also have included victims who would report the incident if an outcome other than imprisonment (the most serious and visible consequence of a conviction) was available and likely. The code "too trivial" may also have captured victims who did not report the incident because they did not want the perpetrator to go to prison. It is likely that some victims did not consider the incident serious enough to warrant a prison sentence, and particularly not a 20 -year prison sentence (which is sometimes perceived to be the usual sentence for rape ${ }^{27}$ ). Victims might perceive an incident as less serious if it does not match the stereotype of a "real rape", if there was some ambiguity about the intention of the perpetrator, or if the incident did not differ markedly from the type of sexual behaviour the victim had experienced previously or that is generally accepted in the victim's community, despite being a criminal offence.

"The police couldn't have done anything" might have included victims who did not report the incident because the kind of resolution they sought was not available: short of initiating a process that, if successful, could only end in the imposition of a prison sentence, there was nothing the police could do for them. Similarly, "would make matters worse" may have included victims who considered that the imposition of a prison sentence, or the threat of it, would do more harm than good. Some victims whose reasons for not reporting were coded as the incident being a "private matter" may have wished to retain some control over how the incident was addressed, perhaps seeing it as a private relationship problem rather than a crime against the public interest to be dealt with by the state. "Other" may also have captured some victims who did not report the incident because they did not want the perpetrator to go to prison.

Accordingly, the prospect of the imposition of a prison sentence on the perpetrator may be a barrier to the reporting of sexual offending to the police, but more empirical research would be needed to confirm whether that is the case (with a larger sample than the NZCASS).

$27 \quad$ McDonald and Souness, above n 16, at 53. 


\section{Non-reporting to avoid the trial process}

The trauma and humiliation experienced by sexual violence complainants as a result of their participation in an adversarial trial is well documented. ${ }^{28}$ The question to be addressed in this section, however, is the extent to which not wanting to go through the trial process influences victims' decisions not to report sexual violence. If it is an important factor, then establishing a resolution process such as the treatment track that incentivises guilty pleas in order to bypass the trial process may make a difference to reporting rates.

The NZCASS did not code not wanting to the go through the trial process as a reason for not reporting an incident. However, as with the inflexibility of sentencing, some of the other codes may have captured victims whose decision not to report was influenced by wanting to avoid a trial. "Shame, embarrassment, and further humiliation" is likely to have captured some victims who did not want anyone to know about the incident. However, it may also have included victims who chose not to report because they were afraid of the humiliation of the adversarial trial process, in particular cross-examination. Similarly, "private matter" might include victims who do not want the publicity associated with the adversarial trial process. While victims' names are suppressed and members of the public are excluded from the courtroom while the victim gives evidence,

trials are still a relatively public process. Further, in small towns in particular, anonymity is often impossible. Again, "other" may have included victims who did not wish to go through the trial process.

\section{Conclusion on reporting}

It is possible that some victims choose not to report sexual offences to police because they do not want the perpetrator to go to prison or because they do not wish to go through the trial process. The empirical evidence on reasons victims choose not to report offences neither rules out this possibility nor confirms it. Direct empirical investigation of these two factors would be useful.

If some victims choose not to report offences for the two reasons discussed in this section, it would also be useful to know how important the trial process and likely sentence are to their decision. That question matters because we need to know whether establishing a treatment track would be enough to increase reporting substantially, or whether other steps also need to be taken to see an improvement. Some barriers to reporting, such as fear of reprisals and fear/dislike of the police, would not be addressed

\footnotetext{
$28 \quad$ See Chapter 1.
} 
by establishing a treatment track. Other changes would be necessary to remove those barriers. Additionally, a high proportion of sexual violence victims in the NZCASS (45 per cent) did not identify their experience as a criminal offence. ${ }^{29}$ That in itself is a significant barrier to reporting, which needs to be addressed with public education about the definitions of sexual offences as a precondition to increasing reporting rates.

Having considered whether establishing a treatment track could affect victims' decisions whether to report a sexual offence to the police, I turn now to a discussion of whether a treatment track could affect attrition of reported offences.

\section{B Attrition}

Attrition is the process whereby cases "fall out" of the criminal justice process, which may occur at different points, including during the police investigation, at the point when the decision whether to prosecute is made, or at any time before or during the trial. ${ }^{30}$ There are two points of attrition which I think the treatment track could affect: the victim's decision to withdraw from the investigation or prosecution process (discussed in section one) and the decision not to prosecute a case (discussed in section two).

\section{$1 \quad$ Victim withdrawal}

The Attrition Study indicated that a substantial number of cases do not proceed because of victim withdrawal, particularly during the investigation stage. ${ }^{31}$ In some of these cases, the victim may have withdrawn because he or she did not want the perpetrator to go to prison or did not want to go through a trial. As with reporting, it is difficult to know the extent to which those possible reasons influenced victims' decisions to withdraw from an investigation or prosecution. However, some of the contextual evidence suggests that they may have been factors in some cases. In this section, I evaluate the evidence in relation to victim withdrawal and consider how likely it is that a treatment track could help to address victim withdrawal.

There is no direct evidence that the inflexibility of sentencing or the difficulty of the trial process play a role in victim withdrawal from the investigation or prosecution process.

\footnotetext{
29 Ministry of Justice, above n 25, at 38.

$30 \quad$ Jo Lovett and Liz Kelly Different systems, similar outcomes? Tracking attrition in reported rape cases across Europe (Child and Women Abuse Studies Unit, London Metropolitan University, 2009) at 17.

31 Sue Triggs and others Responding to Sexual Violence: Attrition in the New Zealand Criminal Justice System (Ministry of Women's Affairs, Wellington, 2009) at 49-50.
} 
However, some of the evidence from the Attrition Study suggests that those factors might be at play.

The Attrition Study found that the accused was significantly more likely to be an expartner or boyfriend in cases where the victim withdrew than in other cases, and less likely to be a stranger. ${ }^{32}$ This suggests that some of the victims may have withdrawn out of concern for the accused or the wider family and a desire to protect their relationships, or out of fear of retaliation or pressure placed on them by the suspect or others. It may be that some of them would not have withdrawn if an outcome other than imprisonment was available. On the other hand, some may have withdrawn on the basis of advice from the police that a prosecution would be difficult because of the relationship between the victim and the suspect, rather than because the victim did not want the perpetrator to be imprisoned. If that were the case, it could be considered that not wanting to go through the difficult trial process was a factor.

In the Attrition Study, the victim did not co-operate with the investigation or withdrew during the investigation stage in 20 per cent (385) of cases recorded by the police as sexual violation. In 139 of those cases, the reasons the victim gave for withdrawing from the investigation were noted in the file. The reasons included that the victim did not want the offender charged (37 cases) and forgave the offender (six cases). In four cases, the authors of the study noted the reason for withdrawal as concern about family reaction. "Concern about family reaction" may mean that the victim was concerned about his or her family finding out about the incident, but it could also mean that the victim was concerned about the family's reaction to the possibility of a sentence of imprisonment being imposed on the perpetrator (if the perpetrator was a partner or other member of the victim's family). ${ }^{33}$ It is possible that some of the victims may have wished to proceed with the investigation if a sentence other than imprisonment was available. However, the concern may also have been worry that the family would reject the victim for proceeding with the complaint or pressure the victim to withdraw it, an issue the treatment track could not do anything about (unless the concern was specifically about the sentence, rather than about intervention in their lives or conviction of the accused).

Victim withdrawal was also an issue during the prosecution stage, although to a lesser degree than during the investigation. There were 349 cases where the accused was prosecuted but not convicted. 17 per cent of those cases were withdrawn by the

$\begin{array}{ll}32 & \text { At } 50 . \\ 33 & \text { At } 49-50 .\end{array}$


prosecution. In two-thirds of withdrawn cases, the reason for withdrawal of charges was not stated. However, 17 cases were withdrawn due to "victim issues." 34 The authors stated that "in three cases the victim admitted lying or retracted her statement, five refused to give evidence or would not sign the depositions, two were reluctant to proceed, one victim disappeared, one victim went overseas, and the rest did not want to proceed." 35 While it is not known what motivated the victims in most of those cases, it is possible that the prospect of a lengthy sentence of imprisonment for the perpetrator played a role in the unwillingness of some to proceed with the prosecution or in the complainant's decision to retract her statement. ${ }^{36}$ The fact that defendants who were current partners of complainants were over-represented in cases that were withdrawn lends support to that suggestion, because when the relationship is ongoing the complainant may wish to protect the defendant from a lengthy sentence. ${ }^{37}$ It is likely that not wanting to go through the trial played a role in at least some of the cases where the complainant refused to give evidence or sign depositions or did not want to proceed.

If the trial process and the inflexibility of sentencing play a role in victims' decisions to withdraw from the investigation or prosecution process, establishing a treatment track could help to address these problems and thus reduce attrition. As with reporting, to reduce attrition substantially, changes that address other reasons for victim withdrawal would also be necessary, including fast-tracking to reduce delay ${ }^{38}$ and increased support from specialist victims' advisors. ${ }^{39}$ Some of these changes are being piloted in the specialist sexual violence courts in Whangarei and Auckland. ${ }^{40}$

\footnotetext{
$34 \quad$ At 62 .

$35 \quad$ At 62 .

$36 \quad$ At 62 .

$37 \quad$ At 63

38 Jeremy Finn, Elisabeth McDonald and Yvette Tinsley "Identifying and qualifying the decisionmaker: The case for specialisation" in Elisabeth McDonald and Yvette Tinsley (eds) From "Real Rape” to Real Justice: Prosecuting Rape in New Zealand (Victoria University Press, Wellington, 2011) at 270-272.

39 Elisabeth McDonald "Complainant desire for information, consultation and support: How to respond and who should provide?" in Elisabeth McDonald and Yvette Tinsley (eds) From "Real Rape” to Real Justice: Prosecuting Rape in New Zealand (Victoria University Press, Wellington, 2011) at 213-218.

40 "Sexual violence courts to be trialled" New Zealand Law Society (20 October 2016) $<$ https://www.lawsociety.org.nz/news-and-communications/latest-news/news/sexual-violencecourts-to-be-trialled $>$.
}

Early indications are that the specialist sexual violence courts reduce delay substantially: "Pilot halves court time for sexual violence cases" Radio New Zealand (15 December 2017) 


\section{Decision to prosecute}

Another point at which the high sentencing levels and difficulty of the trial process might be at play in attrition is the decision to prosecute.

In New Zealand, decisions about prosecutions must be made in accordance with the Solicitor-General's Prosecution Guidelines. ${ }^{41}$ These guidelines set out a two-part test for prosecution. The first limb of the test is evidential sufficiency: there must be sufficient evidence "to provide a reasonable prospect of conviction." 42 This test is predictive in nature, rather than based on the instrinsic merits of the case. ${ }^{43}$ The second limb of the test requires the prosecution to be in the public interest. ${ }^{44}$

In this section, I look for places where the high sentencing level or the difficulty of the trial process might be the reason a case is not prosecuted. I am concerned with two scenarios. The first is cases where there is sufficient evidence (objectively assessed) to support a conviction, but where because of the likely perception of the evidence there is not a reasonable prospect of conviction (and the case would therefore fail the first limb of the test). The second is where the process would be so difficult for the complainant that it would not be in the public interest to proceed with the case (therefore failing the second limb). ${ }^{45}$ These are the two scenarios where establishing a treatment track might increase the proportion of cases prosecuted. I am not at any point advocating prosecution of cases where there is insufficient evidence to support a conviction.

Currently, police and prosecutors may decide not to charge a suspect in situations where there is sufficient evidence that the accused committed sexual violation, but where there is concern that a jury's perception of the evidence - shaped by rape mythology - would result in an acquittal. The Police Association's submission in response to the Law

\footnotetext{
$<$ http://www.radionz.co.nz/national/programmes/ninetonoon/audio/2018626532/pilot-halvescourt-time-for-sexual-violence-cases $>$.

$41 \quad$ Solicitor-General's Prosecution Guidelines (Crown Law, 2013).

$42 \quad$ At $6-8$.

43 For more on the distinction, see Andrew Ashworth and Mike Redmayne The Criminal Process (4 ed, Oxford University Press, New York, 2010) at 201.

44 Solicitor-General's Prosecution Guidelines, above n 41, at 8-10.

45 Operation Clover is a recent New Zealand example of a case in which the police considered they had sufficient evidence against the suspects in respect of five victims, but did not proceed because those victims did not wish to continue with the process: Operation Clover - Investigation Overview (New Zealand Police, October 2014) available at <https:/www.police.govt.nz/aboutus/publication/operation-clover-investigation-overview $>$.
} 
Commission's issues paper provides some support for that possibility. The Police Association noted that many of its members working in sexual assault investigation were concerned about low conviction rates, and: ${ }^{46}$

agreed that this problem stemmed in great part from the fact that the consequences of conviction are so high that fact-finders are not willing to convict in cases they view as marginal in terms of degree of culpability or intent, or which lack elements of overt violence which in a juror's mind place the action on par with the sorts of serious or life-threatening violence necessary to attract similar penalties for nonsexual violence.

I begin by examining the available quantitative evidence from New Zealand that suggests that there are cases in which there is sufficient evidence that the suspect committed sexual violation, but the police decide not to charge the suspect, or the prosecutor discontinues the prosecution prior to trial.

The Attrition Study indicates that there may have been cases where there was sufficient evidence that a suspect committed sexual violation to support a prosecution, but the suspect was not charged because of how a jury would be likely to perceive that evidence (which I will refer to as cases with a "perception problem").

34 per cent of cases initially recorded as sexual violation were classified as "no offence". Up to 20 per cent of them (132 of the 667 cases classified as "no offence") may fall into the "perception problem" category. Triggs and colleagues noted: ${ }^{47}$

In 48 cases, intercourse occurred but the circumstances suggested lack of consent as it is legally defined.

- In 23 cases, the file notes indicated that sex was initially consensual, but at some stage the victim wanted to stop... These included cases where the sex became too rough, a condom was not used or broke, or the activities went beyond what was agreed or acceptable (eg. the victim did not want anal sex).

- In 25 cases, intercourse occurred and consent could not have been obtained due to the victim being intoxicated (ten cases), asleep when the assault started (12 cases), on medication (one case), too scared to say no (one case) or mistaken on identity (one case).

$46 \quad$ Triggs and others, above $\mathrm{n} 31$, at 2.

47 Law Commission Alternative Pre-Trial and Trial Processes: Summary of Submissions to Consultation (NZLC MP, 2012) at 33. 
In 84 cases, there appears to have been an offence committed, or at least no indication that the validity of the claim was doubted and no reason stated why the incident was classified as 'no offence'.

It is possible that the police recognised at least some of those incidents as offences, but decided not to charge the suspect because a jury would be unlikely to convict. Juries may not consider those 48 cases to be sexual violation, may consider the complainant to be as or more blameworthy than the defendant for initially consenting to sex or for being too intoxicated to give consent, or not consider the offences serious enough to warrant a prison term, and therefore acquit. The other 84 cases may also have been cases that did not conform to the "real rape" template, creating a perception problem. These are also the types of cases that are likely to be most difficult for complainants, because of the degree of mismatch with the "real rape" template. The likely impact on complainants of cross-examination in these types of cases may have contributed to the decision not to charge the suspect.

In addition, there were 112 cases where a suspect was identified but no charges laid due to insufficient or conflicting evidence. ${ }^{48}$ It is not possible to know from the study how evidential sufficiency was assessed. In some of those cases the evidence may have been deemed insufficient because of a perception problem, rather than because of insufficiency as such. There were also 95 cases in which the reason for the decision not to charge the suspect was not stated. $^{49}$

The Attrition Study also presented an analysis of the characteristics of cases associated with charges being laid. This analysis provides further support for the possibility that charges were not laid when the "real rape" template might have created a perception problem at trial. The study assessed how many aggravating features were present in each case, on the basis of the file information available. The aggravating features it included were multiple offences, multiple offenders, multiple victims, offender with any criminal history, offender with previous sex convictions, offender with previous violent convictions, any type of force, injury or threat to the victim, and the scale of injury. ${ }^{50}$ It found that the more aggravating factors that were present in a case - and therefore the more the case appeared to be a "real rape" - the more likely it was that the suspect would be charged. A suspect was charged in 17 per cent of cases with no aggravating factors,

\begin{tabular}{ll}
\hline 48 & At 41. \\
49 & At 41. \\
50 & At 71.
\end{tabular}


44 per cent of cases with 1-2 aggravating factors, 63 per cent of cases with 3-4 aggravating factors, and 84 per cent of cases with 5 or more aggravating factors. ${ }^{51}$

Further, suspects were less likely to be charged when various victim factors were present: the victim refused a medical examination, had a mental health problem, had made previous complaints of sexual violence, was intoxicated, or delayed reporting. Some of these factors may have affected evidential sufficiency, but some of them may have been of more relevance to how the evidence would be perceived. ${ }^{52}$ The study found that the more victim factors present, the less likely it was the case would be prosecuted. 61 per cent of cases where none of the factors was present were prosecuted. However, when one or two factors were present the rate was 49 per cent, and dropped to 35 per cent when three or more of them were present. ${ }^{53}$

The question remains, however, whether establishing a treatment track could change the decision not to prosecute in cases where there is sufficient evidence that sexual violation occurred. In how many cases is it a conscious decision by police and prosecutors because of their awareness that juries are influenced by the "real rape" template, and in how many is it that they themselves are influenced by rape mythology? If it is the latter, it is a training and internal review matter, and better dealt with directly. ${ }^{54}$ And to what extent could increasing the flexibility of sentencing in order to incentivise guilty pleas address the problem? It may be that other approaches, such as changing the fact-finder from a jury to a judge sitting alone or with some lay participation other than a jury, as McDonald and Tinsley recommended be investigated, could have a greater impact. ${ }^{55}$ Otherwise, people who would currently be acquitted at trial would have little incentive to plead guilty (something I discuss in the next section), making it pointless and even damaging to increase the number of prosecutions.

Currently the evidence does not rule out the possibility that establishing a treatment track could increase the likelihood of prosecutions in sexual assault cases with sufficient evidence to support a conviction. However, more research into the role of sentencing

\footnotetext{
$51 \quad$ At 77.

52 The difficulties of this disctinction are discussed further in Chapter 7.

$53 \quad$ At 77.

$54 \quad$ See the recommendations made by Yvette Tinsley in "Investigation and the decision to prosecute in sexual violence cases" in Elisabeth McDonald and Yvette Tinsley (eds) From "Real Rape" to Real Justice: Prosecuting Rape in New Zealand (Victoria University Press, Wellington, 2011) at 147-150 and 161-164.

55 Finn, McDonald and Tinsley, above n 38, at 233-252.
} 
levels and the difficulty of the trial process in prosecution decisions (which would be assisted by better record-keeping) is necessary before a stronger conclusion can be drawn.

So far in this chapter, I have discussed whether the treatment track could increase the number of sexual assault perpetrators with whom the criminal justice process can formally intervene, by looking at whether establishing a treatment track could help to increase reporting and decrease attrition in sexual cases. In the following section, I discuss whether establishing a treatment track could increase the proportion of guilty pleas in sexual cases, which would itself reduce attrition, as well as potentially affecting other sources of attrition and reasons for under-reporting.

\section{Guilty Pleas}

Defence counsel with whom McDonald and Tinsley consulted reported that some of their clients might have been willing to admit to an offence if the potential penalty was not so high. However, counsel noted that the lengthy sentences in combination with the difficulty of proving sexual offences beyond reasonable doubt mean that often the best course of action for an accused is to defend the charge. For many accused, it pays off to forgo the sentence discount (of up to 25 per cent) available for a guilty plea in favour of taking the gamble and defending the case. ${ }^{56}$ McDonald and Tinsley suggested that by offering a community-based alternative to a sentence of imprisonment, the treatment track might more effectively incentivise guilty pleas. ${ }^{57}$

Increasing the number of early guilty pleas may also help to address under-reporting and attrition. Beyond the obvious effect of securing a conviction in cases that would ordinarily go to trial and possibly result in an acquittal, ${ }^{58}$ increasing the number of early guilty pleas could also help to address other sources of attrition. Early guilty pleas could help to reduce victim withdrawal, because cases can be resolved more quickly and with less trauma for victims (major barriers to continued participation in the process by victims $^{59}$ ). An increase in the likelihood of guilty pleas in sexual cases could also affect decisions made earlier in the process by police, prosecutors, and victims. It is possible

\footnotetext{
56 Elisabeth McDonald and Yvette Tinsley "Rejecting "one size fits all": Recommending a range of responses" in Elisabeth McDonald and Yvette Tinsley (eds) From "Real Rape" to Real Justice: Prosecuting Rape in New Zealand (Victoria University Press, Wellington, 2011) at 378.

$57 \quad$ At 390 .

58 This would only be a possibility in marginal cases; if the odds are still quite heavily in favour of an acquittal, it is unlikely that a person will plead guilty, even if there is an increased incentive to do so.

59 Hare, above n 20, at 767.
} 
that police and prosecutors would be more likely to charge a suspect and continue with a prosecution if early guilty pleas were secured in more cases (because the prosecution is more likely to be successful ${ }^{60}$ ) and - if the change is sufficiently visible - victims who would like a formal resolution but do not wish to go through the ordeal of a trial may be more likely to report offending.

As background to the discussion, I outline in section one what incentives already exist for guilty pleas and what is known about the proportion and timing of guilty pleas in sexual assault cases. Previous research on the treatment track idea did not present data about the proportion and timing of guilty pleas, as it was reporting primarily on the views of professionals consulted. It is useful also to present data because it shows the effect of the Criminal Procedure Act 2011 on guilty pleas, which has come into force since that work was undertaken.

\section{The current position}

The criminal justice process already has a number of ways of encouraging guilty pleas. They include offering discounted sentences for a guilty plea (with larger discounts for earlier pleas ${ }^{61}$ ), charge bargaining (where the number or seriousness of charges may be reduced in exchange for a guilty plea), and - illicitly - fact bargaining (where the agreed summary of facts on which the defendant is sentenced is more favourable to the accused than it otherwise would have been). ${ }^{62}$ The Criminal Procedure Act 2011 also contains provisions intended to facilitate early guilty pleas. In particular, an accused is required to enter a plea early in the process (ss 39 and 43) and to participate in a case management process to determine whether the case needs to proceed to trial (ss 54-59). The Criminal Procedure Act also formalised in ss 60-65 a process for sentence indications (which involve the court indicating a sentence that is or is not likely to be imposed following a guilty plea).

In this section, I give an overview of the proportion of sexual cases resolved by guilty pleas and the timing of those guilty pleas. The data I discuss were obtained from the Ministry of Justice and are from the years 2010 - 2015. The Ministry does not record victim age, so some of the cases included in the statistics in this section will be sexual

\footnotetext{
$60 \quad$ For discussion of decision-making in relation to prosecutions, see Tinsley, above n 54, at 120-167.

$61 \quad$ In New Zealand, Hessell $v R$ [2010] NZSC 135, [2011] 1 NZLR 607 governs sentence discounts for guilty pleas.

62 Andrew Sanders, Richard Young and Mandy Burton Criminal Justice (4 ed, Oxford University Press, Oxford, 2010) at 439.
} 
assaults of children. Cases where the offence name specifies that the victim is a child were excluded, however. ${ }^{63}$

a) Proportion of guilty pleas

McDonald and Tinsley undertook their research before the Criminal Procedure Act 2011 ("CPA") had come into force. At that time, the proportion of sexual cases resolved by guilty plea was 42.2 per cent. ${ }^{64}$ As they predicted, the CPA seems to have affected the prosecution of sexual cases: ${ }^{65}$ the proportion of sexual cases resolved by guilty pleas has increased under the CPA to 68.7 per cent (a difference of 26.5 per cent). ${ }^{66}$

It appears that that increase in guilty pleas is accounted for by a decrease in the proportion of cases heard and resulting in a verdict (guilty, not guilty, or discharged on the basis of insufficient evidence). That figure has decreased under the CPA by 23.3 per cent (now 17.7 per cent of sexual cases). There have been no substantial changes under the CPA to the proportion of sexual cases that are heard but do not result in a verdict (because of a mistrial or a hung jury), that are not proceeded with, that are resolved by diversion, or resolved in some other way. ${ }^{67}$

Accordingly, the CPA appears to have encouraged some people who previously would have defended a sexual charge to plead guilty instead. The relatively high rate of guilty pleas suggests perhaps a less pressing need than before the CPA for alternatives to the adversarial trial to reduce the number of complainants subjected to the trial process. However, that does not mean there are no cases in which a defendant might plead guilty and thereby save the complainant from the ordeal of the trial if a treatment track were introduced (an issue that will be discussed further in subsection (c) below).

b) Timing of guilty pleas

Most guilty pleas in sexual cases are entered early (at the administration phase of the criminal process) - 53.2 per cent pre-CPA and 51.6 per cent under the CPA. For cases prosecuted under the old system, the next most frequent point for a guilty plea to be

\footnotetext{
63 Information from the Ministry of Justice, on file with author.

64 Ibid.

65 Jeremy Finn, Elisabeth McDonald and Yvette Tinsley "The potential impact of other proposed reforms on processes in sexual violence cases" in Elisabeth McDonald and Yvette Tinsley (eds) From "Real Rape" to Real Justice: Prosecuting Rape in New Zealand (Victoria University Press, Wellington, 2011) at 107-112.

66 Ministry of Justice, above n 63.

67 Ibid.
} 
entered was at trial, with 35.4 per cent of guilty pleas being entered at that late stage (which may be after the complainant has given evidence). For cases prosecuted under the CPA, however, a higher proportion of guilty pleas are entered at the review stage (27.4 per cent compared with 11.3 per cent pre-CPA), reducing the proportion of late guilty pleas to 21 per cent.

Approximately half of guilty pleas in sexual cases are entered in the middle or at the end of the prosecution process, which reduces their benefits to complainants and the efficiency of the criminal justice process. Of particular concern are those guilty pleas entered at trial, where the complainant has prepared herself to give evidence or in some cases has already given evidence. It would be good if the treatment track could encourage defendants to enter the guilty plea earlier.

c) Possible differences if sexual assaults against children were excluded

It may be that the proportion of cases resolved by guilty plea would be lower if the New Zealand data were limited to sexual assaults of adults, because of the frequency with which consent is an issue, which can make the offence more difficult to prove. Data from New South Wales suggests that people charged with sexual assault of an adult are less likely to plead guilty than those charged with sexual assault of a child.

Ringland and Snowball investigated rates of guilty pleas entered in the NSW District Court between 2011 and $2013 .{ }^{68}$ One of the categories of offences for which they reported results was aggravated sexual assault of an adult. The definition of aggravated sexual assault comprised indecent assault with aggravating features (the presence of a weapon, infliction of physical injury, or multiple offenders), sexual violation, and assault with intent to commit sexual violation. ${ }^{69}$ The study found that for aggravated sexual assault, late guilty pleas (defined in that study as guilty pleas entered after committal for trial) were more common than early guilty pleas, and not guilty pleas were more common than either early or late guilty pleas. ${ }^{70}$

68

69

70

Clare Ringland and Lucy Snowball Predictors of guilty pleas in the NSW District Court (NSW Bureau of Crime Statistics and Research, 2014).

Brian Pink Australian and New Zealand Standard Offence Classification (3 ed, Australian Bureau of Statistics, 2011) at 33. The study did not investigate sexual assaults without aggravating features. These criteria are a good match for the treatment track eligibility criteria set out in Chapter 3.

Ringland and Snowball, above n 68, at 7. 
The NSW study split aggravated sexual assault into cases with an adult victim and cases with a child victim. Ringland and Snowball found that the odds of people charged with aggravated sexual assault of an adult pleading not guilty were 4.97 times greater than pleading guilty. However, the odds of those charged with aggravated sexual assault of a child pleading not guilty were only 2.12 times greater than pleading guilty. ${ }^{71}$

In terms of timing of guilty pleas, Ringland and Snowball divided guilty pleas into early (not committed to trial) and late (committed to trial). The odds of an aggravated sexual assault of an adult being resolved by a late guilty plea were 2.78 times greater than the odds of being resolved by an early guilty plea. Guilty pleas for aggravated sexual assaults of a child, on the other hand, were equally likely to be entered early or late. A not guilty plea was more likely than an early guilty plea in both types of cases, however, and more so for aggravated sexual assaults of an adult (where the odds of a not guilty plea were 3.11 times the odds of an early guilty plea, compared with 1.93 for aggravated sexual assault of a child). ${ }^{72}$

If it were possible to separate out sexual assaults of adults from those against children in the New Zealand data, it is possible that a similar pattern would be found. If that were the case, the argument for establishing a treatment track to incentivise guilty pleas in the kinds of cases already prosecuted would be stronger.

If the treatment track were to increase the proportion of people who plead guilty rather than not guilty, that could make some difference in the proportion of perpetrators of sexual violence the criminal justice process can formally intervene with. Another important consideration, particularly in terms of the experience of the complainant, is when a guilty plea is entered. In the next section, I consider whether a treatment track could encourage people who plead guilty late in the process to plead guilty earlier.

\section{Could the Treatment Track increase early guilty pleas?}

In this section, I consider whether the empirical evidence suggests that offering a noncustodial sentence in exchange for a guilty plea could incentivise early guilty pleas. The relevant empirical evidence is limited, and no studies have investigated factors influencing the plea decision in sexual assault cases specifically. What is clear from the evidence is that a number of factors can influence the plea decision. Offering a noncustodial sentence may increase the likelihood of a guilty plea. However, there are other

\footnotetext{
71 These odds ratios were significant at $\mathrm{p}<.001$ (Ringland and Snowball, above $\mathrm{n}$ 68, at 4).

$72 \quad$ At 6 .
} 
factors that may weigh against a guilty plea, particularly in "everyday rapes", which are the cases in which victims may benefit the most from a guilty plea. Accordingly, it is difficult to say how much of a difference a treatment track might make to the likelihood of a guilty plea or to the timing of that plea.

Factors influencing plea decisions are likely to vary between jurisdictions and may change within jurisdictions as legal landscapes change. Accordingly, recent local empirical research would be the most useful literature for evaluating whether introducing a treatment track would be likely to increase the number of guilty pleas. Unfortunately, however, no such research exists. Instead, I will draw on the small body of English and Australian empirical research, not all of which is recent. There is a larger body of research from the United States, but I will not use it because the North American practice of formalised plea-bargaining is markedly different from New Zealand practice and different factors may therefore be at play.

I discuss each factor in turn.

a) Perception of the treatment track as an "enhanced" sentence discount

A qualitative Australian study highlights common reasons for an accused to plead guilty. The researchers identified the four factors most commonly cited by the 64 legal practitioners (defence counsel, prosecutors, and judges) who were interviewed for the study in 1993 and 1994. An anticipated sentence discount was one of them. ${ }^{73}$ Offering a community-based alternative to a custodial sentence could be understood as a much greater sentencing discount than the reduction in the length of the term of imprisonment currently offered for guilty pleas in sexual cases. Whether that is enough to result in a guilty plea instead of a not guilty plea, or an early guilty plea instead of a late one, may depend on two things: how the treatment track is perceived and the strength of other relevant factors in the particular case.

The treatment track would not necessarily be less onerous than a sentence of imprisonment. $^{74}$ The requirements to engage in rehabilitation, comply with risk management conditions, and to make some sort of amends to the victim and/or the community are demanding. The fact that the treatment track is non-custodial may, however, be seen as an important benefit by people accused of a sexual offence. Positive

\footnotetext{
73 Kathy Mack and Sharyn Roach Anleu Pleading Guilty: Issues and Practices (Australian Institute of Judicial Administration Incorporated, Melbourne, 1995) at 18.

74 This issue is discussed fully in Chapter 7.
} 
benefits of engaging in rehabilitation may also be perceived, at least by relatively prosocial accused. For example, some may want to change their behaviour. Others might believe that pleading guilty and participating in the treatment track could help to repair relationships (with the victim or with others who are important to the accused) by demonstrating that the accused is taking steps to address the offending. On the other hand, the treatment track could be perceived as more intrusive or demanding than a sentence of imprisonment. It is difficult to determine in advance how the treatment track might be perceived by potential participants and their counsel, although to some extent perception may be influenced by how the treatment track is "sold" as an alternative response to sexual offending. ${ }^{75}$

When considering how much of an incentive the treatment track might be, it would also be desirable to be able to disentangle the influence on decision-making of the likely sentence, the possibility of the imposition of post-sentence detention or supervision, being labelled as a "sex offender", and the collateral consequences of a conviction (such as stigma, loss of employment opportunities, and travel restrictions). Would substituting a community-based resolution for a sentence of imprisonment be enough to incentivise guilty pleas, or would the conviction and its legal and collateral consequences still discourage people from pleading guilty? The answer to that question has implications for the design of the treatment track. It may be that a diversion-type model would be necessary to incentivise guilty pleas. If so, further consideration would need to be given to whether that type of model would be principled and politically acceptable.

b) The strength of the prosecution's case

The strength of the prosecution's case was the factor most commonly cited by the Australian practitioners as influencing the plea decision. ${ }^{76}$ The evidential difficulties involved in sexual cases generally and in "everyday rapes" in particular may mean that an accused is unlikely to plead guilty, notwithstanding the enhanced sentence discount the treatment track offers. Moreover, if the victim is particularly vulnerable, he or she may be perceived as less credible. Other changes that improve the investigative process or could otherwise affect the likelihood of conviction (such as removing the jury from sexual violation cases, as discussed by McDonald and Tinsley ${ }^{77}$ ) could make it more likely that the treatment track would incentivise guilty pleas.

\footnotetext{
75 The importance of providing accurate information about the treatment track to potential participants is discussed in Chapter 7.

$76 \quad$ Mack and Anleu, above n 73, at 18.

77 Finn, McDonald and Tinsley, above n 38, at 233-252.
} 
c) Acknowledging guilt

Acknowledging guilt was another of the reasons for pleading guilty that the Australian practitioners cited frequently. ${ }^{78}$ That factor may be less likely to come into play in "everyday rapes" because perpetrators may be less likely to recognise the wrongfulness of their behaviour. A guilty plea may, as a result, be unlikely in those cases, notwithstanding the enhanced sentence discount offered by the treatment track.

d) Characteristics of the alleged offence and the alleged offender

Ringland and Snowland found that people were more likely to plead guilty if they were younger, had more than one previous conviction or had previously been sentenced to imprisonment. People who had previously been acquitted of an offence were less likely to plead guilty than those who had not previously been acquitted. ${ }^{79}$ People charged with certain offences, including aggravated sexual assault of an adult (comprising indecent assault with aggravating features, sexual violation, and assault with intent to commit sexual violation), were also less likely to plead guilty than those charged with a nonsexual offence. ${ }^{80}$

The people the NSW study suggests are less likely to plead guilty (in particular those with few or no previous convictions and who have not served a sentence of imprisonment) are those who are least likely to be perceived by criminal justice decisionmakers as "real rapists" and whose victims are consequently likely to have a more distressing experience in the criminal justice process. Incentivising guilty pleas amongst that group in particular would make the biggest difference to victim distress. The reduced likelihood of conviction for defendants not perceived as "real rapists" may, however, make it unlikely that they will plead guilty.

From a public safety perspective, on the other hand, the NSW District Court study's finding that people are more likely to plead guilty if they are young, have more than one previous conviction or have served a sentence of imprisonment may be a positive finding for the treatment track. Those factors are associated with higher rates of recidivism, at

$78 \quad$ Mack and Anleu, above n 73, at 18.

79 Ringland and Snowball, above $\mathrm{n} 68$ at 2-5.

80 At 4-5. See also Mack and Anleu, above n 73 , at 19. 
least on the basis of official recidivism data. ${ }^{81}$ If the people who are most in need of rehabilitation are likely to plead guilty, it is more likely that the treatment track will be able to target the right perpetrators. On the other hand, if those perpetrators are already more likely to plead guilty than other perpetrators, the treatment track may not make very much difference to the rate of guilty pleas amongst that group.

e) Advice of defence counsel

Another factor that may influence the effectiveness of the treatment track in incentivising guilty pleas is the attitude of defence counsel to early guilty pleas and to the treatment track.

The former has been the subject of limited empirical investigation, with two studies in the English Crown Courts (conducted 15 years apart) finding evidence of barristers exerting considerable pressure on their clients to plead guilty. ${ }^{82}$ That evidence is too far removed from contemporary New Zealand to shed any light on current practice. However, if New Zealand defence counsel were engaging in similar practices in contemporary sexual assault cases, it is possible that they would embrace the treatment track as extra "ammunition" for persuading reluctant clients to plead guilty. Ethical issues aside, the treatment track could thus be an effective mechanism for increasing the number of early guilty pleas. However, it seems unlikely that defence counsel are in fact routinely pressuring their clients to plead guilty in sexual assault cases: the views of the practitioners consulted by McDonald and Tinsley indicate that sexual assault cases are often seen as "winnable" by defence counsel. ${ }^{83}$ Empirical research or at least wider consultation into the practice of defence counsel in sexual assault cases would be necessary to reach a clear conclusion on whether they are likely to encourage their clients to enter guilty pleas.

One issue that should be considered as part of that research is the adequacy of legal aid funding. If (as Sanders, Young and Burton argue in the English context and Tague

81 Karl Hanson and Kelly Morton-Bourgon "Characteristics of Persistent Sexual Offenders: A MetaAnalysis of Recidivism Studies" (2005) 73 Journal of Consulting and Clinical Psychology 1154 at 1156-1157.

82 John Baldwin and Michael McConville Negotiated Justice (London, Martin Robertson, 1977) at 45.

83 Elisabeth McDonald and Rachel Souness "From "real rape" to real justice in New Zealand Aotearoa: The reform project" in Elisabeth McDonald and Yvette Tinsley From "Real Rape" to Real Justice: Prosecuting Rape in New Zealand (Victoria University Press, Wellington, 2011) at 51 . 
argues in the New South Wales and Victorian contexts) it is in the financial self-interest of defence counsel to persuade their clients to enter early guilty pleas, the need for financial survival may influence the advice given by counsel. On the other hand, there are a number of professional and ethical concerns that may lead counsel to act against their own financial interests. ${ }^{84}$ Legal Aid must be funded at a level that allows defence counsel to act in the best interests of their clients and maintain a business at the same time. $^{85}$

In terms of attitudes to the treatment track, the consultation carried out by the Law Commission provides preliminary support for the idea from defence counsel, ${ }^{86}$ although views may change depending on the final design of the treatment track, so further consultation would be necessary as part of the development of the model, if the idea were to progress to that stage.

\section{f) Other factors}

The New South Wales Law Reform Commission recently identified from existing research and consultation with stakeholders ten barriers to early guilty pleas. They were: ${ }^{87}$

1. The prosecution serves parts of the brief of evidence late.

2. The defence expects further evidence will be disclosed closer to the trial.

3. The defence believes that it is common practice for the prosecution to overcharge early, and that the charges will be reduced as the proceedings advance.

4. The prosecution accepts a plea to a lesser charge late in the proceedings.

5. Senior Crown Prosecutors with the authority to negotiate are not briefed until late in the proceedings.

84 Peter Tague “Guilty Pleas or Trials: Which Does the Barrister Prefer?” (2008) 32 Melb U L Rev 242. Mack and Anleu, above n 73, at 30-32 and Tague, above n 84. Law Commission Alternative Pre-Trial and Trial Processes: Summary of Submissions to Consultation (NZLC MP, 2012) at 99.

87 New South Wales Law Reform Commission Encouraging Appropriate Early Guilty Pleas (Report 141, 2014) at 9-10. For further discussion of how criminal procedure may affect the likelihood of an early guilty plea, see Sharyn Roach Anleu and Kathy Mack "Intersections Between In-Court Procedures and the Production of Guilty Pleas" (2009) 42 Australian and New Zealand Journal of Criminology 1. 
6. The defence perceives the court to be flexible in the way it applies a sentence discount for the utilitarian benefit of an early guilty plea that occurred later in the proceedings.

7. The defence is skeptical that sentencing discounts will be conferred.

8. The defence believes that they will obtain better results in negotiations that occur just prior to trial.

9. Discontinuity of legal representation means that advice and negotiations are inconsistent.

10. The defendant holds back a plea because the defendant wants to postpone the inevitable penalty; denies the seriousness of his or her predicament until the first day of trial; and/or is hopeful that the case will fall over due to lack of witnesses or evidence.

Ensuring that barriers to early guilty pleas such as these are not present in the New Zealand context would be necessary if the treatment track were to secure early guilty pleas. The NSW Law Reform Commission developed a "blueprint" for overcoming them. Its recommendations encompass the charging decision, disclosure, case management, and sentence discounts. ${ }^{88}$ Some of the recommendations are established practice in New Zealand (such as regulating sentence discounts, although in New Zealand they are governed by a guideline judgment rather than the statutory scheme recommended by the Commission ${ }^{89}$ ) or were put in place by the Criminal Procedure Act 2011. Changes since the Act came into force, such as an increase in the number of guilty pleas in sexual cases, fewer late guilty pleas being entered, and no cases being dismissed by the judge on the basis of insufficient evidence, suggest that the Act has been effective in reducing barriers to early guilty pleas. If a review of the CPA indicates that some barriers are nonetheless present in New Zealand, addressing them would be a precondition for the treatment track to incentivise early guilty pleas successfully.

\section{g) Conclusion}

The information from the Ministry of Justice indicates that nearly 70 per cent of sexual assaults are already resolved by guilty plea, although that proportion might be lower if we could exclude offences against children and the offences against adults that are too serious for the treatment track. We know also that around half of guilty pleas are already entered early (in the administration phase) and just over a quarter during the review stage. Only 21 per cent of guilty pleas are currently late (at the trial stage) which brings into question how much room for improvement there is in the timeliness of guilty pleas. It

\footnotetext{
$88 \quad$ New South Wales Law Reform Commission, above n 87, at 46-53.

$89 \quad$ Hessell $v R$, above $\mathrm{n} 61$.
} 
would be useful to have more information about what makes defendants plead guilty late. It may be that late guilty pleas are a result of factors that could not be addressed by establishing a treatment track, such as the defendant waiting to see if the complainant will attend the trial to give evidence or how convincing the complainant's evidence is.

It may also be that the cases in which a guilty plea would make the most difference (those cases that are likely to be the most difficult for the complainant and which are least likely to result in a conviction) are also the ones in which there is least incentive to plead guilty - even if a treatment track were established. The treatment track may still be able to do something to bring ordinarily undetected perpetrators into the criminal justice process, but it is likely that the difference it could make would be small and perhaps not target those with whom intervention is most necessary.

That conclusion would be strengthened - or perhaps challenged - by some local empirical research on factors influencing plea decisions in alleged sexual assaults of adults. Given the already wide scope of this thesis, it was not feasible to undertake that research as part of it, but the identification of the need for it is in itself a contribution to knowledge.

\section{Conclusion: Is it likely the treatment track would bring in ordinarily undetected perpetrators?}

At this point it is difficult to know how much of an impact the treatment track might have on reporting, the decision to prosecute, victim withdrawal from the investigation or prosecution, and the plea decision.

It may be that an intervention such as the treatment track, which still requires the victim to report the offence to the police, charges to be laid, and the accused to plead guilty, could make some difference to reporting and attrition. It is perhaps unlikely, however, that it could bring in many of those whose offending might be most suitable for the treatment track in terms of relative seriousness - and whose victims could most benefit from the availability of a resolution option other than a trial and sentence of imprisonment. Those "everyday rapes" may still be hugely under-reported, and may still be much more difficult to prosecute and secure a guilty plea and/or conviction.

It would be useful to investigate empirically how much of an impact the lengthy sentences of imprisonment and the difficulty of the trial process have on these 
contributors to under-reporting and attrition, including how important those factors are relevant to other contributing factors.

\section{Could the Treatment Track Intervene Effectively with Ordinarily Undetected Perpetrators?}

The simple answer to this question is that we do not know. The problem with trying to find evidence that treatment can be effective with men whose sexual offending would not ordinarily result in formal intervention is, of course, that intervention has not been undertaken so we do not know whether it could work. For that reason, I limit my discussion in this section to risk assessment with ordinarily undetected perpetrators. Good risk assessment is required to inform interventions to contain and reduce reoffending, and there is a body of literature on risk factors for repeat sexual violence perpetration by ordinarily undetected perpetrators. While there is good evidence for a number of risk factors, which I outline in this section, a satisfactory risk assessment tool has not yet been developed. I suggest some interim solutions that could be used in the context of the treatment track until a risk assessment tool can be developed and validated.

\section{A Risk Assessment with Ordinarily Undetected Perpetrators}

A number of risk assessment tools have been developed for use with men who have been convicted of a sexual offence, but those tools were not intended for use with people who have not been convicted of a sexual offence. There is, however, a substantial (and almost entirely separate) body of literature on the risk factors associated with self-reported sexual violence perpetration by people who are likely not to have gone through the formal criminal justice process. A small subpart of this literature examines predictors of repeat undetected sexual offending (compared with factors that differentiate perpetrators and non-perpetrators, the focus of most of the literature). In this section, I outline what is so far known about risk factors for repeat sexual offending by ordinarily undetected perpetrators.

Most of the studies use Malamuth's confluence model of sexual aggression as a starting point, though all also tested factors additional to those in the model. ${ }^{90}$ Accordingly, it is useful to outline the confluence model before turning to the findings. Malamuth and

\footnotetext{
90 N Malamuth, C Heavey and D Linz "Predicting men's anti-social behaviour against women: The Interaction Model of Sexual Aggression" in GN Hall and others (eds) Sexual Aggression: Issues in Etiology, Assessment and Treatment (Hemisphere, Washington DC, 1993); N Malamuth and others "The characteristics of aggressors against women: Testing a model using a national sample of college students" (1991) 59 Journal of Consulting and Clinical Psychology 670.
} 
colleagues developed the confluence model from data collected from a large, nationally representative sample of university students in the United States. The confluence model identifies two pathways to sexual aggression: preference for impersonal sex and hostile masculinity. Men who have a preference for impersonal sex (sex in the absence of a committed intimate relationship) are likely to commit sexual violence if they also have high levels of hostile masculinity (that is, they are hostile towards women, use sex to dominate women, and derive satisfaction from humiliating and controlling women). The confluence model also includes factors that are thought to contribute to the development of each of the pathways. Parental violence and child abuse put boys at risk for adolescent delinquency. Delinquency makes it more likely that an adolescent boy will develop a preference for impersonal sex (due to peer influence) and hostile masculinity. ${ }^{91}$ For these reasons, adverse childhood experiences and adolescent delinquency are often also measured in studies using the confluence model.

A number of studies have found that the factors in the confluence model predict either the frequency of sexual violence perpetration amongst repeat perpetrators or offending at multiple timepoints. ${ }^{92}$ These findings indicate that the confluence model factors would be good candidates for items in a risk assessment tool designed to predict recidivism amongst ordinarily undetected perpetrators.

Alcohol abuse has been found to predict frequency of sexual violence perpetration and perpetration at multiple time points. ${ }^{93}$ Drug use and perceived peer support for forced sex have also been found to predict sexual violence perpetration at multiple time points. ${ }^{94} \mathrm{~A}$ tendency to mistakenly perceive sexual interest and perceived peer pressure to engage in sex also predict frequency of sexual violence perpetration amongst repeat perpetrators. ${ }^{95}$

$91 \quad$ Antonia Abbey, Angela Jacques-Tiura and James LeBreton "Risk Factors for Sexual Aggression in Young Men" (2011) 37 Aggressive Behavior 450 at 458.

92 At 460; Heidi Zinzow and Martie Thompson "Factors Associated with Use of Verbally Coercive, Incapacitated, and Forcible Sexual Assault Tactics in a Longitudinal Study of College Men" (2015) 44 Archives of Sexual Behavior 213 at 218; Antonia Abbey and others "Cross-Sectional Predictors of Sexual Assault Perpetration in a Community Sample of Single African-American and Caucasian Men” (2006) 32 Aggressive Behavior 54 at 60-62.

93 Abbey and others, above n 92, at 61; Zinzow and Thompson, above n 92, at 218; Abbey, JacquesTiura \& LeBreton, above $\mathrm{n} 91$, at 458.

$94 \quad$ Zinzow and Thompson, above $\mathrm{n}$ 92, at 218.

95 Abbey, Jacques-Tiura and LeBreton, above n 91, at 458; Abbey and others, above n 92, at 61. 
Studies have also investigated the relationship between antisocial or psychopathic personality traits and repeat perpetration of sexual violence. Callousness/low empathy, narcissism, interpersonal manipulation, conning/superficial charm, impulsivity/erratic lifestyle, and pervasive anger have all been found to predict the frequency of repeat sexual violence perpetration and/or offending at multiple time points. ${ }^{96}$ In terms of offence-related factors, diversity in the choice of victim (stranger or acquaintance) and tactics used (assaulting an incapacitated victim or using/threatening to use force) is associated with higher rates of offending. ${ }^{97}$

It would be useful to be able to identify and intervene with those in the increasing and persistently high trajectories identified by Thompson, Swartout and Koss. They found that people in the increasing trajectory had high levels of hostile masculinity and perceived peer support for forced sex at the end of the study but not at the beginning. The reverse was true for the decreasing trajectory. High levels of hostile masculinity and perceived peer support for forced sex at both the beginning and the end of the study, along with a higher number of lifetime sexual partners (a proxy variable for preference for impersonal sex) at the beginning of the study, predicted membership in the persistently high trajectory.

The study does not, however, help us to predict who might desist without treatment, and whose offending might increase if they do not receive treatment. Men in the "increasing" trajectory appeared similar to men in the "low/none" trajectory at the beginning of the study, while men in the "decreasing" trajectory were similar to members of the "persistently high" trajectory. Encouragingly, however, Thompson and colleagues found that as risk factors changed, so did the likelihood of a person perpetrating sexual assault. Sexual compulsivity, hostility towards women, rape supportive beliefs, perceived peer approval of forced sex, and perceived peer pressure to have sex all decreased over time for men on the decreasing trajectory, while men on the increasing trajectory showed larger increases in risk factors compared to those on the other trajectories. ${ }^{98}$ These findings indicate that the risk factors are dynamic in nature.

96

Emily Mouilso and Karen Calhoun "Narcissism, Psychopathy and Five-Factor Model in sexual assault perpetration" (2012) 6 Personality and Mental Health 228 at 233-234; Zinzow and Thompson, above n 92, at 218; Abbey, Jacques-Tiura and LeBreton, above n 91, at 458.

97

98

Stephanie McWhorter and others "Reports of Rape Perpetration by Newly Enlisted Male Navy Personnel" (2009) 24 Violence and Victims 204 at 211.

Martie Thompson and others "Time-Varying Risk Factors and Sexual Aggression Perpetration Among Male College Students” (2015) 57 Journal of Adolescent Health 637 at 639-641. 
While some risk factors for reoffending by ordinarily undetected perpetrators have been identified, the next step of constructing risk assessment tools has not yet been undertaken. In the next section, I outline the benefits of using a risk assessment tool and describe the two main types of tools currently used. I then discuss a risk assessment tool that could be adapted for use in this context, drawing on the research outlined in this section.

\section{B Assessing Risk in the Treatment Track context}

Risk assessment tools, when used properly, produce more accurate predictions than (unstructured) clinical judgement. ${ }^{99}$ There are two main types of risk assessment tools: actuarial and structured professional judgement. Actuarial tools combine and weight the most useful risk factors, and link the score on the tool to a predicted rate of reoffending (for example, 25 per cent of those who score between 5 and 7 on the tool are convicted of a new offence within ten years). ${ }^{100}$ Actuarial tools have been found to be slightly more accurate than structured professional judgement. ${ }^{101}$ Structured clinical judgement tools provide a list of factors to be taken into account, but give the assessor the discretion to weight the factors according to her judgement, and additional factors may be taken into account. Structured professional judgement tools cannot predict the likelihood of reoffending (unless used as an actuarial tool) but can provide information about treatment and risk management targets.

At this point, developing a structured clinical judgement tool using the risk factors identified in the undetected perpetrator literature would be a good next step for that body of research. The information provided by that kind of assessment would be useful for indicating how many risk factors a person has and to what extent those factors are present, which could guide decision-making about treatment track eligibility, treatment targets, and risk management. Its usefulness would depend, of course, on the willingness of the person assessed to provide accurate information.

Having an actuarial tool, however, would be useful, because of the increased accuracy it could provide. Actuarial tools also have the advantage of providing information about absolute levels of risk (that is, indicate the proportion of offenders with similar scores to the person being assessed who reoffend) which are important for considering eligibility

99 Karl Hanson and Kelly Morton-Bourgon "The Accuracy of Recidivism Risk Assessments for Sexual Offenders: A Meta-Analysis of 118 Prediction Studies" (2009) 21 Psychological Assessment 1. Implications for Individual Risk Communication" (2015) 33 Behav Sci Law 111 at 111. Hanson and Morton-Bourgon, above n 99, at 6. 
and risk management - quite different decisions might be made if 50 per cent of those with the highest scores reoffend compared with 5 per cent, for example. ${ }^{102}$

No actuarial tools have yet been developed using the risk factors identified in the repeat undetected perpetrator literature. That would be a useful progression of that body of research, to enable intervention with those who are likely to reoffend without it. An actuarial tool has, however, been developed for use by the police with people who have not necessarily been convicted of a sexual offence. Jones, Harkins, and Beech developed the "Threat Matrix" to assess the risk posed by suspects in sexual offences, who may not have ever been convicted of a sexual offence. ${ }^{103}$ They included as risk factors allegations of sexual offences that did not proceed further and police intelligence about a suspect (such as anonymous information about a sexual offence from a person who did not wish to make a report). ${ }^{104}$ They also added in items related to prostitution and joint offending/association with known sex offenders on the basis that they are positively associated with sexual offending. ${ }^{105}$ The predictive validity of the model has yet to be assessed, although a longitudinal study is underway. ${ }^{106}$

Depending on the outcome of the validation study, the Threat Matrix could be useful in the treatment track context alongside a structured clinical assessment drawing on the risk factors identified in the repeat undetected perpetrator literature. The Threat Matrix may be particularly useful as a screening tool because it is automated and can be scored from information in the police database. It would not be a perfect fit for use with ordinarily undetected perpetrators, however. It was developed for use with men who come to the attention of the police (possibly a distinct sub-set of repeat perpetrators whose offending does not result in a conviction - perhaps more antisocial than most undetected perpetrators, but still more likely to commit "everyday rapes" than "real rapes") and was based on the Risk Matrix 2000/sexual scale, a British tool developed for use with convicted offenders. These limitations would need to be kept in mind if the Threat Matrix was to be used in the treatment track.

\footnotetext{
102 Though as will be discussed in Chapter 6, there is still substantial work to be done to ensure the accuracy of this information. Threat Matrix" (2015) 20 Legal and Criminological Psychology 165.

At 170.

Ibid.

106 At $172-173$.
} 


\section{Conclusion on Effectiveness of Intervention with Ordinarily Undetected Perpetrators}

At this stage, no case can be made that the treatment track could intervene effectively with men whose sexual offending would not ordinarily be detected. However, the reason the evidence does not exist is that intervention with this group has not yet been tried.

My conclusion on this issue is that, in this particular situation, the large gap in evidence should not be a barrier to the establishment of a treatment track to try to reduce recidivism by ordinarily undetected perpetrators. The research provides enough of a starting point to develop a preliminary structured clinical judgement risk assessment tool, which could be developed and refined with use. Decisions about eligibility, treatment, and risk management can be made on the basis of assessments using the tool. Treatment and risk management can, again, be refined with ongoing research and evaluation. Moreover, the alternative to intervening without strong evidence of the likely effectiveness of that intervention is that there will be no intervention at all. I think it would be justifiable to trial the treatment track (or some other intervention) with ordinarily undetected perpetrators in these circumstances.

\section{Conclusion}

I considered in this chapter whether the treatment track could reduce sexual recidivism by bringing into the criminal justice process perpetrators of sexual violence who are likely to reoffend and with whom there would not otherwise be any formal intervention to reduce recidivism. The reason for asking that question was that if the treatment track is to reduce sexual recidivism effectively, and thus comply with the second condition of penal minimalism, it must first be able to reach some of the people who commit sexual offences. I concluded that at this stage, it is not certain that the treatment track could bring ordinarily undetected perpetrators into the criminal justice process.

I recommended empirical investigation to determine how much of an impact not wanting the perpetrator to go to prison and/or not wanting to go through the trial process (two factors which establishing a treatment track could change) is likely to have on the victim's decision to report an offence and to co-operate with an investigation and prosecution. I also recommended inquiry into how much of a difference establishing a treatment track might have on the proportion and timing of guilty pleas.

In this chapter I also explored whether the treatment track could intervene effectively with those whose offending would currently be undetected, assuming that it could bring 
them into the criminal justice process in the first place. The reason for asking these questions was that the treatment track must be able to reduce recidivism by sex offenders effectively if it is to comply with the second condition of penal minimalism. A great deal of work is needed to be able to identify who is most at risk of recidivism and to develop a treatment programme that would be effective with that group. It may, however, be justifiable to pilot a treatment track with that population, because the alternative is that there is no formal intervention with them whatsoever.

In the next chapter, I consider whether the treatment track could intervene effectively with men whose offending would ordinarily result in a conviction, but who might be suitable candidates for the treatment track. 



\section{The Second Condition of Penal Minimalism, Continued: Could the Treatment Track Intervene Effectively with Ordinarily Convicted Offenders?}

\section{Introduction}

In this chapter, I evaluate whether the treatment track could reduce reoffending by those men whose offending would ordinarily result in a conviction. Much more is known about this group of offenders than the ordinarily undetected perpetrators discussed in the previous chapter. As will become clear, however, there are still substantial gaps in the evidence base that mean it cannot yet be said that the treatment track would comply with the second condition of penal minimalism (in this case, effectiveness in reducing reoffending by sexual offenders).

Unlike Chapter 5, which aimed to create a mandate for research on issues that have not received much attention until now, Chapter 6 examines a comparatively well-researched area. In this chapter, I suggest that when the evidence base is to be used to decide whether an alternative resolution such as the treatment track is justified, slightly different questions might need to be asked than those currently focused on by correctional psychology researchers and somewhat more robust findings are required than is needed to support routine operational decisions such as allocation to treatment and release on parole. While this chapter is about whether there is empirical support for the claim that the treatment track could intervene effectively with men who have sexually assaulted an adult, I am still writing from a law perspective, and my approach is influenced by a normative concern with fairness and non-arbitrariness that does not necessarily influence more pragmatic psychology research to the same degree.

I begin by discussing risk assessment with men who have been convicted of sexually assaulting an adult, as good risk assessment underpins both treatment and risk management. I then consider treatment effectiveness with that population.

\section{Risk Assessment}

If a treatment track were to be established, psychologists would need to assess the risk of recidivism posed by potential participants. The psychologists would be looking at whether the potential participant needs treatment to reduce the likelihood of sexual recidivism (that is, how high the person's risk of sexual recidivism is and how significant the person's treatment needs are). They would also need to consider whether the person's 
risk of recidivism (sexual, violent, or general) can be contained in the community for the period in which the person would participate in the treatment track (likely up to six years, depending on the seriousness of the offending ${ }^{1}$ ).

In Part A, as background to the rest of the discussion, I outline the core set of risk assessment tools used by the New Zealand Department of Corrections psychologists when assessing the risk posed by men who have been convicted of a sexual offence.

I outline in Part B the two aspects of accuracy I focus on, and the approach I take to the evaluation of how strong the evidence of accuracy must be.

In Part C, I consider how well evidence about the accuracy of the core risk assessment tools generalises to the treatment track context. I highlight the factors that I consider are likely to be relevant to determining how informative the available evidence about the accuracy of the risk assessment tools will be in the context of the treatment track.

Part D is a discussion of how well the core risk assessment tools are likely to function in the context of the treatment track, based on the factors discussed in Part C. I highlight gaps in the evidence, and conclude that not enough is yet known about the accuracy of the tools in the context described above to satisfy the requirements of penal minimalism.

Finally, in Part E, I consider whether the predictions of reconviction yielded by the tools are valid in light of under-reporting and attrition in sexual cases, arguing that the tools may distort the risk of reoffending because of the systemic bias in favour of "real rapes" throughout the criminal justice process. I recommend further research to ascertain whether distortion in fact occurs.

The main argument in respect of accuracy is that we do not yet know how accurately risk assessment tools would perform in the treatment track context. In respect of validity, I argue it is likely that the risk assessment tools are valid - that is, they do not distort the risk of sexual recidivism, despite having been developed on a population of "real rapists". I discuss each of the steps of my arguments in detail, because it is by no means clear that they are correct.

This is explained fully in Chapter 7. 


\section{A The Risk Assessment Tools}

In my discussion, I focus on the tools most commonly used by the New Zealand Department of Corrections to assess the risk of recidivism by sex offenders, in order to keep the scope of the discussion manageable. ${ }^{2}$ The tools are all actuarial instruments, which means they use group-based data to estimate the risk that an individual will recidivate. Actuarial tools specify items and a method for combining the items into a total score, and the total score is linked with a probability of reoffending. ${ }^{3}$ Actuarial risk assessment tools are developed by following a cohort of offenders (usually upon release from prison or a psychiatric facility, but sometimes from the beginning of a period of supervision in the community) for a certain number of years. For those offenders who recidivate (usually defined as a conviction, or sometimes a charge, arrest or readmission to a psychiatric facility for a new offence) during the follow-up period, the date and type of the recidivism is recorded. The data held about the offenders is then mined to determine which factors are associated with recidivism. The most useful factors are then combined into a risk assessment tool, which is then validated with a different sample. When the tool is used for risk assessment, individuals are placed into a risk category on the basis of their score on the tool. The likelihood that an individual will recidivate is determined by the number of offenders in the relevant risk category from the construction sample who recidivated (with a higher proportion recidivating as the risk level increases).

While I focus on the core New Zealand tools, at several points in this chapter I refer to research that has been undertaken with actuarial tools other than the core tools used by Corrections, in order to highlight the need to undertake similar research with the core New Zealand tools.

In this section, I briefly describe the tools I will focus on in the rest of this chapter. The first four tools were designed specifically for use with sex offenders, while the fifth was not designed specifically for sex offenders but is sometimes used with them.

\section{Automated Sexual Recidivism Scale (ASRS)}

The New Zealand Department of Corrections developed the ASRS as a screening tool to identify those at high risk of sexual recidivism (which became necessary when legislation

\footnotetext{
2 Personal communication with Justine Croxen, New Zealand Department of Corrections, 6 November 2017 (on file with author).

3 Karl Hanson and Kelly Morton-Bourgon "The Accuracy of Recidivism Risk Assessments for Sexual Offenders: A Meta-Analysis of 118 Prediction Studies" (2009) 21 Psychological Assessment 1 at 2 .
} 
enabling the imposition of extended supervision orders on people who had committed sexual offences against children was passed). It is computer-scored, using data routinely collected and stored by Corrections. The ASRS is based on the Static-99. ${ }^{4}$ Like the Static-99, the ASRS is made up of static risk factors (factors associated with the risk of reconviction that do not change in response to intervention, in this case age and a range of criminal history variables). The ASRS has several fewer variables than the Static-99, because Corrections does not collect the information required to score those variables. ${ }^{5}$

\section{STABLE-2007}

The STABLE-2007 was developed with a North American sample of sex offenders subject to community supervision (parole and probation). It was designed to assess risk using dynamic items (risk factors that are thought to change over time) and track changes in risk to help in the management of offenders in the community. It is made up of risk factors that are thought to be relatively stable but able to be changed through "effortful intervention."6 The STABLE-2007 was designed to be used in combination with the Static- $99^{7}$ (and is used with the ASRS in New Zealand).

\section{ACUTE-2007}

The ACUTE-2007 is the partner instrument of the STABLE-2007, and was designed to assess risk factors that can change rapidly (such as having access to a victim, emotional collapse, and rejection of supervision). The ACUTE-2007 has two subscales: one used to predict general recidivism (made up of all seven items) and one used to predict sexual or violent recidivism (made up of four of the items - victim access, sexual preoccupation, rejection of supervision, and hostility). ${ }^{8}$

\section{Violence Risk Scale-Sex Offender Version (VRS-SO)}

The VRS-SO was developed to assess risk of sexual recidivism, identify treatment targets, and assess changes in risk as a result of treatment. It includes static and dynamic risk factors that have been empirically or theoretically linked to recidivism. The

$4 \quad$ Karl Hanson and David Thornton "Improving risk assessments for sex offenders: A comparison of three actuarial scales" (2000) 24 Law and Human Behavior 119. Alexander Skelton and others "Assessing risk for sexual offenders in New Zealand: Development and validation of a computer-scored risk measure" (2006) 12 Journal of Sexual Aggression 277 at 280 .

6 Karl Hanson and others Assessing the Risk of Sexual Offenders on Community Supervision: The Dynamic Supervision Project (Public Safety Canada, 2007) at i.

$7 \quad$ Ibid.

$8 \quad$ At 20 . 
construction sample for the VRS-SO was made up of imprisoned sex offenders in Canada who had been referred for high-intensity treatment as they were considered to be at particularly high risk of sexual recidivism (due to high levels of sexual deviance and antisociality). ${ }^{9}$

\section{Psychopathy Checklist-Revised (PCL-R) and Psychopathy Checklist- Screening Version (PCL-SV)}

The PCL-R, and the shorter PCL-SV, measure a range of traits and behaviours that are argued to capture the construct of psychopathy. The PCL was not initially developed as a risk assessment measure, but high scores on the measures are associated with higher recidivism rates. ${ }^{10}$ The PCL-R or PCL-SV have been used on their own to predict general or non-sexual violent recidivism, and in conjunction with a measure of sexual deviance (such as the sexual deviance subscale of the VRS-SO) to predict sexual recidivism. $^{11}$

In the rest of this chapter, I discuss the accuracy and validity of the risk predictions yielded by these core risk assessment tools.

\section{B What is Accuracy?}

In this section, I outline the two aspects of accuracy that I focus on in relation to risk assessment tools: how well the tools discriminate between recidivists and non-recidivists in section one and the correspondence between predicted and observed recidivism rates in section two. In section three, I explain the approach I take to evaluating the strength of the evidence about accuracy.

\section{Discrimination (accuracy in predicting relative likelihood of recidivism)}

One aspect of the accuracy of risk assessment tools is how well they discriminate between recidivists and non-recidivists. The better the tool discriminates between recidivists and non-recidivists, the more accurate it is, and the more confidently we can

9 Mark Olver and others "A Multisite Examination of Sexual Violence Risk and Therapeutic Change" (2014) 82 Journal of Consulting and Clinical Psychology 312 at 313; Mark Olver and others "Using the Violence Risk Scale: Sexual Offense Version in sexual violence risk assessments: Updated risk categories and recidivism estimates from a multisite sample of treated sexual offenders" (2018) 30 Psychological Assessment 941.

10 Robert Hare and others "Psychopathy and the Predictive Validity of the PCL-R: An International Perspective" (2000) 18 Behavioral Sciences and the Law 623.

11 Mark Olver and Stephen Wong "Psychopathy, sexual deviance, and sexual recidivism among sex offenders" (2006) 18 Sexual Abuse 65. 
rely on the predictions for the purposes of eligibility, treatment, and risk management decisions.

The statistic most commonly used to assess how accurately risk assessment measures discriminate between recidivists and non-recidivists is the Area Under the Receiver Operating Curve (AUC). The AUC tells us the probability that a randomly selected recidivist will have a higher score on a risk measure than a randomly selected nonrecidivist (with higher scores indicating greater likelihood of recidivism). An AUC of 0.5 means an instrument performs no better than chance (there is complete overlap between the scores of recidivists and non-recidivists). An AUC of 1.0 means an instrument performs perfectly (the lowest score of any recidivist is higher than the highest score of any non-recidivist). ${ }^{12}$

By way of example, Craissati, Bierer and South tested how well the Static-99 discriminates between contact adult offenders who were convicted of a new sexual offence during the follow-up period of the study and those who were not. ${ }^{13}$ They found an AUC of $.73 .{ }^{14}$ That means that there is a 73 per cent probability that a randomly selected contact adult offender who was convicted of a new sexual offence during the follow-up period would have a higher score on the Static-99 than a randomly selected contact adult offender who was not convicted of a new sexual offence during follow-up. Conversely, of course, it also means that there is a 27 per cent chance that a randomly selected recidivist would not have a higher score on the Static-99 than a randomly selected non-recidivist.

According to the classifications developed by Rice and Harris, an AUC of between .556 and .639 should be considered a small effect size, an AUC of between .64 and .713 should be considered a medium effect size, and an AUC of greater than .714 should be considered a large effect size. ${ }^{15}$ Those classifications are widely used in the risk assessment literature. However, the classifications are simply translations of Cohen's suggested classifications for the magnitude of the $d$ statistic, which were not contextspecific. Cumming highlights the arbitrary nature of Cohen's classifications and

\footnotetext{
12 See James Bonta and DA Andrews The Psychology of Criminal Conduct (6 ed, Routledge, New York, 2017) at 48.

13 Jackie Craissati, Klive Bierer and Rebecca South "Risk, reconviction, and "sexually risky behaviour" in sex offenders (2011) 17 Journal of Sexual Aggression 135.

$14 \quad$ At 162.

15 Marnie Rice and Grant Harris “Comparing Effect Sizes in Follow-Up Studies: ROC area, Cohen's $d$, and $r$ " (2005) 29 Law and Human Behavior 615.
} 
recommends that context-specific classifications of effect sizes be developed. ${ }^{16}$ Doing so is a normative exercise that I will not attempt in this thesis. Instead, I will use Rice and Harris' classifications, but with the caveat that the classifications do not indicate any value-based judgment about how accurate a risk assessment tool should be before its use can be considered justifiable.

When examining AUCs, it is important to take into account how strong the evidence in favour of a particular AUC value is. In some studies, information about the strength of the evidence is conveyed using confidence intervals. The AUC derived from any single study is a point estimate (an estimate of the "true" AUC for the whole population). The confidence interval around the AUC tells us about the precision of the point estimate. If a 95 per cent confidence interval is used, we can be 95 per cent confident that the true AUC value lies between the upper and lower bounds of the confidence interval.

For example, an AUC of .70 indicates that there is a 70 per cent probability that a randomly selected recidivist would have a higher score on the Static-99 than a randomly selected non-recidivist. However, that AUC should be interpreted in light of the information provided by the confidence interval around the AUC. If the 95 per cent confidence interval for the AUC is $.60-.80$, that tells us that if the study was replicated 100 times, we could expect that the AUC would fall between .60 and .80 in 95 of the replications. The greater the width of the confidence interval, the less precise the AUC is as an estimate of the accuracy of the risk measure. If the confidence interval was .55.85 , the AUC of .70 would tell us less about how well the Static-99 discriminates between recidivists and non-recidivists than if the confidence interval was $.65-.75$ (because the range of plausible AUC values is greater). If the lower-bound estimate of the AUC was .50 or lower, we could not be confident that the instrument performs better than chance in discriminating between recidivists and non-recidivists (because the range of plausible values includes the value indicating that the instrument performs at chance level).

I report confidence intervals for the AUCs for every study in which they were included. For studies that only reported the results of null hypothesis significance testing, I report that information when discussing the strength of the evidence, but it should be noted that null hypothesis significance testing is less informative about the strength of the evidence of discriminative ability than the information provided by confidence intervals.

$16 \quad$ Geoff Cumming Understanding The New Statistics: Effect Sizes, Confidence Intervals, and MetaAnalysis (Routledge, New York, 2012) at 281-285. 
The null hypothesis in respect of AUCs is that there is no difference between the scores assigned to recidivists and non-recidivists on a given instrument (that is, that the instrument performs at chance level). Null hypothesis testing assumes that the null hypothesis is true and estimates the likelihood that an effect size (in this case the AUC) of that size or larger would be obtained if the null hypothesis were true. If the likelihood is below a certain cut-off (conventionally $0.05,0.01$, or 0.001 ) the value is deemed to be statistically significant. For example, Bartosh and colleagues found an AUC of .71 for the Static-99 (when predicting sexual recidivism by contact adult offenders) but the AUC was not significant at the 5 per cent level. ${ }^{17}$ That means that even though the AUC is relatively high (very close to being a large effect size) there is more than a 5 per cent chance that that AUC would be obtained even if the null hypothesis were true (and the Static-99 did not, in fact, perform better than chance) and so the result is not considered statistically significant.

At several points in the chapter, I compare AUC values (for example, when I consider whether a given tool performs better with one sex offender sub-type than another). For studies that reported confidence intervals, I conclude that there is a difference between the AUC values if there is no overlap in the confidence intervals or if the confidence interval around one AUC includes .50 and the confidence interval around the other one does not. For studies that reported only the results of null hypothesis significance testing, I conclude that there is a difference between the AUCs if one AUC was statistically significant and the other was not. That conclusion should be treated with caution, however, because the confidence intervals around the AUCs (if calculated) may well overlap almost completely, indicating no real difference between the effect sizes.

In interpreting the evidence, I adopt Geoff Cumming's recommendations in The New Statistics. For more information, see Appendix B.

\section{Calibration (accuracy in predicting absolute likelihood of recidivism)}

The second aspect of the accuracy of the risk assessment tool is how well calibrated the tool is, that is how well the predicted rates of recidivism correspond to observed rates of recidivism. Actuarial tools link the offender's score on the measure with a rate of recidivism (for example, 10 per cent of people assessed as having a score of 5 on a

17 Darci Bartosh and others "Differences in the Predictive Validity of Actuarial Risk Assessments in Relation to Sex Offender Type" (2003) 47 International Journal of Offender Therapy and Comparative Criminology 422 at 432. 
particular tool recidivate within five years). The more closely the observed rate of recidivism corresponds with the predicted rate, the more accurate the tool is.

Ideally, we would be able to ascertain how closely observed recidivism rates correspond with the recidivism rates predicted by each tool. Unfortunately, however, that research has not been undertaken. ${ }^{18}$ Instead, I discuss what is known about the stability of observed recidivism rates across different studies (that is, do we see similar recidivism rates for people assessed as being at a particular risk level on a particular tool?). I argue that the variation in observed recidivism rates is too large for the predictions to be relied upon.

\section{How certain of accuracy must we be?}

In evaluating the adequacy of the evidence that risk assessment is likely to be accurate in the treatment track context, my starting point is whether a treatment track is justified from the perspective of penal minimalism - specifically, whether it can be established that the treatment track is likely to be effective in reducing sexual recidivism, given that there is an alternative to establishing a treatment track (not establishing a treatment track). That starting point requires perhaps a more stringent evaluation than the pragmatic approach which might be thought appropriate when considering the use of risk assessment for routine decisions that must be made as part of sentence management, such as allocation to treatment and release on parole.

Treatment and parole improve community safety by reducing recidivism. Using risk assessment tools is the best way to ensure that good decisions are made about who is offered treatment and who is paroled before the end of their sentence. Using risk assessment tools about which there is imperfect data to make these decisions is undesirable from the perspective of community safety, but probably imperils community safety less than offering nobody treatment or parole on the basis that there is uncertainty about the accuracy of the tools with the specific population with which they are used. The use of tools in the absence of strong evidence about their accuracy also raises concerns about fairness to the offender, but as no additional restriction is imposed on the offender as a result of risk assessment in these contexts, these concerns are probably outweighed by the benefits to community safety. A commitment by the Department of Corrections to ongoing evaluation and improvement of the tools would, of course,

$18 \quad$ Although the statistical techniques are under development: Karl Hanson "Assessing the Calibration of Actuarial Risk Scales: A Primer on the E/O Index" (2017) 44 Criminal Justice and Behavior 26. 
substantially strengthen the justification for the use of the risk assessment tools for decisions about allocation to treatment and parole.

That pragmatic approach is not, however, appropriate when considering initiatives that do involve a risk to the community and where there is an alternative that (at least in the medium-term when the person's offending would otherwise be contained by imprisonment) poses less of a risk to community safety. Good evidence about the accuracy of risk assessment with the relevant population is required to justify establishing an initiative such as the treatment track, which keeps men in the community when they would ordinarily be imprisoned. For that reason, I take a more stringent approach to the evaluation of the sufficiency of evidence than might be considered appropriate for decisions such as allocation of prisoners to treatment and release on parole.

As an aside, other sentences and orders which assume the ability to predict recidivism accurately (such as preventive detention, extended supervision orders, and public protection orders) should, in my view, also be subject to this more stringent standard. The alternative to using these types of measures is to sentence the offender in the normal way (that is, to a finite sentence that is commensurate with the seriousness of the offending and not impose additional restrictions on the offender once the sentence has been served). Because preventive detention, extended supervision orders, and public protection orders restrict the liberty of the offender so severely, and are such grave breaches of the principle of proportionality in sentencing, there must be a very strong justification for their use (if indeed their use can be justified at all). A good evidence base for the accuracy of the risk assessment tools with the relevant population would be required to justify those measures.

Whatever the standard adopted, risk assessment is an inherently uncertain business, by virtue of the fact that it involves predicting the future. In this chapter, I ask how certain we can be that the core set of risk assessment tools will be accurate in the context of the treatment track, which adds an extra layer of uncertainty. That is because it is quite uncertain which factors make a difference to the accuracy of the tools when used in any particular context. Helmus, Hanson and Morton-Bourgon explained the issues in the following way: ${ }^{19}$

Leslie Helmus, Karl Hanson and Kelly Morton-Bourgon "International Comparisons of the Validity of Actuarial Risk Tools for Sexual Offenders, with a Focus on Static-99" in Douglas Boer, Reinhard Eher, Leam Craig, Michael Miner and Friedemann Pfafflin (eds) International Perspectives on the 
Fundamentally, any actuarial assessment is a generalization from the development sample(s) as it involves an implicit assumption that the individual currently being assessed is substantially similar to the individuals on which the scale was created. This assumption is more tenable in some applications than others (eg., using a scale developed on Canadian inmates for a Canadian inmate versus using a Canadiandeveloped scale for an inmate in India). The further an offender is removed from the development sample (e.g., in time, jurisdiction, offender type), the less tenable this assumption becomes, and the importance of testing the generalizability of the scale increases.

In the following section, I consider which factors are likely to be important when considering the generalisability of findings about the accuracy of the core risk assessment tools to the treatment track context.

\section{Which features are important?}

The treatment track is intended for New Zealand men who have sexually assaulted an adult. It is possible that as many as half of participants/potential participants may be Māori. $^{20}$ In this section, I argue that the accuracy of tools may differ by sex offender subtype (that is, whether the offender targets primarily adult or child victims, and whether the offender commits primarily contact or non-contact offences), jurisdiction, and indigeneity, and that therefore studies using samples with similar features to the men with which the tools would be used in the treatment track will provide the best evidence about the accuracy of the tools in this context.

I also argue that certain features of how the risk assessment tools would be used in the treatment track may affect the accuracy of the tools. Studies validating the tools in the field (rather than in the lab) and in which the assessments have been undertaken by people other than those who developed the tools probably provide the best indications of how accurately the tools will perform in the treatment track context. In addition, I argue that studies that use the recidivism outcomes and timeframes that are of most interest in the treatment track context will provide the best information about how accurately the tools would perform. Specifically, in order to determine whether a potential participant needs treatment and, if so, how much and what kind, the risk of sexual recidivism over a

Assessment and Treatment of Sexual Offenders: Theory, Practice, and Research (Wiley-Blackwell, Chichester, 2011) at 58.

20 Arul Nadesu Reconviction Rates of Sex Offenders: Five year follow-up study: Sex offenders against children vs offenders against adults (Department of Corrections, 2011) at 6. 
long time period is of interest. In order to determine whether a person's risk can be contained in the community while they complete the requirements of the treatment track, and if so what risk management measures are needed, all kinds of recidivism (but perhaps most importantly sexual and non-sexual violence) are relevant, over a period of up to six years (the maximum period a person may be subject to the treatment track requirements).

I discuss each of these features in turn.

\section{Sex offender subtype}

The treatment track is intended for men who have sexually assaulted an adult. In this section, I argue that when considering how accurate the core risk assessment tools are likely to be in the treatment track context, we should focus on estimates of accuracy with contact adult offenders and mixed offenders (rather than with men who have been convicted of any sexual offence, or with men who have been convicted exclusively of offences against children or non-contact sexual offences).

It should be noted at the outset that different studies adopt different victim age cut-offs when classifying offenders by sub-type, so some offenders would be classified as different subtypes in different studies. Victims are commonly classified as adults at the age of $16,{ }^{21}$ but other cut-offs have also been adopted. ${ }^{22}$ Some studies classify offenders with adolescent victims differently on the basis of whether the offending is intra or extrafamilial (with adolescent victims of intra-familial offending deemed children and adolescent victims of extra-familial offending deemed adults). ${ }^{23}$ A number of studies do not specify what age cut-off they are using. ${ }^{24}$ Studies also differ in whether only the

$\overline{21} \quad$ See for example Skelton and others, above n 5, at 280; James Vess and Alex Skelton "Sexual and violent recidivism by offender type and actuarial risk: Reoffending rates for rapists, child molesters and mixed-victim offenders" (2010) 16 Psychology, Crime and Law 541.

22 Such as 15 in Grant Harris and others "A Multisite Comparison of Actuarial Risk Assessments for Sex Offenders" (2003) 15 Psychological Assessment 413 at 415. For example Karl Hanson and others Assessing the risk of sexual offenders on community supervision: The Dynamic Supervision Project (Public Safety Canada, 2007) at 5; Susanne Bengston "Is newer better? A cross-validation of the Static-2002 and the Risk Matrix 2000 in a Danish sample of sexual offenders" (2008) 14 Psychology, Crime and Law 85 at 89; Jan Looman and Jeffery Abracan "Comparison of Measures of Risk for Recidivism in Sexual Offenders" (2010) 25 Journal of Interpersonal Violence 791 at 795; Genevieve Parent, Jean-Pierre Guay and Raymond Knight "An Assessment of Long-Term Risk of Recidivism By Adult Sex Offenders: One Size Doesn't Fit All” (2011) 38 Criminal Justice and Behavior 188 at 191-192.

24 For example Martin Rettenberger and others "A Comparison of Five Risk Assessment Instruments in Different Sexual Offender Subtypes” (2010) 54 International Journal of Offender Therapy and 
index offence (usually the lead offence at sentencing for the offender's current/most recent sentence) or the whole criminal history is used to classify offenders by subtype. For those studies that use the whole criminal history, most classify offenders by their most frequent victim choice (child or adult) but occasionally a "mixed offender" category is used for those who have offended against both adults and children. ${ }^{25}$ The inconsistency across studies contributes to uncertainty about the accuracy of risk assessment tools with men who sexually assault adults, because men may be classified as different subtypes depending on the criteria adopted by the study.

One reason for considering sex offender subtype to be a relevant characteristic is that risk-relevant differences between contact adult and contact child offenders have been found. ${ }^{26}$ Contact adult offenders tend to be younger than contact child offenders. ${ }^{27}$ They also tend to be more generally anti-social. Anti-social orientation has a number of components, including age of onset (contact adult offenders are more likely than contact child offenders to have had conduct problems in childhood and to have engaged in delinquency in adolescence, ${ }^{28}$ and tend to begin offending in adulthood earlier than contact child offenders ${ }^{29}$ ) and criminal versatility (contact adult offenders commit a more diverse range of offences than contact child offenders ${ }^{30}$ ). Other components of anti-

Comparative Criminology" 169; Leslie Helmus and Karl Hanson "Predictive Validity of the Static99 and Static-2002 for Sex Offenders on Community Supervision" (2007) 2 Sexual Offender Treatment 1; Bartosh and others, above n 17.

$25 \quad$ Vess and Skelton, above $\mathrm{n} 21$.

26 Few studies include mixed offenders as a group in their own right, so it is difficult to draw conclusions about their similarities and differences to contact adult and child offenders.

27 Karl Hanson "Recidivism and Age: Follow-Up Data from 4673 Sexual Offenders" (2002) 17 Journal of Interpersonal Violence 1046 at 1053 and 1056-1058.

28 Leonard Bard and others "A Descriptive Study of Rapists and Child Molesters: Developmental, Clinical, and Criminal Characteristics" (1987) 5 Behavioral Sciences and the Law 203 at 213-215; Danielle Harris, Paul Mazerolle and Raymond Knight "Understanding Male Sexual Offending: A Comparison of General and Specialist Theories" (2009) 36 Criminal Justice and Behavior 1051 at 1061.

29 DJ Baxter and others "Deviant Sexual Behavior: Differentiating Sex Offenders by Criminal and Personal History, Psychometric Measures, and Sexual Response" (1984) 11 Criminal Justice and Behavior 477 at 485; Patrick Lussier, Marc LeBlanc and Jean Proulx "The generality of criminal behavior: A confirmatory factor analysis of the criminal activity of sex offenders in adulthood" (2005) 33 Journal of Criminal Justice 177 at 186.

Baxter and others, above n 29, at 485; Gordon Nagayama Hall and William Proctor "Criminological Predictors of Recidivism in a Sexual Offender Population" (1987) 55 Journal of Consulting and Clinical Psychology 111 at 112; Leonore Simon "The Myth of Sex Offender Specialization: An Empirical Analysis" (1997) 23 New Eng J on Crim \& Civ Confinement 387 at 400; Stephen 
sociality are lifestyle instability and anti-social personality, for which the evidence of differences between contact adult and contact child offenders is more mixed. ${ }^{31}$ While contact adult offenders tend be convicted of their first sexual offence at a younger age than contact child offenders, ${ }^{32}$ contact adult offenders are less likely to persist with sexual offending. ${ }^{33}$ Contact adult offenders are also less likely to plan their sexual offences. ${ }^{34}$

Age, degree of anti-social orientation, persistence of sexual offending, and planning of sexual offences are all risk factors that feature in risk assessment tools. The fact that contact adult offenders tend to score higher or lower on a given factor than contact child offenders does not necessarily mean that the factors predict recidivism differently for contact adult and contact child offenders, but it does mean it is important to explore whether they do.

A second reason for considering that sex offender subtype might affect the accuracy of a risk assessment tool is that most risk assessment tools were developed using construction samples made up of a high proportion of contact child offenders. We might expect the tools, therefore, to perform better with contact child offenders than with other types of sex offenders. That is important in the treatment track context, as it is aimed at men who have assaulted another adult.

Smallbone, Julia Wheaton and Donna Hourigan "Trait Empathy and Criminal Versatility in Sexual Offenders" (2003) 15 Sexual Abuse 49 at 54; Terance Miethe, Jodi Olson and Ojmarrh Mitchell "Specialization and Persistence in the Arrest Histories of Sex Offenders" (2006) 43 Journal of Research in Crime and Delinquency 204 at 218; Harris, Mazerolle and Knight, above n 28, at 1061; Danielle Harris and others "Specialisation and Versatility in Sexual Offenders Referred for Civil Commitment" (2011) 23 Sexual Abuse 243 at 253; Philip Howard, Georgia Barnett and Ruth Mann "Specialisation In and Within Sexual Offending in England and Wales" (2014) 26 Sex Abuse 225 at 236.

In respect of lifestyle instability, see Bard and others, above n 28, at 215 and Harris, Mazerolle and Knight, above n 28, at 1061, who found conflicting results about differences in substance abuse; see also Stephen Porter and others "Profiles of Psychopathy in Incarcerated Sexual Offenders" (2000) 27 Criminal Justice and Behavior 216 at 226, who found that contact adult and mixed offenders had higher PCL-R Factor 2 scores than contact child offenders. The difference in scores may, however, be attributable to higher Facet 4 (antisocial behavior) scores for contact adult and mixed offenders rather than reflecting broader lifestyle problems (Facet 3), but the study did not break down the results by facet. Baxter and others, above n 29, at 485.

Miethe, Olson and Mitchell, above n 30, at 218.

Bard and others, above n 28, at 215. 
The proportion of each subtype in the construction sample for the ASRS is unknown. ${ }^{35}$ However, the ASRS was based on the Static-99, which was developed using a construction sample of 677 sex offenders. It is not clear how the mixed offenders in the sample were classified. 74 per cent of the sample was identified as contact child offenders, however. ${ }^{36}$ Dates of reconviction were not available for all offenders in the construction sample, so survival analyses were conducted using only the offenders in the sample for whom reconviction dates were available. Of those offenders, the proportion of contact child offenders was 81 per cent. ${ }^{37}$ The proportion of contact child offenders in the initial validation sample (used to test the tool as part of its development) was 61 per cent. $^{38}$

Risk assessment tools made up of predominately dynamic items (risk factors that may change in response to intervention) fared slightly better in the proportion of contact adult offenders included. The construction sample for the STABLE-2007 and the ACUTE2007 had 35 per cent contact adult and 5.2 per cent mixed offenders (of a total sample size of 997 sexual offenders). ${ }^{39}$ The VRS-SO had a higher percentage of contact adult offenders. $^{40}$

Accordingly, on the basis of the low proportion of contact adult and mixed offenders typically included in sex offender risk assessment tools, we may expect that the tools will not perform as well with them as with contact child offenders.

The most persuasive reason for considering that tools might perform differently with different subtypes of sex offenders would, of course, be studies finding differences in accuracy by subtype. Few studies, however, have investigated whether the core risk assessment tools predict equally well with each sex offender subtype. Vess and Skelton found no differences in the accuracy of the ASRS with contact adult, mixed, and contact

\footnotetext{
$35 \quad$ Skelton and others, above n 5, at 280.

36 Dana Anderson and Karl Hanson "An Actuarial Tool to Assess Risk of Sexual and Violent Recidivism Among Sexual Offenders" in Randy Otto and Kevin Douglas (eds) Handbook of Violence Risk Assessment (Routledge, New York, 2010) at 253-254.

$37 \quad$ Ibid.

$38 \quad$ Ibid.

39 Hanson and others, above n 6, at 5.

40 The VRS-SO was constructed with participants in the Clearwater Treatment Programme, which had 52 per cent contact adult offenders in the years 1983-2007: Mark Olver and Stephen Wong "A Description and Research Review of the Clearwater Sex Offender Treatment Programme" (2013) 19 Psychology, Crime and Law at 480.
} 
child offenders. ${ }^{41}$ However, differences have been found for the PCL-R ${ }^{42}$, the STABLE$2007,{ }^{43}$ and the static subscale of the VRS-SO. ${ }^{44}$ The VRS-SO dynamic subscale or total score has not yet been investigated by subtype, and. ${ }^{45}$

Given the paucity of research, however, it is useful to consider whether differences by subtype have been found in relation to some of the other tools commonly used with sex offenders in other jurisdictions. Differences in accuracy by subtype for other tools would indicate that investigation (or for those tools that have been investigated, replication) might reveal differences by subtype for the core Corrections tools also.

The findings in relation to tools for which more extensive replication has been undertaken are quite mixed. Overall, more studies have found no difference by subtype than have found a difference. However, the proportion of studies that found a difference in accuracy by subtype varies by tool. The Static-99 has the highest proportion of studies finding no difference across subtypes, with a smaller proportion finding no difference for the Static-2002, the Risk Matrix 2000 and the Minnesota Sex Offender Screening ToolRevised. The results were evenly balanced for the Violence Risk Appraisal Guide and the Sexual Violence Risk-20, while more studies found a difference than did not for the Sex Offender Risk Appraisal Guide. The findings are summarised in Appendix B.

The safest conclusion to draw from the literature is, therefore, that accuracy may differ by sex offender subtype and that the best evidence about how accurately a tool will perform with the likely treatment track population comes from studies validating the tool with contact adult and mixed offenders. For that reason, when I evaluate in Part D the strength of the evidence that the tools would perform accurately in the treatment track context, I do not present evidence about the accuracy of a tool with sex offenders generally or with subtypes other than contact adult or mixed offenders. Where a tool has not been validated with contact adult and mixed offenders specifically, I recommend that validation be undertaken before conclusions are drawn about whether the tool is accurate enough for its use to be justified. Where only one study has investigated the accuracy of a tool with a relevant subtype, I recommend replication.

\footnotetext{
$41 \quad$ Vess and Skelton, above n 21, at 550.

$42 \quad$ Parent, Guay and Knight, above n 23, at 198.

43 Hanson and others, above n 6, at 44-45.

44 Mark Olver and others "Some notes on the validation of VRS-SO static scores" (2016) 22 Journal of Sexual Aggression 147 at 153.

45 Hanson and others, above n 6, at 44-45.
} 


\section{Jurisdiction}

The core risk assessment tools are a mix of tools developed in New Zealand and tools developed in North America. "Homegrown" risk assessment tools, such as the ASRS, are only used in New Zealand and have only been validated with New Zealand samples. ${ }^{46}$ However, the other core risk assessment tools were developed overseas (mostly with Canadian offenders) and not all of them have been validated with New Zealand sex offenders. No validations of the STABLE-2007, the ACUTE-2007, or the PCL-SV with New Zealand sex offenders have been reported. ${ }^{47}$ The VRS-SO and the PCL-R have been validated with New Zealand contact child offenders but not with New Zealand contact adult or mixed offenders. ${ }^{48}$

I argue in this section that, for the purposes of the treatment track, the best assessments of the accuracy of the tools developed in North America are studies validating those tools with New Zealand men who have sexually assaulted an adult, though studies with Canadian samples may also provide some insight. Differences in the functioning of the criminal justice system between jurisdictions may affect how well North American tools perform in a New Zealand context.

Helmus, Hanson and Morton-Bourgon have noted that using risk assessment tools in different settings assumes that the propensities the tools measure are related to the outcomes predicted in the same way in each setting. ${ }^{49}$ Actuarial tools used with sexual offenders are usually thought to measure two propensities, sexual deviance and antisociality. Differences between jurisdictions in how strongly these propensities are associated with sexual recidivism would affect the accuracy of the tools. Helmus, Hanson and Morton-Bourgon suggested the following example of when there might be differences in the strength of the association: $:^{50}$

46 I refer to the ASRS as "homegrown" because it was developed with a New Zealand sample, but it was based on the Static-99, a Canadian tool.

47 The PCL-R has been validated with samples that included sex offenders, but separate results were not reported for the sex offenders, so we do not know how accurately the tools perform with New Zealand sex offenders.

48 Sarah Beggs and Randolph Grace "Assessment of Dynamic Risk Factors: An Independent Validation Study of the Violence Risk Scale - Sex Offender Version” (2010) 22 Sexual Abuse 234; Sarah Beggs and Randolph Grace "Psychopathy, Intelligence, and Recidivism in Child Molesters: Evidence of an Interaction Effect” (2008) 35 Criminal Justice and Behavior 683 at 691.

49 Helmus, Hanson and Morton-Bourgon, above n 19, at 60.

50 At $60-61$. 
Many men might have some interest in sexual activity with teenage girls. If their country has few social sanctions against such sexual activities (even if it is considered wrong or illegal), it is likely that relatively "normal" men would do it. If sexual conduct with teenage girls is severely punished, however, those who do it would likely have a stronger propensity for deviant sexual activity.

There is no real reason to think that there are differences in the strength of the association between the propensities measured and sexual recidivism in North America and New Zealand. It is accordingly probably safe to discount differences in the strength of the association between propensities and outcomes as a factor that would affect the accuracy of the tools with New Zealand offenders.

A second factor that Helmus, Hanson, and Morton-Bourgon suggested might, however, affect the accuracy of North American risk assessment tools when used with New Zealand offenders. Risk assessment tools do not measure either propensities or outcomes (sexual recidivism) directly. Rather, they rely on indicators, often from the person's criminal history. The estimates of the likelihood of recidivism produced by risk assessment tools will only be valid if these indicators are stable across jurisdictions (in this context, if recidivism rates in New Zealand are the same as the jurisdiction in which the tool was developed). ${ }^{51}$

Helmus and colleagues noted that jurisdictions may differ in reoffending rates, or may appear to differ because of differences in the proportion of offences reported, and that either of these would affect whether the recidivism estimates from one jurisdiction are valid in another. ${ }^{52}$ They recommended that this possibility be explored further, which I now do, to the extent possible and necessary for the treatment track context. ${ }^{53}$

The main area of concern when using a tool developed in a different jurisdiction is whether the rates of recidivism predicted by the tool are an accurate estimate of recidivism rates in the target jurisdiction. ${ }^{54}$ This does not appear to be of major concern when using tools developed in Canada with a New Zealand population, however, for the reasons set out below.

a) Official recidivism rates - calibration

\begin{tabular}{ll}
\hline 51 & At 61. \\
52 & At $61-62$. \\
53 & At 63. \\
54 & At $61-63$.
\end{tabular}


The base rates of recidivism (the proportion of offenders who are reconvicted within a given timeframe) are not markedly different, although this finding should be treated with caution because of differences in the methodology of the studies relied on. It is estimated that 10 per cent of New Zealand men in prison for a sexual offence against an adult will be re-imprisoned for a new sexual offence within five years of release. ${ }^{55}$ This is roughly similar to the recidivism rates predicted by the VRS-SO, the STABLE-2007 and the ACUTE-2007 (based largely on Canadian reoffending rates).

For the sample used to calculate predicted recidivism rates for the VRS-SO, five year sexual recidivism rates were 12.9 per cent. ${ }^{56}$ Just over half (57.6 per cent) of this sample was men who had sexually assaulted an adult. ${ }^{57}$ Two of the three groups making up the sample were from the Clearwater Treatment Programme, a high-risk, high-need group, which probably accounts for the slightly higher rate of recidivism. ${ }^{58}$

For the sample used to calculate base rates for the STABLE-2007 and the ACUTE-2007 only three year recidivism rates were available. These were, however, quite close to New Zealand's five year re-imprisonment rate, with 9 per cent of rapists sexually recidivating within three years. ${ }^{59}$ This study used a rather more expansive definition of recidivism than that used for the New Zealand study, including any new offence with a sexual motivation that an agency believed had occurred (including prostitution-related offences) whether or not the person had been convicted. ${ }^{60}$ That more expansive definition may be one reason the recidivism rate is perhaps slightly higher than might be expected for the New Zealand sample after three years, based on the five year rate.

It appears that official recidivism rates are roughly the same between Canada and New Zealand. Does that mean, however, that actual recidivism rates are the same, or might the official recidivism rates appear more similar than they actually are because the two jurisdictions differ in the proportion of offences that result in a conviction (or charge)? Or, using Helmus and colleagues' phrasing, do the two jurisdictions differ in how well the indicators of reoffending (new convictions or sometimes charges) are detected? If so,

\footnotetext{
$55 \quad$ Nadesu, above n 20, at 13.

$56 \quad$ Hanson and others, above n 6, at 11.

57 I re-calculated the base rates provided to exclude the sample from Kia Marama, which was made up exclusively of men who have sexually abused a child, using the VRS-SO Calculator at $<$ http://www.psynergy.ca/VRS_VRS-SO.html>.

58 Ibid.

$59 \quad$ Hanson and others, above n 6 , at 45.

$60 \quad$ At 11.
} 
the calibration of the tool (the ability of the tool to predict absolute rates of recidivism) would be affected.

b) Detection of official recidivism outcomes - criminal record quality One important issue to consider when attempting to answer this question is whether the quality of criminal records differs between New Zealand and Canada. Helmus and colleagues noted that there may be differences between jurisdictions in how complete and current criminal record databases are (for example, the United States lacks a centralised database, and the national Canadian database suffers from long delays in data entry and the removal of records due to inactivity). ${ }^{61}$ If accurate offence records cannot be accessed, the indicators of reoffending will be detected less often, which will affect the calibration of the tool. New Zealand has an up-to-date and centralised database, so there should not be the same difficulty with detecting convictions as in Canada, which means the predicted recidivism rates based on Canadian data may be a slight underestimate for the New Zealand population. The Department of Corrections database, which would be the one used for risk assessment purposes, does not include charges, limiting the information available for undertaking risk assessments, unless that information can be obtained from the police.

If there are differences between jurisdictions in how well criminal convictions or charges are detected, this could also affect the discriminative ability of the tool, as indicators of the propensity to reoffend (previous convictions or charges) may not be detected when undertaking a risk assessment. If propensity is not measured accurately (that is, indicators are not picked up) then the risk score might underestimate the actual risk of reoffending. For low risk offenders, who have few or no previous convictions, failing to detect previous convictions would have minimal effect on the measurement of their propensity for reoffending. If previous convictions of higher risk offenders are not detected, however, their propensity for reoffending would be underestimated, and their risk score would be more similar to lower risk offenders. In this situation, the tool's discriminative ability would be reduced - people's previous offending history would appear more similar than it is, and differences between them in the likelihood of reoffending would therefore appear smaller than they are.

\footnotetext{
$61 \quad$ Leslie-Maaike Helmus and David Thornton "Stability and Predictive and Incremental Accuracy of the Individual Items of Static-99R and Static-2002R in Predicting Sexual Recidivism: A MetaAnalysis" (2015) 42 Criminal Justice and Behavior 917 at 919-920; Helmus, Hanson and MortonBourgon, above n 19, at 63-64.
} 
Differences between jurisdictions in how well previous convictions and charges are detected may explain why Hanson and Morton-Bourgon found that the Static-99 (a North American tool) performed more accurately in the United Kingdom $(d=0.90, k=12)$, which has a centralised and up-to-date database, than in Canada $(d=0.58, k=21)$ or the United States $(d=0.60, k=14) .{ }^{62}$ The study did not give a separate estimate for New Zealand, as only two New Zealand studies were included in the meta-analysis, but we may expect results closer to those obtained in the United Kingdom than those obtained in North America, because like the United Kingdom, New Zealand has a centralised and upto-date database.

c) Detection of actual offending and reoffending

It is well established that most sexual offences do not result in a conviction. ${ }^{63}$ The higher the proportion of offences resulting in a conviction, the more accurately the tool will be able to measure propensity for sexual offending (based on previous sexual and nonsexual offending) and outcome (sexual reoffending). Helmus and colleagues argued that if the proportion of offences resulting in a conviction or charge differs between jurisdictions, the calibration of the tool would be affected. ${ }^{64}$ In this section, I argue that the discriminative ability of the tool might also be affected.

It is difficult to compare the proportion of offences resulting in a conviction between jurisdictions, because the methodology of the studies differs. ${ }^{65}$ For that reason these comparisons should be treated cautiously, but I include them here because they are the best data currently available. I present the most recent data available for sexual offences against adult victims. Where possible, the data are for contact sexual offences committed by adult perpetrators. I use convictions for sexual offending, rather than re-offending, for the outcome measure because the data that would enable us to estimate the proportion of actual sexual "re-offences" that results in a conviction are not available.

I leave out the United States, because the way in which the questions are asked appears to include only violent, forcible sexual offences, which yields an artificially low incidence rate. $^{66}$ The National Intimate Partner and Sexual Violence Survey indicates levels of

\footnotetext{
Hanson and Morton-Bourgon, above n 3, at 7.

See the discussion in Chapter 4 of this thesis.

Helmus, Hanson and Morton-Bourgon, above n 19, at 61-62.

At 62 .

National Crime Victimization Survey: NCVS-1 Basic Screen Questionnaire (US Department of Justice, 2008).
} 
sexual victimisation much more similar to New Zealand and Canada, but unfortunately only prevalence rates are reported, whereas incidence rates are needed for these comparisons, so the data cannot be used. ${ }^{67}$

Canada's General Social Survey (GSS) found that there were 2200 incidents of sexual assault per 100,000 adults in $2014 .^{68}$ Only 58 incidents per 100,000 population were recorded by police as sexual assault, however, a rate of 2.64 per cent. ${ }^{69}$ A charge was laid in 60 per cent of cases recorded by police as sexual assault (or a charge was laid in 1.06 per cent of self-reported sexual victimisations). ${ }^{70}$ The conviction rate for cases that were prosecuted in adult criminal court was 45 per cent, representing 0.48 per cent of self-reported sexual victimisation incidents. ${ }^{71}$

The attrition rate for New Zealand is similar. The New Zealand Crime and Safety Survey (NZCASS) 2014 found an incidence rate of 5200 sexual offences per 100,000 adults in $2013 .^{72} 84$ incidents per 100,000 population were recorded by the police as sexual offences in 2013 (1.6 per cent of those experienced). ${ }^{73}$ Statistics about the proportion of recorded offences resulting in a charge are not available, but 50.7 per cent of sexual assaults recorded by the police were resolved (an offender was apprehended and some action taken, though not necessarily a charge), representing 0.82 per cent of self-reported sexual victimisations in $2013 .^{74}$ The conviction rate for sexual assaults prosecuted was 83 per cent. ${ }^{75}$ If all resolved cases were prosecuted, only 0.67 per cent of self-reported

$67 \quad$ Based on 12 month prevalence rates. SG Smith and others The National Intimate Partner and Sexual Violence Survey 2010-2012: State Report (National Center for Injury Prevention and Control, Centers for Disease Control and Prevention, Atlanta, 2017) at 24.

68 Statistics Canada Self-reported sexual assault in Canada, 2014 (The Daily, 2017) at 1.

69 Katherine Keighley Juristat: Police-reported Crime Statistics in Canada, 2016 (Canadian Centre for Justice Statistics, 2017) at 19.

70 "Police reported clearance rates for selected offences, Canada, 2010" Statistics Canada $<$ http://statcan.gc.ca/pub/85-002-x/2012001/article/11647/tbl/tb103-eng.htm>.

71 for Justice Statistics, 2015) at 22.

"NZ Crime and Safety Survey Table 1: Crime rate estimates" Resources and Downloads, Ministry of Justice <https://www.justice.govt.nz/justice-sector-policy/research-data/nzcass/resources-anddownloads/>.

New Zealand Crime Statistics 2014: A Summary of Recorded and Resolved Offence Statistics (Police National Headquarters, Wellington, 2015) at 16.

At 2.

"Adults prosecuted in court: most serious offence calendar year 2013" Statistics New Zealand $<$ http://nzdotstat.stats.govt.nz/wbos/Index.aspx?DataSetCode=TABLECODE7352\#>. 
sexual victimisations would have resulted in a conviction. These findings are shown in numerical form in the following table:

\begin{tabular}{|l|l|}
\hline Self-reported victimisation & 5200 \\
\hline $\begin{array}{l}\text { Recorded by police as sexual } \\
\text { assault }\end{array}$ & 84 \\
\hline $\begin{array}{l}\text { Resolved by police (proxy for } \\
\text { prosecution) }\end{array}$ & 43 \\
\hline Convicted & 35 \\
\hline
\end{tabular}

It appears that roughly the same proportion of actual sexual offences results in a conviction in New Zealand as in Canada, so we do not need to worry about that contributing to inaccuracy when using Canadian tools in New Zealand. The fact that only 0.67 per cent of New Zealand sexual offences results in a conviction should, however, be a serious worry for the validity of risk assessment, and is something I return to in Part D of this chapter.

\section{Indigeneity}

The accuracy of risk assessment tools with indigenous offenders has become a matter of concern in other jurisdictions in recent years. In a Canadian case, Ewert $v R$, an indigenous inmate claimed that using risk assessment tools with indigenous offenders was unconstitutional in the absence that the tools are accurate with them, given that the tools were developed on primarily Caucasian offenders. ${ }^{76}$ The Supreme Court found that the Correctional Services of Canada breached its statutory obligation to take all reasonable steps to ensure that information held about offenders is accurate, because it relied on information provided by the tools despite its awareness of concerns about the lack of validation of those tools with indigenous offenders. ${ }^{77}$ The case has sparked a flurry of comment on the issues associated with cross-cultural validity of risk assessment and research into the accuracy of risk assessment tools with indigenous offenders. ${ }^{78}$

\footnotetext{
$76 \quad$ Ewert $v R 2015$ FC 1093; $R v$ Ewert 2016 FCA 203; $R v$ Ewert 2018 SCC 30.

$77 \quad R v$ Ewert 2016 FCA 203 at [7].

78 For example, a special issue of the Journal of Threat Assessment and Management devoted to issues arising from Ewert was published in 2016. In the Australian context, see Andrew Day and others "Assessing Violence Risk with Aboriginal and Torres Strait Islander Offenders: Considerations for Forensic Practice” (2018) 25 Psychiatry, Psychology and Law 1.
} 
51 per cent of men imprisoned for a sexual offence against an adult in New Zealand are Māori, ${ }^{79}$ so it is important to know how accurately the tools perform with Māori contact adult and mixed offenders. No research has yet been published on whether the core New Zealand risk assessment tools perform as well with Māori as with non-Māori sex offenders. Research from other jurisdictions on accuracy with indigenous sex offenders, however, suggests that there may be some differences - although it cannot be said with any certainty at this point that these findings apply to Māori.

\section{a) Discriminative ability}

Overall, research on the discriminative ability of risk assessment tools with sex offenders in Canada and Australia has found that the tools are predictive with indigenous offenders. Effect sizes appear lower for indigenous than non-indigenous offenders, but this difference tends not to be statistically significant. Where there is a statistical difference, the difference could be accounted for by items or sub-scales measuring anti-sociality, which seem to be less predictive of recidivism by indigenous offenders than nonindigenous offenders. The findings are detailed below.

i) VRS-SO

Olver and colleagues investigated the discriminative ability of the VRS-SO with indigenous and non-indigenous sexual offenders in Canada. ${ }^{80}$ They found that the tool predicted sexual and violent recidivism for both groups, at both five and ten years after release from prison. While the effect sizes were lower for indigenous than nonindigenous offenders (indicating that the tools may be less accurate with indigenous offenders), they concluded it is not certain that the findings represent an actual difference because the confidence intervals around the effect sizes overlapped. ${ }^{81}$

ii) STABLE-2007

Helmus, Babchishin and Blais examined the discriminative ability of the STABLE-2007 with indigenous and non-indigenous sex offenders under community supervision, with an average follow-up time of 3.4 years. They found that the STABLE-2007 appeared to be less accurate with indigenous than non-indigenous offenders when predicting sexual

\footnotetext{
$79 \quad$ Nadesu, above n 20, at 6 .

80 Mark Olver and others "Predictive Accuracy of Violence Risk Scale-Sexual Offender Version Risk and Change Scores in Treated Canadian Aboriginal and Non-Aboriginal Sexual Offenders" (2018) 30 Sexual Abuse 254.

$81 \quad$ At $262-265$.
} 
recidivism, but that the difference was no statistically significant. $^{82}$ There was a statistically significant difference, however, in respect of violent recidivism. ${ }^{83}$

iii) Static-99 and Static-99R

There is no published analysis of the ASRS, but a meta-analysis of the Static-99 and Static-99R (which the ASRS and the revised version, respectively, were based on) has been under-taken. In the meta-analysis, Babchishin, Blais and Helmus found no statistical difference in the discriminative ability of the Static-99 or the Static-99R between indigenous and non-indigenous sexual offenders, in respect of sexual recidivism. ${ }^{84}$

Olver and colleagues found that the Static-99R predicted sexual and violent recidivism for indigenous and non-indigenous sexual offenders, at both five and ten years after release from prison. While the effect sizes were lower for indigenous than nonindigenous offenders (indicating that the tools were less accurate with indigenous offenders) again it is not certain that the findings represent an actual difference because the confidence intervals around the effect sizes overlapped. ${ }^{85}$

In Australia, Smallbone and Rallings investigated the discriminative ability of the Static99 and STATIC-99R with indigenous and non-indigenous sexual offenders over a mean of 29 months after release from prison. ${ }^{86}$ They found that the Static-99 predicted sexual and non-sexual violent recidivism similarly for indigenous and non-indigenous offenders. ${ }^{87}$ Contrary to Olver and colleagues' findings, however, the Static-99R did not predict sexual or non-sexual violent recidivism for indigenous offenders in the Australian study. ${ }^{88}$ Smallbone and Rallings noted that there their finding of a difference between the

82 Leslie Helmus, Kelly Babchishin and Julie Blais "Predictive Accuracy of Dynamic Risk Factors for Aboriginal and Non-Aboriginal Sex Offenders: An Exploratory Comparison Using STABLE2007" (2012) 56 International Journal of Offender Therapy and Comparative Criminology 856 at 866.

$83 \quad$ At 867.

84 Kelly Babchishin, Julie Blais and Leslie Helmus "Do Static Risk Factors Predict Differently for Aboriginal Sexual Offenders? A Multi-site Comparison Using the Original and Revised Static-99 and Static-2002 Scales" (2012) 54 Canadian J Criminology \& Crim Just 1 at 20.

85 Olver and others, above $\mathrm{n} 80$, at 264.

86 Stephen Smallbone and Mark Rallings "Short-Term Predictive Validity of the Static-99 and Static99R for Indigenous and Nonindigenous Australian Sexual Offenders" (2013) 25 Sexual Abuse 302.

$87 \quad$ At 307.

$88 \quad$ Ibid. 
Static-99R and the Static-99 has not been found by researchers using Canadian samples and is not explained by differences between the scales, and concluded that a larger sample size and longer follow-up period is needed to establish whether the difference is stable with an Australian indigenous population. ${ }^{89}$

\section{iv) Static-2002 and Static-2002R}

In their meta-analysis, Babchishin, Blais and Helmus found that the discriminative ability of the Static-2002 and the Static-2002R was lower for indigenous than non-indigenous offenders, and that the discriminative ability of the Static-2002R was just below statistical significance with indigenous offenders. ${ }^{90}$ They found that these differences were also apparent when discriminative ability was examined only with men who had sexually assaulted an adult. ${ }^{91}$ Babchishin, Blais and Helmus suggested that the Static-2002/R may be less predictive with indigenous sex offenders than the Static-99/R because the Static2002/R has more items in its anti-sociality sub-scale, which has been found to be less predictive with indigenous sex offenders than the sexual deviance sub-scale. ${ }^{92}$ They posited that some of the items assessed by the anti-sociality subscale could be, for indigenous sex offenders, not indicators of a propensity for sexual offending but rather indicators of poverty or cultural marginalisation. ${ }^{93}$

\section{v) Psychopathy Checklist Revised}

The Psychopathy Checklist Revised has not yet been examined with indigenous sex offenders. However, Olver and colleagues found that the discriminative ability of the PCL-R total score and Factor 2 (overt anti-sociality) was similar for indigenous and nonindigenous general offenders when predicting violent (including sexual) recidivism. ${ }^{94}$ In a more recent study, they concluded that the PCL-R can be used to predict recidivism by indigenous offenders. ${ }^{95}$ It would be interesting to see whether this finding is replicated

\footnotetext{
At 311.

90 Babchishin, Blais and Helmus, above $\mathrm{n} 84$, at 26.

$91 \quad$ At 29.

92 At 30 .

93 Ibid.

$94 \quad$ Mark Olver and others "The Structural and Predictive Properties of the Psychopathy ChecklistRevised in Canadian Aboriginal and Non-Aboriginal Offenders" (2013) 25 Psychological Assessment 167 at 172 .

$95 \quad$ Mark Olver and others "A Comprehensive Examination of the Psychometric Properties of the Hare Psychopathy Checklist - Revised in a Canadian Multi-Site Sample of Indigenous and Non-Indigenous Offenders" (2018) 30 Psychological Assessment 779.
} 
with sex offenders, because of the potential problem with anti-sociality measures with indigenous sex offenders.

b) Calibration

Higher rates of recidivism by Māori than non-Māori are a matter of serious concern in New Zealand. The burden this places on Māori whanau, hapu and iwi and the Crown's failure to adequately address the issue have recently been the subject of a Waitangi Tribunal claim. ${ }^{96}$ In the context of risk assessment, these higher recidivism rates are also of concern. Māori men convicted of a sexual offence against an adult have been found to have higher recidivism rates than non-Māori. ${ }^{97}$

Taken at face value, the higher recidivism rates for Māori could bring into question the calibration of the tools: do the risk assessment tools actually under-estimate the risk of recidivism by Māori? If the higher recidivism rates for Māori are fully accounted for by Māori overall being at higher risk as measured by the tools then, at least on the surface, the tools are calibrated accurately as between Māori and non-Māori.

No New Zealand analysis on that question has been published. Olver and colleagues have, however, considered it in relation to the VRS-SO and the PCL-R with Canadian indigenous offenders. They found that indigenous offenders had significantly higher recidivism rates than non-indigenous offenders. The higher sexual recidivism rates were fully accounted for by risk and treatment change scores. ${ }^{98}$ The higher violent recidivism rates, however, were not fully accounted for by risk scores (on the PCL-R) or by risk and treatment change scores (on the VRS-SO). ${ }^{99}$ Olver and colleagues did not venture a guess at what unmeasured variables partially accounted for the differences in recidivism rates between indigenous and non-indigenous offenders. On the surface then, the VRS-SO and the PCL-R might appear to underestimate the risk of violent recidivism by indigenous offenders - perhaps extending to Māori also.

However, bias against indigenous offenders at each stage of the criminal justice process must be taken into account when considering the calibration of the tools. If a higher proportion of offences committed by indigenous offenders than by non-indigenous

\footnotetext{
96 Tü Mai Te Rangi! Report on the Crown and Disproportionate Reoffending Rates (WAI 2540, Waitangi Tribunal Report, 2017).

$97 \quad$ Nadesu, above n 20, at 18.

98 Olver and others, above n 94, at 172; Olver and others, above n 80, at 13-14.

$99 \quad$ Ibid.
} 
offenders results in prosecution, conviction, and imprisonment, then it may be that the tools are actually calibrated more accurately for indigenous than non-indigenous offenders. This factor tends not to be considered in psychological risk assessment research.

We need to know that any risk assessment tools used in New Zealand are accurate with Māori offenders, both in terms of discriminative ability and calibration. If the tools continue to be used with Māori without good evidence of accuracy, this is discrimination against Māori (which is particularly egregious given their status as tangata whenua and a partner to the Treaty of Waitangi) and pragmatically undermines the effectiveness of risk management and rehabilitation because of the high proportion of adult sex offenders who are Māori. In this chapter, I highlight the gaps in the research where relevant.

\section{Pre-selection for risk}

A number of studies use samples that have already been selected on the basis of higher risk, to be assessed for the purposes of allocating treatment. ${ }^{100}$ The results of those studies are unlikely to generalise to the treatment track population, because the treatment track is intended for men whose risk can be contained in the community, whilst the samples in those studies are made up of men whose risk has been judged so high that it cannot be contained in the community.

\section{Types of recidivism}

Men who have sexually assaulted an adult may be at risk of sexual, non-sexual violent, and general (that is, non-sexual, non-violent) recidivism. A person's risk of engaging in each type of recidivism may differ, so that one person may be considered at high risk of sexual recidivism but at low risk of non-sexual violent or general recidivism, while the opposite may be true for another. The type of recidivism a person is at risk of is relevant to eligibility (because we may be more willing to tolerate a risk of general recidivism than of sexual or non-sexual violent recidivism), treatment (because knowing what type(s) of risk a person poses can inform what treatment they receive) and risk management (because different types of risk may require different risk management measures). Accordingly, we need to know which types of recidivism a tool can predict and how accurately it predicts each type with men who have been convicted of sexually assaulting an adult.

For example Olver and Wong, above n 11; Parent, Guay and Knight, above n 23. 
Where studies exist that report on discriminative ability for sexual and non-sexual recidivism separately, I use those studies. Where there are no such studies for a given tool, I report on the discriminative ability for combined sexual and non-sexual violence.

\section{Timeframe}

Different timeframes are relevant for different purposes. In respect of risk management, the question is whether it is safe to keep a person in the community instead of sending them to prison. The relevant timeframe is therefore the period of imprisonment to which the person would be sentenced if they were not admitted to the treatment track. As will be discussed in depth in Chapter 8 , a person should only be eligible for the treatment track if the starting point for the sentence of imprisonment they would otherwise receive does not exceed eight years. Studies that use a follow-up period of around six years probably give the best indication of the discriminative ability of a tool in the relevant timeframe. Studies with longer periods may give an inflated estimate of accuracy, because sex offender risk assessment tools tend to become more accurate over time (an effect of the low base rate of new sexual offence convictions/charges). Studies with shorter follow-up periods may underestimate the discriminative ability of the tool in the relevant timeframe.

In respect of treatment, much longer follow-up periods are of interest. The long-term risk of reoffending should be taken into account when determining who should be offered treatment, because some offenders may continue to pose a risk well into the future if untreated. Studies that use very long follow-up periods (fifteen years or more) may give the best indication of the discriminative ability of a tool for treatment-related decisions.

\section{Assessors}

Several meta-analyses have found that validation studies conducted by the developers of a risk assessment tool tend to yield higher estimates of accuracy than studies conducted independently (an "authorship effect"). ${ }^{101}$ There are a number of possible reasons an authorship effect might be found. The "file drawer problem" is one possibility: developers of tools may be unwilling to publish studies in which the tool does not perform well. Another possibility is that developers' familiarity with the tool and fidelity

$101 \quad$ Jay Singh, Martin Grann and Seena Fazel “Authorship Bias in Violence Risk Assessment? A Systematic Review and Meta-Analysis" (2013) 8 PLoS ONE 1 at 4-7; Pamela Blair, David Marcus and Marcus Boccaccini "Is There an Allegiance Effect for Assessment Instruments? Actuarial Risk Assessment as an Exemplar" (2008) 15 Clinical Psychology 346 at 352-356 (in respect of the VRAG, the SORAG and the Static-99) but see Grant Harris, Marnie Rice and Vernon Quinsey “Allegiance or Fidelity? A Clarifying Reply” (2010) 17 Clinical Psychology 82. 
to manualised assessment procedures result in studies that maximise the predictive validity of the tool. A third possibility is that the developers of tools obtain higher estimates of predictive validity because they use the tools with samples similar to the construction sample (because they continue drawing from the same source, such as a particular treatment programme). ${ }^{102}$

Treatment track risk assessments are unlikely to be undertaken by the developers of tools, so studies undertaken by independent researchers may give a better estimate of the accuracy of the tool in the context of the treatment track. I note in the review of evidence whether there are independent validation studies of each of the core tools.

\section{How accurately do the tools discriminate between recidivists and non- recidivists?}

The following table illustrates the gaps in the evidence about the discriminative ability of the core risk assessment tools. It presents results for all studies reporting disaggregated findings for contact adult and/or mixed offenders in either New Zealand or Canada. "Y" indicates that the criterion is met in at least one study. A blank square indicates that the criterion has not been met.

\begin{tabular}{|l|l|l|l|l|l|}
\hline & ASRS & STABLE-2007 & ACUTE-2007 & VRS-SO & PCL-R \\
\hline $\begin{array}{l}\text { NZ contact adult or mixed } \\
\text { offenders }\end{array}$ & Y & & & & \\
\hline $\begin{array}{l}\text { Canada contact adult or } \\
\text { mixed offenders }\end{array}$ & N/A & & & & Y \\
\hline $\begin{array}{l}\text { Mãori contact adult or mixed } \\
\text { offenders }\end{array}$ & & & & & \\
\hline $\begin{array}{l}\text { Not pre-selected } \\
\text { Sexual recidivism }\end{array}$ & & & & & \\
\hline Non-sexual violent recidivism & & & & & Y \\
\hline Timeframe approx. six years & & & & & \\
\hline Timeframe 15 years + & Y & & & & \\
\hline
\end{tabular}

102 Singh, Grann and Fazel, above n 101, at 7. 


\begin{tabular}{|l|l|l|l|l|l|}
\hline & & & & & \\
\hline Independent assessors & N/A & & & & Y \\
\hline Field & N/A & & & & \\
\hline
\end{tabular}

Four of the tools have not been validated at all with contact adult or mixed offenders in any published study. Of the tools that have been validated with those groups, only the ASRS has been validated with New Zealand contact adult and mixed offenders, but the study still does not meet all the criteria set out in Part C.

In the rest of this section, I outline the findings from the studies investigating the discriminative ability of the ASRS and the PCL-R with New Zealand and/or Canadian contact adult or mixed offenders. I also discuss how applicable the findings are to the treatment track context, by reference to the criteria set out in Part C. Overall, it can be seen that the tools discriminate between recidivists and non-recidivists moderately well at best, and that the evidence is not as specific to the treatment track context as would be desirable.

i) ASRS

Only one published validation study of the ASRS has been undertaken that reports the discriminative ability of the ASRS with men who have sexually assaulted an adult. Vess and Skelton investigated the discriminative ability of the ASRS with adult male sex offenders released from New Zealand prisons. ${ }^{103}$ They presented separate AUCs for contact adult offenders and mixed offenders. An adult victim was defined as a person aged 16 years and older. ${ }^{104}$

Vess and Skelton found that the ASRS has moderate predictive accuracy with both contact adult offenders and mixed offenders. For contact adult offenders, the AUC was 0.64, with a 95 per cent confidence interval of .59-.70. ${ }^{105}$ The AUC value indicates that there is a 64 per cent probability that a contact adult offender who is convicted of a new sexual or violent offence during the follow-up period will have a higher score on the ASRS than a contact adult offender who is not. While an AUC of .64 is a moderate effect size, it does not represent a particularly high degree of accuracy, considering that it means that there is a 36 per cent probability that the ASRS will not discriminate between

\footnotetext{
$103 \quad$ Vess and Skelton, above $\mathrm{n} 21$.

104 At 545.

105 At 550 .
} 
a recidivist and a non-recidivist. The confidence interval around the AUC tells us that we can be 95 per cent confident that the true AUC (the AUC for the whole population of convicted contact adult offenders released from a New Zealand prison) lies between the values of .59 and .70. The most plausible value for the AUC is .64, and the plausibility that the AUC for the whole population is higher or lower decreases as we move outwards to the upper and lower bounds of the confidence interval. The fact that the lower-bound estimate is above .50 means that we can be 95 per cent confident that the ASRS will perform better than chance in discriminating between recidivist and non-recidivist contact adult offenders. The upper-bound estimate tells us that the highest plausible AUC for the ASRS is .70, which means that at best there is still a 30 per cent probability that the ASRS will not discriminate between a given recidivist and non-recidivist contact adult offender.

The AUC for mixed offenders (those with both adult and child victims) was .69, with a 95 per cent confidence interval of .62 - .76. There is, therefore, a 69 per cent probability that a mixed offender who is convicted of a new sexual or violent offence during the follow-up period will have a higher score on the ASRS than a non-recidivist. The lowerbound estimate of the confidence interval around the AUC again indicates that we can be 95 per cent confident that the ASRS will perform better than chance in discriminating between recidivist and non-recidivist mixed offenders. ${ }^{106}$ On the face of it, the AUC for mixed offenders is higher than for contact adult offenders (which would mean that the ASRS is more accurate with mixed offenders than with contact adult offenders). However, the overlap between the confidence intervals must also be borne in mind. The fact that the confidence intervals for the two AUCs overlap means that we cannot conclude with certainty that the ASRS is more accurate with mixed offenders than with contact adult offenders.

Overall, we should not feel particularly confident relying on Vess and Skelton's findings about the discriminative ability of the ASRS in the context of the treatment track. While the study is with a representative sample of New Zealand sex offenders, reports separate AUCs for contact adult and mixed offenders, and has a follow-up time that gives a good indication of accuracy for treatment-related decisions (where long-term risk is of most interest), there are some notable limitations of the study for the purposes of the treatment track. 
Vess and Skelton do not report disaggregated results for Māori, so we do not know whether there is a difference in the discriminative ability of the ASRS with Māori and non-Māori. Further, Vess and Skelton report an AUC for combined sexual and violent recidivism only. ${ }^{107}$ As a result, the study does not provide information about the discriminative ability of the ASRS with the two types of recidivism that are of most concern (sexual and non-sexual violent recidivism). It may be that the ASRS predicts sexual recidivism but not non-sexual violent recidivism, or vice versa, but the study cannot tell us whether that is the case. Accordingly, we should be less confident relying on the information provided by the ASRS for decisions about eligibility, treatment, and risk management than if the ASRS had been shown to have good discriminative ability in relation to each type of recidivism. Additionally, the fifteen-year mean follow-up period may overestimate the discriminative ability of the ASRS in the shorter timeframes that are relevant for decisions whether a person's risk can be managed in the community during their participation in the treatment track and what risk management conditions need to be in place. Importantly, Vess and Skelton's study should be replicated before firm conclusions are drawn about the accuracy of the ASRS.

Of less concern, the study cannot be said to be independent because the authors were involved in the development of the ASRS. ${ }^{108}$ The lack of independence may be less of an issue than with other instruments, however, because the ASRS is computer-scored. Another concern is that part of the validation sample was included in the construction sample for the ASRS. ${ }^{109}$ Independence of sample is important, but the relatively small degree of overlap (390 offenders of the total validation sample of 2747) makes the nonindependence of the sample less problematic than it otherwise would be.

\section{ii) PCL-R}

The PCL-R is better validated than the ASRS with contact adult sex offenders. Hawes, Boccaccini and Murrie conducted a meta-analysis of studies investigating how well the PCL-R predicted sexual recidivism by contact adult offenders. ${ }^{110}$ They found an AUC of .659 , with a lower estimate of .603 and an upper estimate of .709. So at worst the PCL-R discriminates between sexual recidivists and non-recidivists 66 per cent of the time, and at best 71 per cent of the time.

\footnotetext{
$107 \quad$ Ibid.

108 Skelton and others, above $\mathrm{n} 21$.

109 Vess and Skelton, above n 21, at 545.

110 They reported their results using Cohen's $d$ (a standardised measure of effect size) but for ease of explanation I translate Cohen's $d$ into AUCs using the tables created by Rice and Harris, above n 15.
} 
Three studies have examined the discriminative ability of the PCL-R in respect of nonsexual violent recidivism by contact adult offenders. As can be seen from the following table, the AUCs are fairly similar to each other:

\begin{tabular}{|l|l|l|l|}
\hline Study & Recidivism def & AUC & $95 \%$ CI \\
\hline $\begin{array}{l}\text { Hildebrand, de Ruiter \& } \\
\text { de Vogel (contact adult) }\end{array}$ & $\begin{array}{l}\text { Reconviction for a } \\
\text { violent non-sexual } \\
\text { offence }\end{array}$ & $.66^{1112}$ & $.55-.77$ \\
\hline $\begin{array}{l}\text { Olver \& Wong (contact } \\
\text { adult/mixed) }\end{array}$ & $\begin{array}{l}\text { Any conviction for a } \\
\text { non-sexual violent } \\
\text { offence }\end{array}$ & $.71^{113}$.114 \\
\hline $\begin{array}{l}\text { Parent, Guay \& Knight } \\
\text { (contact, according to } \\
\text { MTC:R3 criteria) }\end{array}$ & $\begin{array}{l}\text { Any charge for a hands- } \\
\text { on non-sexual violent } \\
\text { offence }\end{array}$ & $.73^{115 * 116}$ & \\
\hline
\end{tabular}

Olver and Wong (with a Canadian sample of high-risk sex offenders treated in the Clearwater Treatment Programme) and Parent, Guay and Knight (with a sample of highrisk sex offenders from the Massachusetts Treatment Centre) both found large effect sizes for the PCL-R with contact adult offenders and mixed offenders. ${ }^{117}$ Neither study reported confidence intervals, however. While the results of the null hypothesis significance test assure us that the confidence interval around the AUC in each study did not include .50 (and therefore we can be 95 per cent confident that the PCL-R performs better than chance in discriminating between recidivists and non-recidivists), it does not provide any information about the precision of the estimated AUC or what the worst case scenario is.

Hildebrand, de Ruiter \& de Vogel (using a Dutch sample of offenders involuntarily committed to a forensic psychiatric hospital on the basis of having committed an offence with diminished responsibility due to a serious mental and/or personality disorder) found

\footnotetext{
$111 \quad$ Martin Hildebrand, Corine de Ruiter and Vivienne de Vogel "Psychopathy and Sexual Deviance in Treated Rapists: Association with Sexual and Nonsexual Recidivism" (2004) 16 Sexual Abuse 1 at 8.

112 At 10 .

113 Olver and Wong, above $\mathrm{n} 11$, at 71.

114 At 75 .

115 Parent, Guay and Knight, above n 23, at 194.

116 At 199.

117 Olver and Wong, above n 11.
} 
a moderate effect size (an AUC of .66, indicating that there is a 66 per cent probability that a randomly-selected recidivist will have a higher score on the PCL-R than a randomly-selected non-recidivist). ${ }^{118}$ The lower estimate of the confidence interval indicates that the worst-case scenario is an AUC of .55 (which is marginally better than chance, but not high enough to be even a small effect size).

In this section, I have argued that we should determine whether the core New Zealand risk assessment tools discriminate between recidivists and non-recidivists accurately enough on the basis of studies with samples similar to the likely treatment track population and that use methods similar to how the tools would be used in practice in the treatment track. I have shown how little research there is that meets those requirements. As a result, it is difficult to draw any conclusion about the discriminative ability of most of the core New Zealand tools.

We do not know how well the STABLE-2007, ACUTE-2007 and the VRS-SO discriminate between recidivist and non-recidivist contact adult or mixed offenders. The ASRS is the only tool for which we have data with New Zealand contact adult and mixed offenders. The one study validating the ASRS shows moderate discriminative ability, but there are a number of reasons to be cautious about relying on that finding in the context of the treatment track. The PCL-R has been found to have moderate discriminative ability in respect of sexual recidivism by contact adult and mixed offenders, although it has not been validated with that group in New Zealand. The PCL-R has higher discriminative ability in respect of non-sexual violence.

Until we know, at the very least, the discriminative ability of all the core New Zealand tools with New Zealand or Canadian contact adult and mixed offenders, we should not, in my view, claim that there is sufficient evidence that the risk assessment tools are accurate with men who have sexually assaulted an adult. Ideally, the studies would also report disaggregated results for Māori. The more closely the studies correspond with the way the way the tools would be used in the treatment track (in respect of timeframes and types of recidivism, independence of assessors and that the assessments are field rather than lab assessments) the more confident we could be relying on the studies. It is also important that the studies are undertaken by independent researchers and that the studies are replicated.

118 Hildebrand, de Ruiter and de Vogel, above n 111, at 10. 


\section{E How closely do observed recidivism rates correspond with predicted recidivism rates?}

Up to this point, I have been talking about how accurately the tools discriminate between recidivists and non-recidivists. I now move to discussing a second aspect of accuracy: how closely the observed recidivism rates correspond with predicted recidivism rates.

For actuarial tools, an offender's risk score is linked to a rate of recidivism (for example, 10 per cent of people assessed as having a score of 4 on a particular tool recidivate within five years). The predicted risk of recidivism should be factored into decisions about treatment track eligibility. For example, whether risk of reoffending can be managed in the community depends in part on the absolute likelihood that the person will reoffend. If 85 per cent of offenders assessed as being at high risk (that is, above a certain score on a given risk tool) recidivate within five years, it is much less likely that the risk posed by a "high risk" offender will be considered manageable in the community than if the absolute recidivism rate for "high risk" offenders was 15 per cent. Similarly, the predicted risk of recidivism may factor into judgments about whether a person is considered to be at high enough risk of reoffending to need treatment: if "low risk" means that 1 per cent of offenders classified as low risk will reoffend, it is unlikely that low risk offenders would be deemed to need treatment, whereas a recidivism rate of 25 per cent for low risk offenders might not exclude "low risk" offenders from eligibility for some treatment (though less than higher risk offenders receive, of course).

The point at which absolute risk is too high or too low for a person to be eligible for the treatment track is a normative and political decision that is outside the scope of this thesis. Wherever the boundaries of acceptable risk are set, however, accurate information about absolute risk of recidivism is needed when determining who falls between them.

Ideally, we would be able to ascertain how closely observed recidivism rates correspond with the recidivism rates predicted by each tool (that is, if 25 per cent of people assessed as being at high risk by a particular tool are predicted to reoffend, we would look at how many people assessed as being at high risk on that tool actually reoffend). Unfortunately, however, that research has not been undertaken. Instead, in this section, I outline what is known about the stability of observed recidivism rates across different studies (that is, do we see similar recidivism rates for people assessed as being at a particular risk level on a particular tool?). I argue that the variation in observed recidivism rates is too large for the predictions to be relied upon. 
There is much less research on the stability of observed recidivism rates than there is on discriminative ability. A meta-analysis published in 2012 by Helmus and colleagues was the first large scale examination of the accuracy of absolute risk predictions for sex offender risk assessment tools. ${ }^{119}$ Helmus and colleagues requested datasets from the researchers who had undertaken validation studies of the Static-99R and the Static2002R. As the authors of most of those studies had not analysed absolute recidivism rates, Helmus and colleagues conducted their own analyses using the datasets and then combined the results using meta-analysis. ${ }^{120}$ They looked at the absolute recidivism rates associated with scores of 0,2 , and 5 on the Static-99R and 1, 3, and 6 on the Static2002R. They found substantial variation across studies in the absolute recidivism rates associated with each score, and calculated that that variation was more than would be expected due to sampling error. The tables below show the range of absolute recidivism rates found in the individual studies, the absolute recidivism rate for each score derived from the meta-analysis and the confidence interval around that effect size, and the percentage of overall variability that is beyond what would be expected by chance (where 50 per cent can be considered moderate variability and 75 per cent high variability). ${ }^{121}$ All figures are for recidivism at five years.

For the Static-99R, the findings were as follows:

\begin{tabular}{|l|l|l|l|}
\hline Static-99R score & $\begin{array}{l}\text { Recdivism rate range } \\
\text { (individual studies) } \%\end{array}$ & $\begin{array}{l}\text { Meta-analysis (random } \\
\text { effects) } \%\end{array}$ & $I^{2}(\%)$ \\
\hline 0 & $.04-18.8$ & $4.3[3.0,6.2]$ & $73.9[60.7,82.7]$ \\
\hline 2 & $.3-33.5$ & $7.3[5.3,10.1]$ & $85.8[80.0,90.0]$ \\
\hline 5 & $.8-61.8$ & $16.0[12.8,19.8]$ & $83.3[75.9,88.4]$ \\
\hline
\end{tabular}

The findings were similar for the Static-2002R:

\begin{tabular}{|l|l|l|l|}
\hline $\begin{array}{l}\text { Static-2002R } \\
\text { score }\end{array}$ & $\begin{array}{l}\text { Recidivism rate range } \\
\text { (individual studies) } \%\end{array}$ & $\begin{array}{l}\text { Meta-analysis (random } \\
\text { effects) } \%\end{array}$ & $I^{2}(\%)$ \\
\hline 1 & $.4-11.0$ & $4.0[1.9,8.0]$ & $73.6[43.6,87.8]$ \\
\hline 3 & $.8-15.0$ & $6.8[3.9,11.8]$ & $79.9[58.9,90.1]$ \\
\hline 6 & $.8-23.2$ & $15.4[10.8,21.5]$ & $81.8[63.6,90.9]$ \\
\hline
\end{tabular}

119 Leslie Helmus, Karl Hanson, David Thornton, Kelly Babchishin and Andrew Harris "Absolute Recidivism Rates Predicted by Static-99R and Static-2002R Sex Offender Risk Assessment Tools Vary Across Samples: A Meta-Analysis" (2012) 39 Criminal Justice and Behavior 1148. At 1152-1157.

At 1157, citing JP Higgins, SG Thompson, JJ Deeks and DG Altman "Measuring inconsistency in meta-analyses” (2003) 327 British Medical Journal 557. 
The lack of stability in absolute recidivism rates is apparent from Helmus and colleagues' findings. For a score of 3 on the Static-99R, for example, the percentage of offenders who recidivate within five years of assessment ranges between .3 and 33.5 per cent. The recidivism rate derived from the meta-analysis (the most reliable figure) is 7.3 per cent, but the plausible range of values is $5.3-10.1$ per cent. 85.8 per cent of the variation is due to something other than sampling error (that is, represents true differences between studies) - a high proportion of variability.

Given the lack of stability found for the Static-99R and the Static-2002R, it would be useful to examine the stability of absolute recidivism rates associated with scores or risk levels for the core New Zealand sex offender risk assessment tools. That has not yet been done. Until it is, we should not be confident that the recidivism rates associated with scores/risk levels are accurate. Decisions about treatment track eligibility should not be made on the basis of predicted absolute recidivism rates until stability is investigated for the ASRS, the VRS-SO, the STABLE-2007 and the ACUTE-2007.

\section{F Conclusion on accuracy}

There is great uncertainty surrounding the accuracy of the core New Zealand sex offender risk assessment tools. For many of the tools, there is no research at all about how accurately the tools predict recidivism by those who would be assessed for participation in the treatment track. What research there is on the accuracy of the tools with that population is limited in its applicability to the treatment track context because key features of the studies differ from how the tools would be used in practice in the treatment track context.

We know something about the discriminative ability of two tools (the ASRS and the PCL-R) with men who have sexually assaulted an adult, although only the ASRS has been validated with a New Zealand sample. It would be difficult to argue that we should feel confident relying on the ASRS and the PCL-R for risk prediction. The ASRS fails to discriminate between recidivists and non-recidivists 36 per cent of the time for contact adult offenders and 31 per cent of the time for mixed offenders. ${ }^{122}$ In respect of sexual recidivism, the PCL-R fails to discriminate between recidivists and non-recidivists 34 per cent of the time. In respect of non-sexual violent recidivism, the PCL-R fails to discriminate between recidivists and non-recidivists between 27 and 34 per cent of the time.

$122 \quad$ Vess and Skelton, above n 5, at 550. 
Even if we felt confident that the risk assessment tools accurately rank offenders by risk (which is what the tool's discriminative ability measures), the offender's risk score on its own provides limited guidance unless we also know how many people with each risk score (or at each risk level) recidivate. Unfortunately, we know next to nothing about that. How closely observed recidivism rates correspond with predicted recidivism rates has not been investigated. The best we can do at present is to try to infer something from the meta-analysis of the stability of observed recidivism rates for the Static-99R and the Static-2002R. That meta-analysis revealed exceptionally wide variation in the observed recidivism rates. It is of very little use to know, for example, when deciding about treatment track eligibility that between 0.3 and 33.5 per cent of people assessed as being at medium risk on the Static-99R (having a score of 2) recidivate. When those studies are meta-analysed, the recidivism rate for a score of 2 on the Static-99R becomes 7.3 per cent (with a 95 per cent confidence interval of 5.3 and 10.1), which is more useful. However, the very high proportion ( 85 per cent) of variability due to something other than sampling error indicates we should be cautious in relying on that figure.

And of course we do not know anything about the stability of the observed recidivism rates for the core New Zealand tools. The predicted recidivism rates could correspond quite closely with the observed rates, but given the lack of stability in observed recidivism rates revealed by the Static-99R and Static-2002R meta-analysis, that does seem unlikely. Research into the stability of observed recidivism rates and correspondence with predicted recidivism rates for the core New Zealand sex offender tools must be undertaken.

It is clear at this point that we do not know nearly enough about the accuracy of the core New Zealand risk assessment tools to ensure that their use protects public safety, ensures fairness, and enables efficient use of resources well enough for an initiative based on risk assessment (such as the treatment track) to be justifiable.

The discussion to this point has considered only how accurately risk assessment tools predict charges and/or convictions for a new offence. However, as discussed in Chapter 4 , the vast majority of sexual offences do not result in a charge or conviction. Given that the ultimate purpose of risk assessment is public safety, risk assessment tools can guide eligibility, treatment, and risk management decisions much more effectively if they can predict the likelihood of a person committing a new offence, not just being caught for one. In the rest of this chapter, I consider the validity of the core risk assessment tools 
with men who have been convicted of sexually assaulting an adult in light of what is known about under-reporting and attrition in sexual cases.

\section{G Are Risk Predictions Valid in Light of Under-Reporting and Attrition?}

In Chapter 4, I discussed what is known about the rates of under-reporting and attrition in sexual cases. I noted that most sexual offences are not reported and that most of those that are reported do not result in a conviction. Most importantly for the purposes of this section, it is much less likely that "everyday rapes" (those in which the victim and perpetrator know each other and which involve little or no gratuitous physical violence) will be reported and result in a conviction than "real rapes" (those in which the victim and the perpetrator are strangers and which involve physical violence and injury).

In this section, I examine whether the core New Zealand sex offender risk assessment tools are valid given high rates of under-reporting and attrition and systematic differences between "real rapes" and "everyday rapes". Larcombe has argued that using convictions (or reports, arrests, or charges) as a measure of recidivism does not just under-estimate reoffending, but results in a distorted picture of the factors associated with sexual recidivism, because of systematic biases in favour of "real rape" in respect of reporting, prosecution, and conviction. ${ }^{123}$ She argued that the factors used to predict recidivism only predict the likelihood that a person will be convicted of another sexual offence, not that they will commit one. ${ }^{124}$ In her review of the Australian reporting and attrition literature, she identified factors that are associated with an increased likelihood of conviction. They include: a child, male or stranger victim (because, she posited, people are more likely to be convicted if the alleged offending is against a person who is not a "potentially appropriate sex partner"); a suspect who has had previous contact with the police in relation to a sexual offence; and a generally antisocial suspect (with previous convictions for non-sexual offences and who is alleged to have committed other offences along with the sexual offence). ${ }^{125}$

If Larcombe is correct, we should be seriously concerned about the validity of risk assessment tools. If the tools only predict certain kinds of offences ("real rapes"), and the likelihood that a person will commit a "real rape" is not associated with the likelihood the

\footnotetext{
123 Wendy Larcombe "Sex Offender Risk Assessment: The Need to Place Recidivism Research in the Context of Attrition in the Criminal Justice System" (2012) 18 Violence Against Women 482.

124 At $493-495$.

125 At $489-493$.
} 
person will commit an "everyday rape", then the tools would not rank offenders in a way that corresponds with their actual risk of reoffending.

In the context of the treatment track, that would mean that people who need treatment might be denied it if they are assessed as being low risk but would be higher risk if it was possible to take their undetected offending into account. Others might be accepted into the treatment track on the basis that their risk can be contained in the community, whereas if their undetected offending could be taken into account their risk might not be considered able to be managed. Further, the recidivism rates that correspond with each risk level would be meaningless because the rankings do not correspond with true risk of reoffending. In that case, the predictions could not be factored into decisions about the degree of risk that can be tolerated in the community.

In this section, I consider further the validity of Larcombe's argument and its implications.

1 How is undetected sexual offending distributed amongst convicted sex offenders?

While the studies discussed in Chapter 4 reported fairly high mean and median numbers of undetected offences, we do not know how undetected offences are distributed amongst convicted sex offenders. If undetected offending is distributed relatively evenly amongst offenders then risk predictions would not be distorted: the ranking of offenders by risk would still be valid. The predicted recidivism rates associated with each risk level would be underestimates, but that could be addressed by using a multiplier derived from the relationship between offences resulting in a conviction and offences not resulting in a conviction. $^{126}$ If, on the other hand, some offenders have committed many more undetected offences than others (which is possible because of differences in offending patterns and expertise that affect the likelihood of reporting, prosecution, and conviction) then risk assessment may be distorted. Some of those who appear low risk may in fact be very high risk if undetected offending could be taken into account. If that were the case, then the risk scores assigned to offenders would give a distorted picture of the risk of reoffending (as opposed to the risk of re-conviction), affecting the validity of the associated probabilities of reoffending.

126 Louise Falshaw, Caroline Friendship and Andrew Bates Sexual Offenders - Measuring reconviction, reoffending, and recidivism (Home Office, London, 2003) at 4. 
Unfortunately, no research has investigated how undetected sexual offending is distributed amongst convicted sex offenders. That research should be undertaken. If the study found that undetected offending is evenly distributed, an appropriate multiplier could perhaps be identified. ${ }^{127}$ If not, the study could provide more information about the nature and degree of distortion in risk assessment. More thinking would then need to be done about whether the problem can be remedied.

In the meantime, we can attempt to think through how likely it is that risk assessment is distorted because of under-reporting and attrition in sexual cases. In section two, I consider further Larcombe's argument that biases towards "real rape" have resulted in the creation of risk assessment tools that predict the likelihood that a person will be convicted of a sexual offence, not that they will commit one.

\section{A logical analysis of the distortion issue}

In this section, I draw on the research that has been undertaken with undetected perpetrators (discussed in Chapters 4 and 5) on the basis that it provides insight into the actual offending patterns of repeat sexual violence perpetrators without the filter of criminal justice processing. However, the undetected perpetrator literature is based predominately on studies with American university students who are assumed not to have been convicted of a sexual offence, so may not generalise to convicted sex offenders. The analysis should, accordingly, be considered exploratory: its purpose is to raise the issue of the impact of under-reporting and attrition on the validity of risk assessment and suggest a direction for further empirical research with convicted sex offenders, rather than to draw any conclusions about their true rates of offending or the real predictive value of established risk factors and tools. I argue that the evidence from the undetected perpetrator literature does not actually support Larcombe's argument.

In her discussion of the risk assessment literature, Larcombe relied on Hanson and Morton-Bourgon's meta-analysis of factors associated with sexual recidivism by convicted sex offenders, which grouped risk factors into two categories: sexual deviance and anti-social orientation. ${ }^{128}$ She focused on anti-social orientation, arguing that it is

127 Though this process is less straightforward than might be assumed: Karl Hanson, David Thornton and Shelley Price "Estimating Sexual Recidivism Rates: Observed and Undetected" (presentation at the Association for Treatment of Sexual Abusers conference, St Louis, October 2003), slides on file with author. of persistent sexual offenders: A meta-analysis of recidivism studies" (2005) 73 Journal of Consulting and Clinical Psychology 1154. Hanson and Morton-Bourgon defined "anti-social 
"doubtful that [anti-social orientation] is predicting the probability of reoffending rather than only the probability of being arrested and convicted for subsequent offending." 129 The basis for her argument was her observation from the attrition literature that men who are convicted of a sexual offence tend to be the more anti-social perpetrators, and that sex offenders who are convicted of a subsequent sexual offence are likely to represent a particularly antisocial sub-group of perpetrators. ${ }^{130}$

The literature on repeat perpetration in non-adjudicated samples does not support that argument, at least not to its full extent. The studies with undetected perpetrators indicate that antisocial orientation is predictive of repeat perpetration itself, rather than only of an incident of sexual violence resulting in a conviction. The risk factors for repeat perpetration in non-adjudicated samples include a number of components of an antisocial orientation: alcohol abuse, drug use, callousness/low empathy, impulsivity/erratic lifestyle, narcissism, conning/superficial charm, and interpersonal manipulation. ${ }^{131}$ Convicted sex offenders may well score higher on measures of antisocial personality and traits than undetected perpetrators, but no empirical studies have compared the two directly, and the separate bodies of literature tend to use different measures.

In his discussion of similarities between undetected and convicted sex offenders, Malamuth suggested that undetected perpetrators have antisocial personality traits, and that those traits indicate a potential for antisocial behaviour that has not necessarily been fulfilled in the way that it has been for most convicted sex offenders. ${ }^{132}$ General antisocial behaviour by repeat undetected perpetrators has not been examined, but it could be assumed from the fact that most of the studies are conducted with university students that their level of anti-social behaviour is less than that exhibited by most convicted sex offenders, by virtue of the fact that the students had attained the educational qualifications to qualify for university entrance and were not in prison.

orientation" as "antisocial personality (e.g., antisocial personality disorder, psychopathy, Minnesota Multiphasic Personality Inventory Scale 4), antisocial traits (e.g., lifestyle instability, substance abuse, hostility), and a history of rule violation (e.g., childhood criminality, history of nonsexual crime, violation of conditional release)" (at 1156).

Larcombe, above n 123, at 493-494.

Ibid.

See the discussion in Chapter 5.

Neil Malamuth "Criminal and Noncriminal Sexual Aggressors: Integrating Psychopathy in a Hierarchical-Mediational Confluence Model” (2003) 989 Ann NY Acad Sci 33 at 46. 
Accordingly, Larcombe's view that antisocial orientation is associated only with the likelihood of being caught for a sexual offence that a person has committed, rather than with the likelihood of committing one, is not supported by the available evidence.

In fact, a comparison of risk factors for repeat undetected sexual violence perpetration (which we can understand as predicting the likelihood of the behaviour itself, rather than merely the likelihood of it being detected) and dynamic risk assessment tools for sexual recidivism (developed using official convictions as a measure of recidivism) reveals a reasonable degree of overlap. I will compare the risk factors in the VRS-SO with the risk factors that have been identified in the undetected perpetrator literature. I have chosen the VRS-SO because it is the tool with the largest number of dynamic risk factors.

The VRS-SO has 17 dynamic risk factors. ${ }^{133}$ Four of them are not relevant to an undetected perpetrator population because they deal with matters related to release from prison or compliance with treatment and supervision. Seven of the dynamic risk factors may be relevant to undetected perpetrators, but their relationship with repeat perpetration in non-adjudicated samples has not been investigated. Those factors are: sexually deviant lifestyle, offence planning, emotional control, insight, deviant sexual preference, intimacy deficits, and sexual offending cycle. Childhood victimisation, adolescent delinquency, and perceived peer support for forced sex are factors that have been found to predict or contribute to repeat perpetration in undetected perpetrator samples, but are not included in the VRS-SO. There are seven VRS-SO factors that have also been associated with repeat perpetration in non-adjudicated samples. I discuss each of them in turn.

Sexual compulsivity, which in the VRS-SO refers to "repetitive deviant or non-deviant compulsive sexual activity", has been found to also predict sexual violence perpetration at multiple time points in a student sample. ${ }^{134}$ One aspect of sexual compulsivity, as defined by the VRS-SO, is promiscuity or one-night stands. ${ }^{135}$ This aspect corresponds with the preference for impersonal sex pathway in the undetected perpetrator literature,

\footnotetext{
133 Stephen Wong and others Violence Risk Scale: Sex Offender Version (2009) at 30-66.

134 At 32; Heidi Zinzow and Martie Thompson "A Longitudinal Study of Risk Factors for Repeated Sexual Coercion and Assault in US College Men” (2015) 44 Arch Sex Behav 213 at 218. 
which is measured variously by number of consensual sex partners, positive attitudes about casual sex and number of one-time sex partners. ${ }^{136}$

Criminal personality (also described as antisocial personality) is a VRS-SO risk factor and has also been found to predict repeat perpetration in non-adjudicated samples. ${ }^{137}$ Mouliso and Calhoun found that scores on a measure of sub-clinical psychopathy were positively associated with the number of sexually aggressive acts reported. ${ }^{138}$ Callousness and lack of empathy, superficial charm, interpersonal manipulation, and narcissism have each been found to predict repeat perpetration by undetected perpetrators. ${ }^{139}$

The VRS-SO includes cognitive distortions as a risk factor. ${ }^{140}$ One aspect of that factor, acceptance of rape myths, has also been found to predict repeat perpetration in undetected perpetrator samples, either as part of the hostile masculinity pathway ${ }^{141}$ or as part of Zinzow and Thompson's "sexually aggressive beliefs and attitudes" factor. ${ }^{142}$ The tendency to misperceive sexual intent, a factor positively associated with the number of sexually aggressive acts reported by undetected perpetrators, ${ }^{143}$ could also be considered a cognitive distortion. A person who tends to interpret a woman's friendliness or politeness as a willingness to engage in sexual activity is likely to be ignoring or discounting relevant information that would disconfirm that view (such as the woman being polite to everyone).

136 See for example Antonia Abbey, Angela Jacques-Tiura and James LeBreton "Risk Factors for Sexual Aggression in Young Men: An Expansion of the Confluence Model” (2011) 37 Aggressive Behavior 450 at 456, which used all three measures for impersonal sexual orientation. See also Martie Thompson, Kevin Swartout and Mary Koss "Trajectories and Predictors of Sexually Aggressive Behaviors During Emerging Adulthood" (2013) 3 Psychology of Violence 247; Zinzow and Thompson, above n 134; and Antonia Abbey and others "Cross-Sectional Predictors of Sexual Assault Perpetration in a Community Sample of Single African-American and Caucasian Men" (2006) 32 Aggressive Behavior 54.

Wong and others, above n 133, at 36-37.

Emily Mouilso and Karen Calhoun "Narcissism, Psychopathy and Five-Factor Model in Sexual Assault Perpetration" (2012) 6 Personality and Mental Health 228 at 233.

Ibid; Abbey, Jacques-Tiura and LeBreton, above n 136, at 457; Zinzow and Thompson, above $n$ 134 , at 218 .

Wong and others, above $n$ 133, at 38-39.

Thompson, Swartout and Koss, above n 136; Abbey, Jacques-Tiura and LeBreton, above n 136. At 218 .

Abbey, Jacques-Tiura and LeBreton, above n 136. 
Impulsivity, the tendency to act without considering the consequences, is a risk factor in both the VRS-SO and the undetected perpetrator literature. ${ }^{144}$

Likewise, substance abuse is found in both the VRS-SO and the undetected perpetrator literature, ${ }^{145}$ although the VRS-SO requires that substance abuse contribute to sexual offending for it to be considered a risk factor, whereas in the undetected perpetrator studies, participants are simply asked about their alcohol use (either in general, in sexual situations, or prior to the incident reported).

The final VRS-SO risk factor that may correspond with a risk factor in the undetected perpetrator literature is interpersonal aggression. The VRS-SO defines interpersonal aggression as habitual or extensive use of physical or verbal aggression in interpersonal interactions. ${ }^{146}$ Hostility towards women, a component of the hostile masculinity pathway in the undetected perpetrator literature, may be a sub-component of interpersonal aggression. Sexual dominance (using sex as a means of asserting control over a person) may also be considered a sub-component of interpersonal aggression. In the undetected perpetrator literature, sexual dominance is sometimes considered part of the hostility towards women factor, and sometimes a factor in its own right that contributes to the hostile masculinity pathway.

The number of overlapping risk factors suggests that the VRS-SO could actually predict all recidivism, not just recidivism that would ordinarily result in a conviction. Empirical research would be necessary to confirm this however, with the VRS-SO and with the other core New Zealand tools.

\section{Conclusion on validity}

Not a great deal of attention has been paid in the risk assessment literature to the issue of the validity of sex offender risk assessment tools in light of the high rates of underreporting and attrition, particularly in "everyday rapes". There is as yet no empirical evidence that could confirm whether distortion is an issue. However, my exploratory analysis suggests that distortion may be less of a concern than has been argued elsewhere.

\footnotetext{
$144 \quad$ Zinzow and Thompson, above n 134; Abbey, Jacques-Tiura \& LeBreton, above n 136; Wong and others, above n 133, at 54 . LeBreton, above n 136; Wong and others, above n 133, at 46. 
Empirical research should be undertaken, however, to confirm that distortion is not an issue before any new initiatives relying on good risk assessment are established.

\section{H Conclusion on risk}

If the treatment track is to intervene effectively to reduce recidivism by sex offenders, good risk assessment is needed. Four questions must be able to be answered in each individual case. First, can the person's risk of reoffending be managed in the community? Secondly, is the person's risk of reoffending high enough that they need treatment? Thirdly, what treatment does the person need? And fourthly, what risk management conditions are necessary to contain the person's risk of reoffending?

I highlighted the lack of evidence about the accuracy of risk predictions yielded by the core tools with New Zealand men who have sexually assaulted an adult, and with Māori offenders, an important subgroup of that population. I also considered whether risk predictions are valid given the high rates of under-reporting and attrition in sexual cases. I argued that it is likely that men convicted of a sexual offence against an adult have also committed undetected offences, but that further research is necessary to establish how many and how those offences are distributed across offenders. Until that research has been undertaken, it is uncertain whether the risk predictions yielded by the core risk assessment tools are distorted or not.

In Part III, I consider whether sex offender treatment - which should be informed by risk assessment - has been found to be effective at reducing recidivism.

\section{Treatment Effectiveness}

Treatment intended to reduce recidivism is a core part of the proposed treatment track, and the treatment track can only fulfil the second condition of penal minimalism if it is effective in reducing recidivism. It is important, therefore, to know whether treatment actually reduces recidivism. Unfortunately, as extensive as the gaps in the risk assessment literature are, the gaps in the evidence about treatment effectiveness with sex offenders are much worse. In a 2014 article reflecting on treatment of sex offenders, Hanson stated: ${ }^{147}$

$147 \quad$ Karl Hanson "Treating sexual offenders: how did we get here and where are we headed?" (2014) 20 Journal of Sexual Aggression 3 at 5, citing L Furby, MR Weinrott and L Blakshaw "Sex offender recidivism: A review" (1989) 105 Psychological Bulletin 3. 
[I]t is hard to make any strong conclusions about whether treatment works at all. This is a depressingly similar conclusion to that of Furby, Weinrott and Blackshaw (1989) more than 20 years earlier. Knowing which treatment works for which type of sexual offender remains a distant dream.

In a meta-analysis published in 2009, Hanson and colleagues found lower recidivism rates for treated groups than comparison groups for sexual and general recidivism, though not for violent (including sexual) recidivism. ${ }^{148}$ However, they tempered their conclusion by noting that the quality of the studies overall was low. Of the 23 accepted studies, 18 were rated as having weak designs and only five as good. ${ }^{149}$ They noted: ${ }^{150}$

Reviewers restricting themselves to the better-quality, published studies ... could reasonably conclude that there is no evidence that treatment reduces sexual offence recidivism.

Even less is known about treatment effectiveness with men who have sexually assaulted an adult than with sex offenders generally. Overseas, men who have sexually assaulted an adult are usually treated alongside men who have sexually abused a child. Men who have sexually assaulted an adult tend to be a minority, if they are included at all. For example, in the UK prison service, men who have sexually assaulted an adult make up only about 15 per cent of treatment groups. ${ }^{151}$ Treatment effectiveness is not usually evaluated separately for men who have sexually assaulted an adult, so there is very little evidence about whether treatment is effective with them. An exception is the Clearwater Treatment Programme, which has an unusually high proportion of offenders with adult victims (around 50 per cent). An evaluation found a small but statistically significant reduction in sexual recidivism amongst men with adult victims: 13.1 per cent of treated participants were convicted of a new offence, compared with 24.3 per cent of untreated participants (odds ratio $0.47[0.29,0.76]){ }^{152}$

\footnotetext{
$148 \quad$ Karl Hanson and others "The Principles of Effective Correctional Treatment Also Apply to Sexual Offenders" (2009) 36 Criminal Justice and Behavior 865 at 877-878.

149 At 869.

150 At 888 .

151 Anthony Beech, Caroline Oliver, Dawn Fisher and Richard Beckett STEP 4: The Sex Offender Treatment Programme in Prison: addressing the offending behaviour of rapists and serial murderers (Birmingham University, Birmingham, 2006) at 5.

152 Karl Hanson and Terry Nicholaichuk "A cautionary note regarding Nicholaichuk et al" (2000) 12 Sexual Abuse: A Journal of Research and Treatment 289 at 292.
} 
New Zealand is unusual in having a treatment programme specifically for men who have sexually assaulted an adult. An evaluation of the ASOTP found that participants showed changes in criminogenic needs, but not enough participants have been released to evaluate whether the programme reduces recidivism. It is important to note also that while participants did show treatment change in the right direction, the average stage of change at the end of the programme was still contemplation (which means that behaviourally there was no reduction in risk) indicating that they should have further treatment before being released. ${ }^{153}$

Carter and Mann have suggested three possible reasons for the lack of robust findings that treatment is effective. The first is that treatment effectiveness is difficult to evaluate, and the poor quality of most of the research in the area makes it difficult to conclude that treatment is effective. The second is that knowledge about treatment is still incomplete, and there may be treatment targets or techniques that have not yet been identified that could improve treatment effectiveness. Thirdly, they suggest that the success of treatment programmes may be undermined by problems with the delivery of treatment, the treatment context, or wider societal problems. ${ }^{154}$ In this section, I explore those possibilities in relation to the treatment track.

\section{A The difficulties of evaluating sex offender treatment}

It is difficult and expensive to evaluate sex offender treatment programmes well. Long follow-up periods (of at least five years) are needed, because of the low base rates (rate of re-conviction) for sexual offences. Using long follow-up periods is less of an issue with retrospective studies (such as those usually undertaken to validate risk assessment tools) but prospective studies are the most robust research design for treatment evaluations because of the desirability of randomly assigning participants to treatment or control conditions. ${ }^{155}$ At least in part because of these difficulties, the quality of research on treatment effectiveness is generally low. In their 2009 meta-analysis, Hanson and colleagues rejected 81 per cent of studies because their quality was too low. ${ }^{156}$

\footnotetext{
$153 \quad$ Nick Wilson, Glen Kilgour and Devon Polaschek "Treating high-risk rapists in a New Zealand intensive prison programme" in Devon Polaschek (ed) Treatment Programmes for High Risk Offenders Routledge, New York, 2016) at 133.

154 Adam Carter and Ruth Mann “The Strengths of Treatment for Sexual Offending” in DR Laws and W O’Donahue (eds) Treatment of Sex Offenders (Springer International Publishing, Switzerland, 2016) at 160 .

155 Hanson, above n 147, at 6.

156 Hanson and others, above n 148, at 869.
} 
More outcome evaluations with strong designs are needed. Random assignment of participants to treatment or control groups is thought of as the strongest design, because it minimises selection bias. ${ }^{157}$ Well-designed cohort studies can also be used, however. ${ }^{158}$ Matching participants on risk-relevant variables, using statistical controls, and using equal and fixed follow-up periods can improve study quality. ${ }^{159}$ Even when participants are matched on static risk, however, treatment and comparison groups may differ on factors such as denial of the offending and the extent of their sexual deviance, so may not be equivalent in all relevant respects. ${ }^{160}$

Using outcome measures other than conviction (or charge) for a new sexual offence may also help to address the base rate problem, and thus allow shorter follow-up periods to be used. Doing so may also allow more sensitive evaluations of treatment effectiveness, because it is difficult to detect statistical differences when base rates are so low to begin with. ${ }^{161}$ For example, Falshaw, Friendship and Bates measured sexual reoffending ("the perpetration of another illegal sexual act, whether caught or not") and sexual recidivism ("offence-related behaviour, legal or illegal, with a clear sexual motivation") along with re-convictions. ${ }^{162}$ While those alternative outcomes measured were used in an evaluation of the programme, there was no control group, so no conclusion can be drawn about their usefulness in addressing the base rate problem. ${ }^{163}$

\section{B Knowledge about treatment}

The second possible reason Carter and Mann suggested for the lack of robust evidence of treatment effectiveness is that knowledge about treatment is still incomplete.

It is clear that not all programmes reduce recidivism. Programmes that adhere to the three main principles of the Risk Need Responsivity model are the most effective. Hanson and colleagues found that for programmes that complied with none of the RNR principles, the odds of recidivism were 17 per cent higher for treated offenders than 
untreated offenders (that is, participants in those programmes were more likely to reoffend than the untreated group). On the other hand, for programmes that complied with all three principles, the odds of recidivism were 79 per cent lower for treated offenders than for untreated offenders. Overall, the more principles adhered to, the greater the decline in the odds of recidivism for treated participants. For each additional principle adhered to, the odds of recidivism for the treated offenders compared to the untreated group declined by an additional 61 per cent - a large effect (although the number of studies is relatively small, so an effect of this magnitude may not be found consistently). ${ }^{164}$ Accordingly, it is important that the treatment delivered in the treatment track complies with the RNR model, so that it has the greatest possible impact on recidivism.

While it is clear that the RNR principles are important, there are still issues requiring further research in relation to each of the three main principles. In the remainder of this section, I briefly outline what is known and what it may be useful to discover, in order to further improve the effectiveness of RNR-based treatment.

\section{Risk}

In their review of the evidence for the risk principle, Wakeling, Mann and Carter argued that there are good reasons to comply with it. ${ }^{165}$ Higher risk offenders have more scope to change and do change more in treatment. ${ }^{166}$ They also tend to have more treatment needs (for example, higher deviance and more extensive offence-related personality pathology) so require more time in treatment than lower risk offenders. ${ }^{167}$ Contact between higher risk and lower risk offenders also risks "contaminating" lower risk offenders, ${ }^{168}$ and intensive treatment for low risk offenders can disrupt pro-social activities or cause them to label themselves as deviant and 'doomed' to recidivism, thereby increasing their risk. ${ }^{169}$

Nonetheless, of the three principles, there is least evidence in support of the influence of the risk principle on treatment effectiveness. ${ }^{170}$ Hanson and colleagues found no

\footnotetext{
164 Hanson and others, above n 148, at 878; Maaike Helmus, personal communication, 26 January 2017 (on file with author).

165 Wakeling, Mann and Carter, above n 161.

166 At 290-291.

167 At 291.

168 At 295.

169 At 289.

170 For a review of evidence for the risk principle, see Wakeling, Mann and Carter, above n 161.
} 
statistical difference in treatment effects between high and low risk offenders, concluding that "the magnitude of these differences is sufficiently small as to be of little practical value in most settings."171 It should be borne in mind, however, that the meta-analysis was not a full application of the risk principle, as it did not investigate whether the treatment offered was proportionate to the risk level of participants. ${ }^{172}$ In contrast to the conclusion of Hanson and colleagues, Wakeling, Mann and Carter argued that the evidence supported the need to adhere to the risk principle when treating sexual offenders. However, only one of the studies they cited in support of their argument about the importance of the risk principle was included in Hanson and colleagues' metaanalysis. ${ }^{173}$ The other studies they drew on provide contextual support, but because they are not outcome evaluations of treatment programmes ${ }^{174}$ or they did not measure sexual recidivism, ${ }^{175}$ they are less persuasive than the findings of the meta-analysis.

Even if we accept that the risk principle is important with sex offenders, uncertainty about the application of the principle (in terms of treatment dosage) remains. Wakeling, Mann and Carter found only two studies on treatment dosage with sex offenders. ${ }^{176}$ They recommended on the basis of those studies that low risk sex offenders should receive no more than 100 hours of treatment. ${ }^{177}$ Even this recommendation is uncertain, however. ${ }^{178}$

These issues with the risk principle may actually be positive in the treatment track context, given the risk assessment difficulties discussed earlier in the chapter. If the risk principle is the least important one for effective treatment, the limitations of risk assessment may be less problematic (at least in the treatment context).

\footnotetext{
$171 \quad$ Hanson and others, above n 148, at 884 .

172 At 885.

173 Caroline Friendship, Ruth Mann and Tony Beech "Evaluation of a national prison-based treatment program for sexual offenders in England and Wales" (2003) 18 Journal of Interpersonal Violence 744. DL Mailloux and others "Dosage of treatment to sexual offenders: Are we overprescribing?" (2003) 47 International Journal of Offender Therapy and Comparative Criminology 171. Brian Lovins, Christopher Lowenkamp and Edward Latessa "Applying the risk principle to sex offenders: can treatment make some sex offenders worse?” (2009) 89 Prison Journal 344. Guy Bourgon and Barbara Armstrong "Transferring the principles of effective treatment into a "real world" prison setting" (2005) 11 Psychology, Public Policy and Law 347; Anthony Beech, David Fisher and R Beckett STEP 3: An Evaluation of the Prison Sex Offender Treatment Programme (UK Home Office Occasional Report, 1998). Wakeling, Mann and Carter, above n 161, at 295-300. 


\section{Need}

There is good evidence about which factors are related to sexual recidivism by convicted sex offenders. These fall into two categories: sexual deviance (for example deviant sexual interests, such as interest in children or sexual arousal to rape, and sexual preoccupation) and anti-sociality (anti-social personality disorder, psychopathy as measured by the PCL-R, general self-regulation problems, hostility, and unstable employment). ${ }^{179}$ According to the need principle of the RNR model, treatment that focuses on these factors should be the most effective in reducing sexual recidivism. In their 2005 meta-analysis of factors related to recidivism, Hanson and Morton-Bourgon recommended further investigation of the most important criminogenic needs of sexual offenders, and of whether treating certain combinations of needs improves outcomes, would be useful. As part of this, linking treatment change on criminogenic needs with recidivism outcomes could shed further light on the need principle. ${ }^{180}$

More recently, however, the concept of dynamic needs has been the subject of exploration and critique, led by Ward and colleagues. Ward argues that dynamic risk factors are predictors of recidivism (that is, dynamic risk factors have been selected as the variables most strongly correlated with recidivism) but do not necessarily themselves cause reoffending. ${ }^{181}$ For that reason, he argues, dynamic risk factors as currently defined are of limited usefulness in the treatment context, because treatment is supposed to address the causes of reoffending. Ward sees dynamic risk factors (and for that matter, static risk factors) as markers of underlying causal processes, ${ }^{182}$ and suggests the factors should be seen as a starting point for formulation guided by theoretical explanations of the causes of reoffending. ${ }^{183}$ What this means in practice for treatment is an open question at this point, but it does seem that further development of this line of thought, grounded in data and with an eye to the concrete application of the ideas in the treatment context, could improve treatment effectiveness.

\footnotetext{
179 Hanson and Morton-Bourgon, above n 128, at 1157-1158; See also Ruth Mann, Karl Hanson and David Thornton "Assessing Risk for Sexual Recidivism: Some Proposals on the Nature of Psychologically Meaningful Risk Factors” (2010) 22 Sexual Abuse 191. Hanson and others, above n 148, at 886-887.

181 Tony Ward "Dynamic risk factors: Scientific kinds or predictive constructs” (2016) 22 Psychology Crime and Law 2 at 4. Psychology Crime and Law 100 at 105-109. 


\section{Responsivity}

"Responsivity" means that treatment should be delivered in a way that is appropriate for the participants. It has two aspects: general and specific responsivity.

General responsivity means that the strategies used in treatment should be behavioural, social learning, cognitive, and skill-building. ${ }^{184}$ There is good evidence for the importance of this aspect of general responsivity. ${ }^{185}$ The relationship between the therapist and the participant is also an important aspect of general responsivity. Therapists who are empathetic, warm, directive, rewarding, and non-aggressively confrontational have been found to facilitate the most change in participants. ${ }^{186}$ It is more difficult to factor this aspect of general responsivity into treatment evaluation, and it may be that programmes that have been found not to be effective are falling down on process and therapeutic alliance, rather than the content and style of the programme. ${ }^{187}$

Specific responsivity means that programmes should be matched to the learning styles of individual offenders. ${ }^{188}$ A number of specific responsivity factors have been identified as relevant to men who have sexually assaulted an adult, particularly those at higher risk of recidivism. Personality pathology, including psychopathy, is prevalent. Participants are also likely to have high levels of hostility and anger, and a dismissive attachment style which can impair their ability to form bonds with the therapist and other group members. Many participants are also likely to have low readiness or motivation to change. These factors can make it difficult to engage participants in treatment and facilitate the necessary changes on factors contributing to the likelihood of reoffending. ${ }^{189}$ The

\footnotetext{
$184 \quad$ Bonta and Andrews, above n 12, at 193-194.

185 At 194.

186 WL Marshall "Therapist style in sexual offender treatment: Influence on indices of change" (2005) 17 Sexual Abuse 109; Ruth Mann, M Daniels and WL Marshall "The use of role plays in developing empathy" in YM Fernandez (ed) In their shoes: Examining the issue of empathy and its place in the treatment of offenders (Wood ' $N$ ' Barnes, Oklahoma City, 2002); Leigh Harkins and Anthony Beech "A review of the factors that can influence the effectiveness of sexual offender treatment: Risk, need, responsivity, and process issues" (2007) 12 Aggression and Violent Behavior 615 at 623.

Jill Levenson and David Prescott "Deja vu: from Furby to Langstrom and the evaluation of sex offender treatment effectiveness" (2014) 20 Journal of Sexual Aggression 257 at 260-261.

Bonta and Andrews, above n 12, at 50-52.

Devon Polaschek and Lucy King "Rehabilitating Rapists: Reconsidering the Issues" (2002) 37 Australian Psychologist 215 at 218-219; Jan Looman, Ida Dickie and Jeffrey Abracen "Responsivity Issues in the Treatment of Sexual Offenders" (2005) 6 Trauma, Violence and Abuse 330 at 336-339 and 345-346; Ralph Serin and S Kennedy Treatment readiness and responsivity:
} 
ASOTP was designed with the likely responsivity issues of high risk rapists in mind. The first module is dedicated to addressing responsivity and treatment readiness issues, and uses a schema therapy model that was designed for people with personality pathology. ${ }^{190}$ For the 41 men who had completed the ASOTP, treatment responsivity (measured by the VRS-SO subscale) improved during the programme, although it is not yet known whether this improvement is related to reduced recidivism. ${ }^{191}$

There are a number of other factors that should also be taken into account as responsivity factors when designing and delivering treatment programmes, such as culture, age, intellectual functioning, and mental health.

The ASOTP is not a kaupapa Māori programme. However, some consultation with Māori stakeholders was undertaken when designing the pilot programme to ensure the programme addressed cultural issues. Consultation highlighted the need for a cultural consultant to work alongside the non-Māori facilitators during the pilot, in addition to the cultural supervision ordinarily in place for the facilitators. Pre- and post-programme cultural assessments were also identified as a way for participants to identify any individualised cultural needs, although it is not clear whether this practice has continued with the implementation of the ASOTP into the special treatment units. ${ }^{192}$ It would be useful for the cultural appropriateness of the ASOTP to be evaluated, and if indicated, the possibility of developing a programme with a stronger kaupapa Māori approach explored.

Other important responsivity factors include age, intellectual functioning, and mental health (including substance use disorders). There is some evidence that younger offenders are more difficult to engage in treatment than older offenders, because they are not yet at a point in their lives where they can see the negative impact of their offending on themselves and their futures. ${ }^{193}$ While programmes have been designed for

Contributing to effective correctional programming (Research Report R-54, Correctional Services of Canada, Ottawa, 1997); Nick Wilson, Glen Kilgour and Devon Polaschek "Treating high-risk rapists in a New Zealand intensive prison programme" (2013) 19 Psychology, Crime and Law 527 at 530; Harkins and Beech, above n 186, at 619-621.

Adult Sex Offender Treatment Programme: Background, theory and overview (Department of Corrections, on file with author) at 21-22.

Wilson, Kilgour and Polaschek, above n 189, at 541.

At 532 .

Jan Looman, Ida Dickie and Jeffrey Abracen "Responsivity Issues in the Treatment of Sexual Offenders" (2005) 6 Trauma, Violence and Abuse 330 at 343-344. 
adolescents (and even children) with harmful sexual behaviour, ${ }^{194}$ less attention has been paid to how to tailor treatment to be suitable for young adults. The ASOTP participants had a mean age of 47.4 years at entry into the programme, which is older than the average for imprisoned rape offenders, because many of the ASOTP participants were serving long finite sentences or indeterminate sentences. ${ }^{195}$ Whether the ASOTP (or a programme based on it) could be adapted to be suitable for younger participants, and what the effects of mixing older and younger participants together might be, may require further exploration if the treatment track were be implemented.

It is important that programmes are appropriate for the intellectual functioning of participants. A high proportion of imprisoned sex offenders have below average intelligence and have had poor experiences in educational settings. ${ }^{196}$ This is probably reflected in the ASOTP, where none of the pilot participants left school with any qualifications. All programmes need to take these potential difficulties into account in the way the content is delivered. Specific programmes have been developed for sex offenders with intellectual disabilities (though not for rapists specifically), ${ }^{197}$ and if numbers indicate the need for it, the adaptation of one of these programmes for the treatment track may be required.

Finally, some mental health problems may also prevent people from engaging well with treatment. Psychosis is the most obvious of these, and must be treated before a person can meaningfully participate in treatment. Other issues, such as depression, anxiety, and substance use disorders, may also be important to address, not only as issues that can make it difficult for participants to benefit from treatment, but also as possible risk factors for the individual (in that these sorts of issues can indicate the person has poor coping strategies, which can increase their risk for sexual offending when distressed, for example). ${ }^{198}$ Whether the treatment track can accommodate treatment for mental health problems that can act as responsivity barriers or as risk factors in themselves, and if so

\footnotetext{
194 "Youth Services" WELLSTOP $<$ http://www.wellstop.org.nz/youth-services.html $>$ and “Children’s Services” WELLSTOP < http://www.wellstop.org.nz/childrens-services.html>. Wilson, Kilgour and Polaschek, above n 189, at 533. Looman, Dickie and Abracen, above n 193, at 344-345.

WR Lindsay, AM Michie and F Lambrook "Community-based treatment programmes for sex offenders with intellectual disabilities" in LA Craig, WR Lindsay and KD Browne (eds) Assessment and Treatment of Sex Offenders with Intellectual Disabilities (John Wiley \& Sons, Chitchester, 2010). 
how treatment would be sequenced, is a question of resourcing, so would need to be addressed at the time of programme design.

It is important that the treatment offered by the treatment track be tailored to be appropriate for the specific responsivity factors relevant to the participants. Good assessment would be necessary to enable this. It may be that the programme could not accommodate certain responsivity issues, for resourcing reasons, for example. If this is the case, these factors should be set out from the beginning as exclusionary criteria.

\section{Context}

It would make sense to guess that another reason for the lack of robust evidence that treatment is effective is that much of it is delivered in prisons, an environment that does not naturally foster change for the better. Indeed, one of the principles of the RNR model is that community-based programmes should be preferred. ${ }^{199}$ In prison, personal safety concerns can often take participants' attention away from treatment and even result in them removing themselves from programmes. ${ }^{200}$ Some of the positive effects of treatment can be lost due to "contamination" (from mixing with other offenders, particularly if the offender spends a substantial period of time with the general population before release) or disrupted by the difficulties most offenders experience when released back into the community. ${ }^{201}$ In the community, on the other hand, participants can maintain social bonds and prosocial activities that are important for desistance from crime, and have the opportunity to put into practice immediately the skills they are learning in treatment, in a way that is not possible to the same extent in prison.

However, in their meta-analysis, Hanson and colleagues found that recidivism rates were not significantly lower depending on whether treatment was delivered in the community or in an institution. ${ }^{202}$ Moreover, no research has compared the effectiveness of a sex offender treatment programme delivered in the two settings. ${ }^{203}$ As yet, it cannot be concluded that community-based treatment is inherently more effective than custodial treatment, and concerns about the lack of robust evidence of treatment effectiveness cannot be dismissed on the basis that prison treatment is less effective.

\footnotetext{
$199 \quad$ Bonta and Andrews, above n 12, at 188.

$200 \quad$ Carter and Mann, above n 153, at 158.

$201 \quad$ At 169.

202 Hanson and others, above n 148, at 885.

203 Looman, Dickie and Abracen, above n 193, at 336-337; Hanson and others, above n 148, at 885.
} 
Even if treatment is effective, it cannot do everything in bringing about change. Treatment can provide offenders with some of the skills required to stop offending and create a more prosocial life, but material and social conditions are also important in bringing about desistance. An extensive criminological body of literature on desistance has developed, one of the main findings of which is that people normally stop offending of their own accord at some point in their lives. Until quite recently, this body of literature has remained largely separate from the psychological literature on treatment and recidivism. Gobbels, Ward, and Willis brought them together when they developed the "Integrated Theory of Desistance from Sex Offending", which locates treatment as part of a process of desistance. ${ }^{204}$ Although specific recommendations of actions to promote desistance are not included, the theory is a good starting point for thinking about treatment as part of a desistance process. It will be important to conceptualise treatment as one factor in desistance when designing the treatment track, and to ensure that other factors (accommodation, employment, and prosocial support, for example) are also attended to. $^{205}$

\section{Conclusion}

At this point, sex offender treatment can at best be thought of as "evidence-informed practice" (defined by the American Psychological Association as "the integration of the best available research with clinical expertise in the context of patient characteristics, culture and preferences"). ${ }^{206}$ Evidence-informed practice, Carter and Mann argue, requires treatment providers to be aware of and use the best available research and that "the best available research is at least adequate in its scope and design." "207 I say that treatment can at best be considered "evidence-informed" because many programmes do not adhere to the best available research, ${ }^{208}$ and, as discussed in this section, the available research cannot be said to be adequate, particularly in relation to men who have sexually

204 Svenja Gobbels, Tony Ward and Gwenda Willis "An integrative theory of desistance from sex offending" (2012) 17 Aggression and Violent Behavior 453.

In the Special Treatment Units in New Zealand, prisoners create release plans as part of the programme, which address these factors. Higher quality release plans are associated with better experiences on parole and lower recidivism within the first 100 days and the first year after release: Devon Polaschek, Julia Yesberg, Rebecca Bell, Alannah Casey and Sophie Dickson "Intensive psychological treatment of high-risk violent offenders: Outcomes and pre-release mechanisms" (2016) 22 Psychology, Crime and Law 344. Carter and Mann, above n 153, at 159-160.

At 160 .

Pamela Yates and Drew Kingston "The Shortcomings of Sexual Offender Treatment: Are We Doing Something Wrong?" in DR Laws and W O'Donahue (eds) Treatment of Sex Offenders (Springer International Publishing, Switzerland, 2016) at 266-270. 
assaulted an adult (rather than in relation to sex offenders generally). ${ }^{209}$ At this point, accordingly, it is difficult to conclude that the second condition of penal minimalism, that the intervention is likely to be effective in reducing recidivism, is satisfied.

\section{Conclusion}

It is currently unclear whether the treatment track could intervene effectively to reduce recidivism by men who would ordinarily be convicted of sexually assaulting an adult.

Accurate and valid risk assessment is required for effective intervention. I have discovered large gaps in the evidence base about the accuracy of the risk assessment tools most commonly used in New Zealand with men convicted of sexually assaulting an adult. The existence of these gaps calls into question whether risk can be predicted accurately enough in the treatment track context to justify having men would ordinarily be in prison in the community instead. On a more positive note, a logical analysis suggests that the tools are at least predicting all sexual recidivism, rather than predicting the likelihood of "real rape" (a concern previously expressed in the legal literature on risk assessment).

The knowledge base for treatment effectiveness is even poorer than that for risk assessment, indicating that a great deal of work is required before we can be confident that treatment reduces the likelihood that men convicted of sexually assaulting an adult will reoffend.

Overall, the second condition of penal minimalism - that the intervention is likely to be effective in preventing the identified harm - is not currently satisfied. 



\section{The Third Condition of Penal Minimalism: Could the Treatment Track Avoid Undue Interference with the Liberties of the Accused/Offender?}

\section{Introduction}

In this chapter, I explore the third condition of penal minimalism: that the proposed reform should not infringe unduly on the liberties of the accused/offender. The focus of the chapter is the principle of proportionality. Proportionality between the seriousness of the offending and the severity of the sentence (or other resolution) protects the offender from undue interference by the state.

If the treatment track were disproportionately severe, it would of course interfere unduly with the liberty of the offender. If it were disproportionately lenient, it could interfere with the liberty of the accused by creating an incentive to plead guilty that could be hard for an accused to resist, thus coercing a guilty plea. ${ }^{1}$ Coercion to plead guilty may amount to a breach of a number of rights that protect the liberties of individuals, namely the presumption of innocence, freedom from self-incrimination, the right to examine witnesses, and possibly freedom from discrimination due to bias in the exercise of police and prosecutorial discretion. If the treatment track amounted to coercion to plead guilty, it may also coerce an accused into accepting psychological treatment against his will, in breach of the right to refuse medical treatment. ${ }^{2}$ The treatment track would also raise issues of consistency if it were disproportionately lenient: it would be unfair if those offenders who were admitted to the treatment track were thereby punished more leniently than those who went to prison for committing offences of similar seriousness.

Ideally, the treatment track would be equivalent in severity or onerousness to the sentence of imprisonment that would otherwise be imposed on a given offender. The qualitative differences between the two dispositions would then act as incentive enough for guilty pleas from those who admit offending and wish to undertake treatment and make amends while remaining in the community. With no actual difference in severity, choice is protected and the treatment track would not inherently coerce guilty pleas or acceptance of treatment, and its availability would not in itself result in inconsistency in the disposition of cases. I develop the theory on sentence severity as far as possible given the

\footnotetext{
McKinnon v Government of the United States and another [2008] UKHL 59.

$2 \quad$ Bill of Rights Act 1990, s 11.
} 
limits on existing empirical knowledge and identify the gaps in knowledge that need to be filled to reach that ideal position. I then consider whether, despite the efforts to maintain proportionality between the sentence that would ordinarily be imposed and the treatment track, there remains a risk of coercion of guilty pleas and acceptance of psychological treatment.

I draw on two models that have been developed to help to maintain proportionality when using different types of sentences: Wasik and von Hirsch's substitution model (which sits within a desert framework) ${ }^{3}$ and Morris and Tonry's interchangeability model (which sits within limiting retributivism). ${ }^{4}$ Neither is suitable in its entirety for the treatment track, but I incorporate aspects from each into a third model that I argue would enable the maintenance of proportionality if the treatment track were established.

The model I propose more closely resembles the interchangeability model, in that desert determines the overall severity of the treatment track, but how each participant spends his time in the treatment track is driven by utilitarian concerns (rehabilitation and amends). However, the way in which severity is assessed draws more from Wasik and von Hirsch's work than from Morris and Tonry's. The model I propose also applies to much more serious offences than Morris and Tonry's model was intended for, and accordingly can assist with the principled development of true alternatives to prison rather than with sentences that are less severe than prison.

In making the argument in this chapter, I assume that the sentence starting points set out in $R v A M$ (the Court of Appeal's guideline judgment for sexual violation) and the kinds of starting points adopted by sentencing judges for other types of sexual offences are commensurate with the seriousness of the offending for which they are used. ${ }^{5}$ My focus,

3 Martin Wasik and Andrew von Hirsch "Non-custodial Penalties and the Principles of Desert" [1988] Crim L Rev 555. See also Andrew von Hirsch, Martin Wasik and Judith Greene "Punishments in the Community and the Principles of Desert" (1989) 20 Rutgers Law Journal 595.

$4 \quad$ Norval Morris and Michael Tonry Between Prison and Probation: Intermediate Punishments in a Rational Sentencing System (Oxford University Press, New York, 1990). See also Michael Tonry "Proportionality, Parsimony and Interchangeability of Punishments" in Antony Duff and David Garland (eds) A Reader on Punishment (Oxford University Press, New York, 1994).

$5 \quad R v A M$ [2010] NZCA 114, [2010] 2 NZLR 750. Of less direct relevance, I note also that I assume for the purposes of this discussion that sentence starting points are currently fixed in a way that achieves or reflects ordinal proportionality and that the current three-step methodology for assessing offence seriousness is appropriate. My proposal is linked to the starting points, rather than to absolute numbers, so if the starting points were changed the limits adopted for the 
therefore, is on establishing whether equivalence can be achieved between that sentence start point and the treatment track, rather than on whether the treatment track is in its own right commensurate with the seriousness of the offending. That approach makes sense because the adequacy of the treatment track as a response to sexual offending would probably be compared with the usual sentence of imprisonment. Moreover, it is generally acknowledged that there is no single, absolute "deserved" sentence for a given offence. ${ }^{6}$ Any consideration of whether a particular sentence or resolution is proportionate to offending is always relative to the sentences imposed for other instances of offending. ${ }^{7}$ It is easier to think about what kind of resolution might be comparable in severity or onerousness to a particular sentence of imprisonment than it is to conjure up a proportionate resolution in a vacuum.

I acknowledge also that the judgements I make in relation to what is and is not proportionate, and the recommendations I make about how proportionality should be built into the treatment track, are ultimately subjective. As much as I wanted to have a perfectly reasoned and logical argument, there came a point at which I had to choose some numbers so I had somewhere to start. Someone else might quite reasonably have chosen different numbers. ${ }^{8}$ If nothing else, my work should provide a good platform for further discussion of proportionality in different kinds of resolutions.

The first task is to create a framework that will enable us to compare the severity of the treatment track with a sentence of imprisonment. I argue in Part II that the severity of sentences and other types of resolutions of criminal offending should be understood along two dimensions: intrusiveness (the number and importance of the interests interfered with, and the degree of that interference) and accountability (the extent to which the resolution holds the offender accountable, which I argue is the positive function of proportionality). I discuss how useful each dimension is for understanding what makes the treatment track onerous and compare the treatment track to a sentence of imprisonment along each dimension.

treatment track could be changed accordingly. If the methodology itself changed, however, my proposal would need to be reconsidered.

6 Andrew von Hirsch "Proportionality in the Philosophy of Punishment" (1992) 16 Crime and Justice 55 at 77.

Ibid.

This issue has been recognised in New Zealand before, in the context of establishing ordinal proportionality for maximum penalties: Law Commission Maximum Penalties for Criminal Offences (NZLC SP21) at 3.7. 
In Part III, I suggest that when used for a period of between two and eight years, the treatment track can be equivalent in severity or onerousness to a prison sentence of the same length, and the two resolutions may accordingly be used interchangeably without breaching the proportionality principle. Using the treatment track as an alternative to a prison sentence of less than two years would be disproportionately severe, and using it in place of a prison sentence of more than eight years would be disproportionately lenient. I recommend that the treatment track only be available for offending that would ordinarily attract an end sentence of more than two years and a starting point of no more than eight years' imprisonment. Without a way of measuring sentence severity along the two dimensions, however, the proposal remains an educated guess.

I turn my attention in Part IV to ensuring that the requirements imposed on individual treatment track participants are not disproportionately severe. I recommend that the time to which any individual participant should be subject to the treatment track should be the term of imprisonment that $A M$ (for sexual violation) and accepted sentencing levels (for other sexual offences) specify as a starting point for that person's offending, minus the 25 per cent discount available for an early guilty plea. ${ }^{9}$ I recommend that the requirements be determined in accordance with the purpose of each component, subject to parsimony or proportionality as limiting principles. The treatment and risk management components should be governed by the Risk, Need and Responsivity model, of which parsimony is an integral part. The amends component is compensatory but should be limited by proportionality with offence seriousness. Adopting these recommendations would help to ensure that the treatment track is not disproportionately intrusive or severe. This is particularly important in the treatment track context because, as discussed in the previous chapter, anything that happens in the period between conviction and sentence is currently unregulated, giving scope for excessive interference with the liberty of treatment track participants.

In Part V, I consider whether, despite attempts at maintaining proportionality, there remains a risk that the treatment track would coerce guilty pleas and acceptance of psychological treatment.

\section{Measuring Sentence Severity}


There is no established way to measure or compare the severity of different types of sentences. It is assumed that prison is more severe than other types of sentences or resolutions of criminal offending, ${ }^{10}$ but this assumption has not been subject to a great deal of attention. The ability to compare the severity or onerousness of different types of sentences is the first - and most difficult - step to working out whether it is possible to establish a resolution such as the treatment track in a way that respects the principle of proportionality.

In this part, I propose two dimensions for measuring sentence severity, drawing on the theoretical development undertaken by Wasik and von Hirsch (in relation to the intrusiveness dimension) and the spark of an idea in the work of Morris and Tonry (in relation to the accountability dimension). I explore how useful each dimension is for understanding the severity of the treatment track and a sentence of imprisonment and compare the two resolutions along each dimension as far as is possible at this point.

\section{A Intrusiveness}

Wasik and von Hirsch suggested that the severity of different types of sentences could be measured by the extent to which they intrude on the offender's interests: ${ }^{11}$

[R]elative severity should be measured by way of the normative importance of the personal interests compromised by operation of the penalty. The more basic the interests infringed, and the greater the extent of their infringement, the more severe the penalty. According to the extent to which the penalty affects a person's survival, physical integrity, psychological well-being, liberty, autonomy, goods, money or reputation, the various penalties could be ranked in order of relative intrusiveness. Regard could be had to the jurisprudential writings on the relative importance of interests, including Feinberg's three-fold grading of welfare, security, and accumulative interests.

No such comprehensive scale has yet been developed, and as Wasik and von Hirsch noted, "any such definition and ranking of interests would by no means be precise." 12 However, parallel work that has been undertaken on measuring offence seriousness could

\footnotetext{
10 Section 10A of the Sentencing Act sets out a hierarchy of sentences with imprisonment at the top, but there has been little theoretical engagement with whether that hierarchy is correct.

11 Wasik and von Hirsch, above n 3, at 564-565.

$12 \quad$ At 565.
} 
provide guidance as to methodology for this task. ${ }^{13}$ The validity of the scale could be improved by research into how those subject to the different sentences/components of sentences or resolutions experience them. The average intrusiveness of each sentence or component should then inform the scale. ${ }^{14}$

The intrusiveness measure would be particularly useful for assessing the severity of sentences that incapacitate the offender (interfering with autonomy, freedom of movement, freedom of association, and privacy). It is clear that a term of imprisonment would be more intrusive in this sense than the treatment track, by virtue of the offender being in custody rather than in the community.

The intrusiveness dimension can also capture interference with the material interests of the offender, whether that is by interference with the ability to accumulate and enjoy property while imprisoned, or of specifically economic sanctions such as a fine or community work (the latter of which may also be required of treatment track participants as part of the amends component). ${ }^{15}$ Overall the economic impact of the two sentences may be similar, as treatment track participants would still be required to support themselves and any dependants while participating in the treatment track and must make amends of some sort.

When it comes to the rehabilitative and restorative components of the treatment track, however, intrusiveness becomes less useful as a measure of severity. It is likely to be

13 Andrew Von Hirsch and Nils Jareborg "Gauging Criminal Harm: A Living-Standard Analysis" (1991) 11 OJLS 1. For a project in the New Zealand context, see Law Commission, above $n 8$.

14 A rash of recent empirical research has made the point that individuals experience punishment in different ways and that the same punishment can cause different degrees of suffering (for example Adam Kolber "The Subjective Experience of Punishment" (2009) 109 Columbia Law Review 182; Adam Kolber "The Comparative Nature of Punishment" (2009) 89 BU L Rev 1565; John Bronsteen, Christopher Buccafusco and Jonathan Masur "Retribution and the Experience of Punishment" (2010) 98 Cal L Rev 1463; Christopher Wildeman, Kristin Turney and Jason Schnittker "The Hedonic Consequences of Punishment Revisited" (2014) 104 Crim L \& Criminology 133). My position is that it is the average intrusiveness that is of interest and that sentencing proportionately does not require the courts to attempt to tailor punishments to cause a particular amount of suffering to individuals (for further discussion see David Gray "Punishment as Suffering" (2010) 63 Vand L Rev 1619; Dan Markel and Chad Flanders "Bentham on Stilts: The Bare Relevance of Subjectivity to Retributive Justice" (2010) 98 Cal L Rev 907 and Dan Markel, Chad Flanders and David Gray "Beyond Experience: Getting Retributive Justice Right" (2011) 99 Cal L Rev 605).

15 Wasik and von Hirsch, above n 3. 
much more difficult to measure the severity of other components of the treatment track by reference to their degree of intrusion into the offender's interests. Components such as restorative justice and treatment undoubtedly place a burden on the offender, but what makes them onerous is not fully captured by an interests-based analysis.

Restorative justice involves some restriction on the offender's autonomy because it requires him to undertake any necessary preparation for the process, attend the conference or panel and participate appropriately, and may result in an economic sanction in the form of reparation of some sort to the victim and the community. However, the essence of restorative justice - facing up to the harm caused and taking responsibility for it - is difficult to measure as an intrusion into interests. While participating in restorative justice is likely to cause some psychological discomfort, taking responsibility for wrongdoing in a safe environment may be considered likely to improve rather than reduce the offender's psychological well-being.

Similarly, the onerousness of rehabilitation cannot be captured by the degree of interference with interests. Rehabilitation infringes on offenders' autonomy in the sense that successful completion of a programme requires a commitment to attend and participate in the programme, and to demonstrate change. That commitment may be significant for some of the longer and more intensive programmes. Nonetheless, the onerousness of rehabilitation is not fully captured by its intrusion into autonomy. If successful, rehabilitation is a process of fundamental change in patterns of thinking and behaviour that contribute to offending. The process of making and maintaining those changes is demanding. The requirement that a person demonstrate change is a substantial interference with the offender's autonomy. ${ }^{16}$ An alternative perspective, however, is that the offender's autonomy is increased because effective rehabilitation expands the range of choices available by creating an opportunity for the offender to reflect on personal goals and develop the tools to achieve those goals in pro-social ways.

Further, participation in rehabilitation is likely to be challenging and distressing for offenders at times, which is part of what makes it onerous, and so could be thought of as infringing on the offender's interest in psychological well-being. However, rehabilitation is likely to result in improved psychological well-being, in the sense that participants are likely to be able to get their needs met more effectively and with fewer harmful

16 See for example, Francis Allen "The Decline of the Rehabilitative Ideal” in Andrew von Hirsch, Andrew Ashworth and Julian Roberts (eds) Principled Sentencing: Readings on Theory and Policy ( $3^{\text {rd }}$ ed, Hart Publishing, Portland, 2009) at 11-12. 
consequences for themselves than if they continued to commit offences. The onerousness of rehabilitation should not then be measured only by negative impact on the offender's interests in autonomy and psychological well-being.

A second dimension is needed to fully capture what makes rehabilitative and restorative sentences or components of sentences onerous. I suggest that this dimension is accountability.

\section{B Accountability}

In this part, I argue that the extent to which the sentence or the component of the sentence holds offenders accountable for their offending should be the second dimension of sentence severity. I note the origins of this idea in the literature addressing different ways of thinking about sentence severity, develop the idea further, then illustrate its application to the treatment track and to imprisonment.

Morris and Tonry suggested possible ways of thinking about sentence severity, in the context of a discussion about equivalence in severity between different types of sentences. The first way of thinking about equivalence they suggested was equivalence from the offender's perspective, which they said could be measured in pain and suffering or intrusion into autonomy. The second was more about the appearance of equivalence, and turns on what the "uninformed public" would generally regard as an acceptable range of punishments for a given offence and offender. ${ }^{17}$

Both ways of thinking about equivalence raise issues when we try to apply them to the treatment track. Morris and Tonry expanded slightly on their understanding of equivalence from the offender's perspective, saying: ${ }^{18}$

Equivalence from an offender's perspective can be measured either in pain or suffering or in intrusion into autonomy. In theory, no doubt much could be said about differences between measures of pain and measures of intrusiveness. In practice, whether a year's incarceration or an intermediate punishment package is weighed in visceral terms of pain or unpleasantness or in more abstract analytical terms of intrusion on autonomy is not likely to matter. Criminal punishments are unpleasant burdens, however conceptualized, and it is principally in terms of this onus that punishments must be roughly equivalent.

$17 \quad$ Morris and Tonry, above n 4, at 100.

18 At 100. 
This way of thinking about severity, however, raises the same issues as Wasik and von Hirsch's interests-based analysis when applied to the treatment track. What makes the treatment track onerous is not fully captured by pain or suffering, nor necessarily by intrusion into autonomy. Something more is needed to understand what makes the restorative and rehabilitative components of the treatment track onerous.

In terms of acceptability to the "uninformed public", we might imagine that the public would never accept that the treatment track is equivalent to a sentence of imprisonment, at least without being informed of the reasons for its use, what it actually involves, and what makes it difficult for participants. I am also not sure that the uninformed public should be the arbiter of justice.

Morris and Tonry did propose a third way of thinking about equivalence: equivalence of function. Achieving rough equivalence of function means asking in each case what function the sentence is to serve, and then imposing a sentence intended to achieve that. ${ }^{19}$ Equivalence of function in that sense may be useful in deciding among sentences within the range of not undeserved sentences, but does not help to determine whether the treatment track is of roughly equivalent penal bite to the range of terms of imprisonment that might otherwise be imposed (because a sentence intended to deter may need to be substantially more severe than one intended to convey the blameworthiness of the offender, for example).

However, if we think about equivalence of function in terms of the functions that proportionality in sentencing is supposed to achieve, we may get closer to an answer about whether the treatment track can be thought of as roughly equivalent to a prison sentence. Thinking about how well the treatment track fulfils the functions of proportionate sentencing, alongside its degree of interference with the offender's interests, might help to determine whether the treatment track could be roughly equivalent to a prison sentence.

Morris and Tonry did not ascribe a positive function to proportionate sentencing. They treated proportionality purely as a limiting factor. However, in most liberal sentencing theories, proportionality does have a positive role, and I think we lose something important if we ignore that. Having said that, the roles that have so far been ascribed to proportionality are not, in my view, very convincing. I will discuss the role of proportionality in three sentencing theories, arguing that each is deficient either $19 \quad$ At $103-104$. 
empirically or as a matter of practical application. I will then put forward an alternative function of proportionality, an obligation-based conception of accountability. I argue that accountability should be seen as the second dimension of sentence severity.

\section{Existing accounts of the functions of proportionality}

In this section I critique three retributive accounts of the function of proportionality: the intuitive account, desert theory, and vindication of the victim.

\section{a) Intuitive accounts}

The first possibility is a purely retributive understanding of the function of proportionality: proportionate sentencing is good in itself, rather than because it achieves some other good. Moore, for example, has argued that the reason for punishing offenders is because morally it is the right thing to do. Sentences should be proportionate to the severity of the offending because proportionate punishment is just. ${ }^{20}$

Moore's claim that people intuitively want offenders to be punished because that is what they deserve (not because punishment serves some other good) is most likely to hold true in respect of serious offences like sexual violence, indicating that the intuitive claim perhaps ought to be taken into account in the design of the treatment track. But how do we know whether the treatment track is the punishment that is deserved? Von Hirsch refers to Moore's answer to this question as the "heroic intuitionist stance", where "if only we ponder hard enough, we will perceive deserved quanta of punishments." ${ }^{21}$ The difficulties of ascertaining how proportionality should be measured in the treatment track context discussed throughout this chapter demonstrate the limits of the intuitionist stance. After five years of hard pondering, I still have mixed feelings about whether the treatment track (or, for that matter, the prison term usually imposed) is a just punishment. Accordingly, I will put the purely retributive account of the function of proportionality to one side and consider a mixed account of proportionality, von Hirsch's desert theory.

b) Desert theory

20 Michael Moore "The Moral Worth of Retribution" in Andrew von Hirsch, Andrew Ashworth and Julian Roberts (eds) Principled Sentencing: Readings on Theory and Policy (3 ed, Hart Publishing, 2009) at 110-114.

21 Andrew von Hirsch "Proportionate Sentences: A Desert Perspective" in Andrew von Hirsch, Andrew Ashworth and Julian Roberts (eds) Principled Sentencing: Readings on Theory and Policy (3 ed, Hart Publishing, Oxford, 2009) at 120. 
In desert theory, the primary function of proportionate sentencing is censure. The severity of the sentence conveys how blameworthy the offender is. ${ }^{22}$ It is the "hard treatment" (deprivation) imposed on the offender that communicates the blameworthiness. The hard treatment also has a back-up function as a "prudential disincentive" (a reason to refrain from offending). The "prudential disincentive" should not be so severe as to "drown out" the moral appeal of the censure; it is not conceptualised as a deterrent, which, von Hirsch argues, fails to treat people as moral agents, but as something to help us resist the temptation to offend that arises from time to time even though we know that offending is wrong. ${ }^{23}$

On the face of it, using the treatment track could disrupt the censuring function of proportionality. If the treatment track is perceived as more lenient than a sentence of imprisonment, the message may be interpreted as the offender being less blameworthy than he is. This would be particularly problematic if the treatment track were used primarily for "everyday rapes", while a sentence of imprisonment continued to be the norm for "real rapes". If a two-tier system was created, it could undermine progress towards having "everyday rapes" acknowledged as serious criminal offences. On the other hand, it could be argued that if the treatment track is to be used primarily in cases that would not ordinarily result in a conviction at all - that is, where a person can sexually assault another with impunity - any formal response is better than the status quo. $^{24}$

In my view, censure is a partial description of the positive function of proportionality: I think it is important, but not the whole answer. I put desert theory aside and move on to consider a third retributive theory, this time an expressive one.

c) Vindicating the victim

Like von Hirsch, Hampton was interested in the message conveyed by the sentence imposed, but focused not on what the sentence says about the blameworthiness of the offender, but about the relative worth of the victim and the offender. She started from the point that all people are of equal intrinsic worth, and that a person's intrinsic worth gives

At 118 .

At 118 .

This is the argument made in Chapter 5 in relation to the adequacy of the empirical basis for establishing a treatment track with the aim of bringing into the criminal justice process men who have sexually assaulted an adult and whose offending would currently not be reported or result in a conviction. 
rise to certain entitlements, such as life, autonomy, bodily integrity, and possession of lawfully obtained property. ${ }^{25}$ Criminal offences (or at least those wrongs with which the criminal law ought to be concerned) diminish the victim: in committing the offence, the offender fails to respect the victim's entitlements (interfering with the victim's realisation of her worth, in other words her ability to secure her entitlements) and represent the victim as being worth less than she is (interfering with the acknowledgement of the victim's worth, whether by the victim herself or by others, and possibly extending beyond the victim to others like her - all women, for example). ${ }^{26}$ In committing the offence, the offender also elevates his own worth above its true level. ${ }^{27}$

A retributive response, Hampton argued, is required to vindicate the value of the victim and re-establish the equality of the victim and the offender. The response should correct the false message about the worth of the victim (re-establish the acknowledgment of the victim's worth) and repair the damage done to the victim's realisation of her value (reestablish the victim's ability to live in conditions in which her entitlements will be respected). The response must also, however, respect the intrinsic worth of the offender. $^{28}$

Interestingly, Hampton argued that the retributive response need not be punishment: the response is retributive if it repairs the damage done to the acknowledgement of the victim's value and the victim's realisation of her value. ${ }^{29}$ Accordingly, compensation paid by the offender to the victim can be understood as retributive, as can an apology. ${ }^{30}$ It should be noted that Hampton did not define "punishment" in her article. Presumably, however, her understanding of retribution is wider than, say, the interests-based analysis expounded by Wasik and von Hirsch. That wider understanding of retribution is perhaps useful in the context of the treatment track, where what makes the core components of the treatment track onerous is not necessarily captured by the interests-based analysis.

Proportionality is important in Hampton's theory: as offending increases in seriousness, so does the degree of diminishment of the victim and the gap between the victim and the

\begin{tabular}{l}
\hline 25 Jean Hampton “Correcting Harms versus Righting Wrongs: The Goal of Retribution” (1992) 39 \\
UCLA L Rev 1659 at $1666-1668$. \\
$26 \quad$ At $1672-1684$. \\
$28 \quad$ At 1677. \\
29 \\
30 \\
At $1684-1687$. \\
At $1694-1698$.
\end{tabular}


offender, and the more substantial the response must therefore be to close that gap. ${ }^{31}$ For Hampton, the problem with a response that is too lenient is that it confirms or exacerbates the diminishment of the victim's value effected by the offending. ${ }^{32}$ The question, then, is whether the treatment track runs that risk.

Unfortunately for my purposes, Hampton's very interesting work provided little guidance on how to answer that question. She emphasised the difficulties of constructing a response that annuls the diminishment of the victim while respecting the worth of the offender, and noted that creating such a response may require creativity and flexibility. ${ }^{33}$ She did say that the criminal justice process does not currently do retribution well, which implies that she did not consider that imprisonment (as the default sanction for most offending) adequately repairs the damage done by the offending to the realisation of the victim's value or the acknowledgement of her value. The core elements of the treatment track, on the other hand, might fulfil Hampton's vision of a retributive response - if not entirely, then at least to a greater extent than imprisonment.

Restorative justice aims to restore "right relationship" between the victim and the offender. ${ }^{34}$ Participating in a dialogue with the victim gives the offender the opportunity to recognise the personhood of the victim, to empathise with her, and to apologise for his wrongdoing. If those outcomes do indeed occur, restorative justice processes help to reestablish the equality of the victim and the offender. The fact that the process also involves the people closest to the victim and the offender, and sometimes also representatives of the wider community, can extend the reach of the acknowledgement of the victim's value beyond the victim-offender dyad to an audience made of up the people most important to them.

The requirements that treatment track participants comply with risk management conditions and participate in treatment could also be understood as having an expressive quality that serves to re-establish equality between the victim and the offender. Imposing risk management conditions indicates that the offender has abused his freedom and can no longer be trusted in the community without restriction and monitoring. Similarly, requiring a person to participate in treatment indicates that his ways of thinking and 
behaving are problematic and must be changed. These messages are not directly about the worth of the victim, but they do convey that the offender behaved towards the victim in a way that is unacceptable given her intrinsic worth. They also indicate that the victim and others like her are worthy of protection from the offender.

Hampton notes that it is more difficult to conceive of a retributive response that repairs the damage to the victim's ability to realise her value. ${ }^{35}$ If that can be done, it would probably be achieved primarily through restorative justice. Hampton argues that requiring the offender to make amends to the victim can enable the victim to realise her value (by compensating her for harm and loss suffered as a result of the offending). ${ }^{36}$ The treatment and risk management components of the treatment track, which are aimed at containing and reducing the risk of reoffending, could also help to repair the damage done to the victim's realisation of her value: imposing those requirements not only conveys to the victim, the offender, and others that she and others like her are entitled to respect for her autonomy and bodily integrity, but makes it more likely that the offender will actually respect those entitlements. It also allows the victim (and others like her) the peace of mind of knowing that something is being done to contain and reduce the risk posed by the offender, allowing them to exercise their entitlements with less fear of the offender.

It is difficult to know, however, whether the components of the treatment track would be adequate to repair the diminishment of the victim and re-establish equality between the victim and the offender. Hampton's theory is objective: the diminishment of the victim's value does not have to be perceived by the victim to have occurred, and the degree of diminishment is not determined by the psychological, physical, or material harm or loss experienced by the victim but by the message that could be "read off of" the criminal behaviour. $^{37}$ Accordingly, the retributive response should presumably be understood objectively also. It is not whether the victim herself believes the response adequately reestablishes the acknowledgement of her worth and repairs the damage to her ability to realise her worth, but whether it would generally be understood as adequate to achieve those aims. Unfortunately, we do not currently have any systematic research on what people perceive responses to offending (or indeed the offending itself) to convey. We would need some investigation (preferably local, and involving a diverse range of

$35 \quad$ Hampton, above n 25, at 1697.

$36 \quad$ At 1697.

$37 \quad$ At $1671-1672$. 
participants, as the meanings of behaviour vary across cultures ${ }^{38}$ ) to determine what would be an adequate retributive response. There is also the possibility that imprisonment is understood as being an appropriate (and possibly the only appropriate) retributive response for serious offending, because imprisonment is the norm and may be perceived as the way that false messages about the relative worth of the victim and offender are corrected (if indeed people do understand offending and retribution in that way).

The unanswered questions about Hampton's theory, however, mean that it is of limited help in determining whether the treatment track could fulfil the functions of proportionate sentencing as well or better than a sentence of imprisonment.

In the next section, I propose a fourth way of thinking about the functions of proportionality, which I argue is more useful in the context of the treatment track than established retributive theories.

\section{Proportionality as accountability}

Holding offenders accountable is one of the purposes of sentencing listed in s 7(1) of the Sentencing Act 2002. "Accountability" is not defined in the Act itself or explored further in the case law, but Adams on Criminal Law interprets the accountability purpose of sentencing as a codification of the retributive justification for punishment: punishment is imposed because it is deserved and its severity should be commensurate with the seriousness of the offending. ${ }^{39}$

While accountability and proportionate punishment have been equated intuitively, the relationship between the two concepts has not been explored explicitly. Probably, the relationship is that sentences at the top of the hierarchy (prison) should be used to hold offenders accountable for more serious offending, whereas the less restrictive sentences towards the bottom of the hierarchy (community work, fines) are sufficient to hold offenders accountable for less serious offending. At the top of the hierarchy, longer terms of imprisonment are needed to hold offenders accountable for more serious offending, whereas shorter terms suffice to hold offenders accountable for less serious offending. I will call that understanding of accountability "accountability-as-retribution".

\footnotetext{
$38 \quad$ At $1669-1671$.

39 Bruce Robertson (ed) Adams on Criminal Law (online looseleaf ed, Brookers) at [SA7.01].
} 
In my view accountability-as-retribution is an unhelpfully limited way of understanding accountability. As argued in the discussion of the limitations of the intrusiveness dimension, accountability-as-retribution does not capture the ways in which sentences/components of sentences imposed for purposes other than retribution hold offenders accountable. ${ }^{40}$ Nor does accountability-as-retribution capture the onerousness of sentences/components of sentences that are onerous for reasons other than their intrusion into the interests of the offender.

The definition of accountability I adopt instead draws on Zehr's conceptualisation of accountability in the context of restorative justice in his foundational text Changing Lenses. $^{41}$

For Zehr, the basis of the restorative conception of accountability is the obligation owed by the offender to the victim because of the offending. ${ }^{42}$ Restorative accountability, he argues, has both a cognitive component and a behavioural one. ${ }^{43}$ The cognitive component of accountability aims to get offenders to understand the impact of the offending on the victim and to take responsibility for the offending. ${ }^{44}$ Taking responsibility means acknowledging that the behaviour resulted from a choice that could have been made differently. ${ }^{45}$ The behavioural component involves the offender taking action to make things right (to repay the debt owed to the victim in concrete ways). ${ }^{46}$

In the context of the treatment track, holding offenders accountable means ensuring that they fulfil the obligations to the victim and the community arising from the offending. There are three principal obligations. The first is to understand and take responsibility for their wrongdoing and the harm caused. Taking responsibility in this context means recognising that there were choices other than offending open to the offender, and that the harm experienced by the victim and others is a result of the offender's choices. The second obligation is to make amends, as far as possible, for the harm done. The third

\footnotetext{
See Part IIA above.

41 Howard Zehr Changing Lenses: A New Focus for Crime and Justice (Herald Press, Pennsylvania, 1990).

42 At 196-199. See also Mark Umbreit "Holding Juvenile Offenders Accountable: A Restorative Justice Perspective" (1995) 46 Juv \& Fam Ct J 31 at 32-34.

43 Zehr, above n 41, at 32-34.

$44 \quad$ Ibid.

45 Office of Juvenile Justice and Delinquency Prevention Guide for Implementing the Balanced and Restorative Justice Model (Office of Justice Programs, Washington DC, 1998) at 9.

46 Zehr, above n 41, at 201-202; Umbreit, above n 42, at 32.
} 
obligation is to take steps to reduce the risk of reoffending. That obligation is not explicitly part of Zehr's discussion of accountability, but I suggest must be included for accountability to be meaningful. I discuss these obligations in more detail now.

a) To understand and take responsibility for the wrongdoing and harm caused In terms of acknowledging having committed the offence, treatment track participants must have pleaded guilty to the offence (admitting the basic elements of the offence). During the treatment programme, however, they are required to disclose the details of their offending to the group and the therapists. That acknowledgement of exactly what they did, thought, and felt before, during, and after the offence may be thought of as achieving a higher level of accountability than a guilty plea on its own.

Throughout the Adult Sex Offender Treatment Programme (ASOTP), participants are required to accept responsibility for their offending. ${ }^{47}$ The programme makes participants aware of and challenges cognitive distortions (including rape myths) that minimise the offending or blame it on other people or on circumstances external to the offender. Participants also become aware of decisions they made in the lead-up to the offending, challenging the idea that the offending "just happened" and instead emphasising responsibility for the choices.

Restorative processes usually involve the victim (or representatives of the victim or a surrogate victim) talking with offenders about the harm they have experienced as a result of the offending. The process aims to get offenders to understand the harm they have caused and to accept that the harm is a result of the decisions they made.

Sexual offenders sentenced to prison in the ordinary way may also take responsibility for their offending and come to understand the harm they have caused, particularly if they undertake treatment for their sexual offending while in prison or on parole or if they undertake pre-sentence restorative justice. An offender sentenced to prison may not participate in either restorative justice or rehabilitation, either because he does not have access to it or because he chooses not to participate. Only a minority of men imprisoned for a sexual offence against an adult participate in the ASOTP, because they must acknowledge having committed the offence, agree to participate (which may involve moving to one of the three prisons in which the programme is delivered), be assessed as being at medium-high or high risk of sexual reoffending, and have a low enough security

47 Adult Sex Offender Treatment Programme Manual (Department of Corrections, Wellington, 2009) (on file with author). 
classification to be eligible. There is no equivalent of the ASOTP available to parolees. Generally then, men sentenced to imprisonment are less likely to actively take responsibility for their offending and demonstrate understanding of the harm they have caused than treatment track participants would, although of course it does vary depending on what the prisoner does pre-sentence, while serving the term of imprisonment, and while on parole.

b) To make amends for the harm done

Restorative processes enable offenders to fulfil their obligation to make amends to the victim and the community for the harm they have done. The kinds of amends made can vary from case to case, but should be acceptable to all parties. The fact that the treatment track is community-based may facilitate plans to make amends, particularly if it involves financial reparation or some kind of community work that would not be possible if the offender were in prison.

Again, it is likely that participants in the treatment track would make amends in a much more extensive way than most prisoners would be able to do. Of course it is possible to think of serving the prison sentence itself as a form of making amends, but in this context I am thinking of amends as some direct form of compensation to the victim or to community for the harm done.

c) To take steps to reduce the risk of reoffending

Treatment aims to equip participants with the skills to behave differently in the future and to promote in participants a sense of responsibility for putting those skills into practice. Participants learn a variety of interpersonal and emotional regulation skills throughout the programme. In the last phase of the programme they create a relapse prevention plan that records their risk factors and strategies to combat them.

The risk management conditions imposed also ensure that offenders fulfil their obligation to change their behaviour. The risk management conditions are there to contain the risk posed by the offender until risk can be reduced to a safe level by treatment. Some conditions may remain in place for the duration of the treatment track, even after treatment has been completed, if that is necessary to prevent reoffending. Risk management conditions are relaxed as participants progress in treatment and prove that they can remain safely in the community. Participants earn their freedom back, and in that way the conditions hold offenders accountable. 
As discussed earlier, all treatment track participants will complete at least some rehabilitation directed at reducing their likelihood of reoffending, whereas some prisoners may not complete any rehabilitation and others may not complete any rehabilitation specifically directed at reducing the likelihood of sexual offending. In that way, the treatment track generally requires more of participants than a sentence of imprisonment.

Similarly, prisoners do earn their freedom back to some extent: they must behave well enough in prison and develop a good enough release plan if they are to be released on parole before the end of their sentence, and must comply with parole conditions to remain in the community. Those who complete sex offender treatment will create a relapse prevention plan. In the treatment track, however, compliance with risk management conditions will be more demanding than for prisoners and parolees because the participant is in the community the whole time, and therefore has many more opportunities to act in breach of the conditions. More discipline, determination and skills are therefore required of treatment track participants to maintain their compliance with the conditions. They must also demonstrate compliance over the full term of the treatment track.

Overall, the treatment track would hold offenders accountable for their offending to a substantially greater degree than a sentence of imprisonment, even allowing for the overlap in some of the components for some prisoners. The treatment track could be thought of as holding participants accountable in a much more active sense than a sentence of imprisonment. When a person is in the community rather than in prison, undertaking treatment and complying with risk management conditions is more effortful than when in prison, because the person has the opportunity to do otherwise. Selfmanagement and self-control are required to a greater extent than in prison, where people have little choice but to do what they are told. In the community people must actively take responsibility for their own lives, whereas in prison almost all responsibility is taken away from them. This extends to supporting dependants as well, for those treatment track participants who have dependant family members. In the community, there is the opportunity, and perhaps the expectation, to contribute to family or whanau life in a way that is not possible while in prison. This extra level of responsibility, though not specifically related to the offending, adds to the active character of the accountability that could be achieved by the treatment track.

Moreover, it is riskier to participate in the treatment track than to simply go to prison, because there is always the background risk of being imprisoned anyway if they breach 
conditions or do not make sufficient progress in treatment. That additional burden of uncertainty and risk also contributes to the active character of accountability in the treatment track, compared with the passivity of imprisonment.

\section{Measuring accountability}

As with intrusiveness, no scale yet exists to measure the degree to which different types of sentences hold offenders accountable. It is possible to develop one, however, using the offender's observable behaviour, as outlined in section two. That is a fairer and more straightforward way of measuring sentence severity than the more abstract ideas critiqued in section one. Further work is required to develop and validate an accountability scale.

Having argued that sentence severity should be measured along two dimensions, I discuss in Part III how different types of sentences or other resolutions could be used in a way that maintains proportionality between them.

\section{Proportionality Between Different Types of Sentences}

I argue in this section that the seriousness of the offending should determine when the treatment track should be available to be used interchangeably with imprisonment and also should determine the time for which a person should be subject to the treatment track. Specifically, I suggest that sexual offending of the degree of seriousness that would ordinarily attract a starting point of between two and eight years' imprisonment should be eligible for the treatment track. Between those time points, the average requirements of the treatment track can be roughly equivalent in severity to the average requirements of a sentence of imprisonment, when both intrusiveness and accountability are taken into account.

In making the argument in this section, I draw on the two approaches introduced in Part II to maintaining proportionality between different types of sentencing. The model I propose for the treatment track is more similar to Morris and Tonry's interchangeability approach than to Wasik and von Hirsch's substitution approach, but it incorporates the more principled approach to desert advocated by Wasik and von Hirsch. I begin by explaining why, despite being the clearer and better reasoned approach, Wasik and von Hirsch's substitution approach is less helpful for the treatment track context. I then move on to illustrate how Morris and Tonry's interchangeability approach can be adapted to 
guide the maintenance of proportionality between the treatment track and the sentence of imprisonment that would ordinarily be imposed.

\section{A Wasik and von Hirsch's substitution approach}

In a 1988 article, Wasik and von Hirsch considered how non-custodial penalties might be substituted for sentences of imprisonment while maintaining proportionality. ${ }^{48}$ They applied the penal rationale of desert to the use of non-custodial penalties. Desert theory justifies punishment on the basis that the hard treatment (deprivation) conveys censure and provides an extra reason for people to refrain from committing offences. The hard treatment must be proportionate to the offender's blameworthiness, so that it conveys the right amount of censure. ${ }^{49}$

Wasik and von Hirsch noted that desert theory allows most offences to be dealt with by non-custodial sentences: parsimony in overall sentencing levels is a feature of the theory. ${ }^{50}$ They also noted that desert theory allows for substitution of sentences, because it prescribes the severity, not the type, of sentence to be imposed: ${ }^{51}$

If $\mathrm{A}$ is a sanction that is appropriate for crimes of a given degree of seriousness, and $\mathrm{B}$ is a sanction of another type that is approximately of equal severity, then B can be substituted for A without infringing desert constraints. One may then even choose between the two severity-equivalent sanctions, A and B, on utilitarian grounds since doing so would not alter the onerousness of the punishment.

Wasik and von Hirsch suggested that five penalty bands be created (mild, lowerintermediate, upper-intermediate, moderately severe, and severe). A grid would indicate the appropriate number of "penalty units" for each penalty band. For example, the mild penalty band would be worth 1-20 penalty units, while at the other end of the scale, the severe penalty band would be worth 121-200 penalty units. In a separate scale, each type of penalty would be assigned a number of "penalty units", reflecting the relative severity of each type of penalty. Any penalty or combination of penalties would be permissible, as long as the sentence carries the appropriate number of penalty units for the penalty band required by the seriousness of the offending. ${ }^{52}$

\footnotetext{
$48 \quad$ Wasik and von Hirsch, above $\mathrm{n} 3$.

49 von Hirsch, above n 21, at 116-119.

$50 \quad$ von Hirsch and Wasik, above n 348, at 558.

51 Ibid.

$52 \quad$ At $559-561$.
} 
In the partial substitution model, a presumptive sanction would be prescribed for each band. However, the presumptive sanction could be replaced by a substitute penalty of equivalent severity for certain stated reasons, such as crime prevention. No substitutions would be allowable in the mild penalty band (in which Wasik and von Hirsch considered a judicial caution to be the appropriate sentence) or the severe penalty band (in which they suggested that a sentence of imprisonment of six months or longer be prescribed ${ }^{53}$ ). That is, in cases where the offending is of a degree of seriousness that makes placement into an intermediate or moderately severe penalty band appropriate, a treatment track order could be substituted.

If the partial substitution model were to be applied to the treatment track, the anchoring of the penalty bands would need to be adjusted to allow for substitution at a higher level. ${ }^{54}$ Six months' imprisonment cannot be said to be a severe sentence in New Zealand's current sentencing regime, and in fact the Sentencing Act 2002 already allows for the substitution of a sentence of home detention for up to two years' imprisonment. ${ }^{55}$ The treatment track is intended to be an alternative to imprisonment, not to existing community-based sentences, so a much higher anchoring of the "severe" band would be necessary for the treatment track to achieve that aim. It is clear that the cut-off for nonsubstitution would need to be rather higher than six months' imprisonment if the treatment track is to be available for any sexual offending other than relatively minor indecent assaults. Establishing the exact cut-off for non-substitution is one task that would need to be undertaken if the partial substitution model were to be applied to the treatment track. The non-substitution cut-off would be the point at which the sentence of imprisonment to which the offender would normally be sentenced cannot be translated into a community-based sentence of equivalent severity.

I like Wasik and von Hirsch's substitution approach because it is theoretically sound (being grounded in desert theory, which is well developed and well-reasoned) and logically presented. However, it is incongruent to try to apply a deontological model to a

\footnotetext{
53 The six month cut-off should be understood in the context of the importance to desert theory, as originally envisaged, of decarceration and, for those offences where a prison sentence was necessary, a reduction in the length of prison sentences. The overarching aim of the committee that developed and recommended the desert model was to reduce the harm done by the state. It abandoned the rehabilitative ideal because it was seen as rationalising too much state intervention and failing to protect offenders' rights. For further discussion, see Andrew von Hirsch Doing Justice: The Choice of Punishments (Hill and Wang, New York, 1976) at xxxiv-xl.

54 "Anchoring" refers to the level at which the penalty is set for each band.

55 Sentencing Act 2002, s 15A.
} 
resolution made up of components with the utilitarian purposes of reducing reoffending and making amends to the victim.

While desert theory has a preventive component (the "hard treatment" provides a "prudential disincentive" - a reason not to commit offences - that supplements the censure communicated by the sentence ${ }^{56}$ ), the severity of the sentence is not determined in accordance with what is needed to prevent offending, but by offence seriousness. Accordingly, desert theory is best characterised as a primarily deontological theory. ${ }^{57}$ The main components of the treatment track, on the other hand, are utilitarian (their purpose is to reduce reoffending by means of incapacitation and rehabilitation) and compensatory (the offender is required to make amends to the victim and/or the community). Using a deontological theory to determine the requirements of a treatment track order for each offender would be incongruent with the instrumental nature of the core components of the treatment track. In the remainder of this section, I illustrate that in relation to each component.

The purpose of imposing risk management conditions is the prevention of future offending. The intrusiveness of the conditions imposed should, for that reason, be determined by reference to the level and type of risk posed by that participant. Doing that would require very different considerations to be taken into account than if sentencing according to offence seriousness. First, the seriousness of the offending is less important: risk assessment predicts the likelihood of offending, not its seriousness. ${ }^{58}$ Secondly, previous offending is important. The more extensive and diverse the person's criminal history, the more likely it is that the person will reoffend. ${ }^{59}$ The relevance of previous convictions is somewhat contested amongst retributive theorists, but in some forms of retributivism, it is only the offence for which the offender is being sentenced that should

\footnotetext{
$56 \quad$ Andrew von Hirsch "Censure and Proportionality" in Antony Duff and David Garland (ed) $A$ Reader on Punishment (Oxford University Press, Oxford, 1994) at 122-123.

57 While hard treatment has a "back-up" function as a prudential disincentive, it should not be more than is necessary to convey censure (von Hirsch, above n 56, at 123-124) so the theory remains a deontological one.

58 Although, as will be discussed below, the seriousness of the offending is relevant to the level of risk that the community is willing to tolerate, influencing both eligibility criteria and risk management conditions.

59 Karl Hanson and Kelly Morton-Bourgon "The Characteristics of Persistent Sexual Offenders: A Meta-Analysis of Recidivism Studies" (2005) 73 Journal of Consulting and Clinical Psychology 1154 at 1157.
} 
be taken into account. ${ }^{60}$ Thirdly, risk assessment takes into account factors for which the offender cannot be considered at all culpable, such as age, and factors that are not necessarily the product of conscious choice (such as traits, attitudes, and desires). ${ }^{61}$ Retributive theories are concerned only with the seriousness of the offending (the culpability of the offender and the harm risked or caused). ${ }^{62}$

Like the requirement to comply with risk management conditions, the purpose of rehabilitation is the prevention of reoffending. Whether rehabilitation is needed, and if so, what kind and how much rehabilitation is required, is determined according to the person's risk of reoffending. ${ }^{63}$ At a policy level, the seriousness of different types of offending plays a role in decisions about the availability of rehabilitation programmes. For example, treatment has been available for many years for men who have sexually abused a child, despite their relatively low risk of recidivism compared with other offenders. ${ }^{64}$ Offence seriousness does not, however, determine how much rehabilitation a person needs or what rehabilitation should target. ${ }^{65}$ Because decisions about whether rehabilitation is needed, how much, and what type of rehabilitation is required are made on the basis of risk, overlaid by policy decisions about types of offending to prioritise for rehabilitation, and not on the basis of desert, it is not appropriate to determine the risk management conditions to be imposed on the basis of desert.

Similarly, the focus of the amends component is providing redress for the harm caused by the offending. The amends component has a restorative basis and so provides redress differently from the way redress is provided in retributive theories. ${ }^{66}$ The amends the

60 For example, George Fletcher Rethinking Criminal Law (Little Brown, Boston, 1978); RG Singer Just Deserts: Sentencing Based on Equality and Desert (Ballinger, Lexington, 1979).

61 See for example the Violence Risk Scale - Sex Offender Version, the static subscale of which includes two items related to age, and which includes a number of items measuring sexual deviance and antisocial personality traits: Stephen Wong and others Violence Risk Scale - Sex Offender Version (2009) - on file with author. Andrew von Hirsch and Andrew Ashworth Proportionate Sentencing: Exploring the Principles (Oxford University Press, Oxford, 2005) at 12.

James Bonta and DA Andrews The Psychology of Criminal Conduct (6 ed, Routledge, New York, 2017) at 190-191.

Devon Polaschek and Lucy King "Rehabilitating Rapists: Reconsidering the Issues" (2002) 37 Australian Psychologist 215 at 215.

Bonta and Andrews, above $\mathrm{n} 63$.

Although it has been argued that restorative justice involves retribution (Kathleen Daly "Restorative Justice: The Real Story" (2002) 4 Punishment and Society 55 at 58-61) and attempts have been made to delineate proportionality-based limits on the outcomes of restorative justice 
offender would be required to make under a restorative approach are determined on the basis of the victim's needs and wishes and the offender's resources. ${ }^{67}$

This is in contrast to retributive approaches, where the offender's culpability and the general level of harm caused by the type of offending in question, rather than the specific harm suffered by the victim, determine the sentence (or the starting point for the sentence under a modified desert approach, as is the case with New Zealand's sentencing methodology ${ }^{68}$ ). Although the actual harm experienced by the victim (communicated to the court with a victim impact statement) is taken into account when assessing offence seriousness, maximum penalties for the different offences and the anchoring of penalty bands under New Zealand's sentencing methodology are informed by the harm generally caused by offending. ${ }^{69}$ The offence-related aggravating and mitigating factors (other than the harm experienced by the victim) that sentencing judges use to place instances of offending into penalty bands and set a starting point within that band are directed at establishing the general harm caused by offending of the nature of the offending in the particular case. $^{70}$

In most cases it is likely that the offender will not have the resources to compensate victims fully for the harm caused by sexual offending (if the harm can even be quantified). At best, the amends an offender can make are probably a contribution towards the victim's recovery. Nonetheless, if the amends are calculated according to offence seriousness rather than the actual needs of the victim, some victims may receive an even smaller contribution towards their recovery than they would if the amends were determined according to need. That would be the case for victims who have suffered more than the "average" victim, which is likely to be the case if the victim has multiple vulnerabilities (such as a history of victimisation, mental or physical health problems, and low socio-economic status ${ }^{71}$ ). Accordingly, using a retributive approach to determine the

practices (Michael Cavadino and James Dignan "Reparation, Retribution and Rights" (1997) 4 International Review of Victimology 233).

This is discussed further in relation to the second proportionality control, towards the end of this chapter.

$R v A M$, above n 5 .

Sentencing Act 2002, s 8. For an argument that individual harm should not be taken into account when assessing offence seriousness, see Danica McGovern "Assessing Offence Seriousness at Sentencing: New Zealand's Guideline Judgment for Sexual Offending” (2014) 26 NZULR 243.

$R v A M$, above n 5.

For a discussion of harm and vulnerability due to factors personal to the victim, see McGovern, above n 69. 
amends a treatment track participant should be required to make does not make sense when the purpose of making amends is restorative.

For these reasons, the substitution approach cannot provide the model required for maintaining proportionality between the treatment track and the sentence of imprisonment that would otherwise be imposed. A model that gives more space to utilitarian goals is required in this context. I explain in Part B how Morris and Tonry's interchangeability approach is helpful.

\section{B Morris and Tonry's interchangeability approach}

Morris and Tonry proposed the interchangeability approach in their book Between Prison and Probation: Intermediate Punishments in a Rational Sentencing System. ${ }^{72}$ The term "intermediate punishments" refers to sentences which are more severe than probation and less severe than imprisonment. ${ }^{73}$ Morris and Tonry were concerned that intermediate punishments were under-utilised, and considered that that was due in part to a lack of guidance as to when and how intermediate punishments should be used. ${ }^{74}$ The book sets out guidance for using intermediate punishments, within the framework of limiting retributivism (the "rational sentencing system" referred to in the title of the book).

Morris first published an account of limiting retributivism in $1974 .^{75}$ The theory evolved as Morris refined his thinking and Tonry and Frase contributed to its development. ${ }^{76}$ As a result, there are different versions of limiting retributivism. In the version I discuss in this chapter, proportionality acts as an upper and lower limit on the severity of the sentence that can be imposed. Between those limits, the sentence is to be determined by parsimony - the principle that the sentence imposed should be the least restrictive sentence that is necessary to serve legitimate social purposes. Morris and Tonry define "legitimate social purposes" as crime prevention and public acceptability of the sentence. ${ }^{77}$ Proportionality accordingly takes a back seat to parsimony and social utility in

\footnotetext{
$72 \quad$ Morris and Tonry, above $\mathrm{n} 4$.

$73 \quad$ At 4

$74 \quad$ At $3-4$ and $12-17$.

75 Norval Morris The Future of Imprisonment (University of Chicago Press, Chicago, 1974) at 5884.

76 See for example Michael Tonry Intermediate Sanctions in Sentencing Guidelines (National Institute of Justice, Washington DC, 1997) and Richard Frase "Limiting Retributivism” in Michael Tonry and Richard Frase (eds) The Future of Imprisonment (Oxford University Press, New York, 2003).

77 Morris and Tonry, above n 4, at 107-108.
} 
determining the choice of punishment within the range of "not undeserved" sentences ("the range of punishments that reasonable people would regard as deserved"). ${ }^{78}$

Morris and Tonry explained their rejection of desert theory's treatment of proportionality as an "overriding moral imperative." 79 They argued that the focus on imposing precisely equivalent punishments is undesirable because it can prevent the criminal justice process from achieving utilitarian aims (such as incapacitation, rehabilitation, reintegration and reparation), and because it causes more expense to the state and more suffering than necessary to achieve those aims. ${ }^{80}$

Morris and Tonry argued that for the most serious offences, imprisonment is the only appropriate punishment. ${ }^{81}$ However, for offences of moderate seriousness, punishments may be treated as interchangeable: a community-based sentence (or package of community-based sentences) may be imposed instead of imprisonment if doing so would better achieve the utilitarian goals of sentencing. ${ }^{82}$ In other words, if there are several different types of sentences available with "roughly equivalent punitive bite", the sentence that best meets legitimate social purposes should be imposed. ${ }^{83}$ This is the interchangeability approach.

Sexual offences are serious, and not within the range of offences which Morris and Tonry considered suitable to be used interchangeably. I extend Morris and Tonry's theory to serious offences, illustrated with the example of sexual offending. If the treatment track were considered to be of "roughly equivalent punitive bite" to the sentence of imprisonment that would ordinarily be imposed on a given offender, then it would be principled to use either the treatment track or prison for that offender. The treatment track could be used where doing so would more effectively achieve legitimate social purposes - in this context containing and reducing the risk that the offender will reoffend, while also preventing secondary victimisation and enabling the offender to make amends.

Morris and Tonry considered that the range of offences for which sentences of imprisonment should be interchangeable with intermediate sanctions should also be

\begin{tabular}{ll}
\hline 78 & At 87. \\
79 & At 145. \\
80 & At $89-90$. \\
81 & At 78. \\
82 & At $77-78$. \\
83 & At 32.
\end{tabular}


determined according to what is "not undeserved". That is, there are some offences for which a sentence of imprisonment will be too severe, and others for which a sentence other than imprisonment will be too lenient. For all other offences, interchangeability should be allowable. ${ }^{84}$

They suggested that sentences of imprisonment of more than two years should not be interchangeable with intermediate sanctions, although they also noted that people could reasonably disagree with the choice of two years as the interchangeability cut-off and stated that each jurisdiction must determine the cut-off for itself. ${ }^{85}$ Their first reason for choosing the two year cut-off was simply a reflection of sentencing practice at the time they were writing: offences involving serious violence were likely to attract prison sentences of more than two years (and, by implication, intermediate sanctions should not be available for serious violent offences because only a prison term is adequate). ${ }^{86}$ Their second and third reasons for choosing a two-year limit on interchangeability were policy reasons. They wanted to avoid the use of short prison sentences (sentences of less than two years) and they could imagine community-based sentences that could be roughly equivalent only to up to two years imprisonment. ${ }^{87}$

Interchangeability of community-based sentences with prison sentences of up to two years is already an accepted part of New Zealand's current sentencing practice. ${ }^{88}$ However, the treatment track is intended as an alternative to prison, rather than to existing community-based sentences. Would it be principled to introduce interchangeability between prison sentences of more than two years and a specific alternative resolution (the treatment track) and if so, what should the upper limit on that interchangeability be?

Using Morris and Tonry's combination of contemporary practice and policy-based reasoning, I think it is possible to argue that another interchangeability range should be introduced for more serious offences than the ones they were dealing with. The types of sexual offending at which the treatment track is aimed are serious offences. However, there are good policy reasons for making an alternative resolution such as the treatment track available in certain cases, so I think there is a case for increasing the

\begin{tabular}{ll}
\hline 84 & At 78. \\
85 & At 79. \\
86 & At 79. \\
87 & At 79. \\
88 & Robertson, above n 39, at [SA10A.01].
\end{tabular}


interchangeability limit above two years' imprisonment. If we accept that, then the lower interchangeability limit should be an end sentence of two years' imprisonment (because a community-based sentence can already be substituted for a prison term of up to two years).

At the upper end of the interchangeability range, I would suggest that interchangeability not be available for offences that would ordinarily attract a sentence starting point of more than eight years. The eight-year upper limit may sound high, especially compared with the two years that Morris and Tonry had envisaged, but I argue that it is appropriate given the nature and goals of the treatment track (though ultimately somewhat arbitrary, as any cut-off will be).

I suggest the starting point rather than the end sentence for the upper limit of the interchangeability range because it is the starting point that reflects offence seriousness, and offence seriousness is the touchstone for this exercise. Using the starting point rather than the end sentence would also help to avoid double-counting factors relevant to risk. For example, a person with previous similar offending (which would be taken into account as an aggravating factor, resulting in an uplift of the starting point and therefore a longer maximum time the person could be subject to the treatment track) would also be assessed as being at higher risk of reoffending and so be required to undertake more treatment and comply with more restrictive risk management conditions. Another advantage to using the starting point as the upper limit is that doing so promotes certainty and consistency. The guideline judgment for sexual violation provides quite clear guidance on how to assess offence seriousness (though of course the interpretation of the facts of the offending and the weight given to relevant factors is always a matter for the individual judge). On the other hand, there is rather less guidance on how to factor in personal aggravating and mitigating factors. The clearer it is whether a person should be eligible for the treatment track, the better, from a rule of law viewpoint. Counsel ought to be able to advise their clients whether it is likely their offending would be eligible for the treatment track, and judges' decisions on eligibility should be predictable, which is easier to achieve if the starting point rather than the end sentence is used.

The eight-year starting point I propose as an upper limit is based on the current guideline judgment for sexual violation by rape (the most serious sexual offence in New Zealand law) ${ }^{89}$ Offences with a starting point of more than eight years are those with significant aggravating factors present, such as use of gratuitous physical violence, cruelty and $R v A M$, above $\mathrm{n} 5$. 
callousness, or home invasion. The maximum penalty for indecent assault is 7 years' imprisonment, so all but relatively minor indecent assaults would be within the interchangeability range, and the decision about whether to use the treatment track would be made on the basis of the risk posed by the offender and the interests of the victim. ${ }^{90}$ Some instances of attempted sexual violation, assault with intent to commit sexual violation, abduction for the purpose of sexual connection, sexual conduct with consent induced by certain threats, sexual exploitation of a person with a significant impairment, and compelling an indecent act with an animal would also fall within the two-eight year interchangeability range. ${ }^{91}$

It should also be borne in mind that an offender who has committed an offence that attracts a starting point of eight years' imprisonment may well receive an end sentence of substantially less, once personal mitigating factors and the guilty plea (which attracts a discount of up to 25 per cent $^{92}$ ) are taken into account. Moreover, offenders are eligible for parole after serving only a third of their sentence, unless a non-parole period has been imposed at sentencing. ${ }^{93}$ Accordingly, the difference between the treatment track and a sentence of imprisonment with an eight year starting point is not necessarily as dramatic as it may sound at first.

The treatment track would be a "not undeserved" sentence for sexual offending that would ordinarily result in a prison sentence of more than two years and would attract a starting point of up to eight years' imprisonment. In the absence of a scale that would enable us to measure intrusiveness and accountability in respect of each sentence, at this stage I can only explain why I think they are roughly equivalent.

A sentence of imprisonment is highly intrusive and involves low or moderate accountability (depending on whether the prisoner does treatment while in prison or on parole or makes amends to the victim). The treatment track involves moderate intrusiveness at the beginning, decreasing over time to low as the participant completes treatment and makes amends and as the risk management conditions become less restrictive. The treatment track holds participants to account at a high level. At that very broad level, I argue that the two are roughly equivalent and therefore an acceptable degree of proportionality would be maintained if the two were used interchangeably.

\begin{tabular}{ll}
\hline 90 & Crimes Act 1961, s 135. \\
91 & Crimes Act 1961, ss 129, 129A, 131, 142A and 208. \\
92 & Hessell $v R$ [2010] NZSC 135, [2011] 1 NZLR 607. \\
93 & Parole Act 2002, s 84(1).
\end{tabular}


That equivalence only holds true for certain time periods, however. At some point, accountability and intrusiveness run out: when treatment is complete and risk has reduced enough to ease risk management conditions, the treatment track would be more lenient than a sentence of imprisonment (which would still be highly intrusive). Eight years should be the upper limit.

There are two other reasons, entirely speculative, why the eight-year upper limit for the interchangeability range seems appropriate. First, I think that the public might accept the use of an alternative to imprisonment for sexual offences against adults that do not have significant aggravating features, if it understands the reasons for doing so and accepts that the treatment track can contain and reduce risk, but would be unlikely to accept it for the more serious offences. Carefully-designed research would be necessary to confirm that.

Secondly, the eight-year cut-off also relates to tolerance of risk, again speculatively. Offence seriousness is not necessarily related to risk: those at highest risk of reoffending may not be those who commit the most serious offences. However, if some offenders have a propensity for committing particularly serious offences (even if some of those offenders are less likely to commit an offence than those who commit less serious offences) there may be some value in restricting the treatment track to less serious offending. That is, offence seriousness is not related to risk itself, but it may have an impact on the level of risk the community is willing to tolerate. The community might tolerate a non-custodial resolution for someone who is at high risk of committing relatively minor indecent assaults, but is unlikely to tolerate a community-based sentence for someone who is at low risk of reoffending, but is likely to commit a very sadistic sexual violation if he does reoffend. If consultation or other evidence established that the point at which the public will not tolerate the use of an alternative resolution is higher or lower than the eight years suggested, the interchangeability cut-off could be adjusted accordingly.

One possible problem with adopting an eight year starting-point as the upper limit on interchangeability is that doing so may exclude some situations of intimate partner sexual violence, where the offending is likely to be serious by virtue of its repeated nature, the breach of trust involved, and the physical and psychological abuse that is likely to accompany the sexual violence. Intimate partner sexual violence is one type of offending where the treatment track might be particularly attractive to victims, provided they can be kept safe from the offender. If offending at the more serious end of the spectrum is 
excluded from the treatment track, there may be no other formal measures available that the victim is willing to use. However, it is difficult to see how an exception could be made in a principled way for intimate partner sexual violence that is above the eight-year cut-off. The better approach may be to characterise the treatment track as a measure that will enable intervention in intimate partner violence before the offending escalates to a point where it is too serious for the treatment track.

In this section, I have suggested an interchangeability range for sexual offending - in other words, the range of offence seriousness for which I think the treatment track would be "not undeserved" based on a rough comparison with the sentence of imprisonment that the offending would ordinarily attract. That is one aspect of maintaining proportionality when using different types of resolutions for instances of offending of similar seriousness. In Part IV, I turn to the other aspect of maintaining proportionality: ensuring that the requirements imposed on each individual treatment track participant are not disproportionately onerous.

\section{Determining Individual Requirements}

One of the tricky things when considering proportionality in the treatment track context, however, it that the requirements of the treatment track will differ for each participant based on their risk level, treatment needs, and the wishes of the victim. In this section, accordingly, I discuss how to ensure that the requirements imposed on individual participants are not disproportionate to the seriousness of the offending. I argue in Part A that proportionality should determine the time a participant may be subject to the treatment track and in Part B that parsimony is a better principle for determining what the participant must do in respect of each component of the treatment track.

\section{A Proportionality determines the time a participant may be subject to the treatment track}

The most important limit on the individual requirements imposed on each treatment track participant is the time that the participant can be subject to the treatment track. I propose that it be determined primarily by desert but reflect the guilty plea entered (in the same way as an early guilty plea is reflected in the 25 per cent discount on the end sentence for those who are sentenced in the ordinary way ${ }^{94}$ ). The time a person is subject to the treatment track should be the same as the starting point that person's offending would

94 Hessell $v R$, above $\mathrm{n} 92$. 
ordinarily attract, minus 25 per cent. It would be unjust to interfere with a person's liberty for a longer period than is deserved according to offence seriousness.

It is probably feasible for a person at medium or high risk of reoffending to complete the required rehabilitation within that timeframe. Careful planning will be required, particularly for those at relatively high risk of reoffending, to ensure that they can complete treatment, attend to other desistance-related needs, and make amends within the timeframe. Those who are at very high risk of reoffending (and who might therefore not be able to complete the required treatment while also fulfilling the other requirements of the treatment track) will be excluded anyway because it will not be safe to have them in the community. The difficult situation would be if a person had committed an offence towards the more minor end of the scale of eligible offences, but was assessed at being high risk. In those situations, careful thought would need to be given to whether the person could feasibly complete all the requirements of the treatment track within the timeframe allowed. A practical advantage of the community-based intervention is that treatment can begin at the start of the treatment track (rather than waiting until the person is eligible for parole, which is current practice in New Zealand prisons) and time does not have to be spent on reintegration planning and resettlement. That helps with the feasibility of completing rehabilitation within the limit set by offence seriousness.

\section{B Parsimony as the determining principle for each component}

Within the timeframe determined by desert, we still need a way of limiting the onerousness of the requirements imposed on participants of the treatment track. Otherwise, there is a risk that the treatment track could become disproportionately severe. I argue in this part that the operating principle for determining the onerousness of each component should be parsimony.

The Risk Need Responsivity model has parsimony built into it already: it says that people should receive only as much treatment as indicated by risk and need. ${ }^{95}$ The determination about how much treatment is required should be made by the psychologist undertaking the risk assessment, and updated by treatment providers during the course of the programme as more information about the participant becomes available and the participant's progress in treatment can be taken into account.

Similarly, the risk management conditions imposed on participants should be no more intrusive than is necessary to manage risk. This is a decision for the judge, taking into

$95 \quad$ Bonta and Andrews, above n 63 . 
account the information about risk provided by the assessing psychologist and any further information that comes to light during treatment. Judges do have the ability to evaluate risk management conditions in light of liberty concerns, as seen for example in Te Whatu $v$ Department of Corrections, where the Judge determined that the condition that $\mathrm{Mr} \mathrm{Te}$ Whatu not associate with his own partner was excessive. ${ }^{96}$ In a culture where Corrections (and to some extent, judges) are blamed for reoffending, it is important for treatment track officials to be mindful of the dangers to liberty of taking a strongly risk averse approach and to commit to parsimony as an important ideal. ${ }^{97}$

Whether parsimony should act as the limiting principle for the amends component of the treatment track is the most difficult question. The amends component is restorative in purpose. Applying the principle of parsimony might mean that the amends should be limited to what is required to put the victim in the position she would have been in if not for the offending - that is, that the amends component should be understood as compensatory, with no additional punitive aspect. In itself, that proposition is entirely unproblematic. However, given the seriousness of sexual violence and the wide-ranging and long-term consequences for the victim, parsimony may not act as much of a limit at all.

The more realistic limit is probably the practical one of what could be achieved within the timeframe of the treatment track, taking into account the other requirements imposed on the participant as conditions of participation in the treatment track (rehabilitation and risk management). Requiring the participant to continue making amends after their participation in the treatment track has ended would, in my view, punish the participant in excess of that person's desert (keeping in mind that the upper time-limit on treatment track participation is determined by the seriousness of each person's offending). It may also be more difficult to enforce because the threat of imprisonment for the original offending would no longer be available as an incentive for compliance (although other legal measures could, of course, be used).

The material resources of the participant should also act as a practical limit on monetary reparation or work undertaken for the victim or the community. There are two reasons for this. In terms of the primary purpose of the treatment track - reducing recidivism putting participants under undue financial strain or stress from managing too many

96 Te Whatu v Department of Corrections [2017] NZHC 3233.

97 Andrew Ashworth and Lucia Zedner Preventive Justice (Oxford University Press, New York, 2014) at $120-121$. 
commitments could act as a risk factor for reoffending rather than assist in rehabilitation. Moreover, the courts generally try not to impose requirements that offenders cannot meet, particularly when (as with the treatment track) the outcome of that failure would be imprisonment. $^{98}$

There has been debate in the literature over whether desert should limit reparation. In sexual cases, much of the harm is less tangible than physical injury or damage to property - although of course both of those can occur as a result of sexual offending. Emotional, psychological, social, spiritual, and long-term economic harms suffered by victims of sexual offending are not necessarily commensurate with the seriousness of the offending (that is, the number of aggravating features of the offending) and of course aggravating and mitigating factors personal to the offender do not usually affect the harm suffered by the victim. ${ }^{99}$ Scholars disagree on whether desert should act as a limit on reparation. For example Ashworth has argued that it should not, if the purpose is really compensatory. ${ }^{100}$ Cavadino and Dignan, on the other hand, argued that desert can act as a limit on a measure imposed for a purpose other than desert. ${ }^{101}$ The approach I have taken is perhaps somewhere in between the two. By acting as a limit on the time to which a person can be subject to the treatment track, offence seriousness does limit the amends a participant can be required to make, but the limit is a step removed because it is not imposed directly on the amends component. That treatment of the amends component is consistent with the treatment of the rehabilitation and risk management components, which are also not directly limited by offence seriousness except in respect of the time limit.

So far I have suggested that the amends required of a treatment track participant should be limited by what can be achieved within the timeframe of the treatment track (itself determined by offence seriousness), taking into account the other requirements imposed on the participant (determined by risk/need) and the material resources of the participant. The question remains, however, how the amends should be determined. Are they compensatory like loss-based damages imposed by the court in a civil case? Or should

\footnotetext{
98 The question of scaling down a repartion order in accordance with an offender's resources was raised in Andrew Ashworth "Some doubts about restorative justice" (1993) 2 Criminal Law Forum 277 at 292.

$99 \quad$ McGovern, above $\mathrm{n} 69$.

$100 \quad$ Ashworth, above n 98, at 290.

101 Michael Cavadino and James Dignan "Reparation, Retribution, and Rights" (1997) 4 International Review of Victimology 233 at 246-247. Their view is broadly consistent with Morris and Tonry's model, though the justifications for it differ.
} 
the amends required of an offender be understood in the more restorative sense of allowing the victim to feel as if justice has been done?

The distinction between the two probably becomes less stark when we remember that nothing the participant can do will actually undo the harm caused by the offending. The amends a participant can make are largely symbolic, except perhaps to the extent that they help the victim with some of the material losses suffered as a result of the offending. For that reason, I lean towards the broader "restorative" interpretation of the purpose of the amends component.

An additional reason in favour of the restorative interpretation is the difficulty of assessing the harm suffered by victims of sexual offending. Many of the consequences of sexual violence are highly personal in nature, and requiring victims to submit to psychological assessment in an attempt to measure those effects seems overly intrusive in the circumstances. Further, some consequences may not reveal themselves until a long time after the offending, making it difficult to accurately gauge the harm suffered by each victim. $^{102}$

Perhaps the amends required of a participant should be chosen by the victim from a "menu" of possibilities that has been tailored to the material resources of the participant and the time he has available. The victim could make that choice as an outcome of a restorative justice conference, if she wishes to engage with the offender in that way, or as a separate process. In circumstances in which the victim does not wish to be involved at all, the judge could order the participant to make amends to the community using the mid-point of actions on the "menu".

To sum up the discussion of proportionality of individual requirements of the treatment track, I have argued that the time a person may be subject to the treatment track should be determined by desert minus the guilty plea discount (that is, the starting point the offending would ordinarily attract under $A M$ for sexual violation or the relevant case law for other offences, reduced by 25 per cent in accordance with Hessell). The individual requirements imposed on the offender should be determined by parsimony, taking into account the resources available to the participant. Using these principles would help to ensure that a reasonable degree of proportionality is maintained between the treatment track and the sentence of imprisonment that would ordinarily be imposed.

102 McGovern, above n 69. 


\section{$V$ Proportionality and Coercion}

In this chapter, I have discussed how the treatment track could be designed so that it is of equivalent severity to the sentence of imprisonment that would ordinarily be imposed. One of the reasons maintaining proportionality is so important is to ensure that potential participants are not coerced into pleading guilty and accepting psychological treatment, which could occur if the treatment track was disproportionately lenient. Coercion of that nature may violate the principle of penal minimalism with which this chapter is concerned (that the treatment track not unduly interfere with the liberties of participants or potential participants).

The issue of what kinds or degrees of coercion are unacceptable in the criminal justice process, itself extraordinarily coercive, is difficult. In this section, I aim to raise some issues and questions about whether possible coercion to plead guilty and accept psychological treatment violates penal minimalism. These questions arise from the way I have conceptualised the treatment track and, in particular, the argument put forward in this chapter about how proportionality can be maintained. I think they require deeper exploration than is possible within the scope of this thesis.

\section{A Plea decision}

The practice of offering sentence discounts for guilty pleas has come under heavy fire over the years. For example, Ashworth and Redmayne have argued that the English sentencing discount of one third may breach the presumption of innocence (and as a result, the right to freedom from self-incrimination and the right to examine or have examined witnesses against the accused) and the right to freedom from discrimination. ${ }^{103}$ They noted that the European Court of Human Rights had found that an accused can waive the right to trial in exchange for a lesser penalty, but must do so free from constraint. ${ }^{104}$ In Ashworth and Redmayne's view, the one third sentence discount is so substantial that it may operate as a constraint on the decision-making power of an accused, and could even induce an innocent accused to plead guilty. ${ }^{105}$ Nonetheless, the practice is entrenched in New Zealand sentencing law. ${ }^{106}$

\footnotetext{
103 Andrew Ashworth and Mike Redmayne The Criminal Process (4 ed, Oxford University Press, New York, 2010) at 312.

$104 \quad$ At 313. The case referred to is Deweer v Belgium (1980) 2 EHRR 439.

$105 \quad$ At 313.

106 Hessell $v R$, above $\mathrm{n} 92$. But see recent criticism of the practice of sentence discounts by the New Zealand Chief Justice: Sian Elias "Managing Criminal Justice" (Criminal Bar Association
} 
The discount for early guilty pleas is built into the model I have set out in this chapter. If the treatment track really could be equivalent in severity to the prison sentence an offender who has pleaded guilty would ordinarily receive, then the treatment track is best thought of as a continuation of the problems that have been argued to have been associated with sentence discounts, rather than exacerbating them. It is logically possible for the treatment track to incentivise guilty pleas despite being of equivalent severity to imprisonment, because it adds an option for those who have a genuine preference for the demands of community-based treatment, risk management, and making amends to the victim over the deprivations and hardships of imprisonment. In that sense, the availability of the treatment track could arguably increase the autonomy of the accused, rather than overpowering his will to coerce him into pleading guilty.

I am still troubled, however, by the idea of attempting to incentivise guilty pleas from people who may not otherwise be convicted. The incentive to plead guilty would be intended to be directed only towards people who did commit the offence(s) charged and against whom there is sufficient admissible evidence to support a finding of guilt beyond reasonable doubt. Those people can be divided into further groups of interest. The first is those who would inevitably be convicted at trial, who we would like to encourage to plead guilty to spare the complainant the ordeal of giving evidence. The second is those who may not be convicted at trial, because the jury may assess the evidence in accordance with the "real rape" schema and other rape myths, concluding on the basis of improper reasoning that the evidence is insufficient. The reason for wanting people in the second group to plead guilty is to improve the ability of the criminal justice process to convict the guilty. Assuming that the treatment track could actually incentivise guilty pleas from those in the second group (an assumption that is not necessarily borne out, as discussed in Chapter 5) the question I address in this section is whether trying to do so would amount to unfair coercion and a resulting breach of rights. In section one, I discuss the need to prevent wrongful convictions, and in section two, the need to prevent abuse of state power.

\section{Preventing wrongful convictions}

One argument against offering sentence discounts is that they increase the risk of miscarriages of justice, because they encourage the innocent as well as the guilty to plead

$\begin{array}{lllll}\text { Conference, } & \text { Auckland, } & 5 & \text { July } & \text { 2017). }\end{array}$

$<$ https://www.courtsofnz.govt.nz/speechpapers/CBA.pdf $>$. 
guilty. ${ }^{107}$ This concern was considered in two English reports, the Royal Commission on Criminal Justice (1993) and the Auld Review (2001). Both acknowledged that sentence discounts have the potential to contribute to miscarriages of justice, but concluded that the benefits of offering sentence discounts outweighed the risk. ${ }^{108}$ The Auld review, for example, concluded: ${ }^{109}$

$[\mathrm{N}]$ o system can guarantee that individual defendants, however innocent, will not regard the likelihood of a lesser sentence as an incentive to trade it for the risk of conviction and a more serious sentence, or that lawyers will not sometimes advise their clients badly. But these are not reasons for rejecting a sentencing practice if in general it serves a proper sentencing purpose, operates justly and assists the efficient administration of justice.

Criminal justice scholars have criticised that view, arguing that prevention of wrongful convictions is not something to be balanced against other interests, but must be given special weight. For example, Sanders, Young and Burton said of the conclusion in the Auld report: ${ }^{10}$

A sentencing practice which results in the conviction of the innocent can be described as 'in general' operating 'justly' only once one accepts that no special weight should be placed on avoiding such miscarriages of justice.

Similarly, Ashworth characterised the Royal Commission's view as "a dreadful example of the 'balancing' metaphor, assigning no special priority to avoiding the fundamental harm of convicting innocent individuals."111

Clearly it would be wrong to establish the treatment track if doing so resulted in more innocent people pleading guilty. The risk of convicting an innocent person cannot be balanced against the benefits to complainants and the criminal justice process of avoiding

$107 \quad$ Andrew Sanders, Richard Young and Mandy Burton Criminal Justice (4 ed, Oxford University Press, Oxford, 2010) at 492-493. Ibid.

Robin Auld Review of the Criminal Courts of England and Wales: Report (2001) at 440, cited by Sanders, Young and Burton, above n 107, at 492.

At 492-493.

Andrew Ashworth Sentencing and Criminal Justice (6 ed, Cambridge University Press, Cambridge, 2015) at 179. 
a trial and to society from the opportunity to intervene with more people who are guilty of serious offending.

The only issue for debate is whether the treatment track actually would have such an effect. It may be that because sexual assaults are so difficult to prove - and the more the case departs from the "real rape" stereotype, the more difficult it is for the prosecution to prove guilt beyond reasonable doubt - that establishing a treatment track would not actually encourage guilty pleas from anyone, let alone from those who are innocent of the offence. $^{112}$ Given the fundamental importance of protecting the innocent from conviction, however, the burden should perhaps be on those arguing in favour of sentencing discounts or other incentives of any kind to prove that they do not increase the risk of guilty pleas from the innocent.

In the meantime, it is sensible to think about the protections already in place that may decrease the likelihood of an innocent person pleading guilty, and whether stronger protections are needed (whether or not the treatment track is established). Prosecutors are already bound by the Solicitor-General's Prosecution Guidelines, which include an evidential test that helps to reduce the likelihood that a prosecution is initiated or continued against an innocent person. ${ }^{113}$ Good legal advice can also help to guard against convicting an innocent person. An innocent accused is probably less likely to plead guilty to avoid a custodial sentence if well-informed about the strength of the prosecution case and elements of unfairness in the investigation or prosecution. The importance of good legal advice highlights the need for legal aid to be well-funded and available to those who need it, and to be administered in a way that attracts competent counsel and does not disincentivise good practice. Avoiding remanding an accused in custody pretrial unless absolutely necessary is also important for reducing improper pressure to plead guilty, and one reason the recent changes to the Bail Act, which reduced the availability of bail, ought to be revisited, ${ }^{114}$ as is ensuring that remand conditions are humane for those who must be held in custody pre-trial so that they are less likely to plead guilty in order to be moved out of remand.

\footnotetext{
$112 \quad$ As discussed in Chapter 5.

113 Solicitor-General's Prosecution Guidelines (Crown Law, 2013) at 6-8.

$114 \quad$ Bail Amendment Act 2013.
} 


\section{Preventing abuse of state power (whether or not the accused committed the offence)}

The purpose of the presumption of innocence is wider than protecting the innocent from conviction. Requiring the state to prove guilt in accordance with law protects against abuse of state power. In a speech to the New Zealand Criminal Bar Association, the Chief Justice expressed concern about changes to criminal procedure intended to improve the efficiency of the process, including offering incentives for guilty pleas: ${ }^{115}$

The reference to "convicting the guilty" and "acquitting the innocent" is ... something of a change in focus from the view that the purpose of criminal justice is the sufficiency of proof of guilt. The traditional understanding was expressed by Baroness Hale: ${ }^{116}$

Innocence as such is not a concept known to our criminal justice system. We distinguish between the guilty and the not guilty. A person is only guilty if the state can prove his guilt beyond reasonable doubt. This is, as Viscount Sankey LC so famously put it in Woolmington $v$ Director of Public Prosecutions, the "golden thread" which is always to be seen "throughout the web of the English criminal law". Only then is the state entitled to punish him. Otherwise he is not guilty, irrespective of whether he is in fact innocent.

In the treatment track context, what is interesting about trying to incentivise guilty pleas from people who would not otherwise be convicted is that the justification for doing so is that there $i s$ sufficient proof of guilt, but that the jury may not assess the evidence as sufficient. The more a case departs from the "real rape" stereotype, the less likely it is that the jury will consider the evidence to be sufficient, because it will apply illegitimate heuristics about the characteristics of a "real rape". ${ }^{117}$ Might there be an argument that attempting to incentivise guilty pleas would be a breach of the presumption of innocence only in the case of a person against whom the state cannot present sufficient evidence, and not in the case of a person who is "not guilty" because evidence that should be considered sufficient is instead judged insufficient due to pervasive social bias against rape complaints?

The obvious next question is, of course, who gets to decide whether the evidence is

\footnotetext{
$115 \quad$ Elias, above $\mathrm{n} 106$, at 6.

116 (Adams) $v$ Secretary of State for Justice [2011] UKSC 18, [2012] 1 AC 48 at [116].

117 Jennifer Temkin and Barbara Krahé Sexual Assault and the Justice Gap: A Question of Attitude (Hart Publishing, Oxford and Portland, Orgeon, 2008).
} 
sufficient? How can it be determined whether a jury's doubt in a particular case would be due to the effects of rape mythology rather than genuine and well-founded concern about the sufficiency of the prosecution's case? For example, a jury might decide that a complainant's evidence is not credible because there is no independent evidence to corroborate it. In making that decision, the jury may be influenced by the myth that women often falsely claim rape to cover up their sexual indiscretions. On the other hand, if there are two competing narratives about the incident giving rise to the charge, and no other evidence to support the complainant's account, then the standard of beyond reasonable doubt may simply not be reached. Perhaps in another case the jury might decide that the complainant's evidence is not credible because she was intoxicated at the time or has mental health problems. That decision about the complainant's credibility could be influenced by ideas about how a "real" victim ought to behave, or perhaps the jury draws the conclusion because there are gaps or inconsistencies in the complainant's evidence due to her state of mind at the time of the offence that cast doubt on what happened. The point is that there may be quite a fine line between "legitimately" insufficient evidence of guilt and sufficient evidence assessed as insufficient because of illegitimate reasoning. We will never usually know whether a particular jury's reasoning was legitimate, illegitimate, or a mix of both - making it difficult to predict what a hypothetical jury would do with the next case.

For that reason, I do not think there is a strong argument that it might be permissible to try to encourage guilty pleas from a person who is "illegitimately not guilty" but not from a person who is "legitimately not guilty". The presumption of innocence has to protect all accused.

\section{Conclusion}

Whether attempting to incentivise guilty pleas using the treatment track is in fact an unacceptable breach of penal minimalism turns on the factual question of whether the establishment of the treatment track would actually increase guilty pleas - a question which cannot yet be answered. The purpose of the discussion in this section is to highlight normative concerns about the attempt to incentivise guilty pleas, particularly from those who would not currently be convicted. This is an issue which needs further thought and exploration, as it represents a possible violation of penal minimalism.

\section{B Psychological treatment}

If the treatment track coerced people into pleading guilty, it could also coerce them to accept psychological treatment. Forced psychological treatment was one of the concerning features of correctional practice highlighted by critics of the rehabilitative 
ideal in the $20^{\text {th }}$ century. Attempts to reduce reoffending by psychological means were seen as undermining agency and as potentially more intrusive than physical confinement: ${ }^{118}$

[E]fforts to influence by coercive means the very thoughts feelings, and aspirations of offenders threaten trespass by the state upon areas of dignity and choice posited as immune by the liberal creed.

Forced psychological treatment was considered to undermine the dignity and autonomy of those subject to it. Those same interests, along with bodily integrity and perhaps privacy, underpin the right now recognised in s 11 of the New Zealand Bill of Rights Act 1990 ("NZBORA") to refuse medical treatment. The white paper for NZBORA signalled that psychological treatment should be included within the scope of s 11, and the courts have held that s 11 applies to any direct interference with the body or state of mind. ${ }^{119}$ That scope is broad enough to encompass protection for the right of men who have sexually assaulted an adult to refuse to participate in psychological treatment intended to reduce the likelihood that they will commit another sexual assault.

A difference between the obviously "medical" procedures generally discussed under s 11 and the psychological treatment at issue in the treatment track context is that psychological treatment primarily targets the mind, whereas the other procedures target the body. Attempting to stop a person committing sexual offences by changing their thoughts, feelings, and even their sexuality may be thought of as at least as intrusive as the interferences with the body involved in surgery, blood transfusions and medications (the usual types of "medical" treatment considered by the courts). Perhaps psychological treatment interferes to a greater extent with the core of who someone is than most physical procedures, which makes it important that it is included within the scope of s 11 . The kind of treatment envisaged in the context of the treatment track (primarily groupbased cognitive and/or behavioural therapies) does not, however, rise to the same level of intrusiveness as some of the practices discussed in literature critiquing the rehabilitative ideal, such as psychosurgery. ${ }^{120}$

\footnotetext{
$118 \quad$ Allen, above n 16, at 12.

119 New Health New Zealand Inc v South Taranaki District Council [2014] NZHC 395 at [86]; Geoffrey Palmer "A Bill of Rights for New Zealand: A White Paper" [1984 - 1985] 1 AJHR A6 at 109.

120 See the discussion in Chapter 1 of this thesis.
} 
However, psychological treatment is active rather than passive - it is not something that can be "done to" a person or can occur without their knowledge, unlike most medical treatments. Rather, it requires conscious participation by the person being treated, though some of the influencing techniques used may be relatively subtle and outside the conscious awareness of treatment participants. ${ }^{121}$ The nature of psychological treatment as requiring conscious and active participation may have been the underlying rationale for the High Court's finding that a condition that a parolee attend sessions with a Department of Corrections psychologist to develop a safety plan was not a breach of s 11 because the parolee was only required to attend the sessions and did not have to participate. $^{122}$

Assuming that the scope of $\mathrm{s} 11$ does include the kind of psychological treatment envisaged for the treatment track, it is at least arguable that establishing a treatment track could be a prima facie breach of s 11 . At the time of entry into the treatment track, the alternatives to consenting to treatment are either entering a guilty plea and receiving an almost inevitable sentence of imprisonment, or going to trial and receiving a sentence of imprisonment if convicted. Once accepted into the treatment track, the consequence of withdrawal of consent to treatment is termination of participation in the treatment track and sentencing, probably to imprisonment. Both sets of consequences are serious, and a person motivated to avoid prison - despite the comparable severity (in objective terms) of the requirements of the treatment track - may well feel coerced into accepting treatment. On the face of it, there may be a breach of the right to refuse medical treatment. On the other hand, it may be possible to argue that while the choice is a constrained one, as many choices are, it is still a choice - the consequences of refusing treatment are not so severe that the will of the accused/offender is overborne and he cannot be said to be consenting at all.

Either way, I think it is likely that if there is a breach, it would be considered justified, given that the person has been convicted of committing a serious offence and the purpose of the treatment is to reduce the likelihood of them doing it again. Accordingly, the treatment track would not violate the principle of penal minimalism by forcing offenders to accept psychological treatment. The state need not try to remove or minimise adverse consequences for offenders who refuse to engage in treatment to reduce the likelihood they will reoffend, beyond ensuring that the alternative is not disproportionately severe.

\footnotetext{
$121 \quad$ Allen, above n 16, at 12.

122 Wilson v New Zealand Parole Board and Chief Executive of Department of Corrections [2012] NZHC 2247 at [43].
} 
While not strictly necessary for the thesis given the conclusion just reached, I want to suggest that psychological treatment delivered in the correctional context sits uneasily within s 11 and would perhaps be better regulated using a concept other than human rights. I think it is worth considering this point because of how embedded treatment is within the correctional system, not to mention the proliferation of the so-called "therapeutic" or problem-solving courts discussed in Chapter 1.

The status of psychological treatment in the correctional context is not straightforward, and in my view has not yet been the subject of sufficient discussion. It is occasionally observed that prisoners cannot be said to be voluntarily engaging in psychological treatment when, for example, there is little or no prospect that they will be released on parole if they do not. ${ }^{123}$ Yet the need for "informed consent" to correctional treatment is formally maintained, and the Sentencing Act 2002 includes an explicit provision that nothing in the Act overrides the need for people to consent before receiving treatment. ${ }^{124}$

Pragmatically, a consent provision makes sense: it is very difficult to engage people in treatment when they do not wish to participate, and in a group-based setting the presence of people who do not wish to engage can disrupt the therapy for those who are amenable to treatment. It would be counter-productive to attempt to force people into the treatment track when they would prefer to go to prison (or to force them into treatment in any other correctional setting) so from that pragmatic perspective, the requirement of consent should be maintained.

However, I have argued that correctional treatment ought to be conceputalised and punishment and made available for the purpose of reducing reoffending. When understood in that way, there is less reason - as a matter of principle - to require consent. That proposition would no doubt cause psychologists providing treatment in correctional settings some disquiet. ${ }^{125}$ Psychologists concerned with the ethics of correctional treatment, including the voluntariness or otherwise of treatment, have tended to characterise their role as "treating the punished" rather than providing "treatment-as-

\footnotetext{
123 Armon Tamatea, Nick Lascelles and Devon Polaschek "Criminal Justice Psychology in Aotearoa New Zealand: Issues for Practitioners" in Waikaremoana Waitoki, Jacqueline Feather, Neville Robertson and Julia Rucklidge (eds) Professional Practice of Psychology in Aotearoa New Zealand (3 ed, The New Zealand Psychological Society, Wellington) at 464. Sentencing Act 2002, s 146.

Bill Glaser "Treaters or punishers? The ethical role of mental health clinicians in sex offender programs" (2009) 14 Aggression and Violent Behavior 248 at 251.
} 
punishment" because of their primary obligation not to cause harm (and their explicit or implicit understanding that punishment is equivalent to causing harm). ${ }^{126}$ In that conceptualisation, it remains possible to understand treatment as voluntary. The danger of that position, in my view, is that it obscures the intrusive and burdensome nature of correctional treatment, denies the very constrained choices that offenders make about whether to accept treatment, and - perhaps counter-intuitively - actually makes it more difficult to protect offenders from over-reaching by the state. ${ }^{127}$

When correctional treatment is understood as one of a range of mechanisms used by the state to reduce reoffending by people convicted of an offence, the consent requirement begins to appear slightly anomalous. The kinds of risk management conditions contemplated in the treatment track can already be imposed on offenders as part of a community-based sentence, as part of parole or release conditions, or as part of an extended supervision order. None of these things require the consent of the offender. What, if anything, is there about the treatment component that uniquely requires the consent of offenders? How does psychological treatment differ from risk management conditions routinely imposed without consent, for example that a person not enter a certain geographic area, consume alcohol, or contact the victim of their offending?

One difference may be permanence: perhaps treatment is thought of as aiming to have a permanent effect on the offender's behaviour, whereas the risk management conditions are intended only to reduce reoffending for the period that the offender is subject to them. The permanence of the change may be part of why consent is required for treatment. However, it is questionable whether treatment can reasonably be expected to have a permanent effect. $^{128}$ Moreover, risk management conditions could be thought of as having an effect on behaviour beyond the end of the sentence or order, if the person subject to them internalises them as habits that enable them to remain safely in the community. That kind of planning is, in fact, the final third of the Adult Sex Offender Treatment Programme, again blurring the distinction between treatment (which requires consent) and risk management (which does not). ${ }^{129}$

\footnotetext{
126 I have borrowed these terms from Glaser (at 249) who is an exception to that trend.

127 See chapter 1 for the full argument.

128 See interview with Devon Polascheck in "By the numbers: Surviving the First Year" The Press (18 July 2015) <http://www.pressreader.com/new-zealand/thepress/20150718/281998966142782/TextView> .

129 Adult Sex Offender Treatment Programme: Background, theory and overview (Department of Corrections).
} 
Perhaps the way in which treatment interferes with the privacy of the person subject to it is what makes treatment delivered in a correctional context different. Imprisonment, home or community detention, and community work - none of which require the consent of offenders - involve surveillance of the offender's body, and various degrees of control over the offender's geographical movement and freedom of association. In treatment, privacy is engaged differently: therapists use their interpersonal skills to elicit information about the thoughts, emotions, and past actions of offenders, and draw inferences about the internal states and traits of the offender from closely observing their behaviour. Perhaps that more internal focus, in combination with the use of skills gained through professional training and experience, is why treatment requires consent while other correctional responses do not.

It may be worthwhile to explore further whether there is a meaningful difference between treatment and the other forms of risk management or reduction that are used in the correctional context. If there is, then the coercive and burdensome nature of correctional treatment is assumed. In that case, then further thought would need to be given to regulating the severity of sentences or orders that include treatment, perhaps drawing on some of the ideas set out earlier in this chapter in the context of the treatment track.

\section{Conclusion}

In this chapter, I began exploring whether the treatment track could avoid undue interference with liberty by respecting the principle of proportionality. As with the previous two conditions, there are gaps in knowledge that mean this question cannot be answered clearly. Thinking about proportionality in this context also required me to develop the theory further, to encompass resolutions based on rehabilitation and restoration. Overall, I argue there is potential for the treatment track to be used in a way that maintains the principle of proportionality, but to be sure of that, we need a way to measure the extent to which different types of resolutions interfere with the interests of those subject to them and hold those subject to them accountable. I recommend that that conceptual and empirical work be undertaken before the treatment track or other alternatives incorporating rehabilitation and/or restoration are established. 




\section{Conclusion}

In this thesis, I considered whether the proposed treatment track could comply with the requirements of penal minimalism. In this context, those requirements are that the treatment track be necessary to reduce sexual recidivism, be likely to be effective in reducing sexual recidivism, and not infringe unduly on the liberties of participants and potential participants. In the course of answering the question whether the treatment track could comply with the requirements of penal minimalism, I had to develop the treatment track idea beyond the basic model originally proposed. I concluded that the treatment track could not yet comply with those requirements.

\section{Findings}

In this section, I summarise the main findings of this thesis and discuss their significance. Part A focuses on the answer to the research question and Part B on the development of the treatment track model undertaken in the course of answering that central question.

\section{A Could the Treatment Track Comply with the Principles of Penal Minimalism?}

I synthesised and evaluated empirical evidence from psychology and criminology in relation to the first two requirements of penal minimalism, and found that there are extensive gaps in knowledge that mean it cannot be said at this point that the treatment track could comply with the necessity and effectiveness requirements.

One of the ways the treatment track could reduce sexual recidivism is by bringing into the criminal justice process men whose offending would not currently be reported, prosecuted, or result in a conviction, and who can accordingly continue to offend with impunity. Perhaps unsurprisingly, given the hidden nature of their behaviour, it is about this group that the least is known. The evidence suggests that there is a small group of men who commit a large proportion of sexual offences, but most of that research has been undertaken with American university students. We do not know if it generalises to the New Zealand population. For that reason, we cannot be certain if the first condition of penal minimalism - that the treatment track is necessary - is justified in relation to ordinarily undetected perpetrators.

The biggest hurdle for the effectiveness of the treatment track with ordinarily undetected perpetrators may be getting them into the treatment track in the first place. At this point, we do not know enough about the influence of two possible factors in under-reporting 
and attrition that the treatment track could address directly (the victim not wanting the perpetrator to go to prison and the victim not wanting to go through the trial process) to conclude whether it could even bring those people into the criminal justice process. Once in, we do not know whether we could intervene effectively to reduce their risk of recidivism. The American literature has identified some risk factors associated with repeat perpetration, but at this stage no risk assessment tool has been developed and no treatment programme tried, so we have no idea whether the treatment track could be effective in reducing their recidivism. Accordingly, it cannot be said that the second condition of penal minimalism is satifisfied in respect of ordinarily undetected perpetrators.

The other way the treatment track could reduce recidivism is by intervening more effectively than the current process with men whose offending ordinarily results in a conviction. On the face of it, there is little need for another treatment stream, because official reconviction rates for sexual offending are so low: those who need treatment are offered it already. Studies of undetected sexual recidivism by men who have been convicted of sexually assaulting an adult suggest that actual rates of reoffending are much higher, but those studies do not provide an adequate evidence-base to conclude that the finding holds true of contemporary New Zealand offenders. As with ordinarily undetected perpetrators, the first condition of penal minimalism is not satisfied in respect of ordinarily convicted offenders.

Even if treatment is needed for some of those men convicted of sexually assaulting an adult who do not currently access it in prison, we again - and perhaps surprisingly in this case given the widespread use of risk assessment and treatment with sexual offenders do not know enough to conclude that the treatment track could reduce their recidivism. The research on the accuracy of risk assessment does not tell us much about how accurate the tools are with the specific population of convicted sexual offenders with whom the treatment track is intended to be used. Even less is known about whether treatment is effective in reducing sexual recidivism by men who have sexually assaulted an adult.

The treatment track would probably be no less effective in reducing reoffending by ordinarily convicted offenders than the treatment currently delivered in prisons, but I do not think we have an adequate basis to claim that we can manage their risk safely if they are in the community instead of in prison. Although in the longer-term the treatment track could conceivably reduce reoffending more effectively than imprisonment, the medium-term sacrifice of up to six years of incapacitation is an enormous political risk to 
take. For those reasons, the requirement that the treatment track be effective in reducing recidivism by men ordinarily convicted of a sexual offence is not yet satisfied.

The conclusion that there is insufficient evidence to support the establishment of a treatment track is of major significance to law reform efforts. Many of these gaps had not been identified before, because existing research had not been analysed in relation to its utility and completeness as an evidence base for an intervention like the treatment track. Identifying the evidence required (by reference to the theoretical framework adopted for this thesis and the specifics of the treatment track context), synthesising the evidence from multiple separate bodies of literature, and evaluating its sufficiency was a major undertaking. No previous large-scale reviews had addressed the questions specifically enough to be of use for this task. Moreover, little attention had been paid to the effect of the "real rape" bias on the validity of risk assessment, and the bodies of literature on "ordinarily convicted" and "ordinarily undetected" perpetrators were almost entirely separate.

Translating the findings about the sufficiency of the evidence into language that is accessible to those who need that knowledge - legal academics, lawyers, judges, and policy-makers - was also a major undertaking. This thesis provides an accessible catalogue of the extensive gaps in evidence supporting the necessity and likely effectiveness of a treatment track, and should serve as a warning that caution is required in the adoption of treatment-based resolutions of sexual offending against adult victims.

The picture is brighter when it comes to whether the treatment track could avoid undue interference with the liberties of participants and potential participants, the third condition of penal minimalism. I focused on proportionality, because it is fundamentally important in itself and also has an impact on whether the treatment track could coerce potential participants into pleading guilty and accepting psychological treatment. I developed a framework for measuring the severity of different types of sentences that accommodates restorative and treatment-based sentences or components of sentences. That framework then informs how to use the treatment track interchangeably with a sentence of imprisonment without violating proportionality.

This work is a major advancement of sentencing theory, which previously could not offer a principled way to use restorative and treatment-based sentences as alternatives to imprisonment. The development of the principle of proportionality is particularly important because it is a fundamental principle in sentencing, but is not well-defined and 
becomes particularly troublesome in a context such as the treatment track, where utilitarian aims are pursued within a retributive framework. Moreover, the application of the third principle of penal minimalism provided valuable assistance for negotiating in a principled way other tensions that appear in the treatment track context, most notably between trying to increase enforcement of the criminal law but avoid state over-reach, and incentivise guilty pleas without coercing them.

That theory should next be tested and refined. The theoretical development I have undertaken lays the ground work for further empirical investigation to ascertain whether the treatment track is in fact of comparable severity to a sentence of imprisonment of between two and six years as claimed. The question of whether, despite maintaining proportionality, the treatment track could coerce people into pleading guilty and accepting treatment warrants further investigation outside the scope of this thesis. It is important because doing so could breach fundamental rights, in particular the right of the innocent not to be punished, the presumption of innocence, and the right to refuse medical treatment (which protects dignity, autonomy, bodily integrity, and privacy). These rights are specific manifestations of the requirement that the criminal justice process not interfere unduly with the liberty of the accused or offender.

\section{B Development of the Treatment Track Model}

In the course of answering the question whether the treatment track could comply with penal minimalism, I needed to develop the treatment track model beyond what was proposed by McDonald and Tinsley. Although my conclusion is that the treatment track should not be established at this time, the development I have undertaken will be of use if evidence supporting the likely effectiveness of a treatment track is found and the idea is pursued further. The development is consistent with the three requirements of penal minimalism (necessity, effectiveness, and avoidance of undue interference with liberty).

In my version of the treatment track, reducing reoffending is its primary purpose, consistent with the centrality of psychological treatment. This is a shift in emphasis from the original model, which was proposed as part of a project to improve victims' experience of the criminal justice process. In that model, reducing reoffending was a concomitant aim but not the main aim of the treatment track. I set out three components: rehabilitation, risk management, and making amends (with the latter a new addition to the model). 
The original model did not contain any detail about the kind of rehabilitation that would be offered. I explored the suitability of existing treatment programmes run by the New Zealand Department of Corrections for the likely treatment track participants and considered what other kinds of desistance-focused measures might be required. I also discussed in more detail what risk management measures might be of use and what models could be drawn on for the design of the amends component.

The most substantial contribution I have made to the development of the model is proposing offence and offender-related eligibility criteria. This was a difficult task as it required understanding of the psychological literature on recidivism and risk, the criminological literature on under-reporting and attrition, and detailed knowledge of sentencing methodology. Moreover, in order to propose the offence-related criteria (one purpose of which was to help maintain proportionality) I first had to undertake the theoretical development in Chapter 7.

In terms of offence-related eligibility criteria, I identified qualifying sexual offences and then narrowed down the instances of those offences to those which fall within an appropriately serious range. I also developed an approach for determining when the commission of multiple offences (including non-sexual offences) should exclude a person from eligibility for the treatment track, and lastly considered the effects of the three strikes legislation on eligibility.

To develop offender-related eligibility criteria, I argued that the treatment track should aim to include men whose offending would not currently be reported, prosecuted, or reach trial ("ordinarily undetected perpetrators") but warned that much less is known about that group than those men who are ordinarily convicted of sexual offences. I argued also that men who have sexually abused a child as well as sexually assaulting an adult ("mixed offenders") should be eligible for the treatment track, but again noted that less is known about these men, which may present additional difficulties for treatment and risk management. The most important offender-related eligibility criterion I argued for is that the person's risk of reoffending be high enough that treatment is required but not so high that the risk cannot be managed in the community. This criterion is essential for public safety and appropriate use of resources. Finally, I noted that some prospective participants may have characteristics or problems that make it difficult for them to engage in treatment, and that guidelines as to whether these should exclude a person from treatment track eligibility altogether should be developed once it is known what resources will be available. 
The rest of the development I undertook was directed primarily at the third condition of penal minimalism, avoiding undue interference with liberty. I specified a way to determine how long a person should be subject to the requirements of the treatment track (to assist with the maintenance of proportionality). In the interests of transparency and procedural fairness, I set out who should be responsible for each major decision made in relation to the treatment track and how they should be made, and discussed how issues in relation to compliance with the requirements of the treatment track should be dealt with.

\section{Broader Contribution to Knowledge}

The application of the principle of penal minimalism to an alternative resolution such as the treatment track is an important contribution to knowledge because questions about state over-reach tend to be neglected in the enthusiasm for innovative responses to offending. The thesis demonstrates that penal minimalism is a useful framework for analysing whether new types of criminal justice interventions - particularly those that take place in the gap between conviction and sentence, which is currently unregulated are justified. It is the first attempt to integrate empirical evidence and criminal justice theory to create a principled approach to alternative responses to offending.

The finding that we do not know whether the risk assessment tools currently being used with sexual offenders are accurate with New Zealand men who have sexually assaulted an adult, particularly Māori men, has serious implications for current sentencing and correctional practice. Most importantly, there is no adequate evidence base for sentencing people in that group to preventive detention, or for imposing extended supervision orders (which impose restrictions on offenders living in the community for up to ten years after they have finished serving their sentence) or public protection orders (which enable the Department of Corrections to detain offenders who have finished serving their sentence on prison grounds). These are enormous infringments on the liberties of offenders and are not justified when we cannot even be certain how uncertain the risk assessment tools are. The accuracy of risk assessment tools is, of course, also important to decisions about treatment and parole. These may not affect offenders' rights to the same degree, but they have implications for public safety.

This research also helps to highlight the importance of focusing research efforts on intervention with ordinarily undetected perpetrators. It appears that a small group of them are responsible for a great deal of harm, but little is known about how to identify 
and intervene with them. This finding is of international significance: undetected perpetrators are of concern in every jurisdiction with low reporting and high attrition rates for sexual violence.

The theoretical development I have undertaken can be applied beyond the treatment track to thinking creatively about other possible alternatives to prison, particularly those with restorative and/or treatment bases. The accountability dimension of severity I propose could help to refute popular concern that alternatives are "soft options" and therefore not able to be used for serious types of offending or as a genuine alternative to prison. The theoretical development may also be useful for thinking about mitigation at sentencing, when offenders have undertaken a treatment programme or engaged in restorative justice pre-sentence. There is no systematic way for judges to take that into account, despite being required to under the Sentencing Act. The framework might accordingly be useful for maintaining proportionality in conventional sentencing by ensuring that the efforts offenders have been made are properly accounted for in the final sentence. The framework can also be adapted for use in other jurisdictions: the concerns are international though the details of sentencing methodologies differ.

Finally, the research demonstrates that it may be possible to re-design problem-solving courts, following the model discussed in this thesis, to ensure that they cannot be criticised for infringing unacceptably on the liberties of participants, while still being treatment-focused and more constructive than imprisonment. Again, this is important internationally as well as in New Zealand. Problem-solving courts are popular across North America and are increasingly being established in other jurisdictions. ${ }^{1}$

\section{A proposed empirical research agenda}

In this thesis, I have identified a large number of gaps in knowledge. To attain the ideal set out by the penal minimalism framework I adopted, all those gaps would need to be filled. In this section, however, I move beyond the ideal to consider in more pragmatic terms which pieces of research should be prioritised. I take into account the relative

Problem-Solving Courts: A Delivery Plan (Centre for Justice Innovation, London, 2016); Elizabeth Richardon, Katey Thom and Brian McKenna "The Evolution of Problem-Solving Courts in Australia and New Zealand: A Trans-Tasman Comparative Perspective" in Richard Wiener and Eve Brank (eds) Problem Solving Courts: Social Science and Legal Perspectives (Springer, New York, 2013); "Samoa launches new Alcohol and Drug Court" (Radio New Zealand, 15 February 2016) $<$ https://www.radionz.co.nz/international/pacific-news/296582/samoa-launches-new-alcohol-anddrug-court> 
importance of each area of knowledge to the development of the treatment track or other intervention intended to reduce sexual recidivism, the applicability of the desired knowledge to current practice, and the feasibility of undertaking the research.

\section{A First condition of penal minimalism: necessity}

I argued in Chapter 4 that it is likely that official conviction rates under-estimate sexual recidivism by men who have been convicted of a sexual offence, but that at this point we do not know how undetected offending is distributed between them. If it is not evenly distributed, then some of those who currently do not appear to need treatment to reduce their risk of sexual recidivism actually should receive it. If that were the case, then the condition that the intervention be necessary to reduce reoffending would be fulfilled.

It would be very useful to collect self-report data about undetected offending from men who have been convicted of sexually assaulting an adult. If possible, that self-report data should be triangulated with information about offences or offence-related behaviour from other sources, including any agencies working with the men and people close to them (such as partners and friends). The men in the sample should not have received treatment to reduce their risk of sexual recidivism, as the question being asked is whether more people need treatment than can currently access it.

I also argued that it would be useful to investigate the rates of repeat undetected sexual offending against adults by men who have never been convicted of sexually assaulting an adult, to establish whether the need for formal intervention with that group is as high as it appears on the basis of the data collected with American university students. Again, that self-report data could be triangulated with information from partners and friends.

Having more information about the extent and distribution of undetected sexual offending would be helpful for ensuring that an intervention such as the treatment track, which is intended to reduce sexual reoffending, is actually needed and therefore fulfils the first condition of penal minimalism. As a matter of principle, there should be strong evidence that intervention is necessary in order to prevent serious harm. Having information about the levels of undetected reoffending before an intervention such as the treatment track is established may also be useful for trying to measure its overall impact. I expect, however, that the overall reduction in sexual recidivism that a treatment track could achieve would be relatively low, given the fairly narrow range of perpetrators for whom it would be suitable (those whose offending is reported, prosecuted, are willing to plead guilty and enter the treatment track, who have committed offending of the appropriate 
degree of seriousness, and who are assessed as being at high enough risk of sexual recidivism to require treatment but not so high that their risk cannot be managed in the community). Any overall reduction in repeat sexual offending would also be difficult to isolate and attribute to the treatment track, given the possible effects of other initiatives and cultural change.

Pragmatically, I would venture that it is not imperative that research into the extent and distribution of undetected sexual offending be undertaken for the purposes of fulfilling the first condition of penal minimalism. There is probably already reason enough to believe that most sexual reoffending is undetected and that some offenders are less likely to be caught and convicted than others. Given the difficulty of researching undetected offending, in my view that work should not be required in order to establish a treatment track.

\section{B Second condition of penal minimalism: effectiveness}

\section{Ordinarily undetected perpetrators}

To be effective in reducing recidivism, the treatment track would need to bring into the criminal justice process men whose offending does not ordinarily result in a conviction. Accordingly, it needs to address factors which contribute to under-reporting and attrition in sexual cases.

To be able to say for sure how much of a difference (if any) establishing a treatment track could make to under-reporting and attrition, it would be helpful to have local quantitative data about the extent to which not wanting to go through the trial process and not wanting the perpetrator to be imprisoned affect victims' decisions whether to report offending and to continue with the investigation and prosecution. If these two factors play a substantial role in under-reporting and attrition, then the treatment track - an intervention intended to address the factors - would be more likely to be effective in reducing recidivism.

In terms of whether establishing a treatment track could incentivise guilty pleas - another way in which it could reduce attrition and thereby bring more perpetrators into the criminal justice process - it would be useful to know more about what factors actually influence a person to plead guilty. Is there a sizeable enough group of people accused of sexually assaulting an adult, who fit the eligibility criteria for the treatment track, who might plead guilty if the treatment track were available? It would be possible to forego that research and wait and see if the pilot attracts sufficient numbers. However, given the investment required to create a treatment track for men who would not ordinarily be 
convicted in particular, it may well not be worth the risk to pilot in the absence of further investigation about reasons for pleading guilty. That research would also help to determine whether the treatment track could coerce people into pleading guilty, which is important in relation to the third condition of penal minimalism.

Developing a risk assessment tool that would be suitable for use with ordinarily undetected perpetrators poses a considerable challenge. It may be that a structured professional judgement tool is most appropriate in the first instance, drawing together factors that have been empricially linked to repeat undetected perpetration. Another possibility would be to attempt to validate the VRS-SO with ordinarily undetected perpetrators, in a research setting. It would then need to be established whether the VRSSO can actually be scored meaningfully in a real-life assessment setting, where people will be less forthcoming about past offending behaviour and there is not the large amount of file information to draw on that accompanies most convicted sexual offenders.

Evaluating the effectiveness of a treatment programme with ordinarily undetected perpetrators also poses some challenge, though probably less than developing and/or validating a risk assessment tool. In the absence of information about actual perpetration levels in the ordinarily undetected perpetration population, it would be difficult to measure whether the treatment programme actually reduces recidivism. It may be that treatment change would have to substitute for recidivism as an outcome measure.

Overall, a great deal of work is needed to be able to identify who is most at risk of recidivism and to develop a treatment programme that would be effective with that group. It may, however, be justifiable to pilot a treatment track with that population, because the alternative is that there is no formal intervention with them whatsoever.

\section{Ordinarily convicted offenders}

Until we know, at the very least, the discriminative ability of the core New Zealand tools with New Zealand or Canadian contact adult and mixed offenders, we should not, in my view, claim that there is sufficient evidence that the risk assessment tools are accurate with men who have sexually assaulted an adult. Without that evidence, the effectiveness condition of penal minimalism is not satisfied.

In terms of a way forward, we should start with one high quality study validating the core New Zealand tools with New Zealand contact adult and mixed offenders and with Māori specifically that also establishes New Zealand norms (predicted recidivism rates for each 
risk level on a given tool). In designing that study, we should ensure that the relevant methodological features of the study match the way the tools would be used in practice in the treatment track. In the longer-term, we should continue to monitor the accuracy of the tools (both their discriminative ability and the stability of observed recidivism rates/correspondence between observed and predicted recidivism rates). Continued monitoring and replication of studies would allow for meta-analysis of studies with different samples, to produce more precise estimates of accuracy.

In addition to that empirical work, some policy development also should be undertaken. We should establish a standard for how accurate the tools have to be before their use is acceptable (and the standard may vary by context). That policy work is important, for the treatment track and for other criminal justice contexts such as preventive detention, extended supervision orders, public protection orders, and parole.

In terms of treatment, pragmatically we should continue to deliver treatment to contact adult and mixed offenders, and evaluate it using outcome data when possible (given the long timeframes required when base rates for official re-convictions are low). The uncertainty around the importance of the risk principle is actually reassuring in the treatment context, because it makes the current limitations of risk assessment less important than they otherwise would be in respect of treatment. Perhaps in terms of improving treatment, the focus should be on identifying treatment needs and targeting them successfully, and on producing well-designed evaluations. Doing so would help us to conclude that the second condition of penal minimalism is satisfied in terms of the effectiveness of treatment.

\section{Third condition of penal minimalism: avoiding undue interference with liberty}

Maintaining proportionality between the seriousness of the offending and the severity of the sentence is important for ensuring that criminal justice interventions do not interfere unduly with the liberty of the offender. In order to satisfy that requirement in respect of the treatment track, investigation of whether the two dimensions of sentence severity proposed, intrusiveness and accountability, do indeed capture what is onerous about different types of sentences, and whether the treatment track would in fact be of comparable severity to imprisonment is required.

The empirical investigation recommended into how people accused of offences make decisions about whether to plead guilty to serious offences, in particular sexual offences, 
is also necessary to ensure that the treatment track would not breach the third requirement of penal minimalism by coercing people into pleading guilty.

\section{Conclusion}

Overall, the state of knowledge does not yet support the establishment of a treatment track. In terms of the specific question asked in this thesis, we cannot yet conclude that the treatment track could comply with the principle of penal minimalism. Establishing a treatment track without undertaking the further work recommended in this thesis would not offer sufficient protection to the liberties of participants or to the safety of the community. 


\section{Appendix A: The New Statistics}

To the extent possible, I adopt the recommendations made by Geoff Cumming in The New Statistics. These recommendations were intended to guide the design and interpretation of new empirical research, but are also applicable to critiques of existing research, and I use them in that way.

The "new statistics" refers to a move away from null hypothesis significance testing (which yields $p$ values) towards routine use of estimation (a focus on effect size and confidence intervals) and meta-analysis. ${ }^{674}$ Cumming and other proponents of the new statistics reject null hypothesis significance testing on the basis that it can be misleading and that the information it provides is less useful than that provided by estimation. ${ }^{675}$

Cumming highlights the amount of uncertainty in research findings. He argues that null hypothesis significance testing creates a false sense of certainty (an effect is statistically significant or not) whereas reporting the confidence intervals around effect sizes allows us to appreciate the degree of uncertainty in findings. ${ }^{676}$ Cumming also emphasises the importance of replication, which must be done because sampling error means the results of a single study are unlikely to give a reliable estimate of the effect size. ${ }^{677}$ Replication also allows meta-analysis to be undertaken. Meta-analysis combines the findings of similar studies. It reduces uncertainty by yielding more precise estimates of effect sizes and can help make sense of findings that appear to conflict. ${ }^{678}$ Meta-analysis can also help to answer questions that were not addressed in the individual studies, for example whether a particular variable can account for variation in excess of what would be expected due to sampling variability (that is, acts as a moderating variable). ${ }^{679}$

In the discussion of risk assessment, I only report $p$ values when studies do not report confidence intervals. If studies report both $p$ values and confidence intervals, I report confidence intervals only. All confidence intervals reported are 95 per cent confidence intervals. Throughout the discussion, I highlight areas where replication and metaanalysis would be useful. I also suggest possible moderator variables that meta-analysis

\begin{tabular}{ll}
\hline 674 & At 6. \\
675 & For more information, see $21-38$. \\
676 & At $8-9$. \\
677 & At 120. \\
678 & At $181-187$. \\
679 & At $240-248$.
\end{tabular}


could test. When interpreting meta-analyses, I follow Cumming's recommendation that random effects models should be preferred over fixed effect models. ${ }^{680}$ 
Appendix B: Proportion of studies finding differences by subtype for non-core tools

\begin{tabular}{|c|c|c|c|c|}
\hline Tool & Finding & $\begin{array}{l}\text { Sexual } \\
\text { recidivism }\end{array}$ & $\begin{array}{l}\text { Non-Sexual Violent } \\
\text { recidivism }\end{array}$ & $\begin{array}{l}\text { Combined Sexual \& } \\
\text { Violent Recidivism }\end{array}$ \\
\hline \multirow[t]{6}{*}{ Static-99 } & $\begin{array}{l}\text { No differences } \\
\text { across } \quad \text { sub-types } \\
\text { (contact adult and } \\
\text { contact child only) }\end{array}$ & 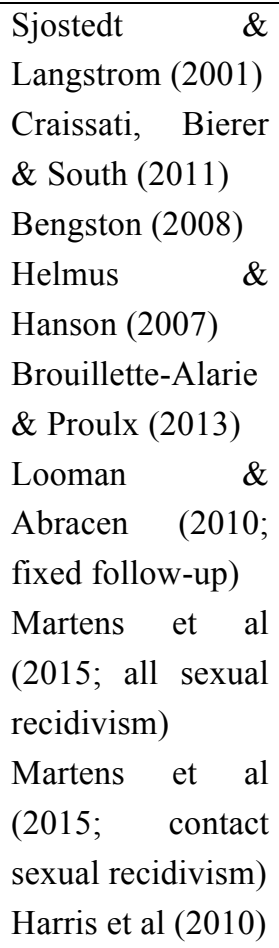 & $\begin{array}{l}\text { Brouillette-Alarie \& } \\
\text { Proulx (2011) } \\
\text { Bengston (2008) }\end{array}$ & $\begin{array}{l}\text { Looman \& Abracen } \\
\text { (2010; variable follow- } \\
\text { up) } \\
\text { Looman \& Abracen } \\
\text { (2010; fixed follow- } \\
\text { up) } \\
\text { Bengston (2008) } \\
\text { Martens et al (2015) } \\
\text { Hanson et al (2010) }\end{array}$ \\
\hline & $\begin{array}{lr}\text { No } & \text { differences } \\
\text { across } & \text { subtypes } \\
\text { (contact } \quad \text { adult, } \\
\text { contact child, and } \\
\text { mixed offenders) }\end{array}$ & & $\begin{array}{l}\text { Parent, Guay \& } \\
\text { Knight (2011) }\end{array}$ & \\
\hline & 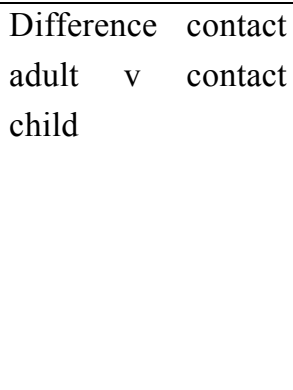 & 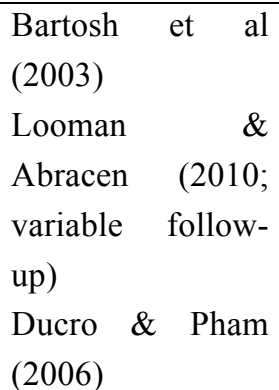 & Bartosh et al (2003) & $\begin{array}{l}\text { Bartosh et al (2003) } \\
\text { Rettenberger et al } \\
(2010) \\
\text { Ducro \& Pham (2006) }\end{array}$ \\
\hline & $\begin{array}{l}\text { Difference contact } \\
\text { adult only }\end{array}$ & & & \\
\hline & $\begin{array}{l}\text { Difference contact } \\
\text { child only }\end{array}$ & & & \\
\hline & $\begin{array}{l}\text { Difference mixed } \\
\text { only }\end{array}$ & $\begin{array}{l}\text { Parent, Knight \& } \\
\text { Guay (2011) }\end{array}$ & & \\
\hline
\end{tabular}




\begin{tabular}{|c|c|c|c|c|}
\hline & Difference IF only & $\begin{array}{l}\text { Hanson et } \\
(2007)\end{array}$ & & Hanson et al (2007) \\
\hline \multirow[t]{7}{*}{ Static-2002 } & $\begin{array}{l}\text { No differences } \\
\text { across } \quad \text { sub-types } \\
\text { (contact adult and } \\
\text { contact child only) }\end{array}$ & $\begin{array}{l}\text { Bengston (2008) } \\
\text { Helmus \& } \\
\text { Hanson (2007) } \\
\text { Martens et al } \\
(2015 \text {; contact } \\
\text { sexual recidivism) }\end{array}$ & Bengston (2008) & $\begin{array}{l}\text { Looman \& Abracen } \\
\text { (2010; variable follow- } \\
\text { up) } \\
\text { Bengston (2008) } \\
\text { Martens et al (2015) }\end{array}$ \\
\hline & $\begin{array}{lr}\text { No } & \text { differences } \\
\text { across } & \text { subtypes } \\
\text { (contact } & \text { adult, } \\
\text { contact } & \text { child and } \\
\text { mixed offenders) }\end{array}$ & & $\begin{array}{l}\text { Parent, Knight \& } \\
\text { Guay (2011) }\end{array}$ & \\
\hline & 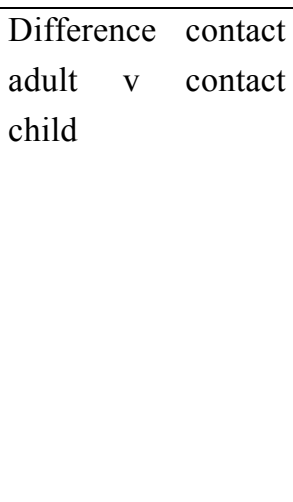 & $\begin{array}{lr}\begin{array}{lr}\text { Looman } \\
\text { Abracen }\end{array} & \text { \& } \\
\text { variable } & \text { follow- } \\
\text { up) } & \\
\text { Looman } & \& \\
\text { Abracen } & (2010 ; \\
\text { fixed follow-up) } \\
\text { Martens et al } \\
\text { (2015; all sexual } \\
\text { recidivism) }\end{array}$ & & $\begin{array}{l}\text { Looman \& Abracen } \\
\text { (2010; fixed follow- } \\
\text { up) }\end{array}$ \\
\hline & $\begin{array}{l}\text { Difference contact } \\
\text { adult only }\end{array}$ & & & \\
\hline & $\begin{array}{l}\text { Difference contact } \\
\text { child only }\end{array}$ & $\begin{array}{l}\text { Parent, Knight \& } \\
\text { Guay (2011) }\end{array}$ & & \\
\hline & $\begin{array}{l}\text { Difference mixed } \\
\text { only }\end{array}$ & & & \\
\hline & Difference IF only & & & \\
\hline \multirow[t]{2}{*}{ RM2000 ${ }^{681}$} & $\begin{array}{l}\text { No differences } \\
\text { across sub-types } \\
\text { (contact adult and } \\
\text { contact child only) }\end{array}$ & $\begin{array}{l}\text { Bengston (2008) } \\
\text { Barnett et al } \\
(2010)\end{array}$ & $\begin{array}{l}\text { Barnett, Wakeling \& } \\
\text { Howard (2010) }\end{array}$ & $\begin{array}{l}\text { Looman \& Abracen } \\
\text { (2010; variable follow- } \\
\text { up) } \\
\text { Looman \& Abracen } \\
\text { (2010; fixed follow- } \\
\text { up) } \\
\text { Barnett, Wakeling \& } \\
\text { Howard (2010) } \\
\text { Bengston (2008) }\end{array}$ \\
\hline & differences & & & \\
\hline
\end{tabular}

681 I report results for the sexual subscale for sexual recidivism, the violent subscale for violent recidivism, and the combined subscale for combined sexual and violent recidivism. 


\begin{tabular}{|c|c|c|c|c|}
\hline & $\begin{array}{l}\text { across subtypes } \\
\text { (contact } \\
\text { contact child and } \\
\text { mixed offenders) }\end{array}$ & & & \\
\hline & $\begin{array}{ll}\text { Difference } & \text { contact } \\
\text { adult v contact } \\
\text { child }\end{array}$ & 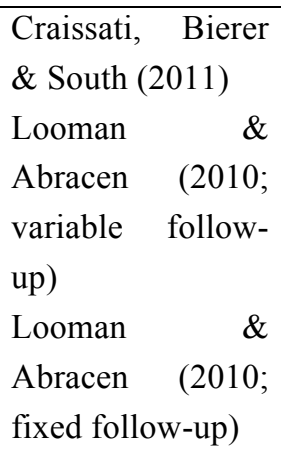 & Bengston (2008) & \\
\hline & $\begin{array}{l}\text { Difference contact } \\
\text { adult only }\end{array}$ & & & \\
\hline & $\begin{array}{l}\text { Difference contact } \\
\text { child only }\end{array}$ & $\begin{array}{l}\text { Parent, Knight \& } \\
\text { Guay (2011) }\end{array}$ & & \\
\hline & $\begin{array}{l}\text { Difference mixed } \\
\text { only }\end{array}$ & & $\begin{array}{l}\text { Parent, Guay \& } \\
\text { Knight }(2011)\end{array}$ & \\
\hline & $\begin{array}{l}\text { Difference IF child } \\
\text { only }\end{array}$ & & & \\
\hline \multirow[t]{7}{*}{ MnSOST-R } & $\begin{array}{l}\text { No } \\
\text { across } \\
\text { (contact } \text { adult and } \\
\text { contact child only) }\end{array}$ & $\begin{array}{l}\text { Bartosh et al } \\
(2003)\end{array}$ & Bartosh et al (2003) & Bartosh et al (2003) \\
\hline & $\begin{array}{lr}\text { No } & \text { differences } \\
\text { across } & \text { subtypes } \\
\text { (contact } & \text { adult, } \\
\text { contact child and } \\
\text { mixed offenders) }\end{array}$ & & & \\
\hline & $\begin{array}{ll}\text { Difference } & \text { contact } \\
\text { adult v } & \text { contact } \\
\text { child } & \end{array}$ & & & \\
\hline & $\begin{array}{l}\text { Difference contact } \\
\text { adult only }\end{array}$ & & & \\
\hline & $\begin{array}{l}\text { Difference contact } \\
\text { child only }\end{array}$ & & & \\
\hline & $\begin{array}{l}\text { Difference mixed } \\
\text { only }\end{array}$ & $\begin{array}{l}\text { Parent, Knight \& } \\
\text { Guay (2011) }\end{array}$ & $\begin{array}{l}\text { Parent, Knight \& } \\
\text { Guay }(2011)\end{array}$ & \\
\hline & $\begin{array}{l}\text { Difference IF child } \\
\text { only }\end{array}$ & & & \\
\hline SORAG & $\begin{array}{lr}\text { No } & \text { differences } \\
\text { across } & \text { sub-types }\end{array}$ & Harris et al (2010) & & $\begin{array}{l}\text { Rettenberger et al } \\
(2010)\end{array}$ \\
\hline
\end{tabular}




\begin{tabular}{|c|c|c|c|c|}
\hline & $\begin{array}{l}\text { (contact adult and } \\
\text { contact child only) }\end{array}$ & & & Harris et al (2010) \\
\hline & $\begin{array}{lr}\text { No differences } \\
\text { across } \\
\text { (contact adypes } \\
\text { contact child and } \\
\text { mixed offenders) }\end{array}$ & & & \\
\hline & 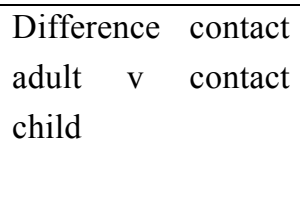 & $\begin{array}{l}\text { Rettenberger \& } \\
\text { Eher (2007) } \\
\text { Ducro \& Pham } \\
(2006)\end{array}$ & Bartosh et al (2003) & $\begin{array}{l}\text { Bartosh et al (2003) } \\
\text { Ducro \& Pham (2006) }\end{array}$ \\
\hline & $\begin{array}{l}\text { Difference contact } \\
\text { adult only }\end{array}$ & & $\begin{array}{l}\text { Parent, Guay \& } \\
\text { Knight (2011) }\end{array}$ & \\
\hline & $\begin{array}{l}\text { Difference contact } \\
\text { child only }\end{array}$ & & & \\
\hline & $\begin{array}{l}\text { Difference mixed } \\
\text { only }\end{array}$ & $\begin{array}{l}\text { Parent, Knight \& } \\
\text { Guay (2011) }\end{array}$ & & \\
\hline & $\begin{array}{l}\text { Difference IF child } \\
\text { only }\end{array}$ & & & \\
\hline & $\begin{array}{l}\text { Difference EF child } \\
\text { only }\end{array}$ & $\begin{array}{lll}\begin{array}{l}\text { Bartosh } \\
(2003)\end{array} & \text { et } & \text { al } \\
\end{array}$ & & \\
\hline \multirow[t]{6}{*}{ VRAG } & $\begin{array}{l}\text { No differences } \\
\text { across sub-types } \\
\text { (contact adult and } \\
\text { contact child only) }\end{array}$ & Harris et al (2010) & & Harris et al (2010) \\
\hline & $\begin{array}{lr}\text { No } & \text { differences } \\
\text { across } & \text { subtypes } \\
\text { (contact adult, } \\
\text { contact child and } \\
\text { mixed offenders) }\end{array}$ & & & \\
\hline & 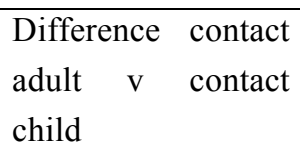 & & & \\
\hline & $\begin{array}{l}\text { Difference contact } \\
\text { adult only }\end{array}$ & & $\begin{array}{l}\text { Parent, Guay \& } \\
\text { Knight (2011) }\end{array}$ & \\
\hline & $\begin{array}{l}\text { Difference contact } \\
\text { child only }\end{array}$ & & & \\
\hline & Difference mixed & Parent, Knight \& & & \\
\hline
\end{tabular}

682 Rettenberger and Eher broke their contact child offenders down into intra and extra-familial offenders, but too few intra-familial offenders reoffended to calculate an AUC for them. I have accordingly treated the study as if it compared all contact child offenders with contact adult offenders, although it should be borne in mind that the contact child offenders are exclusively extrafamilial offenders. 


\begin{tabular}{|c|c|c|c|c|}
\hline & only & Guay (2011) & & \\
\hline & $\begin{array}{l}\text { Difference IF child } \\
\text { only }\end{array}$ & & & \\
\hline & $\begin{array}{l}\text { Difference EF child } \\
\text { only }\end{array}$ & & & \\
\hline SVR-20 & $\begin{array}{lr}\text { No } & \text { differences } \\
\text { across } & \text { sub-types } \\
\text { (contact } & \text { adult and } \\
\text { contact child only) }\end{array}$ & $\begin{array}{l}\text { Rettenberger, } \\
\text { Boer \& Eher } \\
\text { (2011; any sexual } \\
\text { offence) } \\
\text { Rettenberger, } \\
\text { Boer \& Eher } \\
\text { (2011; contact } \\
\text { sexual offence) }\end{array}$ & & $\begin{array}{l}\text { Rettenberger, Boer \& } \\
\text { Eher (2011) }\end{array}$ \\
\hline & $\begin{array}{lr}\text { No } & \text { differences } \\
\text { across } & \text { subtypes } \\
\text { (contact } & \text { adult, } \\
\text { contact } & \text { child and } \\
\text { mixed offenders) }\end{array}$ & & & \\
\hline & 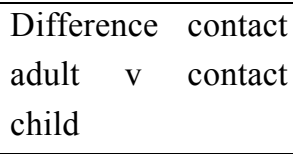 & & & \\
\hline & $\begin{array}{l}\text { Difference contact } \\
\text { adult only }\end{array}$ & & $\begin{array}{l}\text { Parent, Guay \& } \\
\text { Knight (2011) }\end{array}$ & \\
\hline & $\begin{array}{l}\text { Difference contact } \\
\text { child only }\end{array}$ & & & \\
\hline & $\begin{array}{l}\text { Difference mixed } \\
\text { only }\end{array}$ & $\begin{array}{l}\text { Parent, Knight \& } \\
\text { Guay (2011) }\end{array}$ & & \\
\hline & $\begin{array}{l}\text { Difference IF child } \\
\text { only }\end{array}$ & & & \\
\hline & $\begin{array}{l}\text { Difference EF child } \\
\text { only }\end{array}$ & & & $\begin{array}{lll}\text { Rettenberger et al } \\
(2010)\end{array}$ \\
\hline
\end{tabular}





\section{BIBLIOGRAPHY}

\section{Cases}

Hessell v R [2010] NZSC 135, [2011] 1 NZLR 607.

New Health New Zealand Inc v South Taranaki District Council [2014] NZHC 395.

$R v A M$ [2010] NZCA 114, [2010] 2 NZLR 750.

$R v$ Taueki [2005] 3 NZLR 372 (CA).

Te Whatu v Department of Corrections [2017] NZHC 3233.

Wilson v New Zealand Parole Board and Chief Executive of Department of Corrections [2012] NZHC 2247.

Ewert $v R 2015$ FC 1093.

$R v$ Ewert 2016 FCA 203.

$R v$ Ewert $2018 \mathrm{SCC} 30$.

McKinnon v Government of the United States and another [2008] UKHL 59.

$R$ (Adams) v Secretary of State for Justice [2011] UKSC 18, [2012] 1 AC 48.

Deweer v Belgium (1980) 2 EHRR 439.

\section{Legislation}

Bail Amendment Act 2013.

Bill of Rights Act 1990, s 11.

Crimes Act 1961.

Crimes Amendment Act (No. 3) 1985.

Evidence Act 2006.

Evidence Amendment Act (No. 2) 1985.

Parole Act 2002.

Sentencing Act 2002.

Sentencing Council Act 2007.

Summary Proceedings Amendment Act (No. 4) 1985.

\section{Books and Chapters in Books}

Annalise Acorn Compulsory Compassion: A Critique of Restorative Justice (UBC Press, Vancouver, 2004). 
Adult Sexual Assault Programme Manual (Wellstop, Wellington, 2009).

Adult Sex Offender Treatment Programme: Background, theory and overview (Department of Corrections).

Solicitor-General's Prosecution Guidelines (Crown Law, 2013).

Dana Anderson and Karl Hanson "An Actuarial Tool to Assess Risk of Sexual and Violent Recidivism Among Sexual Offenders" in Randy Otto and Kevin Douglas (eds) Handbook of Violence Risk Assessment (Routledge, New York, 2010).

Andrew Ashworth Sentencing and Criminal Justice (6 ed, Cambridge University Press, Cambridge, 2015).

Andrew Ashworth and Lucia Zedner Preventive Justice (Oxford University Press, New York, 2014).

Andrew Ashworth, Lucia Zedner and Patrick Tomlin (eds) Prevention and the Limits of the Criminal Law (Oxford University Press, Oxford, 2013).

Andrew Ashworth and Mike Redmayne The Criminal Process (4 ed, Oxford University Press, New York, 2010).

Andrew von Hirsch and Andrew Ashworth Proportionate Sentencing: Exploring the Principles (Oxford University Press, New York, 2005).

John Baldwin and Michael McConville Negotiated Justice (London, Martin Robertson, 1977).

Anthony Beech, Caroline Oliver, Dawn Fisher and Richard Beckett STEP 4: The Sex Offender Treatment Programme in Prison: addressing the offending behaviour of rapists and serial murderers (Birmingham University, Birmingham, 2006).

James Bonta and DA Andrews The Psychology of Criminal Conduct (6 ed, Routledge, New York, 2017). 
Adam Carter and Ruth Mann "The Strengths of Treatment for Sexual Offending” in DR Laws and W O'Donahue (eds) Treatment of Sex Offenders (Springer International Publishing, Switzerland, 2016).

Geoff Cumming Understanding The New Statistics: Effect Sizes, Confidence Intervals, and Meta-Analysis (Routledge, New York, 2012).

Kathleen Daly and Brigitte Bouhours Rape and Attrition in the Legal Process: A Comparative Analysis of Five Countries (University of Chicago, Chicago, 2010).

RA Duff Punishment, Communication and Community (Oxford University Press, Oxford, 2001).

Susan Estrich Real Rape (Harvard University Press, Cambridge Massachusetts, 1987).

Joel Feinberg The Moral Limits of the Criminal Law Volume 1: Harm to Others (Oxford University Press, Oxford, 1987).

George Fletcher Rethinking Criminal Law (Little Brown, Boston, 1978).

Richard Frase "Limiting Retributivism" in Michael Tonry and Richard Frase (eds) The Future of Imprisonment (Oxford University Press, New York, 2003).

HLA Hart Punishment and Responsibility (2 ed, Oxford University Press, Oxford, 2008).

Leslie Helmus, Karl Hanson and Kelly Morton-Bourgon "International Comparisons of the Validity of Actuarial Risk Tools for Sexual Offenders, with a Focus on Static-99" in Douglas Boer, Reinhard Eher, Leam Craig, Michael Miner and Friedemann Pfafflin (eds) International Perspectives on the Assessment and Treatment of Sexual Offenders: Theory, Practice, and Research (Wiley-Blackwell, Chichester, 2011).

Ralph Henham Sentence Discounts and the Criminal Process (Ashgate, Aldershot, 2001).

Barbara Hudson Justice in the Risk Society (Sage, London, 2003).

D Richard Laws and Tony Ward Desistance from Sex Offending: Alternatives to Throwing Away the Keys (The Guilford Press, New York, 2011). 
WR Lindsay, AM Michie and F Lambrook "Community-based treatment programmes for sex offenders with intellectual disabilities" in LA Craig, WR Lindsay and KD Browne (eds) Assessment and Treatment of Sex Offenders with Intellectual Disabilities (John Wiley \& Sons, Chitchester, 2010).

Jo Lovett and Liz Kelly Different systems, similar outcomes? Tracking attrition in reported rape cases across Europe (Child and Women Abuse Studies Unit, London Metropolitan University, 2009).

Kathy Mack and Sharyn Roach Anleu Pleading Guilty: Issues and Practices (Australian Institute of Judicial Administration Incorporated, Melbourne, 1995).

N Malamuth, C Heavey and D Linz "Predicting men's anti-social behaviour against women: The Interaction Model of Sexual Aggression" in GN Hall, R Hirschman, J Graham and M Zaragoza (eds) Sexual Aggression: Issues in Etiology, Assessment and Treatment (Hemisphere, Washington DC, 1993).

Ruth Mann, M Daniels and WL Marshall "The use of role plays in developing empathy" in YM Fernandez (ed) In their shoes: Examining the issue of empathy and its place in the treatment of offenders (Wood 'N' Barnes, Oklahoma City, 2002).

William Marshall, Liam Marshall, Geris Serran and Matt O’Brien Rehabilitating Sexual Offenders: A Strength-Based Approach (American Psychological Association, Washington DC, 2011).

Elisabeth McDonald and Yvette Tinsley (eds) From "Real Rape" to Real Justice: Prosecuting Rape in New Zealand (Victoria University Press, Wellington, 2011).

John Stuart Mill On Liberty (Cambridge University Press, Cambridge, 2011).

Norval Morris and Michael Tonry Between Prison and Probation: Intermediate Punishments in a Rational Sentencing System (Oxford University Press, New York, 1990).

Norval Morris The Future of Imprisonment (University of Chicago Press, Chicago, 1974). 
Graeme Panckhurst "Consent in Rape: An Elusive Concept" in J Bruce Robertson (ed) Essays on Criminal Law (Brookers, Wellington, 2004).

Khylee Quince "Maori tikanga and the criminal justice system" in Julia Tolmie and Warren Brookbanks (eds) Criminal Justice in New Zealand (LexisNexis, Wellington, 2007).

Elizabeth Richardon, Katey Thom and Brian McKenna "The Evolution of ProblemSolving Courts in Australia and New Zealand: A Trans-Tasman Comparative Perspective" in Richard Wiener and Eve Brank (eds) Problem Solving Courts: Social Science and Legal Perspectives (Springer, New York, 2013).

Bruce Robertson (ed) Adams on Criminal Law (online looseleaf ed, Brookers).

Edgardo Rotman Beyond Punishment: A New View on the Rehabilitation of Criminal Offenders (Greenwood Press, Connecticut, 1990).

Andrew Sanders, Richard Young and Mandy Burton Criminal Justice (4 ed, Oxford University Press, Oxford, 2010).

AP Simester and Warren Brookbanks Principles of Criminal Law (4 ed, Thomson Reuters, 2012).

AP Simester, Antje du Bois-Pedain and Ulfrid Neumann (eds) Liberal Criminal Theory: Essays for Andreas von Hirsch (Hart Publishing, Oxford, 2014).

RG Singer Just Deserts: Sentencing Based on Equality and Desert (Ballinger, Lexington, 1979).

Armon Tamatea, Nick Lascelles and Devon Polaschek "Criminal Justice Psychology in Aotearoa New Zealand: Issues for Practitioners" in Waikaremoana Waitoki, Jacqueline Feather, Neville Robertson and Julia Rucklidge (eds) Professional Practice of Psychology in Aotearoa New Zealand (3 ed, The New Zealand Psychological Society, Wellington). 
Jennifer Temkin and Barbara Krahé Sexual Assault and the Justice Gap: A Question of Attitude (Hart Publishing, Oxford and Portland, Orgeon, 2008).

Michael Tonry "Proportionality, Parsimony and Interchangeability of Punishments" in Antony Duff and David Garland (eds) A Reader on Punishment (Oxford University Press, New York, 1994).

Andrew von Hirsch, Andrew Ashworth and Julian Roberts (eds) Principled Sentencing: Readings on Theory and Policy (3 ed, Hart Publishing, Oregon, 2009).

Andrew von Hirsch and Andrew Ashworth Proportionate Sentencing: Exploring the Principles (Oxford University Press, Oxford, 2005).

Andrew von Hirsch "Censure and Proportionality" in Antony Duff and David Garland (ed) A Reader on Punishment (Oxford University Press, Oxford, 1994).

Andrew von Hirsch Doing Justice: The Choice of Punishments (Hill and Wang, New York, 1976).

Waikaremoana Waitoki, Jacqueline Feather, Neville Robertson and Julia Rucklidge Professional Practice of Psychology in Aotearoa New Zealand (3 ed, The New Zealand Psychological Society, Wellington, 2016).

David Wexler and Bruce Winick (eds) Law in a Therapeutic Key: Developments in Therapeutic Jurisprudence (Carolina Academic Press, North Carolina, 1996).

David Wexler and Bruce Winick Essays in Therapeutic Jurisprudence (Carolina Academic Press, North Carolina, 1992).

Nick Wilson, Glen Kilgour and Devon Polaschek "Treating high-risk rapists in a New Zealand intensive prison programme" in Devon Polaschek (ed) Treatment Programmes for High Risk Offenders (Routledge, New York, 2016).

Stephen Wong, Mark Olver, Terry Nicholaichuk and Audrey Gordon Violence Risk Scale: Sex Offender Version (2009). 
Pamela Yates and Drew Kingston "The Shortcomings of Sexual Offender Treatment: Are We Doing Something Wrong?" in DR Laws and W O'Donahue (eds) Treatment of Sex Offenders (Springer International Publishing, Switzerland, 2016).

Lucia Zedner Criminal Justice (Oxford University Press, Oxford, 2004).

Howard Zehr Changing Lenses: A New Focus for Crime and Justice (Herald Press, Scottsdale Pennsylvania,1990).

\section{Journal Articles}

Antonia Abbey, Angela Jacques-Tiura and James LeBreton "Risk Factors for Sexual Aggression in Young Men” (2011) 37 Aggressive Behavior 450.

Antonia Abbey, Rhiana Wegner, Jennifer Pierce and Angela Jacques-Tiura "Patterns of Sexual Aggression in a Community Sample of Young Men: Risk Factors Associated with Persistence, Desistance, and Initiation Over a 1-Year Interval" (2011) Psychology of Violence 1.

Antonia Abbey, Michele Parkhill, Renee BeShears, A Monique Clinton-Sherrod and Tina Zawaki "Cross-Sectional Predictors of Sexual Assault Perpetration in a Community Sample of Single African-American and Caucasian Men" (2006) 32 Aggressive Behavior 54.

Sharyn Roach Anleu and Kathy Mack "Intersections Between In-Court Procedures and the Production of Guilty Pleas" (2009) 42 Australian and New Zealand Journal of Criminology 1.

Andrew Ashworth "Some doubts about restorative justice" (1993) 2 Criminal Law Forum 277.

Kelly Babchishin, Julie Blais and Leslie Helmus "Do Static Risk Factors Predict Differently for Aboriginal Sexual Offenders? A Multi-site Comparison Using the Original and Revised Static-99 and Static-2002 Scales" (2012) 54 Canadian J Criminology \& Crim Just 1. 
Leonard Bard, Danielle Carter, David Cerce, Raymond Knight, Ruth Rosenberg and Beth Schneider "A Descriptive Study of Rapists and Child Molesters: Developmental, Clinical, and Criminal Characteristics" (1987) 5 Behavioral Sciences and the Law 203.

Mirko Bargaric "Injecting Content into the Mirage that is Proportionality in Sentencing" (2013) 25 NZULR 411.

Darci Bartosh, Tina Garby, Deborah Lewis and Steve Gray "Differences in the Predictive Validity of Actuarial Risk Assessments in Relation to Sex Offender Type" (2003) 47 International Journal of Offender Therapy and Comparative Criminology 422.

Andrew Bates, Louise Falshaw, Carmen Corbett, Vaneeta Patel and Caroline Friendship "A follow-up study of sex offenders treated by Thames Valley Sex Offender Group Work Programme, 1995-1999” (2004) 10 Journal of Sexual Aggression 29.

DJ Baxter, WL Marshall, HE Barbaree, PR Davidson and PB Malcolm "Deviant Sexual Behavior: Differentiating Sex Offenders by Criminal and Personal History, Psychometric Measures, and Sexual Response” (1984) 11 Criminal Justice and Behavior 477.

Sarah Beggs and Randolph Grace "Assessment of Dynamic Risk Factors: An Independent Validation Study of the Violence Risk Scale - Sex Offender Version" (2010) 22 Sexual Abuse 234.

Sarah Beggs and Randolph Grace "Psychopathy, Intelligence, and Recidivism in Child Molesters: Evidence of an Interaction Effect" (2008) 35 Criminal Justice and Behavior 683.

Susanne Bengston "Is newer better? A cross-validation of the Static-2002 and the Risk Matrix 2000 in a Danish sample of sexual offenders" (2008) 14 Psychology, Crime and Law 85.

Pamela Blair, David Marcus and Marcus Boccaccini "Is There an Allegiance Effect for Assessment Instruments? Actuarial Risk Assessment as an Exemplar" (2008) 15 Clinical Psychology 346.

Richard Boldt "Rehabilitative Punishment and the Drug Treatment Court Movement" (1998) 76 Wash ULQ 1206. 
Guy Bourgon and Barbara Armstrong "Transferring the principles of effective treatment into a "real world" prison setting" (2005) 11 Psychology, Public Policy and Law 347.

John Bronsteen, Christopher Buccafusco and Jonathan Masur "Retribution and the Experience of Punishment" (2010) 98 Cal L Rev 1463.

Jennifer Brown, Carys Hamilton and Darragh O’Neill “Characteristics associated with rape attrition and the role played by scepticisim or legal rationality by investigators and prosecutors" (2007) 13 Psychology Crime and Law 355.

John Burrows “Academics and Law Reform” (2013) 25 NZULR 667.

Esther Calzada, Elissa Brown and Megan Doyle "Psychiatric Symptoms as a Predictor of Sexual Aggression Among Male College Students” (2011) 20 Journal of Aggression, Maltreatment and Trauma 726.

Michael Cavadino and James Dignan "Reparation, Retribution and Rights" (1997) 4 International Review of Victimology 233.

Jackie Craissati, Klive Bierer and Rebecca South "Risk, reconviction, and "sexually risky behaviour" in sex offenders (2011) 17 Journal of Sexual Aggression 135.

Kathleen Daly "Restorative Justice: The Real Story" (2002) 4 Punishment and Society 55.

Andrew Day, Armon Tamatea, Sharon Casey and Lynore Geia "Assessing Violence Risk with Aboriginal and Torres Strait Islander Offenders: Considerations for Forensic Practice" (2018) Psychiatry, Psychology and Law 1.

Andrew Day, Stuart Ross, Sharon Casey, James Vess, Diana Johns and Gaynor Hobbs “The Intensity and Timing of Sex Offender Treatment" (2017) Sexual Abuse 1.

Louise Falshaw, Andrew Bates, Vaneeta Patel, Carmen Corbett and Caroline Friendship "Assessing reconviction, reoffending and recidivism in a sample of UK sexual offenders" (2003) 8 Legal and Criminological Psychology 207. 
Caroline Friendship, Ruth Mann and Tony Beech "Evaluation of a national prison-based treatment program for sexual offenders in England and Wales" (2003) 18 Journal of Interpersonal Violence 744.

Theresa Gannon, Rachael Collie, Tony Ward and Jo Thakker "Rape: Psychopathology, Theory and Treatment” (2008) 28 Clinical Psychology Review 982.

Bill Glaser "Treaters or punishers? The ethical role of mental health clinicians in sex offender programs" (2009) 14 Aggression and Violent Behavior 248.

Svenja Goebbels, Tony Ward and Gwenda Willis "An integrative theory of desistance from sex offending" (2012) 17 Aggression and Violent Behavior 453.

David Gray "Punishment as Suffering” (2010) 63 Vand L Rev 1619.

AN Groth, RE Longo and JB McFadin "Undetected recidivism among rapists and child molesters" (1982) 28 Crime and Delinquency 450.

Jean Hampton "Correcting Harms versus Righting Wrongs: The Goal of Retribution" (1992) 39 UCLA L Rev 1659.

Karl Hanson "Assessing the Calibration of Actuarial Risk Scales: A Primer on the E/O Index" (2017) 44 Criminal Justice and Behavior 26.

Karl Hanson "Treating sexual offenders: how did we get here and where are we headed?" (2014) 20 Journal of Sexual Aggression 3.

Karl Hanson, Guy Bourgon, Leslie Helmus and Shannon Hodgson "The Principles of Effective Correctional Treatment Also Apply to Sexual Offenders" (2009) 36 Criminal Justice and Behavior 865.

Karl Hanson and Kelly Morton-Bourgon "The accuracy of recidivism risk assessments for sexual offenders: A meta-analysis of 118 prediction studies” (2009) 21 Psychological Assessment 1. 
Karl Hanson, Guy Bourgon, Leslie Helmus and Shannon Hodgson "The Principles of Effective Correctional Treatment Also Apply to Sexual Offenders: A Meta-Analysis" (2009) 36 Criminal Justice and Behavior 865.

Karl Hanson and Kelly Morton-Bourgon "The Characteristics of Persistent Sexual Offenders: A Meta-Analysis of Recidivism Studies" (2005) 73 Journal of Consulting and Clinical Psychology 1154.

Karl Hanson "Recidivism and Age: Follow-Up Data from 4673 Sexual Offenders" (2002) 17 Journal of Interpersonal Violence 1046.

Karl Hanson and Andrew Harris "Where Should We Intervene? Dynamic Predictors of Sexual Assault Recidivism” (2000) 27 Criminal Justice and Behavior 6.

Karl Hanson and Terry Nicholaichuk "A cautionary note regarding Nicholaichuk et al" (2000) 12 Sexual Abuse: A Journal of Research and Treatment 289.

Karl Hanson and David Thornton "Improving risk assessments for sex offenders: A comparison of three actuarial scales" (2000) 24 Law and Human Behavior 119.

Karl Hanson and Monique Bussière "Predicting relapse: A meta-analysis of sexual recidivism studies" (1998) 66 Journal of Consulting and Clinical Psychology 348.

Sara Hare “Intimate Partner Violence: Victims' Opinions About Going to Trial” (2010) $25 \mathrm{~J}$ Fam Viol 765.

Robert Hare, Danny Clark, Martin Grann and David Thornton "Psychopathy and the Predictive Validity of the PCL-R: An International Perspective" (2000) 18 Behavioral Sciences and the Law 623.

Leigh Harkins and Anthony Beech "A review of the factors that can influence the effectiveness of sexual offender treatment: Risk, need, responsivity, and process issues" (2007) 12 Aggression and Violent Behavior 615.

Danielle Harris, Paul Mazerolle and Raymond Knight "Understanding Male Sexual Offending: A Comparison of General and Specialist Theories” (2009) 36 Criminal Justice and Behavior 1051. 
Danielle Harris, Stephen Smallbone, Susan Dennison and Raymond Knight "Specialization and Versatility in Sexual Offenders Referred for Civil Commitment" (2009) 37 Journal of Criminal Justice 37.

Grant Harris, Christopher Lowenkamp and Zoe Hilton "Evidence for Risk Estimate Precision: Implications for Individual Risk Communication” (2015) 33 Behav Sci Law 111.

Grant Harris, Marnie Rice and Vernon Quinsey "Allegiance or Fidelity? A Clarifying Reply" (2010) 17 Clinical Psychology 82.

Grant Harris, Marnie Rice, Vernon Quinsey, Martin Lalumiere, Douglas Boer and Carol Lang “A Multisite Comparison of Actuarial Risk Assessments for Sex Offenders" (2003) 15 Psychological Assessment 413.

Leslie-Maaike Helmus and David Thornton "Stability and Predictive and Incremental Accuracy of the Individual Items of Static-99R and Static-2002R in Predicting Sexual Recidivism: A Meta-Analysis” (2015) 42 Criminal Justice and Behavior 917.

Leslie Helmus, Kelly Babchishin and Julie Blais "Predictive Accuracy of Dynamic Risk Factors for Aboriginal and Non-Aboriginal Sex Offenders: An Exploratory Comparison Using STABLE-2007' (2012) 56 International Journal of Offender Therapy and Comparative Criminology 856.

Leslie Helmus, Karl Hanson, David Thornton, Kelly Babchishin and Andrew Harris "Absolute Recidivism Rates Predicted by Static-99R and Static-2002R Sex Offender Risk Assessment Tools Vary Across Samples: A Meta-Analysis” (2012) 39 Criminal Justice and Behavior 1148.

Leslie Helmus and Karl Hanson "Predictive Validity of the Static-99 and Static-2002 for Sex Offenders on Community Supervision” (2007) 2 Sexual Offender Treatment 1.

Marianne Hester and Sarah-Jane Lilley "Rape investigation and attrition in acquaintance, domestic violence and historical rape cases” (2016) J Investig Psych Offender Profil 1. 
Martin Hildebrand, Corine de Ruiter and Vivienne de Vogel "Psychopathy and Sexual Deviance in Treated Rapists: Association with Sexual and Nonsexual Recidivism" (2004) 16 Sexual Abuse 1.

Morris Hoffman "Therapeutic Jurisprudence, Neo-Rehabilitationism, and Judicial Collectivism: The Least Dangerous Branch Becomes Most Dangerous" (2002) 29 Fordham Urban LJ 2063.

Katrin Hohl and Elisabeth Stanko "Complaints of rape and the criminal justice system: Fresh evidence on the attrition problem in England and Wales" (2015) 12 European Journal of Criminology 325.

Peggy Fulton Hora, William Schma and John Rosenthal "Therapeutic Jurisprudence and the Drug Court Movement: Revolutionizing the Criminal Justice System's Response to Drug Abuse and Crime in America” (1999) 74 Notre Dame L Rev 439.

Philip Howard, Georgia Barnett and Ruth Mann "Specialisation In and Within Sexual Offending in England and Wales" (2014) 26 Sex Abuse 225.

Tim Hughes "Predictive Analytics for Policy and Practice: Reflections from the Criminal Justice System” (2015) 11 Policy Quarterly 37.

Emma Jones, Leigh Harkins and Anthony Beech "The development of a new risk model: The Threat Matrix” (2015) 20 Legal and Criminological Psychology 165.

Jeffrey Jones, Carmen Alexander, Barbara Wynn, Linda Rossman and Chris Dunnuck "Why Women Don't Report Sexual Assault to the Police: The Influence of Psychosocial Variables and Traumatic Injury" (2009) 36 The Journal of Emergency Medicine 417.

Adam Kolber "The Subjective Experience of Punishment" (2009) 109 Columbia Law Review 182.

Adam Kolber "The Comparative Nature of Punishment” (2009) 89 BU L Rev 1565.

Nicola Lacey and Hanna Pickard "The Chimera of Proportionality: Institutionalising Limits on Punishment in Contemporary Social and Political Systems" (2015) 78 MLR 216. 
Wendy Larcombe "Sex Offender Risk Assessment: The Need to Place Recidivism Research in the Context of Attrition in the Criminal Justice System" (2012) 18 Violence Against Women 482.

Jill Levenson and David Prescott "Deja vu: from Furby to Langstrom and the evaluation of sex offender treatment effectiveness" (2014) 20 Journal of Sexual Aggression 257.

David Lisak and Paul Miller "Repeat Rape and Multiple Offending Among Undetected Rapists" (2002) 17 Violence and Victims 73.

Jan Looman and Jeffery Abracan "Comparison of Measures of Risk for Recidivism in Sexual Offenders” (2010) 25 Journal of Interpersonal Violence 791.

Jan Looman, Ida Dickie and Jeffrey Abracen "Responsivity Issues in the Treatment of Sexual Offenders" (2005) 6 Trauma, Violence and Abuse 330.

Brian Lovins, Christopher Lowenkamp and Edward Latessa "Applying the risk principle to sex offenders: can treatment make some sex offenders worse?" (2009) 89 Prison Journal 344.

Patrick Lussier, Marc LeBlanc and Jean Proulx "The generality of criminal behavior: A confirmatory factor analysis of the criminal activity of sex offenders in adulthood" (2005) 33 Journal of Criminal Jusitce 177.

DL Mailloux, J Abracen, Ralph Serin, C Cousineau, B Malcolm and Jan Looman "Dosage of treatment to sexual offenders: Are we overprescribing?" (2003) 47 International Journal of Offender Therapy and Comparative Criminology 171.

Neil Malamuth "Criminal and Noncriminal Sexual Aggressors: Integrating Psychopathy in a Hierarchical-Mediational Confluence Model” (2003) 989 Ann NY Acad Sci 33.

Neil Malamuth, Daniel Linz, Christopher Heavey, Gordon Barnes and Michelle Acker "Using the Confluence Model to Predict Men's Conflict with Women: A 10-Year Follow-Up Study" (1995) 69 Journal of Personality and Social Psychology 353. 
N Malamuth, R Socklosckie, Mary Koss and J Tanaka "The characteristics of aggressors against women: Testing a model using a national sample of college students" (1991) 59 Journal of Consulting and Clinical Psychology 670.

Ruth Mann and Georgia Barnett "Victim Empathy Intervention with Sexual Offenders: Rehabilitation, Punishment, or Correctional Quackery?” (2012) 25 Sexual Abuse 282.

Ruth Mann, Karl Hanson and David Thornton "Assessing Risk for Sexual Recidivism: Some Proposals on the Nature of Psychologically Meaningful Risk Factors" (2010) 22 Sexual Abuse 191.

Dan Markel, Chad Flanders and David Gray "Beyond Experience: Getting Retributive Justice Right” (2011) 99 Cal L Rev 605.

Dan Markel and Chad Flanders "Bentham on Stilts: The Bare Relevance of Subjectivity to Retributive Justice” (2010) 98 Cal L Rev 907.

WL Marshall "Therapist style in sexual offender treatment: Influence on indices of change" (2005) 17 Sexual Abuse 109.

William McColl "Baltimore City's Drug Treatment Court: Theory and Practice in an Emerging Field" (1996) 55 MD L Rev 467.

Elisabeth McDonald and Yvette Tinsley “"“The Law as it Should Be" When Prosecuting Sexual Offences: The Contribution of Legal Academics to Law Reform" (2013) 25 NZULR 758.

Danica McGovern “Assessing Offence Seriousness at Sentencing: New Zealand's Guideline Judgment for Sexual Offending” (2014) 26 NZULR 243.

Stephanie McWhorter, Valerie Stander, Lex Merrill, Cynthia Thomsen and Joel Milner "Reports of Rape Perpetration by Newly Enlisted Male Navy Personnel" (2009) 24 Violence and Victims 204.

Tamar Meekins "Risky Business: Criminal Specialty Courts and the Ethical Obligations of the Zealous Criminal Defender" (2007) 12 Berkeley J Crim L 75. 
Tamar Meekins “"'Specialized Justice”: The Over-Emergence of Specialty Courts and the Threat of a New Criminal Defense Paradigm" (2006) 40 Suffolk U LRev 1.

Terance Miethe, Jodi Olson and Ojmarrh Mitchell "Specialization and Persistence in the Arrest Histories of Sex Offenders" (2006) 43 Journal of Research in Crime and Delinquency 204.

Emily Mouilso and Karen Calhoun "Narcissism, Psychopathy and Five-Factor Model in sexual assault perpetration” (2012) 6 Personality and Mental Health 228.

Shane Muldoon, S Caroline Taylor and Caroline Norma "Patterned Characteristics of Continued and Discontinued Sexual Assault Complaints in the Criminal Justice Process" (2013) 24 Current Issues Crim Just 395.

Gordon Nagayama Hall and William Proctor "Criminological Predictors of Recidivism in a Sexual Offender Population” (1987) 55 Journal of Consulting and Clinical Psychology 111.

James Nolan "Redefining Criminal Courts: Problem-Solving and the Meaning of Justice" (2003) 40 Am Crim L Rev 1541.

Mark Olver, Craig Neumann, Lindsay Sewall, Kathy Lewis, Robert Hare and Stephen Wong "A Comprehensive Examination of the Psychometric Properties of the Hare Psychopathy Checklist - Revised in a Canadian Multi-Site Sample of Indigenous and Non-Indigenous Offenders" (2018) 30 Psychological Assessment 779.

Mark Olver, James Munt, David Thornton, Sarah Beggs Christofferson, Drew Kingston, Justina Sowden, Terry Nicholaichuk, Audrey Gordon and Stephen Wong "Using the Violence Risk Scale-Sexual Offense Version in Sexual Violence Risk Assessments: Updated Risk Categories and Recidivism Estimates from a Multisite Sample of Treated Sexual Offenders” (2018) 30 Psychological Assessment 941.

Mark Olver, Justina Sowden, Drew Kingston, Terry Nicholaichuk, Audrey Gordon, Sarah Christofferson and Stephen Wong "Predictive Accuracy of Violence Risk Scale-Sexual Offender Version Risk and Change Scores in Treated Canadian Aboriginal and NonAboriginal Sexual Offenders" (2018) 30 Sexual Abuse 254. 
Mark Olver, Gabrielle Klepfisz, Keira Stockdale, Drew Kingston, Terry Nicholaichuk and Stephen Wong "Some notes on the validation of VRS-SO static scores" (2016) 22 Journal of Sexual Aggression 147.

Mark Olver, Terry Nicholaichuk, Drew Kingston and Stephen Wong "A Multisite Examination of Sexual Violence Risk and Therapeutic Change" (2014) 82 Journal of Consulting and Clinical Psychology 312.

Mark Olver, Craig Neumann, Stephen Wong and Robert Hare "The Structural and Predictive Properties of the Psychopathy Checklist-Revised in Canadian Aboriginal and Non-Aboriginal Offenders" (2013) 25 Psychological Assessment 167.

Mark Olver and Stephen Wong "A Description and Research Review of the Clearwater Sex Offender Treatment Programme” (2013) 19 Psychology, Crime and Law at 480.

Mark Olver and Stephen Wong "Psychopathy, sexual deviance, and sexual recidivism among sex offenders" (2006) 18 Sexual Abuse 65.

Eryn O’Neal, Katharine Tellis and Cassia Spohn "Prosecuting Intimate Partner Sexual Assault: Legal and Extra-Legal Factors that Influence Charging Decisions" (2015) 21 Violence Against Women 1237.

Gerry Orchard “Sexual Violation: The Rape Law Reform Legislation” (1987) 12 NZULR 97.

Geoffrey Palmer "A Bill of Rights for New Zealand: A White Paper" [1984 - 1985] 1 AJHR A6.

Genevieve Parent, Jean-Pierre Guay and Raymond Knight "An Assessment of LongTerm Risk of Recidivism By Adult Sex Offenders: One Size Doesn’t Fit All” (2011) 38 Criminal Justice and Behavior 188.

Harold Pashler and Eric-Jan Wagenmakers "Editors' Introduction to the Special Section on Replicability in Psychological Science: A Crisis of Confidence?" (2012) 7 Perspectives on Psychological Science 528. 
Devon Polaschek, Julia Yesberg, Rebecca Bell, Allanah Casey and Sophie Dickson "Intensive psychological treatment of high-risk violent offenders: Outcomes and prerelease mechanisms" (2016) 22 Psychology, Crime and Law 344.

Devon Polaschek "An appraisal of the risk-need-responsivity (RNR) model of offender rehabilitation and its application in correctional treatment" (2012) 17 Legal and Criminological Psychology 1.

Devon Polaschek and Lucy King "Rehabilitating Rapists: Reconsidering the Issues" (2002) 37 Australian Psychologist 215.

Stephen Porter, David Fairweather, Jeff Drugge, Hugues Herve, Angela Birt and Douglas Boer "Profiles of Psychopathy in Incarcerated Sexual Offenders" (2000) 27 Criminal Justice and Behavior 216.

Mae Quinn "Whose Team Am I On, Anyway? Musings of a Public Defender about Drug Treatment Court Practice" (2000) NYU Review of Law and Social Change 37.

Martin Rettenberger, Anna Mathes, Douglas Boer and Reinhard Eher "A Comparison of Five Risk Assessment Instruments in Different Sexual Offender Subtypes" (2010) 54 International Journal of Offender Therapy and Comparative Criminology" 169.

Marnie Rice and Grant Harris "Comparing Effect Sizes in Follow-Up Studies: ROC area, Cohen's $d$, and r" (2005) 29 Law and Human Behavior 615.

Elizabeth Ross, Devon Polaschek, and Tony Ward "The therapeutic alliance: A theoretical revision for offender rehabilitation" (2008) 13 Aggression and Violent Behavior 462 .

Leonore Simon "The Myth of Sex Offender Specialization: An Empirical Analysis" (1997) 23 New Eng J on Crim \& Civ Confinement 387.

Jay Singh, Martin Grann and Seena Fazel "Authorship Bias in Violence Risk Assessment? A Systematic Review and Meta-Analysis" (2013) 8 PLoS ONE 1. 
Alexander Skelton, David Riley, David Wales and James Vess "Assessing risk for sexual offenders in New Zealand: Development and validation of a computer-scored risk measure" (2006) 12 Journal of Sexual Aggression 277.

Stephen Smallbone and Mark Rallings "Short-Term Predictive Validity of the Static-99 and Static-99R for Indigenous and Nonindigenous Australian Sexual Offenders" (2013) 25 Sexual Abuse 302.

Stephen Smallbone, Julia Wheaton and Donna Hourigan "Trait Empathy and Criminal Versatility in Sexual Offenders" (2003) 15 Sexual Abuse 49.

Peter Tague "Guilty Pleas or Trials: Which Does the Barrister Prefer?” (2008) 32 Melb U L Rev 242.

EW Thomas “Was Eve Merely Framed; or Was She Forsaken?” [1994] NZLJ 368.

Martie Thompson, Jeffrey Kingree, Heidi Zinzow and Kevin Swartout "Time-Varying Risk Factors and Sexual Aggression Perpetration Among Male College Students" (2015) 57 Journal of Adolescent Health 637.

Martie Thompson, Kevin Swartout and Mary Koss "Trajectories and Predictors of Sexually Aggressive Behaviors During Emerging Adulthood" (2013) 3 Psychology of Violence 247.

Kieran Tranter "Citation Practices of the Australian Law Reform Commission in Final Reports 1992-2012” (2015) 38 UNSW Law Journal 323.

Mark Umbreit "Holding Juvenile Offenders Accountable: A Restorative Justice Perspective" (1995) 46 Juv \& Fam Ct J 31.

James Vess and Alex Skelton "Sexual and violent recidivism by offender type and actuarial risk: reoffending rates for rapists, child molesters and mixed-victim offenders" (2010) 16 Psychology, Crime and Law 541.

Andrew von Hirsch "Proportionality in the Philosophy of Punishment" (1992) 16 Crime and Justice 55. 
Andrew von Hirsch, Martin Wasik and Judith Greene "Punishments in the Community and the Principles of Desert” (1989) 20 Rutgers Law Journal 595.

Andrew Von Hirsch and Nils Jareborg "Gauging Criminal Harm: A Living-Standard Analysis" (1991) 11 OJLS 1.

Helen Wakeling, Ruth Mann and Adam Carter "Do Low-risk Sexual Offenders Need Treatment?” (2012) 51 Howard Journal of Criminal Justice 286.

Tony Ward "Dynamic risk factors: Scientific kinds or predictive constructs" (2016) 22 Psychology Crime and Law 2.

Tony Ward and Anthony Beech "Dynamic risk factors: A theoretical dead-end?" (2015) 21 Psychology Crime and Law 100.

Tony Ward and Astrid Birgden "Accountability and dignity: Ethical issues in forensic and correctional practice" (2009) 14 Aggression and Violent Behavior 227.

Tony Ward and Karen Salmon "The Ethics of Punishment: Correctional practice implications" (2009) 14 Aggression and Violent Behavior 239.

Martin Wasik and Andrew von Hirsch "Non-custodial Penalties and the Principles of Desert" [1988] Crim L Rev 555.

Mark Weinrott and Maureen Saylor "Self-Report of Crimes Committed by Sex Offenders" (1991) 6 Journal of Interpersonal Violence 286.

David Wexler “An Orientation to Therapeutic Jurisprudence” (1994) 20 New England Journal on Criminal and Civil Confinement 259.

Christopher Wildeman, Kristin Turney and Jason Schnittker "The Hedonic Consequences of Punishment Revisited” (2014) 104 Crim L \& Criminology 133.

Emma Williams, Jennifer Norman and Daniela Wunsch "Too Little Too Late: Assessing Vulnerability" (2009) 3 Policing 355. 
Gwenda Willis and Randy Grace "Assessment of Community Reintegration Planning for Sex Offenders: Poor planning predicts recidivism" (2009) 36 Criminal Justice and Behavior 494.

Nick Wilson, Glen Kilgour and Devon Polaschek "Treating high-risk rapists in a New Zealand intensive prison programme" (2013) 19 Psychology, Crime and Law 527.

Bruce Winick and David Wexler "Drug Treatment Court: Therapeutic Jurisprudence Applied" (2015) 18 Touro Law Review 479.

Kate Wolitzky-Taylor, Heidi Resnick, Ananda Amstadter, Jenna McCauley, Kenneth Ruggiero and Dean Kilpatrick "Reporting Rape in a National Sample of College Women” (2011) 59 Journal of American College Health 582.

Kate Wolitzky-Taylor, Heidi Resnick, Jenna McCauley, Ananda Amstadter, Dean Kilpatrick and Kenneth Ruggiero "Is Reporting of Rape on the Rise? A Comparison of Women with Reported versus Unreported Rape Experiences in the National Women's Study-Replication” (2011) 26 Journal of Interpersonal Violence 807.

Lucia Zedner "Penal subversions: When is a punishment not punishment, who decides and on what grounds?” (2016) 20 Theoretical Criminology 3.

Heidi Zinzow and Martie Thompson "A Longitudinal Study of Risk Factors for Repeated Sexual Coercion and Assault in US College Men" (2015) 44 Archives of Sexual Behavior 213.

Heidi Zinzow and Martie Thompson "Factors Associated with Use of Verbally Coercive, Incapacitated, and Forcible Sexual Assault Tactics in a Longitudinal Study of College Men” (2015) 44 Archives of Sexual Behavior 213.

Heidi Zinzow and Martie Thompson "Barriers to Reporting Sexual Victimization: Prevalence and Correlates among Undergraduate Women" (2011) 20 Journal of Aggression, Maltreatment and Trauma 711.

\section{Reports}


An Overview of Sexual Offending in England and Wales (Ministry of Justice, Home Office, and Office for National Statistics, 2013).

Female Victims of Sexual Violence, 1994-2010 (US Department of Justice, 2013).

Formative Evaluation for the Alcohol and Other Drug Treatment Court Pilot (Ministry of Justice, 2014).

National Crime Victimization Survey: NCVS-1 Basic Screen Questionnaire (US Department of Justice, 2008).

National Intimate Partner and Sexual Violence Survey: 2010 Summary Report (National Center for Injury Prevention and Control, Atlanta, Georgia, 2011).

New Zealand Crime Statistics 2014: A Summary of Recorded and Resolved Offence Statistics (Police National Headquarters, Wellington, 2015)

New Zealand Crime and Safety Survey: Key Findings (Ministry of Justice, Wellington, 2006).

New Zealand Crime and Safety Survey Main Findings Report (Ministry of Justice, Wellington, 2015).

Operation Clover - Investigation Overview (New Zealand Police, October 2014).

Problem-Solving Courts: A Delivery Plan (Centre for Justice Innovation, London, 2016).

The Proceedings of “Rape: Ten Years' Progress? An Inter-Disciplinary Conference (Wellington, March 1996).

Tū Mai Te Rangi! Report on the Crown and Disproportionate Reoffending Rates (WAI 2540, Waitangi Tribunal Report, 2017).

Anthony Beech, David Fisher and R Beckett STEP 3: An Evaluation of the Prison Sex Offender Treatment Programme (UK Home Office Occasional Report, 1998). 
Sue Carswell Process Evaluation of the Christchurch Youth Drug Court Pilot (Ministry of Justice, Wellington, 2004).

Louise Falshaw, Caroline Friendship and Andrew Bates Sexual Offenders - measuring reconviction, reoffending and recidivism (Home office Research, Development and Statistics Directorate, London, 2003).

Families Commission Family Violence Statistics Report (Wellington, 2009).

Karl Hanson, Andrew Harris, Terri-Lynne Scott and Leslie Helmus Assessing the Risk of Sexual Offenders on Community Supervision: The Dynamic Supervision Project (Public Safety Canada, 2007).

Andrew Harris and Karl Hanson Sex Offender Recidivism: A Simple Question (Public Safety and Emergency Preparedness Canada, Ottawa, 2004).

Shirley Jülich, John Buttle, Christine Cummins and Erin Freeborn Project Restore: An Exploratory Study of Restorative Justice and Sexual Violence (AUT University, 2010).

Katherine Keighley Juristat: Police-reported Crime Statistics in Canada, 2016 (Canadian Centre for Justice Statistics, 2017).

Venezia Kingi and Jan Jordan Responding to Sexual Violence: Pathways to Recovery (Wellington, Ministry of Women's Affairs, 2009).

Mary Koss and others "Revising the SES: A Collaborative Process to Improve Assessment of Sexual Aggression and Victimization" (2007) 31 Psychology of Women Quarterly 357.

Law Commission Disclosure to the Court of Defendants' Previous Convictions, Similar Offending and Bad Character (NZLC R103, 2008).

Law Commission Invasion of Privacy: Penalties and Remedies (NZLC R113, 2010).

Law Commission Harmful Digital Communications: The Adequacy of Current Sanctions and Remedies (NZLC MP, 2012). 
Law Commission Alternative Pre-Trial and Trial Processes: Possible Reforms (NZLC IP30, 2012).

Law Commission Alternative Pre-Trial and Trial Processes: Summary of Submissions to Consultation (NZLC MP, 2012).

Law Commission The Justice Response to Victims of Sexual Violence: Criminal Trials and Alternative Processes (NZLC R136, 2015).

Law Commission Review of the Search and Surveillance Act 2012: Issues Paper (NZLC IP40, 2016).

Law Commission Maximum Penalties for Criminal Offences (NZLC SP21).

Ashley Maxwell Juristat: Adult criminal court statistics in Canada, 2013/2014 (Canadian Centre for Justice Statistics, 2015).

Arul Nadesu Reconviction Rates of Sex Offenders: Five year follow-up study (Department of Corrections, 2011).

New South Wales Law Reform Commission Encouraging Appropriate Early Guilty Pleas: Report 141 (2014).

New Zealand Family Violence Clearinghouse Data Summary 6: Child Sexual Abuse and Adult Sexual Assault Perpetration by Gender (June, 2017).

Office of Juvenile Justice and Delinquency Prevention Guide for Implementing the Balanced and Restorative Justice Model (Office of Justice Programs, Washington DC, 1998).

Samuel Perreault Criminal Victimization in Canada, 2014 (Statistics Canada, 2015).

Brian Pink Australian and New Zealand Standard Offence Classification (3 ed, Australian Bureau of Statistics, 2011).

Clare Ringland and Lucy Snowball Predictors of guilty pleas in the NSW District Court (NSW Bureau of Crime Statistics and Research, 2014). 
Ralph Serin and S Kennedy Treatment readiness and responsivity: Contributing to effective correctional programming (Research Report R-54, Correctional Services of Canada, Ottawa, 1997).

SG Smith, J Chen, KC Basile, LK Gilbert, MT Merrick, N Patel, M Walling and A Jain The National Intimate Partner and Sexual Violence Survey 2010-2012: State Report (National Center for Injury Prevention and Control, Centers for Disease Control and Prevention, Atlanta, 2017).

Statistics Canada Self-reported sexual assault in Canada, 2014 (The Daily, 2017).

Taskforce for Action on Sexual Violence Te Toiora Mata Tauherenga-Report of the Taskforce for Action on Sexual Violence, Incorporating Views of Te Ohāki a Hine National Network Ending Sexual Violence Together (Ministry of Justice, Wellington, 2009).

Katey Thom, Stella Black and Michele Yeoman Ngā Whenu Raranga/ Weaving Strands: The therapeutic framework of Te Whare Whakapiki Wairua/ The Alcohol and Other Drug Treatment Court (University of Auckland, Auckland, 2017).

Katey Thom, Stella Black and Michele Yeoman Ngā Whenu Raranga/ Weaving Strands: The roles of Te Whare Whakapiki Wairua/ The Alcohol and Other Drug Treatment Court Team (University of Auckland, Auckland, 2017).

Michael Tonry Intermediate Sanctions in Sentencing Guidelines (National Institute of Justice, Washington DC, 1997).

Sue Triggs, Elaine Mossman, Jan Jordan and Venezia Kingi Responding to Sexual Violence: Attrition in the New Zealand Criminal Justice System (Ministry of Women's Affairs, Wellington, 2009).

United Nations Committtee Against Torture Concluding observations on the sixth periodic report of New Zealand (CAT/C/NZL/CO/6, 2 June 2015). 
Kim Workman "Māori Over-Representation in the Criminal Justice System - Does Structural Discrimination Have Anything to Do with It?" (Rethinking Crime and Punishment, Wellington, 2011).

Warren Young Rape Study Volume 1: A Discussion of Law and Practice (Department of Justice, Wellington, 1983.

\section{Dissertations and Theses}

Elizabeth Ross Investigating the Relationship Between the Therapeutic Alliance and Treatment Outcome in Violent Offender Treatment (Unpublished doctoral thesis, Victoria University of Wellington, 2008).

\section{Internet Resources}

"Adults prosecuted in court: most serious offence calendar year 2013" Statistics New Zealand $<$ http://nzdotstat.stats.govt.nz/wbos/Index.aspx?DataSetCode=TABLECODE735 2\#>.

"Alternative Models for Prosecuting and Trying Criminal Cases" Law Commission $<$ http://lawcom.govt.nz/our-projects/alternative-models-prosecuting-and-trying-criminalcases $>$.

“Annual Conference 2017" (November 2017) New Zealand Psychological Society $<$ http://www.psychology.org.nz/wp-content/uploads/Sarah-Christofferson-Child-SexualAbuse-PREHABILITATION.pdf $>$.

"Commission resumes alternative trial processes review" Law Commission $<$ http://www.lawcom.govt.nz/news/commission-resumes-alternative-trial-processesreview $>$.

“Judges' sentencing lacks consistency" Newshub (2 December 2017) $<$ http://www.newshub.co.nz/home/politics/2017/12/judges-sentencing-lacks-consistencyandrew-little.html> .

"NZ Crime and Safety Survey Table 1: Crime rate estimates" Resources and Downloads, Ministry of Justice <https://www.justice.govt.nz/justice-sector-policy/researchdata/nzcass/resources-and-downloads/ $>$. 
Personal Safety Survey 2012, Table 17, available at <http://www.abs.gov.au/AUSSTATS/abs@.nsf/DetailsPage/4906.02012>.

"Pilot halves court time for sexual violence cases" Radio New Zealand (15 December 2017)<http://www.radionz.co.nz/national/programmes/ninetonoon/audio/2018626532/pil ot-halves-court-time-for-sexual-violence-cases $>$.

"Police reported clearance rates for selected offences, Canada, 2010" Statistics Canada <http://statcan.gc.ca/pub/85-002-x/2012001/article/11647/tbl/tbl03-eng.htm>.

"Rehabilitation Programmes" Department of Corrections $<$ http://www.corrections.govt.nz/working_with_offenders/prison_sentences/employment _and_support_programmes/rehabilitation_programmes.html>.

"Rehabilitation Units" Department of Corrections $<$ http://www.corrections.govt.nz/working_with_offenders/prison_sentences/employment _and_support_programmes/rehabilitation_programmes.html>.

SAFE < http://www.safenetwork.org.nz/professional-services $>$.

"Samoa launches new Alcohol and Drug Court" (Radio New Zealand, 15 February 2016) $<$ https:/www.radionz.co.nz/international/pacific-news/296582/samoa-launches-newalcohol-and-drug-court>.

"Sentencing Establishment Unit" Law Commission <http://www.lawcom.govt.nz/ourprojects/sentencing-establishment-unit>.

"Sexual Abuse Statistics" HELP: Support for Sexual Abuse Survivors $<$ http://helpauckland.org.nz/get-info/statistics $>$.

"Sexual violence courts to be trialled" New Zealand Law Society (20 October 2016) $<$ https://www.lawsociety.org.nz/news-and-communications/latest-news/news/sexualviolence-courts-to-be-trialled $>$.

"Specialist Units" Department of Corrections $<$ http://www.corrections.govt.nz/working_with_offenders/prison_sentences/employment _and_support_programmes/rehabilitation_programmes/specialist_units.html $>$.

STOP $<$ http://www.stop.org.nz/>. 
"The NSW Pre-Trial Diversion of Offenders Program (Cedar Cottage)" Western Sydney Local Health District $<$ http://www.wslhd.health.nsw.gov.au/Cedar-Cottage $>$.

"Therapeutic Courts" Ministry of Justice $<$ https://www.justice.govt.nz/courts/criminal/therapeutic-courts/>.

"Three strikes law to be scrapped: Little" Radio New Zealand (online ed, New Zealand, 1 November 2017) <https://www.radionz.co.nz/news/political/342837/three-strikes-law-tobe-scrapped-little $>$.

WELLSTOP $<$ www.wellstop.org.nz $>$.

Aimee Gulliver "Law Commission 'stretched to the limit"” (19 February 2015) Stuff $<$ http://www.stuff.co.nz/national/politics/66401130/law-commission-stretched-to-thelimit>.

Rod Vaughn "Sexual violence reform - change at last" ADLS (Auckland, 5 February 2016) <http://www.adls.org.nz/for-the-profession/news-and-opinion/2016/2/5/sexualviolence-reform-change-at-last/>.

\section{Other Resources}

"By the numbers: Surviving the First Year" The Press (18 July 2015) $<$ http://www.pressreader.com/newzealand/thepress/20150718/281998966142782/TextView>.

Karl Hanson, David Thornton and Shelley Price "Estimating Sexual Recidivism Rates: Observed and Undetected" (presentation at the Association for Treatment of Sexual Abusers conference, St Louis, October 2003).

Sian Elias "Managing Criminal Justice" (Criminal Bar Association Conference, Auckland, 5 July 2017). Available at $<$ https://www.courtsofnz.govt.nz/speechpapers/CBA.pdf $>$. 